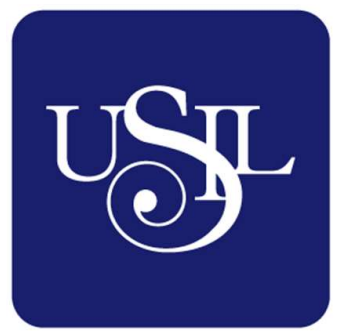

UNIVERSIDAD

SAN IGNACIO

DE LOYOLA

ESCUELA DE POSTGRADO

Maestría en Administración de Negocios - Executive MBA

\title{
PLAN ESTRATÉGICO 2019 - 2021 PARA LAS UNIDADES DE NEGOCIO DE CONSULTAS PRIMARIAS, EXÁMENES AUXILIARES Y CIRUGÍA DE LA EMPRESA INSTITUTO OFTALMOSALUD S.A.C.
}

Trabajo de Investigación para optar el grado de Maestro en Administración de Negocios - Executive MBA

\author{
MARIA ISABEL GRANDA NEGGLI \\ JOSE ARMANDO SALAZAR REVATTA
}

Asesor:

Mg. Carlos Ossio Sal y Rosas

Lima - Perú 
"PLAN ESTRATÉGICO 2019 - 2021 PARA LAS UNIDADES DE NEGOCIO DE CONSULTAS PRIMARIAS, EXÁMENES AUXILIARES Y CIRUGÍA DE LA EMPRESA INSTITUTO OFTALMOSALUD S.A.C." 
Dedicatoria:

A nuestro amigo y hermano José Ramos Izaguirre, el mismo que ya no se encuentra entre nosotros y quién nos impulsó a concluir con este Plan Estratégico, brindándonos toda su ayuda durante el proceso A nuestras familias por su paciencia, comprensión y apoyo durante el tiempo que nos tomó desarrollar este Proyecto 


\section{Resumen Ejecutivo}

En el presente Trabajo de Investigación se ha desarrollado el Plan Estratégico para la empresa OftalmoSalud S.A. para el periodo 2019 - 2021 en la búsqueda de incrementar el valor de la empresa para sus accionistas y seguir manteniendo el liderazgo en el mercado oftalmológico.

OftalmoSalud cuenta con 5 unidades de negocio, las cuales son cirugía, exámenes auxiliares, consultas primarias, farmacia y óptica. En este trabajo nos limitaremos al análisis de consultas primarias, exámenes auxiliares y cirugía debido a que son las generadoras del margen del negocio.

Dentro del desarrollo del trabajo, para obtener las mejores estrategias se realizaron distintos análisis, tanto interno como externo y de la industria, utilizando el modelo analítico de Fred R. David (2013), determinando que la empresa conoce sus fortalezas y sabe cómo manejar sus debilidades. Del mismo modo también está preparada para aprovechar las oportunidades, así como dispuesta y en capacidad de enfrentar las amenazas que se pueden presentar y que ya cuenta con fuertes ventajas contra sus competidores actuales tales como son: Infraestructura, localización estratégica, staff médico de renombre y uso de la mejor tecnología de la actualidad.

Adicionalmente y propio de este análisis se detectó que la problemática principal de la empresa radica en su capacidad instalada actual, la misma que se encuentra en el límite superior y que pone en riesgo el crecimiento que vino experimentando en los últimos años.

También se encontró como necesidad el desarrollar estrategias de marketing, buscar la implementación de tecnología y lograr un cambio en el manejo en la estructura organizacional ya que el sistema actual de toma de decisiones familiar, muchas veces limita la toma de decisiones estratégicas.

Al analizar la viabilidad de la implementación de las estrategias mencionadas anteriormente vimos que se requiere una inversión en un primer momento de casi 4 millones de soles, los mismos que serán financiados a través de un leasing operativo a una tasa bastante adecuada y, que si bien suben el nivel de endeudamiento de la empresa, no limitan el cumplimiento de otros objetivos, principalmente financieros.

Con respecto a la evaluación financiera bajo la metodología de descuentos del flujo de caja libre, y estableciendo una base comparativa entre la situación actual y la proyección con 
las estrategias planteadas, se pudo determinar que el valor de la empresa crece cerca de $160 \%$ generando un importante valor para los accionistas. 


\section{Tabla de contenido}

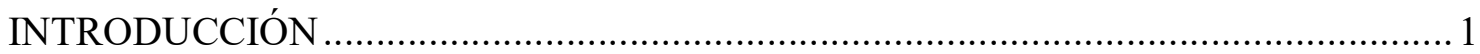

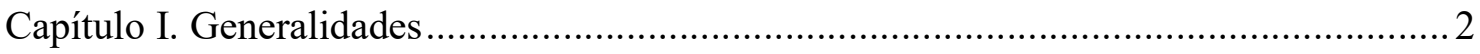

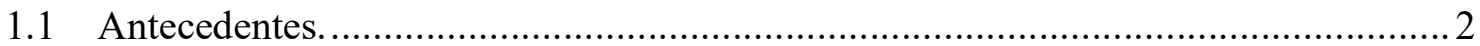

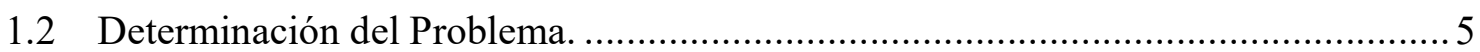

1.3 Justificación del Proyecto......................................................................... 6

1.4 Objetivos Generales y específicos. ................................................... 7

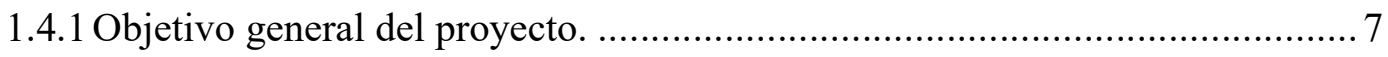

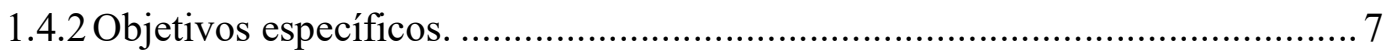

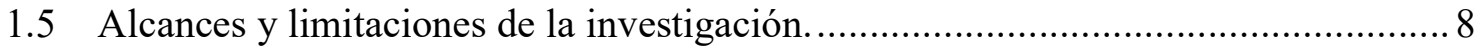

2.1 Antecedentes de la empresa..................................................................... 10

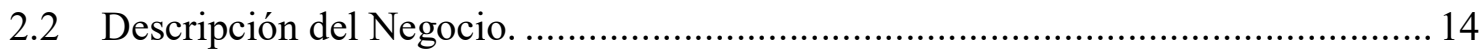

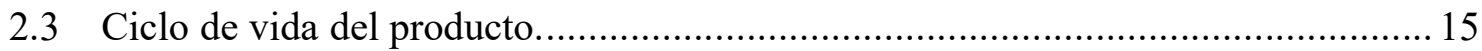

2.4 Estructura organizacional actual de la empresa........................................ 16

2.5 Situación de Mercado y Financiera actual de la Industria. ................................. 19

Capítulo III. Formulación de la Visión, Misión y Valores de la Empresa ...................... 21

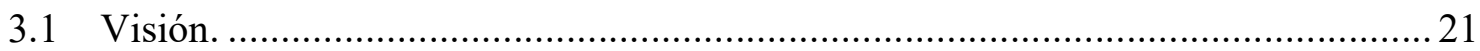

3.1.1 Visión actual de la empresa........................................................... 21

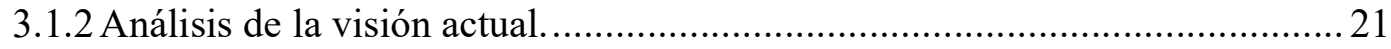

3.1.3 Matriz de la visión propuesta para la empresa. ......................................22

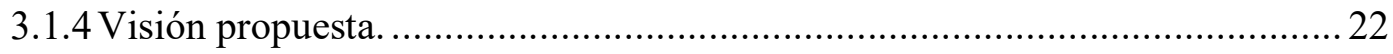

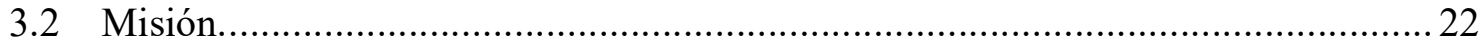

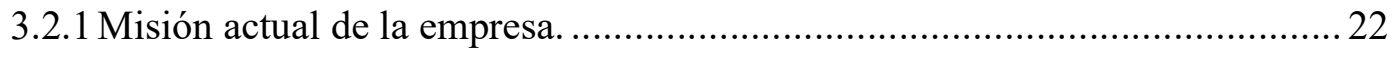

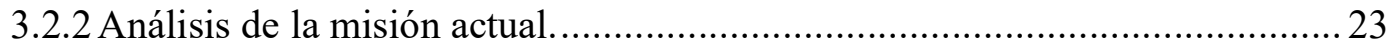


3.2.3 Elementos de la misión propuesta para la empresa..................................23

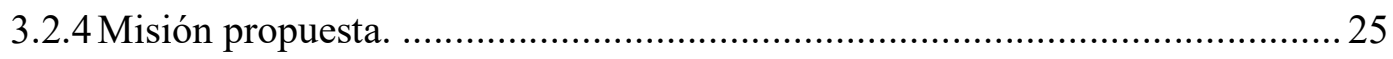

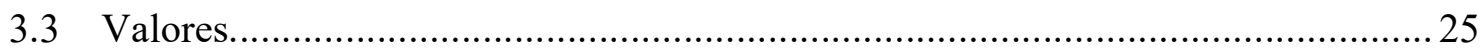

3.3.1 Valores actuales de la empresa......................................................... 25

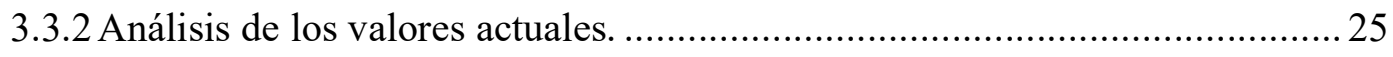

3.3.3 Elementos de los valores propuestos para la empresa.............................25

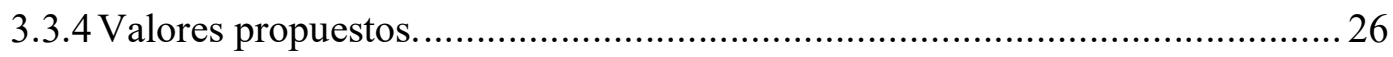

3.4 Alineamiento estratégico de la Visión, Misión y Valores de la empresa................26

4.1 Tendencias de las variables del entorno................................................ 28

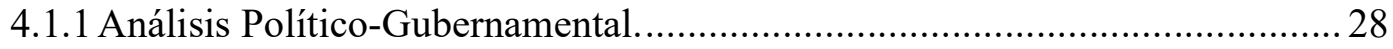

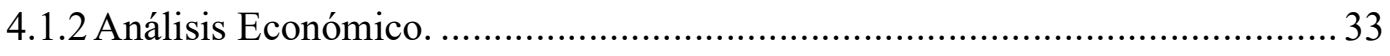

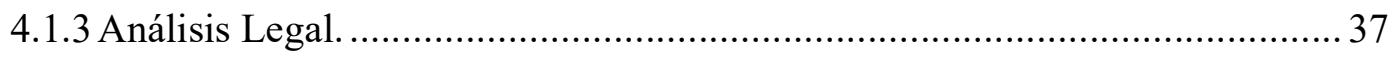

4.1.4 Análisis de variables sociales, demográficas y culturales. ......................... 40

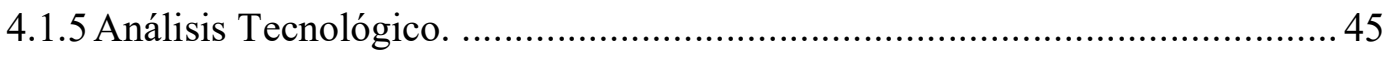

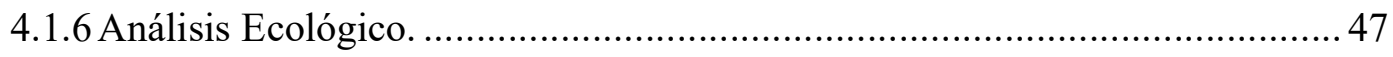

4.2 Impacto en clientes / proveedores de cada una de las variables del entorno. ..........48

4.3 Efecto en la empresa de cada una de las variables del entorno..........................50

4.4 Oportunidades y Amenazas. .................................................................. 51

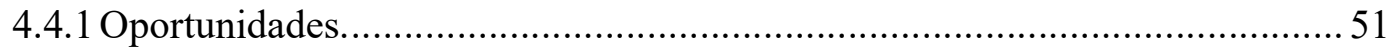

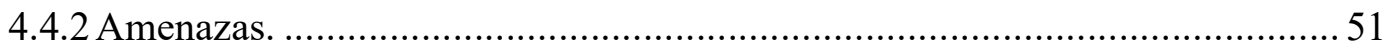

4.5 Matriz de Evaluación de los Factores Externos EFE........................................53

5.1 Descripción del Mercado (demanda) e Industria (oferta). .....................................55

5.2 Descripción las cinco fuerzas competitivas de la industria...............................59

5.2.1 Desarrollo Potencial de Servicios Sustitutos............................................... 59 
5.2.2 Entrada Potencial de Nuevos Competidores. 61

5.2.3 Poder de Negociación de los Clientes. 63

5.2.4 Poder de Negociación de los Proveedores. 65

5.2.5 Rivalidad entre Competidores. 66

5.3 Matriz de atractividad de cada una de las cinco fuerzas. 68

5.4 Análisis del Grado de atractividad de la industria. 79

5.5 Matriz de Perfil Competitivo MPC. 80

Capítulo VI. Análisis Interno 83

6.1 Descripción de las actividades de la cadena de valor de la empresa: Logística interna, Operaciones, Logística externa, Mercadotecnia, Servicios, Adquisiciones, Recursos

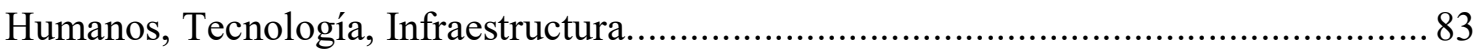

6.1.1 Procesos de Gestión o Procesos Estratégicos........................................... 84

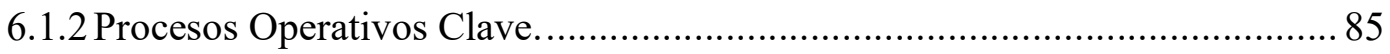

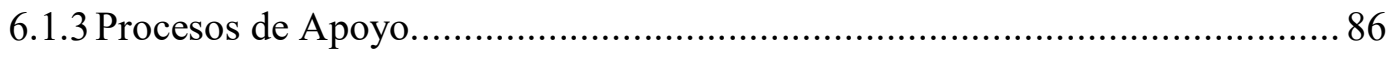

6.2 Indicadores de cada una de las actividades de la cadena de valor........................ 88

6.3 Benchmarking y comparación con los líderes de la industria de cada una de las

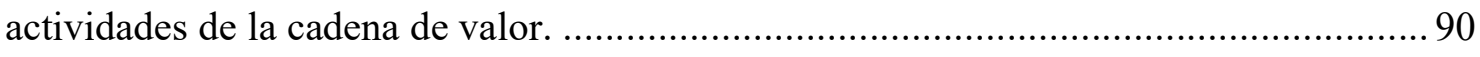

6.4 Determinar las competencias de la empresa............................................... 92

6.5 Identificación y determinación de las ventajas competitivas de la empresa............94

6.6 Matriz de Evaluación de los Factores Internos EFI.......................................96

7.1 Alcance y planteamiento de los objetivos estratégicos................................. 98

7.1.1 Objetivos Estratégicos..................................................................... 98

7.1.2 Análisis de los objetivos estratégicos. ........................................... 99

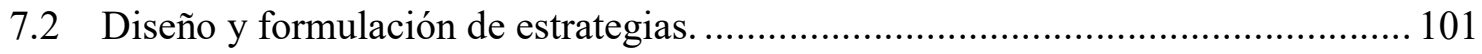


7.2.2 Matrices de formulación de estrategias............................................. 108

7.3 Resumen de las Estrategias Formuladas. ..................................................... 120

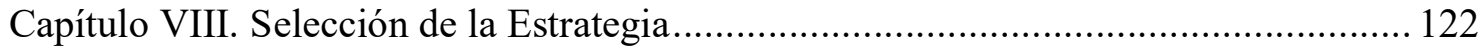

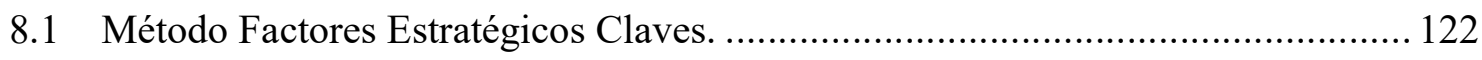

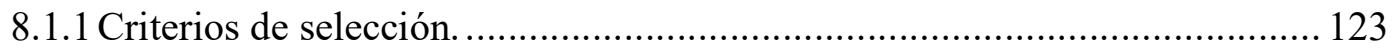

8.1.2 Matriz de evaluación de estrategias.................................................... 123

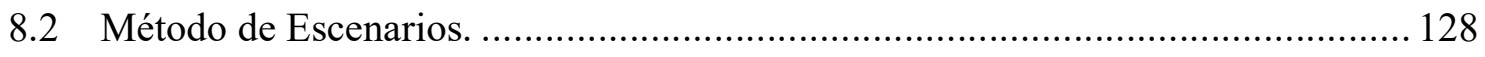

8.2.1 Descripción de escenarios considerados. ........................................... 129

8.2.2 Comparación de estrategias con escenarios. ........................................ 133

8.3 Matriz de Planeación Estratégica Cuantitativa (MCPE)................................. 135

8.4 Elaboración Propia Descripción de estrategia seleccionada. ............................ 137

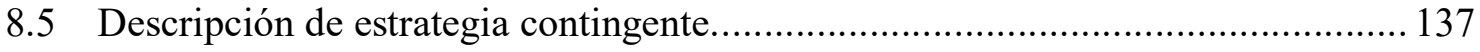

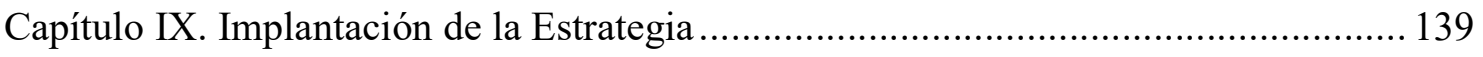

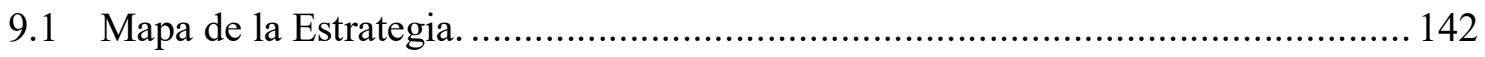

9.2 Objetivos específicos según el mapa de la estrategia. ..................................... 146

9.3 Indicadores para cada uno de los objetivos específicos .............................. 148

9.4 Metas para cada uno de los objetivos específicos....................................... 149

9.5 Iniciativas (acciones a llevar a cabo para cada uno de los objetivos específicos) Estrategias, programas, políticas, reglas, procedimiento.................................... 154

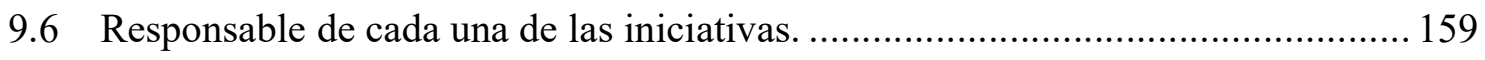

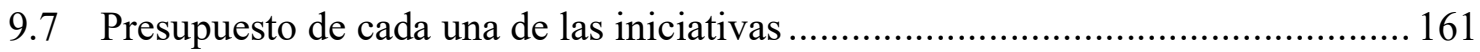

9.8 Cronograma de cada una de las iniciativas. ............................................ 163

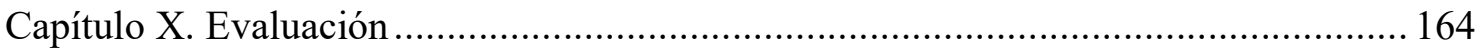




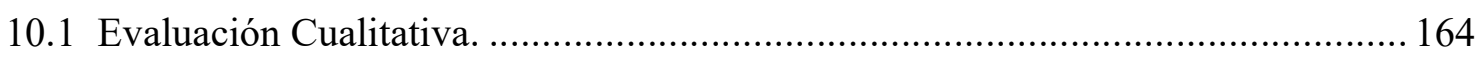

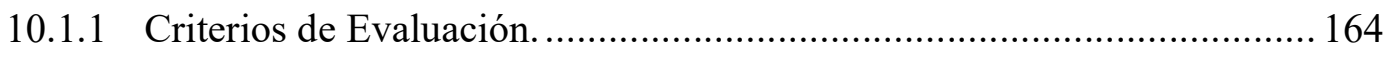

10.1.2 Comparación de la estrategia con los criterios........................................ 164

10.2 Evaluación Financiera de la Estrategia................................................................. 165

10.2.1 Proyección de estados financieros (sin estrategia y con estrategia)......... 165

10.2.2 Estado de resultados (sin estrategia y con estrategia).............................. 166

10.2.3 Estado de Situación Financiera (sin estrategia y con estrategia)............... 170

10.2.4 Flujo de efectivo (sin estrategia y con estrategia).................................. 173

10.2.5 Proyección de flujos (sin estrategia y con estrategia).............................. 174

10.2.6 Evaluación Financiera (VAN, TIR y ratios financieros)........................ 175

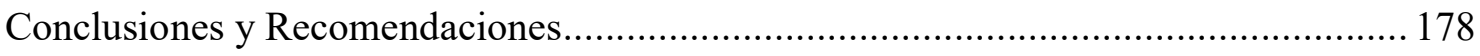

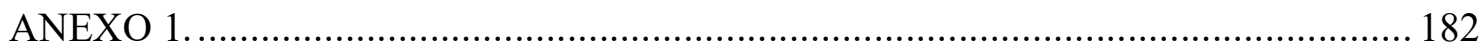

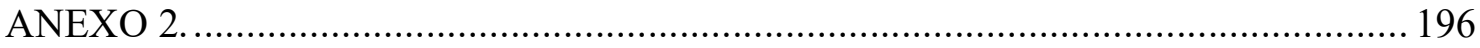

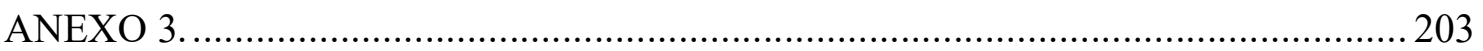

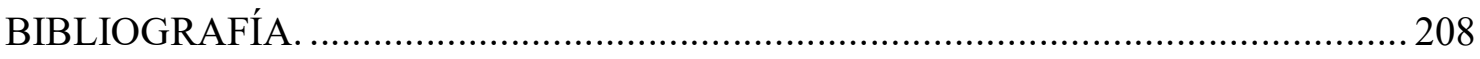

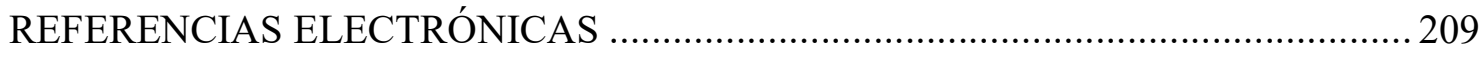




\section{Lista de Tablas}

Tabla 1 Ficha Técnica OftalmoSalud .................................................................... 13

Tabla 2 Ratios Financieros Actuales OftalmoSalud............................................... 14

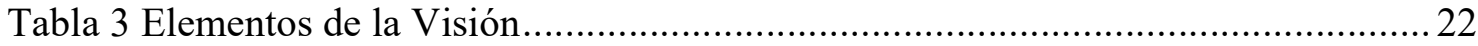

Tabla 4 Elementos de la Misión ...................................................................................... 23

Tabla 5 Componentes de la Misión ....................................................................... 24

Tabla 6 Valores Propuestos para OftalmoSalud.................................................. 26

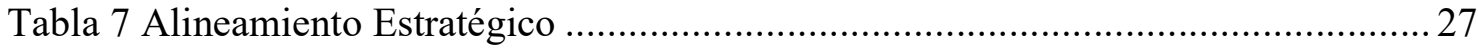

Tabla 8 Impacto en Clientes / Proveedores............................................................ 49

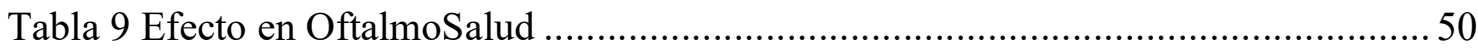

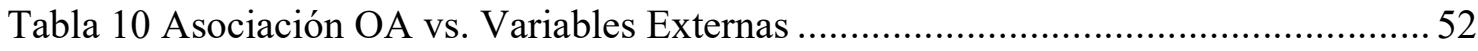

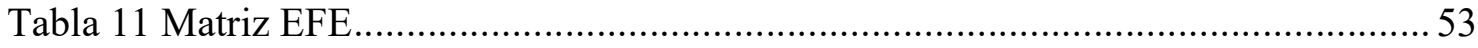

Tabla 12 Participación Unidades de Negocio por tipo de paciente...............................56

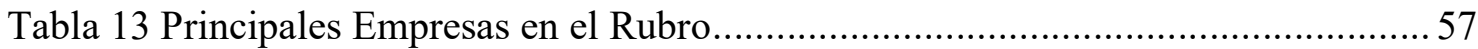

Tabla 14 Evolución de la Participación de Mercado de las empresas dentro del Mercado

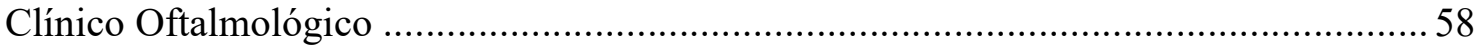

Tabla 15 Principales Proveedores Industria Oftalmológica....................................... 59

Tabla 16 Presiones Competitivas de Productos Sustitutos ............................................ 60

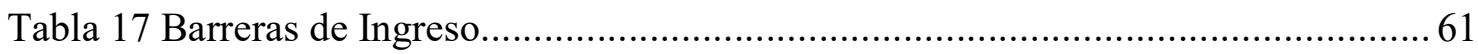

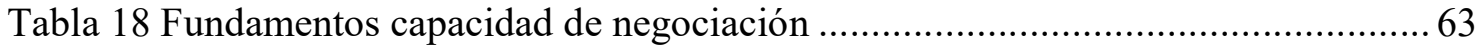

Tabla 19 Aspectos Capacidad de Negociación con Proveedores................................. 65

Tabla 20 Elementos para el Factor de Rivalidad entre Empresas Competidoras .............66

Tabla 21 Matriz de Atractividad: Amenaza de Productos Sustitutos ............................. 70

Tabla 22 Matriz de Atractividad: Amenaza de Competidores Potenciales .................... 71

Tabla 23 Matriz de Atractividad: Poder de Negociación de los Clientes....................... 73

Tabla 24 Matriz de Atractividad: Poder de Negociación de los Proveedores ................. 75

Tabla 25 Matriz de Atractividad: Rivalidad entre competidores existentes ................... 77

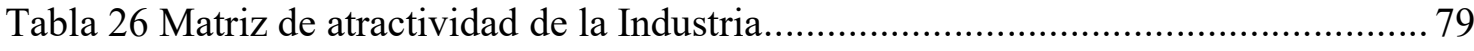

Tabla 27 Matriz de perfil competitivo (MPC) …................................................... 81

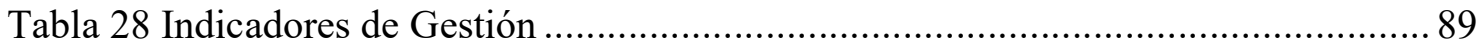

Tabla 29 Ranking Servicio Oftalmológico Iberoamericano ..................................... 92

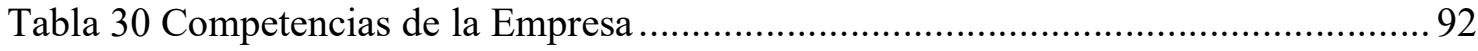


Tabla 31 Ventajas Competitivas OftalmoSalud ............................................................ 94

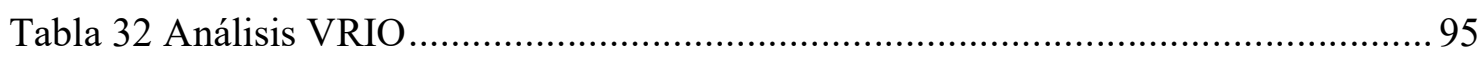

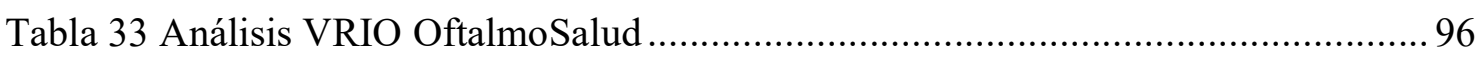

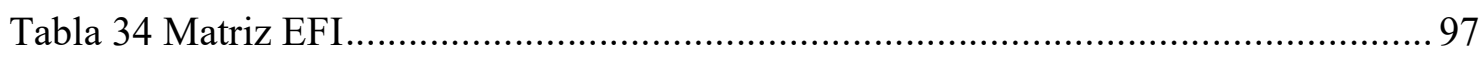

Tabla 35 Objetivos Estratégicos ................................................................................ 98

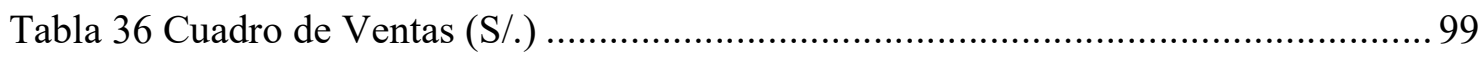

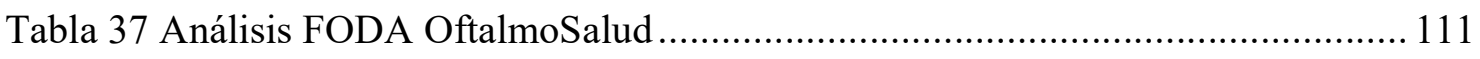

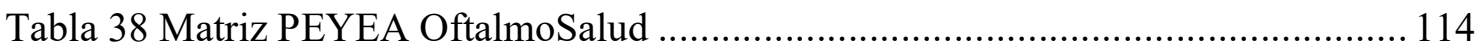

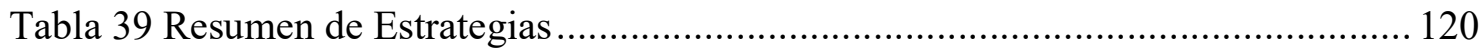

Tabla 40 Repetición de las estrategias en los diferentes análisis .................................... 122

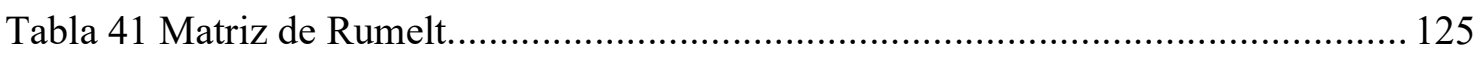

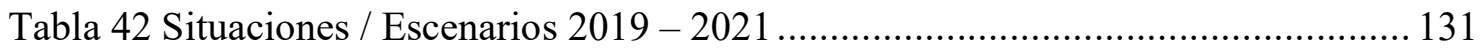

Tabla 43 Escenarios Mas y Menos Probables 2019 - 2021........................................... 132

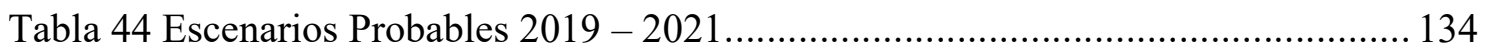

Tabla 45 Impactos de los Escenarios en las Estrategias ................................................. 134

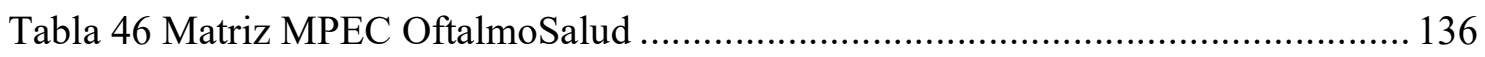

Tabla 47 Objetivos del Mapa Estratégico de OftalmoSalud............................................. 144

Tabla 48 Formulación de Objetivos Estratégicos....................................................... 146

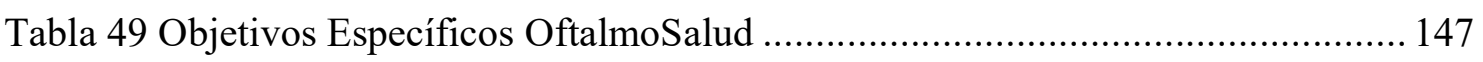

Tabla 50 Indicadores Objetivos Específicos OftalmoSalud ......................................... 148

Tabla 51 Métrica para cada Objetivo Especifico asociado al Objetivo Estratégico ....... 150

Tabla 52 Metas para cada Objetivo Especifico …………....................................... 152

Tabla 53 Iniciativas Estratégicas asociadas a los Objetivos Específicos ....................... 155

Tabla 54 Planes de Acción de cada Iniciativas Estratégicas.......................................... 156

Tabla 55 Clasificación Cranfield Iniciativas Estratégicas ............................................. 158

Tabla 56 Responsables de las Iniciativas Estratégicas y sus respectivos Planes de Acción 160

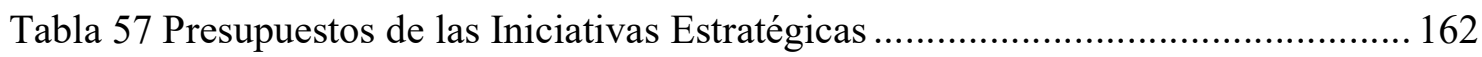

Tabla 58 Cronograma de actividades por iniciativa ...................................................... 163

Tabla 59 Estado de Resultados Situación Actual .......................................................... 167

Tabla 60 Estado de Resultados Nueva Estrategia ....................................................... 169

Tabla 61 Balance General Situación Actual ............................................................. 171 


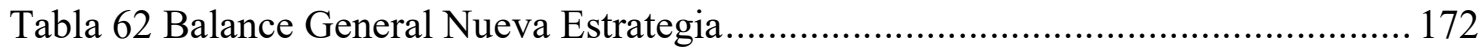

Tabla 63 Flujo de Efectivo Situación Actual ........................................................ 173

Tabla 64 Flujo de Efectivo Nueva Estrategia................................................... 174

Tabla 65 Flujos Netos de Actividades de Operación Situación Actual......................... 174

Tabla 66 Flujos Netos de Actividades de Operación Nueva Estrategia ....................... 175

Tabla 67 Cálculo del Costo del Patrimonio (Ke) ................................................... 175

Tabla 68 Valoración Situación Actual ................................................................. 176

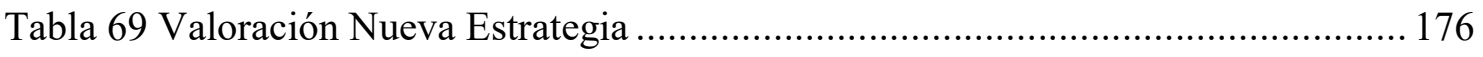

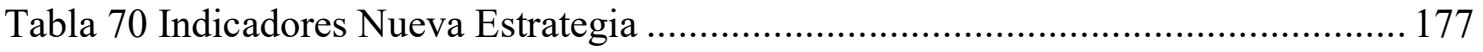




\section{Lista de Figuras}

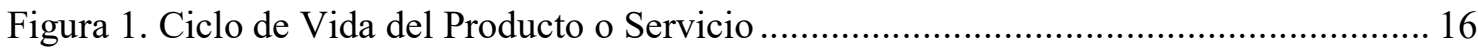

Figura 2. Organigrama Corporativo OftalmoSalud .......................................................... 16

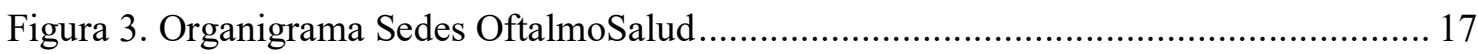

Figura 4. Gasto del Gobierno en el Sector Salud........................................................... 35

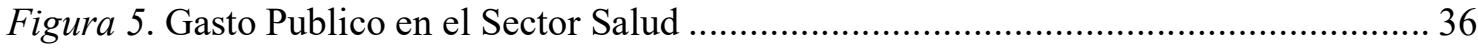

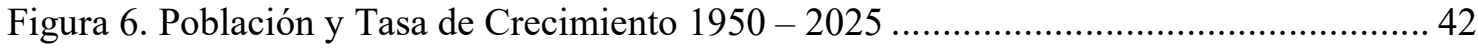

Figura 7. Participación por Unidad de Negocio ............................................................... 56

Figura 8. Mercado Clínico Oftalmológico .............................................................................. 58

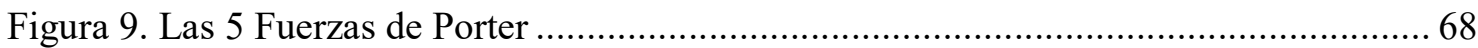

Figura 10. Matriz de Potencial de Utilidad de Porter (atractividad) .................................. 80

Figura 11. Mapa de Procesos OftalmoSalud ................................................................... 83

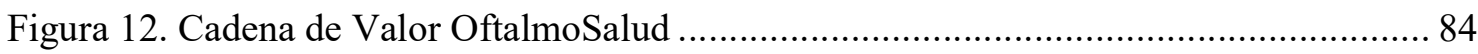

Figura 13. Radar de Factores Competitivos Sector Oftalmológico, .................................. 90

Figura 14. Radar de Factores Competitivos Ponderado Sector Oftalmológico ..................... 91

Figura 15. Lienzo Estrategia Actual OftalmoSalud....................................................... 104

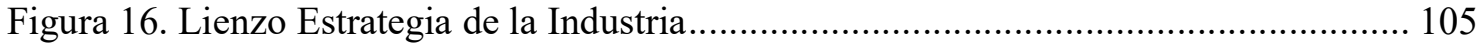

Figura 17. Matriz (eliminar, reducir, incrementar, crear) ............................................ 106

Figura 18. Lienzo de la nueva estrategia considerada.................................................. 107

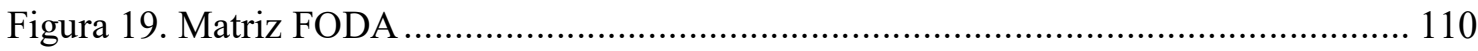

Figura 20. Matriz Interna Externa OftalmoSalud .................................................... 115

Figura 21. Tipos de Estrategia según el cuadrante..................................................... 116

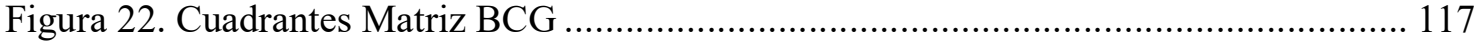

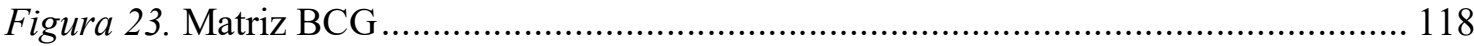

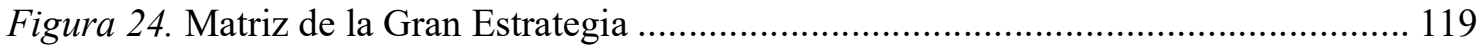

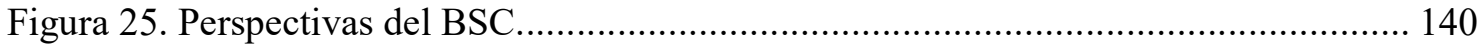

Figura 26. Mapa Estratégico OftalmoSalud ................................................................... 145

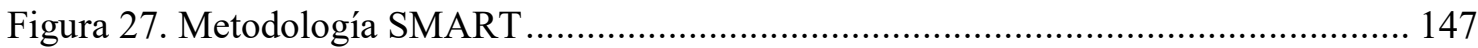

Figura 28. Requisitos para la elaboración de metas..................................................... 149

Figura 29. Alineación de las Organización con la Estrategia .......................................... 154

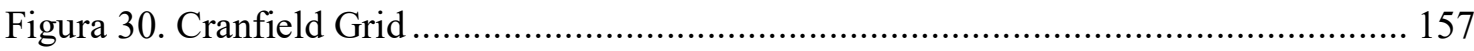

Figura 31. Comparativo Utilidad Neta Situación Actual vs Nueva Estrategia ................... 170 


\section{INTRODUCCIÓN}

Durante el tiempo de vida de una empresa en el mercado, existen momentos que permiten identificar oportunidades de mejora y procesos de cambios, ya sea por adaptarse al entorno, así como para poder seguir creciendo y posicionándose cada vez mejor en su propia industria. A estos factores deben sumarse los cambios que ocurren en la población y las tendencias a las que se van dirigiendo los mercados, así como la valoración del servicio al cliente que es un punto clave para el crecimiento o declive de una organización.

Es justo antes estos cambios que se abren nuevas posibilidades y explotar nuevas herramientas para generar nuevos mercados potenciales y seguir creciendo con el mercado cautivo actual. Para ello se hace necesario preparar un plan estratégico viable, que permita a la empresa OftalmoSalud, la misma que es objeto de este estudio que, utilizando diversas estrategias, probar que la organización es capaz de adaptarse y lograr mantener un posicionamiento adecuado a través de la generación de mayores ventajas competitivas sostenibles en el tiempo, que impactarán de manera positiva en la organización, sin dejar de tener presente la complejidad del mercado y la competencia que también busca seguir creciendo.

Es así que, en los siguientes capítulos nos adentraremos en la búsqueda del conocimiento de la industria oftalmológica y la empresa; analizaremos el entorno y todos los factores internos y externos que pueden afectarlos, así como el análisis de la competencia que nos permitan desarrollar estrategias acordes con las necesidades de la empresa. Finalmente, mediante la comparación de la proyección de los estados financieros incrementales (con y sin estrategias) probaremos la eficacia de la implementación de estas. 


\section{Capítulo I. Generalidades}

En el presente capítulo se exponen los términos generales del estudio llevado a cabo. Iniciaremos con una explicación de los antecedentes y la determinación de la problemática actual, la cual motiva la elaboración de un plan estratégico. Luego detallamos los argumentos y la justificación para finalmente plasmar los objetivos generales y específicos de la presente tesis.

\subsection{Antecedentes.}

A continuación, se presenta una breve reseña de las principales situaciones previas ocurridas en el ámbito internacional y en el Perú con respecto a las enfermedades oftalmológicas que contribuyen y respaldan el presente Plan estratégico.

Ámbito Internacional: Según la Organización Panamericana de la Salud (OPS) en su Plan Estratégico Nacional 2014 - 2021 de Salud Ocular y Prevención de la Ceguera Evitable emitido en el año 2013, en el mundo existen 39 millones (MM) de ciegos (13\% de la población), en Latinoamérica 2.4 MM y en Perú 160,000 ciegos. Para el año 2020 la cifra de ciegos en Latinoamérica alcanzará los $5 \mathrm{MM}$ de habitantes. De acuerdo a diversos estudios, la prevención y el tratamiento oportuno de la pérdida de la visión se cuentan entre las intervenciones de salud más costo-efectivas, en comparación con otros padecimientos.

En 1997 se reunió el Grupo Asesor para la Prevención de la Ceguera de la Organización Mundial de la Salud (OMS) y señalaron que, en el próximo cuarto de siglo, la ceguera y la limitación visual severa - problemas de salud ya existentes - se convertirían en una de las principales cargas socioeconómicas a nivel mundial y consecuentemente podrían interferir con el progreso de muchos países en vías de desarrollo.

En el Perú: Según el informe anteriormente mencionado de la OPS, los problemas 
visuales son la segunda causa de discapacidad a nivel nacional, involucrando a cerca de 300,000 personas con severa discapacidad visual, en adición a los 160,000 ciegos por diversas causas; con un alto componente de invalidez para las personas que la padecen. Desde 1983 se vienen realizando estudios sobre la problemática: morbilidad ocular y ceguera, de catarata y prevalencia de ceguera bilateral estimada a nivel nacional en personas mayores de 50 años, indicando que más de la mitad fue por catarata. También se vienen estudiando otras patologías oculares que presentan alta prevalencia en nuestro medio como son el glaucoma y la retinopatía diabética; y en la población escolar cinco de cada cien alumnos presentan deficiencia visual debido a vicios de refracción no corregidos.

Causas de ceguera: La Evaluación Rápida de Ceguera Evitable del 2011, revela que las principales causas de ceguera fueron la catarata no tratada (58\%), el glaucoma $(13.7 \%)$ y la degeneración macular relacionada a la edad (11.5\%), las que, en conjunto, constituyeron el 83.2\% de todas ellas. Las causas de ceguera menos frecuentes fueron otras opacidades corneales $(5.3 \%)$ y otras enfermedades del segmento posterior $(4.6 \%)$.

Casi la totalidad de las causas de la ceguera y discapacidad visual identificadas (de $83.2 \%$ a $93.8 \%$ ) fueron evitables (tratables, prevenibles y potencialmente prevenibles).

El sistema de salud y los recursos humanos: Con datos hasta el año 2013, se puede decir que en el Perú hay 830 oftalmólogos de los cuales 620 pertenecen a la Sociedad Peruana de Oftalmología.

Se estima que hay un oftalmólogo por cada 34,000 habitantes, $98 \%$ en las grandes urbes $(100,000$ habitantes o más) y $2 \%$ en ciudades intermedias o menores $(<100,000$ habitantes).

Existen 128 servicios oftalmológicos públicos con 403 oftalmólogos. El 44.2\% de 
servicios oftalmológicos se ubican en regiones de Lima y Callao (capital), 30.8\% en otras regiones de la costa, el 25\% restante, cobertura 14 regiones de la sierra y selva. El $64.8 \%$ de los oftalmólogos públicos laboran en regiones de Lima y Callao (capital), 23.9\% en otras regiones de la costa y $11.3 \%$ en regiones de sierra y selva. El $56.7 \%$ son oftalmólogos generales y $43.1 \%$ son sub-especialistas.

Las regiones de Lima y Callao (capital) concentran el 52.0\% de oftalmólogos generales y $82.7 \%$ de sub-especialistas.

Historia de OftalmoSalud: la formación del Instituto OftalmoSalud SAC (en adelante OftalmoSalud) obedece a la iniciativa del Dr. Luis Izquierdo Vásquez, quien, al consolidarse como un Médico Oftalmólogo de renombre a nivel nacional e internacional, detecta en el mercado la necesidad de brindar una atención especializada e integral.

El mercado había empezado a cambiar. Los rubros de Oftalmología y Odontología eran dos especialidades que las Clínicas Generales no podían manejar y se empezó a gestar el desarrollo de marcas específicas. OftalmoSalud inicia actividades comerciales en 1993 y en poco tiempo logra consolidarse como líder en la especialidad.

Los pilares de este crecimiento se centraron en el soporte tecnológico de última generación y la actualización constante del Staff Médico, lo que ha generado que en la actualidad sea la empresa que brinda el mayor número de atenciones por paciente a nivel nacional.

Actualmente, OftalmoSalud brinda servicios de salud oftalmológica y cuenta con cinco unidades de negocio, las cuáles son: atención clínica (consultas primarias), exámenes auxiliares, cirugías, farmacia y óptica. En este estudio nos limitaremos al análisis de consultas primarias, exámenes auxiliares y cirugía dado que como se mencionará más adelante estas 
tres unidades de negocio concentran el $73 \%$ de los ingresos y son las generadoras del margen del negocio.

Como se verá más adelante, a la fecha la situación financiera de la empresa es saludable, con niveles de crecimiento promedio de los últimos 5 años (al 2017) del 19.2\%; debido a los sucesos políticos y económicos actuales; así como a la falta de capacidad instalada, que explicaremos más a detalle en los siguientes capítulos, se estima cerrar el año 2018 con un crecimiento de ventas para el mismo periodo del 6\%.

\subsection{Determinación del Problema.}

Ante la pregunta si OftalmoSalud cuenta o no con un plan estratégico para el mediano o largo plazo, la respuesta del Director de Operaciones, Sr. José Ramos Izaguirre, fue que, si bien es cierto, no cuentan con un plan estratégico estructurado, se cuenta con lineamientos establecidos por parte del directorio - el cual está compuesto principalmente por la familia que guían el rumbo de la empresa en cuanto a crecimiento (infraestructura) y tecnología (equipamiento).

Es en base a estas carencias tanto por el lado de (i) los pacientes a nivel de prevención, (ii) especialistas de calidad dedicados a estas atenciones, (iii) la falta de centros especializados de atención, (iv) la falta de un plan estratégico establecido y (v) el pleno empleo de la capacidad instalada actual de la empresa, que este proyecto encuentra fundamento, y busca enfocarse en el crecimiento ordenado y sustentado de OftalmoSalud, ya que como se puede apreciar las enfermedades relacionadas con el sector oftalmológico seguirán avanzando y creciendo en número, situación para la cual la empresa debe estar preparada. 


\subsection{Justificación del Proyecto.}

Como ya se ha mencionado anteriormente, OftalmoSalud cuenta con una buena administración y manejo financiero, sin embargo, el crecimiento que viene presentando en los últimos años se verá frenado en el futuro, principalmente por el pleno empleo de su actual capacidad instalada. Esta saturación en su capacidad instalada viene afectando la percepción de calidad en el servicio; y si a esto le sumamos que el crecimiento de la industria no se detiene y que la empresa no cuenta con un plan estratégico que defina metas y objetivos claros como directrices institucionales y no familiares, el manejo del negocio se puede ver comprometido principalmente en su nivel de ventas y reputación a la fecha ganada.

En conversaciones con el Director de Operaciones de la empresa, se determinó que el análisis de crecimiento esperado se debe enfocar principalmente en la capacidad instalada de la unidad de negocio de consultas primarias, la misma que a su vez generará un crecimiento en las unidades de exámenes auxiliares y cirugía por estar directamente pero no proporcionalmente relacionadas. Es importante mencionar que las unidades de farmacia y óptica no son parte principal del giro del negocio dado que su venta es marginal y su crecimiento, puede estar o no, en función a las otras tres unidades. Otra razón por la cual no han sido consideradas para este análisis es que ambas no fueron concebidas como parte del objetivo central del negocio y más bien su existencia se debe a la necesidad de cubrir los requerimientos de los pacientes.

Bajo este contexto se hace necesario que OftalmoSalud cuente con un plan estratégico que le permita mantener e incrementar el nivel de crecimiento que viene experimentando en los últimos años, sin descuidar la calidad de su servicio. Para ello se plantean objetivos estratégicos del negocio, relacionados principalmente a la capacidad instalada, la calidad en el servicio y el desarrollo de indicadores de gestión que permitan el monitoreo y control de 
los resultados de sus unidades de negocio.

El análisis de crecimiento en la capacidad instalada de las unidades de negocio de consultas primarias se centrará en la inversión en crecimiento físico de las clínicas actualmente en operación, principalmente la Sede de Javier Prado.

\subsection{Objetivos Generales y específicos.}

\subsubsection{Objetivo general del proyecto.}

El objetivo general de este proyecto es desarrollar un plan estratégico para OftalmoSalud para el periodo 2019 - 2021, que permita establecer la ruta a seguir para continuar, sostener y mejorar el crecimiento de la empresa manteniendo la calidad en el servicio.

\subsubsection{Objetivos específicos.}

Los objetivos específicos que se desarrollan durante el presente trabajo son:

- $\quad$ Analizar el mercado de servicios oftalmológicos (consultas y cirugía).

- Analizar y redefinir como parte de la elaboración del Plan Estratégico estructurado, la misión, visión y valores de la empresa.

- Identificar oportunidades de crecimiento en capacidad instalada para la unidad de negocio de consultas primarias.

- Definir y evaluar las mejores estrategias de crecimiento posibles para la empresa, en las unidades de consultas, exámenes y cirugía.

- Realizar la evaluación financiera de cada estrategia y el impacto que generarán en la empresa y en sus estados financieros. 


\subsection{Alcances y limitaciones de la investigación.}

La información para desarrollar el siguiente plan estratégico de las unidades de negocio de consultas primarias, exámenes auxiliares y cirugía para el periodo 2019 - 2021, se obtendrá tanto de fuentes primarias como secundarias dentro de las que podemos mencionar: (i) información existente en la empresa, (ii) entrevistas a profundidad con expertos dentro de la empresa, (iii) libros y revistas especializadas, (iv) estadísticas del sector, (v) investigación en bibliotecas, entre otros.

La investigación en campo se centrará básicamente en entrevistas a profundidad y reuniones con los expertos. como son el Director de Operaciones, el Presidente del Directorio y el Director de Finanzas de la empresa.

Alcance: Este Plan Estratégico está elaborado a la medida para OftalmoSalud siendo su ámbito de Operaciones la ciudad de Lima Metropolitana no pudiendo replicarse ni tomarse como modelo para la elaboración de Planes Estratégicos de otras empresas aun cuando estén relacionados al sector oftalmológico. La implementación o no del presente plan será decisión del directorio, para lo cual el documento en su integridad será presentado a la empresa para su evaluación.

Limitaciones: El presente trabajo considera como limitante la poca información pública respecto al servicio oftalmológico en la ciudad de Lima, tendiendo que confiar en la información obtenida y desarrollada por la propia empresa como parte de su análisis de inteligencia comercial.

Del mismo modo, la empresa cuenta con información interna, preparada a través de una empresa especializada como es Global Research Marketing, sobre Clima Laboral y Satisfacción al Cliente, la misma que fue mencionada en varias de las conversaciones 
sostenidas con los directivos de la empresa, sin embargo, esta información no se nos suministró físicamente.

Por otro lado, también se tuvo limitaciones para el desarrollo de un benchmark debido a que no existe en el mercado información que se pueda utilizar y las empresas no desean compartir información sobre sus mejores prácticas, 


\section{Capítulo II. La Empresa}

En este capítulo se va a llevar a cabo un análisis profundo de la empresa, empezando por los antecedentes de la organización y seguido por una descripción del negocio, considerando la revisión de su organización y sus principales procesos.

\subsection{Antecedentes de la empresa.}

OftalmoSalud es un instituto de reconocido liderazgo a nivel nacional e internacional, dedicado a brindar servicios médicos oftalmológicos integrales, combinando la excelencia profesional con tecnología de avanzada.

Fue fundado el 15 de abril de 1993 por el Doctor Luis Izquierdo Vásquez (expresidente de la Sociedad Peruana de Oftalmología) con el objetivo de fundar una clínica para ojos que combine la experiencia del más selecto personal médico que desarrolle modernas técnicas de diagnóstico y tratamiento, contando con equipos de última generación en tecnología oftalmológica, y siendo su compromiso principal el satisfacer las necesidades y expectativas de sus pacientes y socios estratégicos, a través de la implementación de un sistema de gestión de calidad, basado en la mejora continua de sus procesos, servicios y competencia de su personal.

OftalmoSalud cuenta con 4 sedes ubicadas estratégicamente en las principales zonas de Lima Metropolitana como son: Lima Norte (Los Olivos), Lima Sur (San Juan de Lurigancho), el Polo y San Isidro (Sede Javier Prado).

En ellas cuenta en total con cinco salas de operaciones totalmente equipadas con equipos de última tecnología lo cual les faculta a realizar todo tipo de cirugías oftalmológicas en las más óptimas condiciones.

Adicionalmente, en sus sedes cuenta en total con las siguientes facilidades: 
- Salas de espera con todas las comodidades.

- Ascensores

- Rampas para discapacitados y pacientes de edad avanzada.

- Estacionamiento externo e interno.

- Farmacia y Óptica.

- Cafetería

A continuación, mencionaremos algunos de los puntos más resaltantes en la historia de OftalmoSalud en la búsqueda de mantenerse actualizados con la tecnología más avanzada.

- En el año 1995 fueron los primeros en adquirir un equipo de Excimer láser de marca Nidek, convirtiéndose de esta manera, en la primera clínica privada en el Perú en adquirir este equipo de avanzada.

- En el año 1999 se crea Laser Visión Center, un centro de salas quirúrgicas equipadas para realizar las intervenciones oculares más complejas, las cuales están equipadas especialmente con sistemas de bio-seguridad.

- En el año 2002 se adquiere un nuevo láser de última generación marca Schwind modelo ESIRIS de la empresa Schwind eye-tech-solution, de procedencia alemana.

- En el año 2003 se crea el área Docente - Académica, la cual recibe a oftalmólogos y residentes de la especialidad, que completan su formación en el instituto, siendo a la fecha la única clínica oftalmológica privada en el Perú donde se pueden formar futuros oftalmólogos.

- En el año 2005 se inaugura la Sede Norte (los Olivos), la misma que cuenta con todos los servicios oftalmológicos en cirugías y exámenes especiales.

- En el 2006 el Director el Dr. Luis Izquierdo Vásquez, es nombrado Rector de la Universidad Mayor de San Marcos. 
- En el 2007 es otorgada la Medalla de Honor del Congreso de la República, en el Grado de Gran Oficial 2007, al director médico Luis Izquierdo Villavicencio, por la creación del programa "Ver para Creer". Campaña medica orientada al despistaje y cirugías gratuitas de catarata para las personas de escasos recursos.

- En el 2010 nuestro Director Médico el Dr. Luis Izquierdo Villavicencio, recibe el Premio Achivement 2010 de la Academia Americana de Oftalmología Chicago.

- Ese mismo año, se adquiere el Láser Intralase FS (femtosegundo) el último avance tecnológico dentro del campo de la Cirugía Refractiva y de la Cirugía Corneal.

- En el año 2011 se adquieren equipos de la más alta tecnología para el diagnóstico y tratamiento de enfermedades oftalmológicas en el mundo (IOL Master, Sistema Láser de Glaucoma Selecta II, Cirrus ${ }^{\text {TM }}$ HD-OCT, Visante OCT, Oculus Pentacam, GDx, HRT 3).

- Ese mismo año, debido a problemas regulatorios, OftalmoSalud absorbe "Ojos del Perú" un plan social ubicado en el distrito de San Juan de Miraflores, con ello se apertura OftalmoSalud Sede Sur.

- En el año 2013, siguiendo con los planes de expansión, se realizó una remodelación y ampliación de la Sede Principal ubicada en la Av. Javier Prado; asimismo se apertura la Sede El Polo y se adquirió un terreno adicional en los Olivos (actual Sede Norte).

- En el año 2015 OftalmoSalud Sede Norte, Central, El Polo y Sur reciben la certificación ISO 9001:2008, Sistema de Gestión de Calidad, ese mismo año se volvió a posicionar como la clínica para ojos con la mejor tecnología de nivel mundial al adquirir los equipos Excimer Láser Schwind Amaris 705S y Femtosegundo 8.

- Ese mismo año se adquiere una casa aledaña a la Sede Javier Prado con la finalidad de, en el mediano plazo incrementar la capacidad de consultas primarias con una nueva torre de consultorios cuya construcción está planificada para el año 2020 y entrará en operaciones el 2021. Dicho esto, el incremento de capacidad instalada del presente estudio no 
contemplará esta estrategia de crecimiento, sino que centrará sus esfuerzos en la remodelación de la Sede Javier Prado actual.

- En el año 2016 es otorgada la Medalla de Oro a nuestro director médico Luis Izquierdo Villavicencio, en las Olimpiadas WOC2016 en México, por el desarrollo de una novedosa Técnica en Cirugía de Catarata logrando ser reconocido como el mejor oftalmólogo del mundo y fue nombrado como embajador de la marca Perú.

A la fecha, OftalmoSalud cuenta con 26 años de experiencia ininterrumpida, brindando servicios de salud oftalmológica y tal como mencionamos anteriormente, cuenta actualmente con cinco unidades de negocio, las cuáles son: atención clínica (consultas primarias), cirugía, exámenes auxiliares, farmacia y óptica. A la fecha su situación financiera es saludable, y cuenta con niveles de crecimiento promedio de los últimos 5 años del 19.2\%; siendo su nivel de ventas en el año 2017 de S/. 52.7 millones, obteniendo un margen neto promedio esos mismos años del 6.4\%.

A continuación, se puede apreciar la ficha técnica de la empresa:

Tabla 1

Ficha Técnica OftalmoSalud

\begin{tabular}{|l|l|}
\hline \multicolumn{1}{|c|}{ Descripción } & \multicolumn{1}{c|}{ Contenido } \\
\hline Razón Social & Instituto OftalmoSalud Sociedad Anónima Cerrada \\
\hline Razón Comercial & Instituto OftalmoSalud SAC \\
\hline RUC & 20205557181 \\
\hline CIIU & $\begin{array}{l}8710-\text { Actividades de Atención de Enfermería e Instituciones } \\
4772-\text { Venta al por menor de Productos Farmacéuticos y } \\
\text { Médicos, Cosméticos y Artículos de Tocador en Comercios } \\
\text { Especializados } \\
4690-\text { Venta al por mayor no Especializada }\end{array}$ \\
\hline Giro del Negocio & Clínica Oftalmológica, Actividades Médicas, Farmacia y Óptica \\
\hline Dirección Legal & Av. Javier Prado Este $N^{\circ} 1148$ dpto. 901 San Isidro \\
\hline
\end{tabular}




\begin{tabular}{|l|l|}
\hline Página Web & www.oftalmosalud.com.pe \\
\hline Representantes Legales & $\begin{array}{l}\text { Izquierdo Vásquez, Luis Fernando - DNI Nº } 08257232 \\
\text { Izquierdo Villavicencio, Fernando - DNI N } 09338307\end{array}$ \\
\hline
\end{tabular}

Elaboración con información obtenida de OftalmoSalud

Los indicadores de financieros de OftalmoSalud son los siguientes, los mismos

muestran una sólida estabilidad. En el lado operativo, el ciclo de conversión de efectivo

refleja la madurez de la empresa, donde la rotación de cuentas por cobrar, cuentas por pagar e

inventarios no muestran sobresaltos y son predecibles. Asimismo, los márgenes de

rentabilidad mostraron una recuperación en años pasados y ahora ya se muestran estables y

saludables dado el giro de negocio:

Tabla 2

Ratios Financieros Actuales OftalmoSalud

\begin{tabular}{|c|c|c|c|c|c|c|c|c|c|c|c|c|}
\hline & Dic-07 & Dic-08 & Dic-09 & Dic-10 & Dic-11 & Dic-12 & Dic-13 & Dic-14 & Dic-15 & Dic-16 & Dic-17 & Dic-18 \\
\hline \multicolumn{13}{|l|}{ LQUUIDEZ } \\
\hline Corriente & 0.38 & 0.73 & 0.66 & 0.80 & 1.09 & 1.22 & 1.19 & 1.27 & 1.15 & 1.22 & 1.37 & 1.55 \\
\hline Liquidez Inmediata (Prueba Ácida) & 0.19 & 0.53 & 0.43 & 0.62 & 0.88 & 1.02 & 0.96 & 1.01 & 0.97 & 0.99 & 1.14 & 1.31 \\
\hline \multicolumn{13}{|l|}{$\underline{\text { RIESGO DE CREDITO }}$} \\
\hline Endeudamiento (Apalancamiento) & $78 \%$ & $72 \%$ & $67 \%$ & $58 \%$ & $40 \%$ & $52 \%$ & $37 \%$ & $35 \%$ & $45 \%$ & $48 \%$ & $46 \%$ & $42 \%$ \\
\hline Margen bruto & $47 \%$ & $53 \%$ & $59 \%$ & $52 \%$ & $51 \%$ & $53 \%$ & $55 \%$ & $53 \%$ & $57 \%$ & $54 \%$ & $54 \%$ & $54 \%$ \\
\hline Margen operativo & $-5 \%$ & $1 \%$ & $3 \%$ & $11 \%$ & $10 \%$ & $10 \%$ & $9 \%$ & $8 \%$ & $13 \%$ & $12 \%$ & $12 \%$ & $12 \%$ \\
\hline Margen EBITDA & $3 \%$ & $6 \%$ & $8 \%$ & $16 \%$ & $15 \%$ & $15 \%$ & $13 \%$ & $14 \%$ & $17 \%$ & $15 \%$ & $15 \%$ & $15 \%$ \\
\hline Margen neto & $-3 \%$ & $-2 \%$ & $0 \%$ & $5 \%$ & $6 \%$ & $6 \%$ & $5 \%$ & $5 \%$ & $8 \%$ & $7 \%$ & $7 \%$ & $7.4 \%$ \\
\hline Rendimiento sobre la Inversión (ROI) & $-15 \%$ & $-9 \%$ & $1 \%$ & $17 \%$ & $18 \%$ & $19 \%$ & $9 \%$ & $9 \%$ & $18 \%$ & $15 \%$ & $18 \%$ & $18 \%$ \\
\hline Rotación de las Cuentas por Cobrar (Veces) & 34 & 34 & 38 & 42 & 27 & 43 & 45 & 39 & 48 & 34 & 35 & 35 \\
\hline Período Promedio de Cobranzas (Días) & 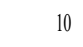 & 11 & 9 & 9 & 13 & 8 & 8 & 9 & 7 & 11 & 10 & 10 \\
\hline Rotación de las Cuentas por Pagar (Veces) & 112 & 121 & 118 & 88 & 62 & 54 & 51 & 38 & 47 & 40 & 40 & 40 \\
\hline Período Promedio de Pagos (Días) & 3 & 3 & 3 & 4 & 6 & 7 & 7 & 10 & 8 & 9 & 21 & 2 \\
\hline
\end{tabular}

Información EEFF OftalmoSalud

\subsection{Descripción del Negocio.}

OftalmoSalud es un Instituto dedicado a la prevención y atención de enfermedades oftalmológicas. 
Es importante hacer hincapié que el núcleo del negocio se encuentra en las consultas primarias, ya sean de atención correctiva o aquellas previsionales (menos del 30\% aún), debido a que de ellas parte la utilización de los servicios de las otras unidades de negocio (exámenes auxiliares, cirugía, farmacia y óptica), es decir que, a mayor número de consultas, mayor probabilidad de que las otras unidades de negocio se activen.

Es en este sentido que centraremos nuestra atención a los procesos de atención al cliente, principalmente de las unidades de negocio de consultas primarias, exámenes auxiliares y cirugía. Sin embargo, mencionaremos los otros procesos en los cuáles se involucra la empresa para el normal desarrollo de sus actividades.

El desarrollo de los procesos se podrá apreciar en detalle en el Capítulo 6 (Análisis Interno).

\subsection{Ciclo de vida del producto.}

El ciclo de vida de un servicio es determinado principalmente por factores de mercado, cambios tecnológicos, costos de producción, clientes, competencia, investigación y desarrollo y las ventas de la empresa.

En el ciclo de vida del servicio se puede apreciar como al inicio del negocio las ventas se incrementan en pequeña medida, para posteriormente aumentar su ritmo de crecimiento al llegar a ser conocidos por los clientes. Posteriormente este ritmo va decayendo en la medida que los mercados se saturan y dan paso a nuevos servicios que cubran de manera más satisfactoria la necesidad de los clientes o consumidores.

Dicho esto, y tal como se puede apreciar en el grafico siguiente, analizando las ventas históricas de OftalmoSalud, el negocio se encuentra en una etapa de madurez, en donde las ventas y costos se han estabilizado abriendo espacio a la innovación y mejora continua como 
factores clave para marcar la diferencia y mejorar sus utilidades. Es tiempo de analizar la capacidad instalada actual y tomar decisiones importantes para sostener este periodo de madurez.

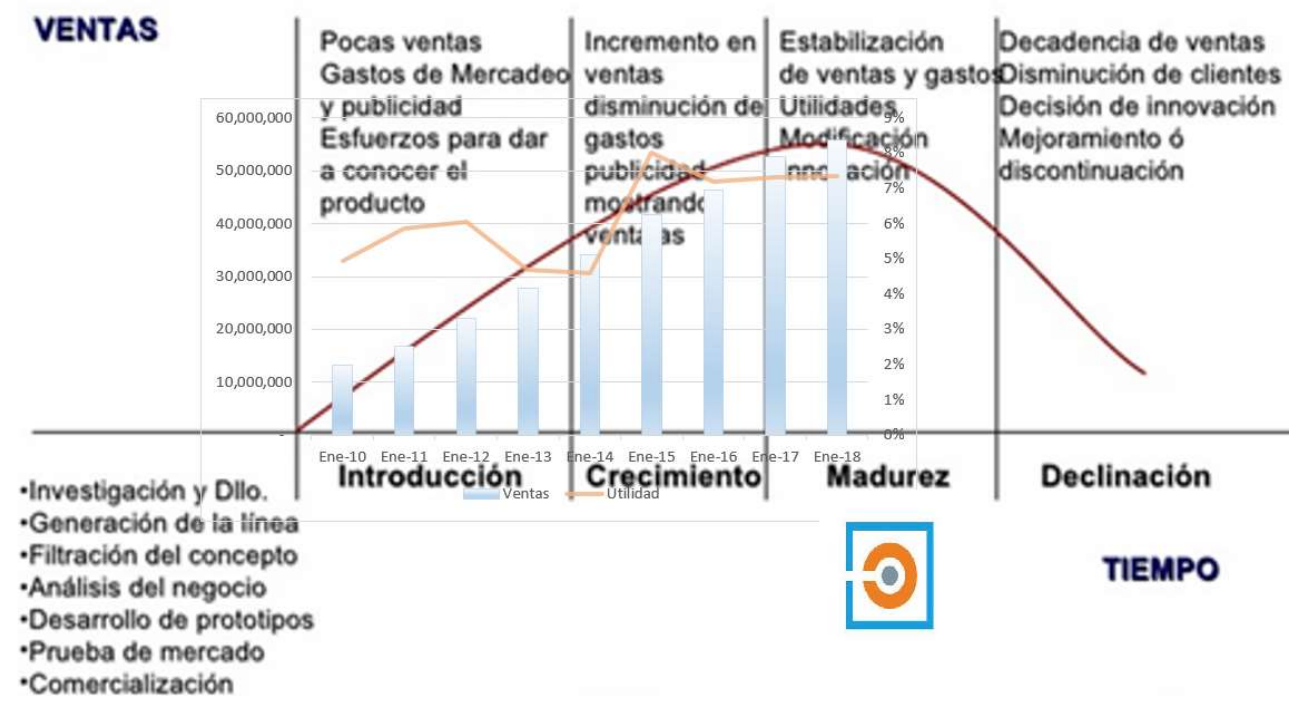

Figura 1. Ciclo de Vida del Producto o Servicio, elaboración en función al modelo desarrollado por el economista alemán Theodore Levitt

\subsection{Estructura organizacional actual de la empresa.}

El organigrama funcional Corporativo se puede apreciar en el siguiente gráfico:

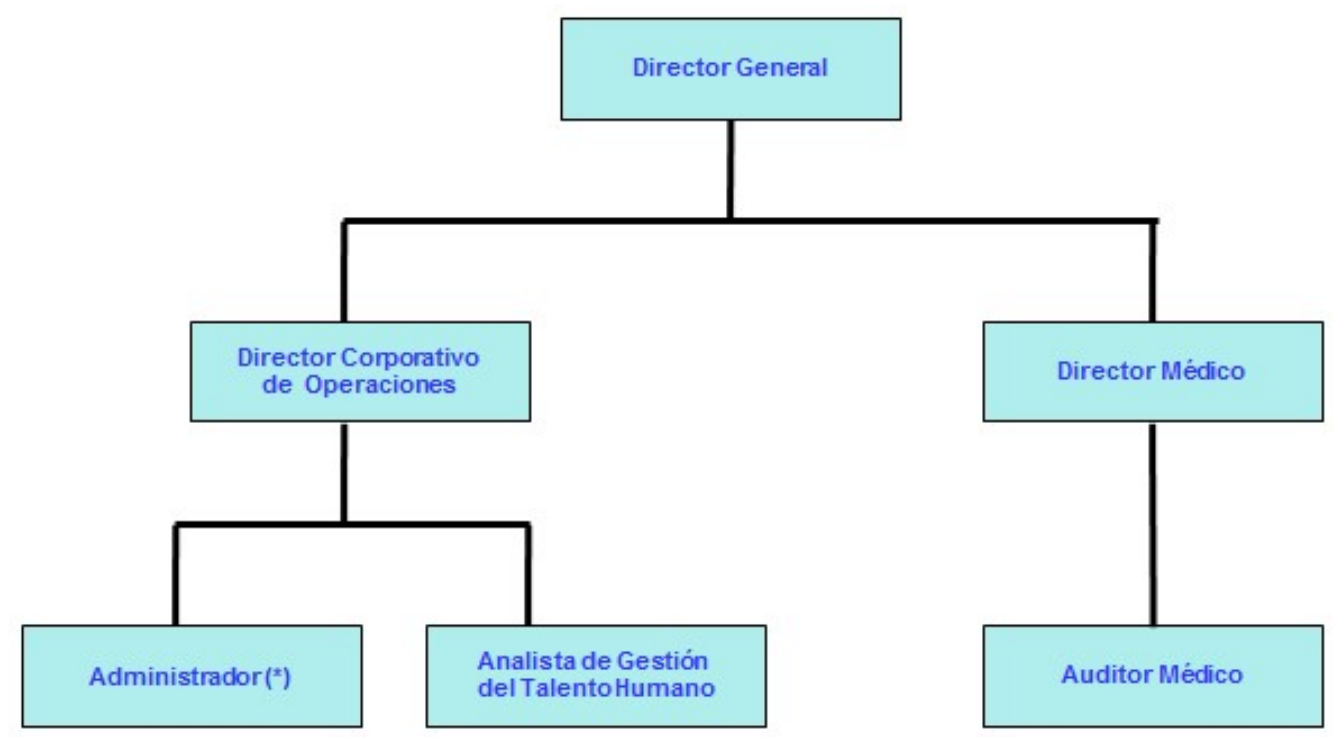

Figura 2. Organigrama Corporativo OftalmoSalud, elaboración con información obtenida de OftalmoSalud 
El organigrama funcional en cada una de las Sedes de OftalmoSalud se puede apreciar en el siguiente gráfico:

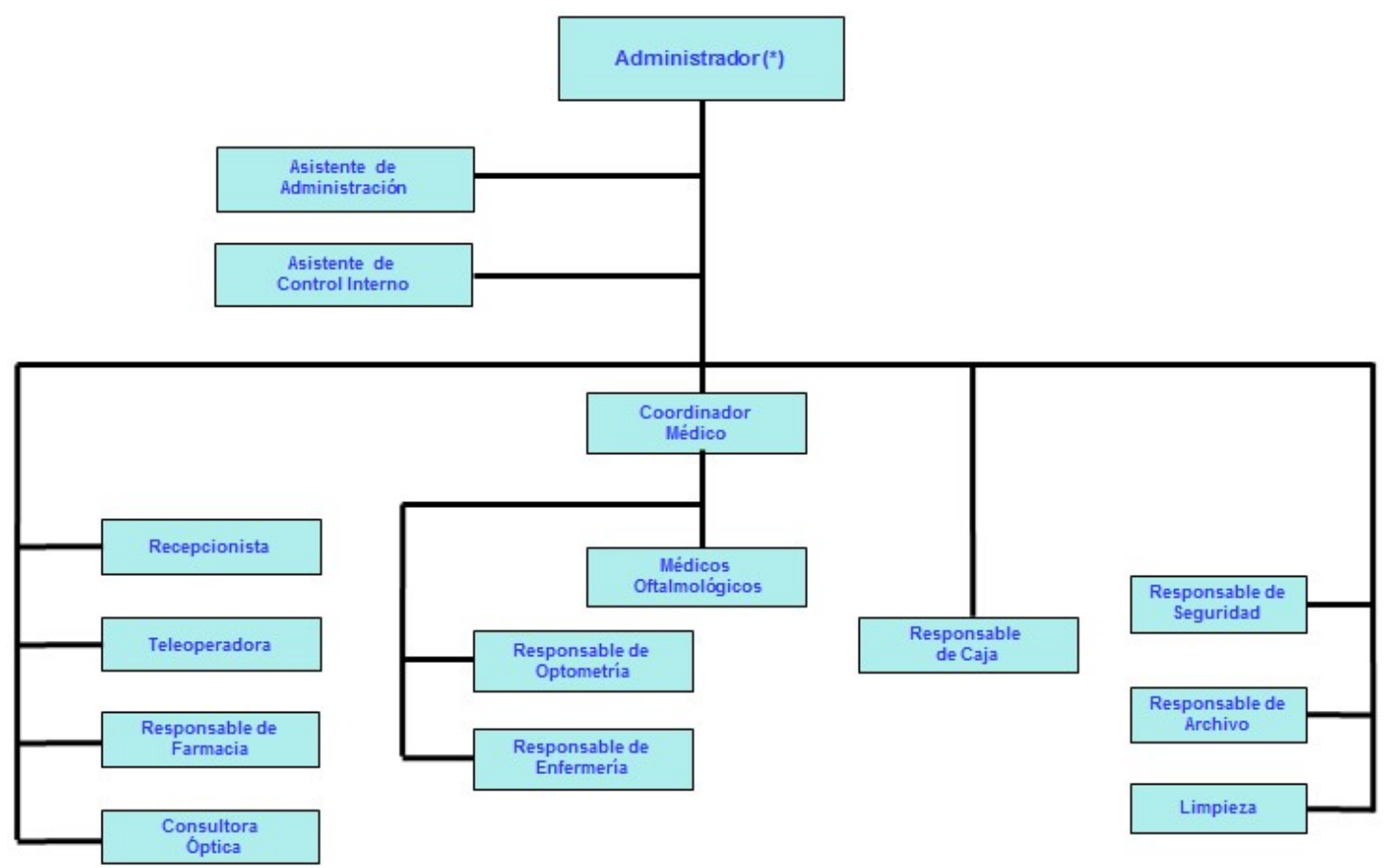

Figura 3. Organigrama Sedes OftalmoSalud, elaboración con información obtenida de OftalmoSalud

Tal como se puede apreciar, la estructura organizacional de OftalmoSalud es matricial y se caracteriza por ser una estructura que es utilizada por empresas de regular tamaño, que cuentan con varias sedes o proyectos operativos.

Por otro lado, hay que mencionar que no es frecuente que en las empresas que utilizan este tipo de organización, el dueño y el director gerente sean uno mismo; sin embargo, al tratarse de una empresa familiar como lo es OftalmoSalud, la dirección recae en uno de los miembros principales de la familia, el Sr. Fernando Izquierdo Villavicencio. Esta particularidad de la empresa muchas veces tiende a limitar algunas decisiones estratégicas de carácter corporativo por conflictos de intereses familiares. Actualmente la empresa se encuentra en un nivel de crecimiento y madurez que demanda un gobierno corporativo, ya que ha dejado de ser una empresa pequeña para ser la líder en el mercado. En este sentido y 
dada la mayor inversión en el sector y el fortalecimiento de la competencia, se requiere toma de decisiones dejando de lado el manejo familiar que se le viene dando hasta la fecha.

La estructura matricial de una organización divide la autoridad, tanto por área funcional y por proyecto o en este caso sedes.

En la estructura matricial de OftalmoSalud, cada uno de los empleados responde a dos supervisores inmediatos: un supervisor funcional (corporativo) y un supervisor del proyecto o sede. El supervisor funcional se encarga de supervisar los empleados en un área funcional específica. Los supervisores de proyecto gestionan un proyecto específico y a menudo transitorio.

Las principales ventajas de esta Organización son la coordinación de recursos, especialización, amplitud de habilidad, comunicación y flexibilidad.

OftalmoSalud cuenta con un excelente clima laboral y es producto de una buena comunicación y liderazgo y aunque, como se he mencionado previamente, tiene algunas deficiencias sobre todo en el gobierno corporativo, se está trabajando para realizar cambios que beneficien a la organización.

OftalmoSalud, ha monitoreado todas las instancias que se refieren al clima laboral y liderazgo a través de un estudio realizado con la empresa Global Research Marketing (GRM) y según lo manifestado en las conversaciones con sus directivos, obtuvieron excelentes resultados en todo lo estudiado, salvo en rotación del personal, que si bien tiene un indicador alto, el número no obedece a que la empresa cuente con un mal clima laboral o que el personal se encuentre poco motivado, sino que según lo revisado el perfil de los puestos administrativos no corresponde o no ha sido elaborado de manera adecuada. Es por ello que dentro de las acciones a trabajar se encuentra revisar y modificar estos perfiles para encontrar 
personal más idóneo sobre todo en las áreas administrativas que es donde se presenta la mayor rotación.

Esta información se obtuvo en las entrevistas, pero el informe realizado por GRM no nos fue proporcionado de manera física.

\subsection{Situación de Mercado y Financiera actual de la Industria.}

Proyectándonos hacia el cierre del 2018, y pese a la moderada recuperación experimentada en el 2017 a nivel socioeconómico, el empresariado del sector Salud se muestra no tan optimista. A esto se suma que, según información obtenida en una nota de prensa del diario El Comercio en su sección Dia 1 de fecha 26 de febrero de 2018, el presupuesto de Gobierno para este sector en el año 2018 el cual ha sido de S/. 16,027 millones ha disminuido en $4.6 \%$ respecto del 2017 , pese a esto no deja de ser uno de los puntos prioritarios de mejora que el gobierno desea trabajar en los próximos años, con una expectativa medianamente favorable.

En el sector privado, en aras de lograr este anhelado crecimiento del sector es necesario combatir el déficit de infraestructura, tanto para el sector público como privado, a fin de ampliar la base de asegurados, brindando una mejor calidad y calidez en la atención. Es conocido que a la fecha algunos grupos de inversionistas extranjeros vienen realizando inversión en infraestructura y activos médicos; adicionalmente a ello se espera que las EPS y algunos grupos comerciales locales ingresarán al campo oftalmológico.

Consultando con el Director de Operaciones de OftalmoSalud; debido al crecimiento país; la coyuntura política y la situación de la salud pública se espera que el mercado de salud privada continúe presentando un crecimiento del $6 \%$ y se espera que el mercado oftalmológico crezca en un rango del 10\% (atenciones), el mismo que podría también crecer 
en rangos de 15 a $20 \%$ si se logra concretar buenas negociaciones a través de los tarifarios de las EPS, los cuales no han sido actualizados por el alto poder de negociación de estas entidades. 


\section{Capítulo III. Formulación de la Visión, Misión y Valores de la Empresa}

El presente capítulo identifica la visión, misión y valores actuales del negocio, se realiza un análisis de los mismos para finalmente, en caso de ser necesario formular los cambios respectivos con la finalidad de alinearlos al planteamiento estratégico a elaborar.

\subsection{Visión.}

Definida por Fleitman Jack en su obra "Negocios Exitosos" (McGraw Hill, 2000) como “el camino al cual se dirige la empresa a largo plazo y sirve de rumbo y aliciente para orientar las decisiones estratégicas de crecimiento junto a las de competitividad”. Algunas preguntas frecuentes para elaborar la Visión son: ¿Qué queremos llegar a ser en el futuro?, ¿Qué resultados queremos alcanzar en el futuro?, ¿Cómo queremos vernos o que nos vean en el futuro? entre otras similares.

\subsubsection{Visión actual de la empresa.}

OftalmoSalud cuenta con la siguiente visión del negocio: "Ser el Instituto de Oftalmología de referencia nacional e internacional, mejorando la visión de nuestros pacientes con experiencia profesional, académica y calidad de servicio”.

\subsubsection{Análisis de la visión actual.}

Como parte del análisis de la visión se identificó que siendo que actualmente el ámbito de acción es Lima Metropolitana con posibilidades de posicionarse en las principales capitales de provincia, en pretender "ser referente nacional e internacional" es un objetivo no alcanzable en el mediano plazo por lo tanto es una declaración demasiado futurista.

Adicionalmente la declaración de "mejorar la visión de los pacientes con experiencia profesional, académica y calidad de servicio” no responde a la pregunta ¿Cómo queremos vernos o que nos vean en el futuro? 


\subsubsection{Matriz de la visión propuesta para la empresa.}

En la siguiente tabla de los elementos de la visión se intenta responder las preguntas claves para una buena declaración de la visión.

Tabla 3

Elementos de la Visión

\begin{tabular}{|l|l|}
\hline \multicolumn{1}{|c|}{ Pregunta } & \multicolumn{1}{|c|}{ Análisis } \\
\hline $\begin{array}{l}\text { ¿Qué queremos llegar a } \\
\text { ser en el futuro? }\end{array}$ & $\begin{array}{l}\text { Empresa líder en el mercado peruano en servicios } \\
\text { oftalmológicos. }\end{array}$ \\
\hline $\begin{array}{l}\text { ¿Qué resultados } \\
\text { queremos alcanzar en el } \\
\text { futuro? }\end{array}$ & $\begin{array}{l}\text { Posicionar la marca en el mercado nacional y } \\
\text { maximizar la rentabilidad de los accionistas. }\end{array}$ \\
\hline $\begin{array}{l}\text { ¿Cómo queremos } \\
\text { vernos o que nos vean } \\
\text { en el futuro? }\end{array}$ & $\begin{array}{l}\text { Empresa líder, reconocida por la calidad de su } \\
\text { servicio, una adecuada atención al cliente y el } \\
\text { empleo de tecnología de punta a nivel mundial. }\end{array}$ \\
\hline
\end{tabular}

Elaboración con información obtenida de OftalmoSalud

\subsubsection{Visión propuesta.}

"Mantener el liderazgo en el mercado peruano en servicios oftalmológicos, siendo reconocidos por la calidad de nuestro servicio, teniendo como pilares del servicio la atención al cliente y la utilización de la tecnología más avanzada del momento a nivel mundial”.

\subsection{Misión.}

Considerado por Philip Kotler y Gary Armstrong (Marketing, 2004) como "un importante elemento de la planificación estratégica"; la Misión describe el rol que desempeña actualmente la organización para el logro de su visión, es la razón de ser de la empresa.

\subsubsection{Misión actual de la empresa.}

OftalmoSalud cuenta con la siguiente misión del negocio: “Trabajar con la dedicación de siempre, apoyarlos por la excelencia profesional y la tecnología más avanzada del mundo. 
Así ofrecemos la mejor atención y tratamiento Oftalmológico a nuestros pacientes, contribuyendo a mejorar la calidad de vida de la sociedad".

\subsubsection{Análisis de la misión actual.}

La declaración actual de la misión no responde de manera clara la pregunta ¿Cuál es nuestro negocio? Asimismo, el indicar el "trabajar con la dedicación de siempre" es totalmente subjetivo ya que no se cuenta con una línea base con la cual comparar la dedicación. Por otro lado, en la misión deben estar bien identificados todos los interesados del negocio.

\subsubsection{Elementos de la misión propuesta para la empresa.}

Existen 7 preguntas claves cuya respuesta apoyaran al análisis de la misión, estas son:

Tabla 4

Elementos de la Misión

\begin{tabular}{|l|l|}
\hline \multicolumn{1}{|c|}{ Pregunta } & \multicolumn{1}{|c|}{ Análisis } \\
\hline ¿Quién es mi cliente? & $\begin{array}{l}\text { Toda persona que desee realizar un tratamiento preventivo } \\
\text { o paciente con algún padecimiento oftalmológico. }\end{array}$ \\
\hline $\begin{array}{l}\text { ¿Qué necesidad o beneficio } \\
\text { satisfago? }\end{array}$ & Salud para nuestros pacientes. \\
\hline $\begin{array}{l}\text { ¿En dónde compite la empresa } \\
\text { geográficamente? }\end{array}$ & Lima Metropolitana, Mercado Peruano. \\
\hline $\begin{array}{l}\text { ¿Qué tecnología } \\
\text { importante? }\end{array}$ & Equipos de tratamiento oftalmológico. \\
\hline ¿Cuál es el insumo principal? & $\begin{array}{l}\text { Personal calificado, equipos de última generación, } \\
\text { ambientes de atención. }\end{array}$ \\
\hline ¿Qué valores son importantes? & $\begin{array}{l}\text { Excelencia, Integridad, Trabajo en } \\
\text { Sustentabilidad, Innovación, Orientación al Cliente. }\end{array}$ \\
\hline ¿Porque lo hacemos? & Bienestar en la sociedad y rentabilidad para los accionistas. \\
\hline
\end{tabular}

Elaboración con información obtenida de OftalmoSalud 
Por otro lado, toda declaración de misión debe de tomar en consideración nueve componentes, las cuales exponemos a continuación:

Tabla 5

Componentes de la Misión

\begin{tabular}{|c|c|}
\hline Componente & Descripción \\
\hline 1. Cliente & $\begin{array}{l}\text { Toda persona que desee realizar un tratamiento preventivo o } \\
\text { paciente con algún padecimiento oftalmológico. }\end{array}$ \\
\hline 2. Producto o Servicio & $\begin{array}{l}\text { Tratamientos oftalmológicos en general (consultas, cirugías, } \\
\text { exámenes auxiliares, óptica y farmacia). }\end{array}$ \\
\hline 3. Mercados & $\begin{array}{l}\text { Lima Metropolitana, Mercado Peruano (pacientes de } \\
\text { provincia que vienen a Lima a ser atendidos) }\end{array}$ \\
\hline 4. Tecnología & $\begin{array}{l}\text { Equipos de tratamiento oftalmológico de última generación, } \\
\text { software para almacenamiento de historias clínicas, } \\
\text { inventarios, atención al cliente y facturación y cobranzas. }\end{array}$ \\
\hline 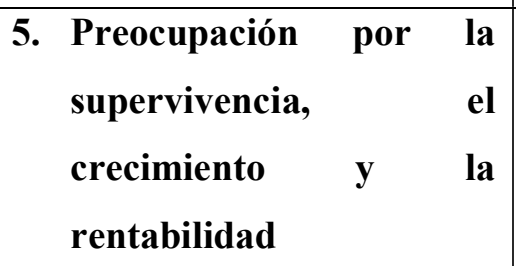 & $\begin{array}{l}\text { Liderazgo en el mercado nacional con un crecimiento } \\
\text { sostenido el cual se busca mantener de acuerdo a las } \\
\text { tendencias de mercado, maximizando la rentabilidad de los } \\
\text { accionistas. }\end{array}$ \\
\hline 6. Filosofía & $\begin{array}{l}\text { Búsqueda del bienestar de todos los pacientes respaldados } \\
\text { en el expertise y tecnología en materia oftalmológica y para } \\
\text { los colaboradores generando un ambiente agradable y } \\
\text { seguro de trabajo. }\end{array}$ \\
\hline 7. Auto-concepto & $\begin{array}{l}\text { Comprometidos a mantener el liderazgo en el mercado } \\
\text { nacional en tratamientos oftalmológicos en general } \\
\text { empleando para ello tecnología de punta. }\end{array}$ \\
\hline $\begin{array}{l}\text { 8. Preocupación por la } \\
\text { imagen publica }\end{array}$ & $\begin{array}{l}\text { Búsqueda constante del bienestar de la sociedad con } \\
\text { responsabilidad por el entorno que nos rodea. }\end{array}$ \\
\hline $\begin{array}{l}\text { 9. Preocupación por los } \\
\text { empleados }\end{array}$ & $\begin{array}{l}\text { Desarrollo de un ambiente idóneo de trabajo para nuestros } \\
\text { colaboradores con remuneraciones competitivas de acuerdo } \\
\text { al mercado laboral actual. }\end{array}$ \\
\hline
\end{tabular}

Elaboración con información obtenida de OftalmoSalud 


\subsubsection{Misión propuesta.}

"Brindar servicios oftalmológicos respaldados en el expertise de nuestro staff médico y el empleo de la tecnología más avanzada del momento, con el firme propósito de generar valor y mejorar la calidad de vida de nuestros clientes, colaboradores, accionistas y la sociedad.".

\subsection{Valores.}

\subsubsection{Valores actuales de la empresa.}

Los valores declarados por OftalmoSalud son 6: Ética, Orientación al Cliente, Iniciativa, Desarrollo de las Personas, Conciencia Organizacional y Adaptabilidad al Cambio.

\subsubsection{Análisis de los valores actuales.}

En la declaración de los valores del negocio, se aprecia que estos no están definidos (explicados); una definición clara de lo que se intenta cubrir, es importante para no generar interpretaciones diversas sobre cada valor.

Adicionalmente se aprecia que algunos de los valores expuestos no son necesariamente valores, sino más bien habilidades o buenos deseos que se requieren de los colaboradores o de la empresa hacia los colaboradores y/o clientes.

\subsubsection{Elementos de los valores propuestos para la empresa.}

Siendo que los valores de una empresa son los pilares más importantes de toda organización, la declaración de los mismos debe describir íntegramente al negocio en sí, a sus colaboradores y principalmente a sus funcionarios.

En ese sentido, los valores propuestos para la empresa deben de cubrir todo aquello que la empresa es (misión) con la finalidad de lograr los objetivos trazados (visión) teniendo siempre en consideración que: 
- Forman parte de una decisión estratégica a largo plazo.

- Son factores que definirán la manera de cómo debe vivir la organización.

- La voluntad y perseverancia siempre serán necesarios para ponerlos en acción.

\subsubsection{Valores propuestos.}

En base a la información obtenida previamente, se proponen y describen los siguientes valores:

Tabla 6

Valores Propuestos para OftalmoSalud

\begin{tabular}{|c|c|}
\hline Valor & Descripción \\
\hline 1. Excelencia & $\begin{array}{l}\text { Lograr los objetivos mediante la gestión eficiente de los } \\
\text { recursos. }\end{array}$ \\
\hline 2. Integridad & Actuar siempre de forma ética y transparente. \\
\hline $\begin{array}{l}\text { 3. Trabajo } \\
\text { Equipo }\end{array}$ & $\begin{array}{l}\text { Trabajar en forma coordinada sobre la base de relaciones } \\
\text { de confianza con un objetivo común. }\end{array}$ \\
\hline 4. Sustentabilidad & $\begin{array}{l}\text { Actuar en armonía con el medio ambiente, el entorno } \\
\text { social, promover la seguridad y cuidar la salud de nuestros } \\
\text { pacientes y colaboradores. }\end{array}$ \\
\hline 5. Innovación & $\begin{array}{l}\text { Fomentar una cultura de mejora continua y el desarrollo de } \\
\text { nuevas soluciones. }\end{array}$ \\
\hline $\begin{array}{l}\text { 6. Orientación } \\
\text { Cliente }\end{array}$ & $\begin{array}{l}\text { Entender las necesidades de nuestros clientes y buscar } \\
\text { altos niveles de satisfacción a través de la calidad de } \\
\text { nuestro servicio. }\end{array}$ \\
\hline
\end{tabular}

Elaboración con información obtenida de OftalmoSalud

\subsection{Alineamiento estratégico de la Visión, Misión y Valores de la empresa.}

A continuación, se puede apreciar una tabla en donde se resumen la visión, misión y valores propuestos. En ella se aprecia el alineamiento estratégico obtenido: 
Tabla 7

Alineamiento Estratégico

\begin{tabular}{|l|l|}
\hline \multicolumn{2}{|c|}{ VISIÓN } \\
\hline $\begin{array}{l}\text { Mantener el liderazgo en el mercado peruano en servicios oftalmológicos, siendo reconocidos } \\
\text { por la calidad de nuestro servicio, teniendo como pilares del servicio la atención al cliente y la } \\
\text { utilización de la tecnología más avanzada del momento a nivel mundial. }\end{array}$ \\
\hline \multicolumn{2}{|c|}{ MISIÓN } \\
\hline $\begin{array}{l}\text { Brindar servicios oftalmológicos respaldados en el expertise de nuestro staff médico y el } \\
\text { empleo de la tecnología más avanzada del momento, con el firme propósito de generar valor y } \\
\text { mejorar la calidad de vida de nuestros clientes, colaboradores, accionistas y la sociedad. }\end{array}$ \\
\hline \multicolumn{2}{|c|}{ Valor } \\
\hline 1.
\end{tabular}

Elaboración con información obtenida de OftalmoSalud

La nueva propuesta de Misión nos permitirá alcanzar la Visión también propuesta para la Organización fundamentada principalmente en el expertise de su staff médico y la tecnología que utilizan para la atención de sus clientes, buscando mejorar su calidad de vida y a la vez generando valor para los accionistas. Resultaría imposible lograr la Visión, si la organización no tuviese clara su Misión y la misma se apoyase en los valores propuestos.

Es importante hacer hincapié que tanto el análisis de estos tres componentes como el resultado obtenido fueron expuestos tanto con el Director de Operaciones como con el Director Gerente los cuales estuvieron de acuerdo con las nuevas propuestas. 


\section{Capítulo IV. Análisis Externo}

En este capítulo se revisarán todas aquellas variables externas que puedan influenciar en el desarrollo y crecimiento de la empresa en análisis. Se iniciará con un marco político y económico mundial y posteriormente se complementará la información con el panorama local que es donde OftalmoSalud realiza sus operaciones.

\subsection{Tendencias de las variables del entorno.}

\subsubsection{Análisis Político-Gubernamental.}

Situación Actual en el mundo: Las crecientes tensiones geopolíticas y geoeconómicas destacan de manera importante con respecto al año pasado. Por ejemplo, las continuas tensiones entre Estados Unidos y China, las guerras comerciales, el Brexit y los cambios en la zona Euro, el futuro de los programas nucleares de Irán y Corea del Norte, y las tensiones entre Rusia y Occidente, son los principales riesgos que se deben tener en cuenta en el ámbito político.

Nuevamente, Estados Unidos y China están intensificando su competencia geopolítica en la región del Indo-Pacífico y, al aumentar las actividades militares en el Mar de China Meridional, es posible un choque militar no deseado. Mientras tanto, las relaciones de Rusia con Occidente se mantendrán tensas en 2019 como resultado de la supuesta interferencia del Kremlin en la política interna de Estados Unidos y la Unión Europea. El incidente de envenenamiento de Skripal en el Reino Unido, la piratería de laboratorios en Suiza y los conflictos en Siria y Ucrania. Todo esto podría llevar a más sanciones de Estados Unidos y/o la Unión Europea a Rusia. La retirada del presidente de los Estados Unidos, Donald Trump, del Tratado de Fuerzas Nucleares de Alcance Intermedio entre los Estados Unidos y la Unión Soviética de 1987, también plantea la posibilidad de un nuevo misil en Europa. 
En pocas palabras el 2019 será un año movido para las elecciones en los mercados emergentes y en algunos estados desarrollados, lo que podría aumentar el clima de volatilidad política. Se viene mucha incertidumbre por delante

Tendencia Mundial: La tendencia indica que las principales amenazas macro se encuentran en las llamadas economías desarrolladas, en oposición a los mercados emergentes.

En Latinoamérica, los principales datos indican que los riesgos políticos en varios países latinoamericanos han mejorado como son Guatemala, Chile y Paraguay. En el caso de Guatemala mejoró a medida que el presidente Jimmy Morales obtuvo más apoyo del Congreso y el sistema que en el 2017, al tiempo que evitó las protestas a gran escala.

En Chile, la elección del presidente Sebastián Piñera en diciembre de 2017 puso fin a un período de incertidumbre, con mejoría económica y menor desempleo. Mientras tanto, Paraguay experimentó una mayor claridad en la política y una disminución de las tensiones sociales tras la elección del presidente Mario Abdo Benítez en abril.

Sin embargo, hay otros países cuyas coyunturas han empeorado, tal es el caso de Nicaragua que enfrentó protestas masivas contra su gobierno en 2018; Venezuela, cuya inflación alcanzará el 10,000,000\% en el 2019, mientras que el nuevo escenario político -con Juan Guaidó, presidente del parlamento, reconocido por muchos países como presidente interino- aumenta la incertidumbre sobre el futuro del país.

Si vamos hacia el Norte, en Estados Unidos, el regreso de la mayoría demócrata a la Cámara de Representantes en las elecciones intermedias de 2018 viene conduciendo al país a un panorama político más combativo; ya se ha presentado el cierre de gobierno más 
prolongado de la historia estadounidense; con una cámara de representantes más activista podría iniciar investigaciones sobre las faltas percibidas por el presidente Trump u otros. Los candidatos ya se están postulando para la nominación presidencial demócrata de 2020, El Congreso se encuentra dividido y esto probablemente retrasará la formación de políticas y su promulgación, por lo que es probable que el enfoque del presidente Trump se centre en la política exterior, donde el ejecutivo tiene más margen de maniobra que en la política nacional.

Los aranceles comerciales y las disputas geopolíticas con China están escalándose en el 2019, lo que aumenta el riesgo de nuevas represalias chinas y la respuesta a ellas por parte de Estados Unidos. Además, la nueva imposición de sanciones por parte de Trump a Irán, dadas en noviembre de 2018 podría generar una postura más dura por parte de Teherán, lo que aumentaría el riesgo de conflicto o el inicio de un nuevo acercamiento.

Otro objetivo importante a nivel político para Estado Unidos será asegurar que el acercamiento con Corea del Norte siga en el buen camino.

Por el lado de Europa, la política del Reino Unido en el 2019 se mantendrá centrada en las negociaciones del Brexit y el período de transición posterior fuera de la Unión Europea. (UE). Aparte del Brexit, la UE estará en un estado de transición mientras se prepara para las elecciones parlamentarias en mayo y los nuevos presidentes de la Comisión Europea, del Banco Central Europeo y del Consejo Europeo, en noviembre y diciembre, respectivamente.

Por el lado del Medio Oriente, si bien el equilibrio de poder en Siria ha cambiado a favor del presidente Bashar al-Assad, un acuerdo de paz parece poco probable en el futuro inmediato. El conflicto plantea el riesgo de un enfrentamiento entre los militares rusos y estadounidenses. Cualquier choque que involucre a tropas "oficiales" sería peligroso y podría escalar a una crisis mayor. 
Situación actual en el Perú: La situación política en el Perú está pasando por un momento bastante difícil, luego de la vacancia de Pedro Pablo Kuczinsky y la toma de mando por parte de Martín Vizcarra quien fuera vicepresidente y ahora es Presidente de la República. Sin embargo, a un año del nuevo Gobierno, no han llegado nuevos aires, sino que, por el contrario, se destapó una crisis en el poder judicial que arrastró a jueces y fiscales que otorgaron favores de manera irregular.

Pese a este escenario totalmente contraproducente para el país, aún hay confianza, principalmente de los inversionistas extranjeros, lo cual deja entrever que en el mediano plazo podría empezar a sentirse una muy ligera reactivación económica que iría de la mano con una buena gestión política y siempre y cuando los reveses políticos del mundo no influyan demasiado.

Tendencia en el Perú: El año 2018 fue el año del asentamiento del gobierno de Martín Vizcarra. En el 2019, las iniciativas legislativas que se han venido proponiendo y que se propongan durante los próximos meses serán cruciales para mejorar las perspectivas de crecimiento económico. Sin embargo, los principales retos de su gobierno estarán en el terreno del poder judicial y en el terreno legislativo, donde tendrá que tomar decisiones importantes que le permitan gobernar.

Por otro lado y ya llevando este análisis político un poco más al ámbito sectorial de Salud, como se ha mencionado anteriormente, vemos que el sector salud hace falta infraestructura para atender a los asegurados por lo que se hace imprescindible que el sector privado esté preparado asumir el reto de incrementar infraestructura y a su vez iniciar negociaciones con el estado para poder atender una masa de pacientes que por falta de capacidad o complejidad requieran ser atendidos en clínicas más preparadas.

Para mejorar el problema de capacidad de atención el gobierno ha iniciado un plan para 
que dentro de los hospitales del estado donde se puedan atender los asegurados también se incluyan los hospitales de las fuerzas armadas. Bajo el Decreto Supremo N 012-2019-SA, estipula que las personas aseguradas al Seguro Integral de Salud (SIS) del Ministerio de Salud (Minsa), a ESSalud y a la Sanidad de las Fuerzas Armadas, serán atendidas en cualquiera de sus establecimientos médicos, ya que se ha dispuesto que estas entidades articulen entre ellas para garantizar y utilizar la oferta pública existente en el país centradas en el ciudadano con accesibilidad, equidad y oportunidad.

El intercambio prestacional es entre Instituciones Administradoras de Fondos de Aseguramiento en Salud (IAFAS), Unidades de Gestión de las IPRESS (UGIPRESS) e Instituciones Prestadoras de Servicios de Salud (IPRESS) públicas, generarán mayor cobertura y utilizando en forma eficiente la oferta pública disponible a nivel nacional.

El presente Decreto Supremo fue firmado por el presidente Martín Vizcarra y refrendado por la ministra de Salud, Zulema Tomás Gonzáles; la ministra de Trabajo y Promoción del Empleo, Silvia Cáceres; el ministro de Defensa, José Huerta y el ministro del Interior, Carlos Morán en junio del 2019.

Cómo afecta a los clientes, proveedores y a OftalmoSalud: Entendemos que las distintas coyunturas políticas afectan de manera importante la estabilidad de todos los países y en especial los emergentes, que en sí son los más débiles. Si a ello le sumamos que el Perú por su parte viene enfrentando una inestabilidad debido a la situación actual del gobierno y las medidas propuestas, se puede percibir que aún los mercados no se han reactivado lo cual repercute directamente con los ingresos de las personas y por lo tanto en sus atenciones de salud principalmente en el ámbito preventivo.

Si pensamos en nuestros clientes, se puede inferir que los tratamientos principalmente preventivos serán los que más se verán afectados, ya que mientras que la confianza política 
por el nuevo gobierno no se consolide y se vea reflejado en el plano económico, los clientes o futuros clientes no contarán o no desearán destinar sus ingresos a tratamientos preventivos de su salud frente a otros aspectos en su consumo o gastos corrientes que consideren de mayor importancia.

Dicho esto, tanto los proveedores y OftalmoSalud se verán perjudicados en la medida que el lado preventivo deje de desarrollarse al vender menos en ambos casos. Estimamos que los tratamientos correctivos, al ser necesarios para tratar las enfermedades actuales no se verán mayormente afectados.

\subsubsection{Análisis Económico.}

Situación Actual en el mundo: Según el Informe de Estrategia Global 1Q19 emitido por Inteligo Bank, el mundo viene enfrentando un escenario económico de muy lento crecimiento y con un posible escenario recesivo para una de las principales economías del mundo como es Estados Unidos.

Tendencia Mundial: El crecimiento económico mundial se mantuvo estable en 2018, en un 3,1\% gracias a que la aceleración que se produjo con los cambios en las políticas fiscales en los Estados Unidos que contrarrestó la disminución del ritmo de crecimiento de otras economías importantes. Se prevé que la actividad económica a nivel mundial se expandirá a un ritmo sostenido del $3 \%$ en 2019 , pero cada vez hay más indicios de que el crecimiento podría haber alcanzado su punto máximo. El crecimiento de la producción industrial mundial y de los volúmenes del comercio de mercancías viene disminuyendo desde

principios de 2018, especialmente en los sectores de bienes de capital y bienes intermedios en los que el intercambio comercial tiene un peso significativo. Los principales indicadores señalan un cierto debilitamiento del impulso económico en muchos países para el 2019, en medio de una escalada de las disputas comerciales, riesgos de tensiones financieras y de 
volatilidad en un trasfondo de tensiones geopolíticas. Al mismo tiempo, varias economías desarrolladas están enfrentando limitaciones de capacidad, que pueden ser un lastre para el crecimiento a corto plazo.

Situación actual en el Perú: El Ministerio de Economía y Finanzas (MEF) publicó en Agosto del 2019, el Marco Macroeconómico Multianual 2020 - 2023 (MMM) en el cual se proyectó un crecimiento del PBI de 3\% para 2019 y 4,4\% en promedio para los próximos cuatro años, con una senda gradual de aceleración de 4,0\% en 2020 a 5,0\% en 2023. Con esta proyección se espera que el Perú continúe liderando el crecimiento en la región, a pesar del entorno internacional adverso.

Esta aceleración sería impulsada, principalmente, por la demanda interna reflejada en el fortalecimiento de la inversión privada y pública; además, de las medidas de política económica orientadas a mejorar la productividad y competitividad del país. Para esta proyección también se consideraron factores como los proyectos vinculados a obras públicas y a los Juegos Panamericanos, y la recuperación sostenida de la inversión minera

Otro factor que influye en las variaciones de las proyecciones económicas es la renovación de autoridades, factor que, tras el resultado del referéndum que solicitó Vizcarra, generará atrasos adicionales en la ejecución de los trabajos de la Reconstrucción, los proyectos de infraestructura concesionada y las obras del Gobierno Central.

También es importante destacar que las familias continúan con dificultades para encontrar empleos adecuados, por lo que reducimos nuestra proyección de consumo privado de $3.2 \%$ a $3.0 \%$. Finalmente, se debe tener en cuenta que nuevos deterioros de la situación política podrían reducir el crecimiento de la economía hasta $2.7 \%$, siendo bastante pesimistas.

Enfocándonos un poco más en el sector salud directamente, si bien el Perú destina cada 
vez mayores recursos a este sector, en esta materia el país aún tiene importantes desafíos, pues aún está rezagado con respecto a otros países de América Latina.

El presupuesto asignado al sector salud se incrementó un $63.4 \%$ en los últimos cinco años, no de manera lineal, pero a pesar de este crecimiento, nuestro país mantuvo una menor participación del gasto en salud sobre el PBI en comparación con los países de la Alianza del Pacífico (Perú, Colombia, Chile, a excepción de México).

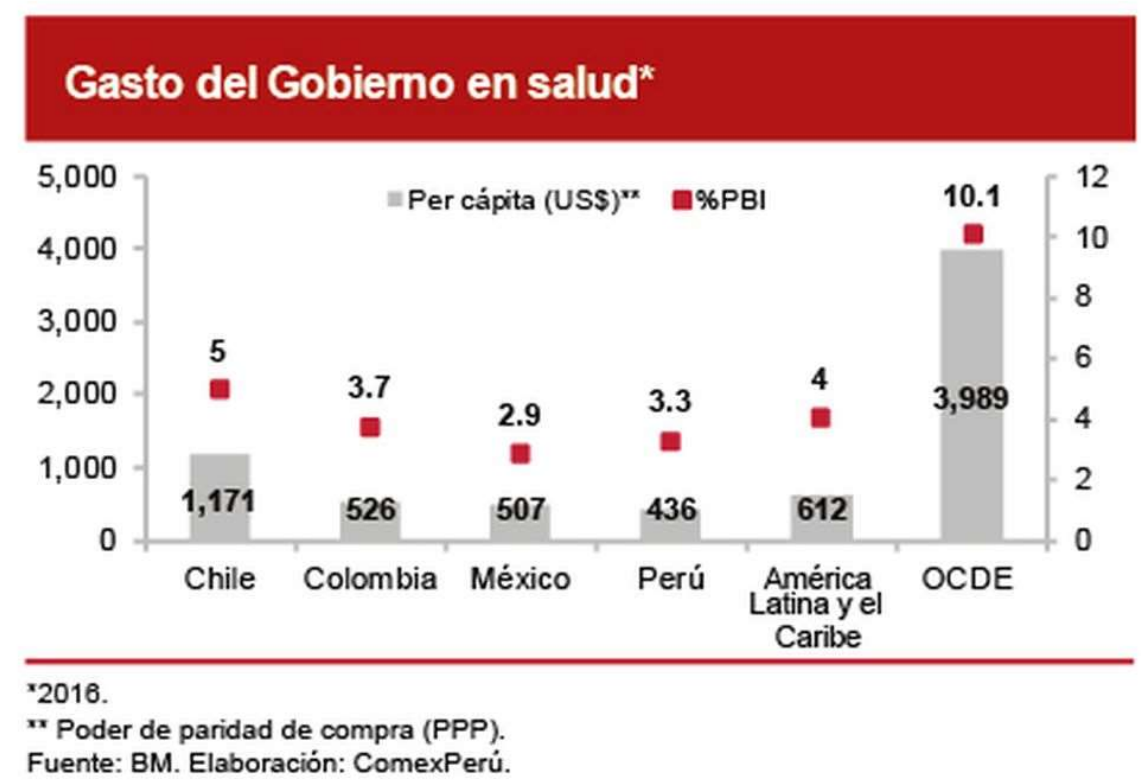

Figura 4. Gasto del Gobierno en el Sector Salud, fuente Comex

Así, ese gremio destaca que más del 70\% de ese gasto corresponde a abordar problemas de salud individual, es decir, aquellas acciones orientadas a la recuperación y rehabilitación de la salud de las personas; mientras que, únicamente, entre un 6\% y 7\% es asignado a la salud colectiva, que involucra la promoción de la salud y la prevención de riesgos y daños en la población, lo que en buena parte implicaría que no tenemos un enfoque preventivo. 


\section{Perú: gasto público en salud (S/ millones)}

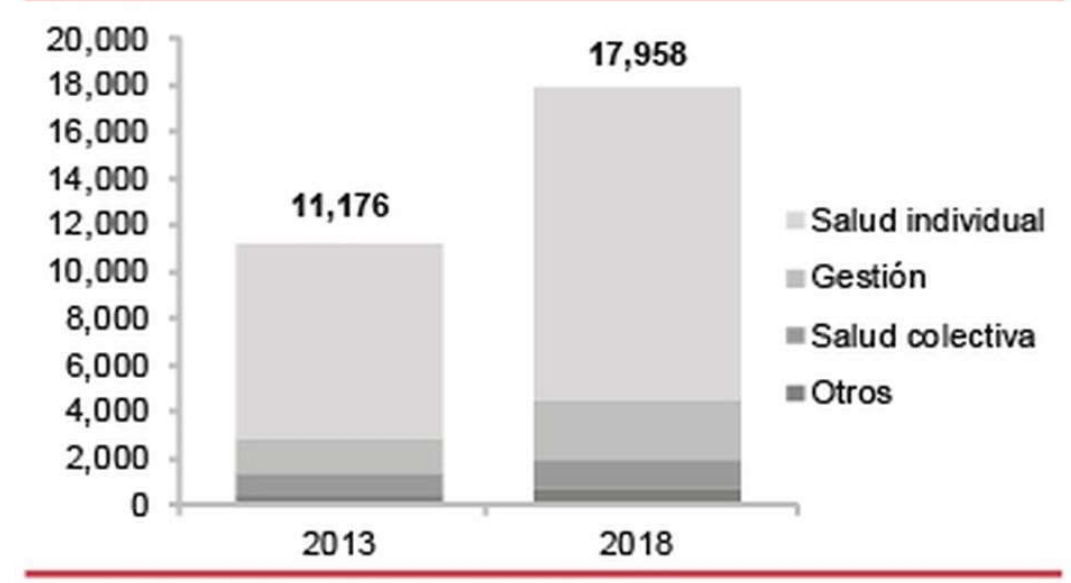

Fuente: MEF. Elaboración: ComexPerú.

Figura 5. Gasto Publico en el Sector Salud, fuente Comex

Como se observa, la estructura en el gasto antes mencionada se ha mantenido a lo largo de los últimos cinco años, periodo en el que se observa, además, un incremento del $86 \%$ del gasto por concepto de personal y obligaciones sociales del Estado.

Según el MEF, en 2018, el 51.1\% del Gasto Público fue ejecutado por el Gobierno Nacional, principalmente por el Ministerio de Salud (MINSA), con el 62\% del total; mientras que los Gobiernos regionales y locales, un $46.6 \%$ y $2.3 \%$, respectivamente.

Con respecto al tipo de cambio, el mismo finalizaría el 2019 en S/ 3.37 por dólar estadounidense y el 2020 en 3.34 por USD, estimaron los analistas de Focus Economics en su informe LatinFocus Consensus Forecast, pero bajo un posible escenario de recorte de tasas probablemente el sol terminaría depreciándose frente al dólar.

Por el lado de la inflación, la misma se mantiene estable y se proyecta igual para el cierre del año (2.2\%). Los precios del transporte y las comunicaciones, los combustibles domésticos y los servicios educativos y culturales registraron los aumentos más pronunciados. Para el 2020, las presiones inflacionarias deberían fortalecerse gracias al fortalecimiento del PBI y al 
crecimiento de la demanda interna, y al aumento de los precios de los alimentos. Se prevee que la inflación terminará el 2019 en $2.5 \%$ y el 2020 en $2.4 \%$.

Con respecto a la tasa de interés, la misma ha venido moviéndose localmente en la medida que la FED la ha venido recortando en Estados Unidos. Y aunque los escenarios aún son inciertos, se estima que la tasa de política monetaria finalizará el 2019 en 3.50\% y un incremento en 30 puntos básicos para el 2020.

Cómo afecta a los clientes, proveedores y a OftalmoSalud: Por el lado económico, podemos inferir que el país debería mantenerse en uno de sus peores momentos económicos en los últimos 10 años y totalmente influido por la situación económica mundial, aunado a que la situación política interna, ha frenado y puesto en stand by muchos proyectos y decisiones que podrían llevarnos por la senda del crecimiento.

El Perú, al momento, presenta una economía que está bastante venida a menos con respecto a periodos anteriores. Es por ello que, consideramos que, a nivel de nuestros clientes, los mismos todavía se verán afectados un tiempo más en cuanto a su poder adquisitivo, por lo que tal vez los tratamientos de índole preventiva dejen de ser una prioridad en sus gastos mensuales o anuales.

Por el lado de nuestros proveedores y OftalmoSalud se verán afectados en la misma medida que se pierda este ingreso y por el lado de OftalmoSalud también hay que mencionar que el factor de tipo de cambio puede ser contraproducente ya que muchas de las compras de productos y equipo médico se realizan en dólares, por lo que el tipo de cambio influye de manera importante en los rendimientos finales

\subsubsection{Análisis Legal.}

Situación Actual: En cuanto al marco legal, el sector Salud, se encuentra regulado por 
aquellas leyes, decretos supremos y resoluciones ministeriales del sector en mención.

Es importante mencionar la regulación de la Dirección de Salud (DISA) del Ministerio de Salud (MINSA), la cual es estricta en sus parámetros para otorgar la categorización la cual aplica desde un puesto de salud hasta un instituto especializado.

De acuerdo a la Resolución Ministerial N²17 - 2004 del MINSA del año 2004, al igual que cualquier negocio indistintamente del sector en el que se desempeñe es necesario cumplir con los requisitos necesarios para su normal funcionamiento (licencias de construcción y funcionamiento municipales y compatibilidades de uso), el pago de tributos y cumplimiento de aspectos laborales para con los colaboradores y el manejo de residuos a través de una norma cuyo cumplimiento es obligatorio en todos los establecimientos de salud a nivel nacional, siendo su objetivo principal mejorar la calidad de los servicios hospitalarios mediante un sistema eficaz y eficiente de administración de residuos en el ámbito intra nosocomial, que asegure el manejo adecuado de los residuos sólidos generados en los hospitales, con el fin de minimizar y controlar los riesgos sanitarios y ocupacionales de la población hospitalaria, así como los impactos en la salud pública y el ambiente.

Otro aspecto a tomar en cuenta es la jurisprudencia de la Superintendencia Nacional de Salud (SUSALUD) para todo aquello referido con la protección de los derechos de los clientes del sector (pacientes).

Por otro lado, en los aspectos legales de los asegurados, la Ley Marco de Aseguramiento Universal en Salud fue creada en 2009 para garantizar el derecho pleno y progresivo de todo peruano a la seguridad social. La sanidad pública se encuentra saturada de pacientes y la privada aún tiene capacidad para hacer alianzas público-privadas para atender a un alto número de pacientes. 
Como se ha mencionado anteriormente, las principales clínicas de Lima están incrementando su capacidad o planean hacerlo, sin embargo, se enfrentan a la escasa disponibilidad de espacios para la salud, debido a que las áreas destinadas para ello son pocas y están cada vez más restringidas por las municipalidades.

Por otro lado, en junio de 2012, la Comisión de Descentralización, Regionalización, Gobiernos Locales y Modernización de la Gestión del Estado aprobó el proyecto de ley en el que se propone crear una superintendencia nacional de fiscalización laboral, donde se obliga a las empresas a realizarle chequeos médicos preventivos a sus colaboradores, y a la fecha, los mismos ya se vienen aplicando. Con esta ley se abre un mercado importante para la realización de chequeos médicos obligatorios y dentro de ellos los despistajes oftalmológicos con el fin de asegurar la salud ocupacional.

Otro aspecto legal pendiente para el Estado es la corrección de las disposiciones legales respecto a los aportes por afiliación a ESSalud, los cuáles son de carácter mensual a cargo de la entidad empleadora y equivalen al 9\% de la remuneración. Si bien existe el aseguramiento obligatorio al régimen de la Seguridad Social para aquellos trabajadores activos que laboran bajo relación de dependencia cuya base legal es la Ley 26790 y su Reglamento en Decreto Supremo No 009-97-SA y las normas modificatorias: Ley 28791 y Decreto Supremo No 0202006-TR, los trabajadores pueden optar complementariamente por programas de atención médica privados que son usados principalmente para reemplazar la atención primaria y son brindados a través del propio empleador o por medio de entidades privadas contratadas por estos (Entidades Prestadoras de Salud - EPS). Si un trabajador decidiera tomar este seguro, su empleador ya no destinará el equivalente al $9 \%$ de su salario a ESSalud, sino solo el $6.75 \%$. El 2.25\% restante lo aportará a la EPS elegida, monto que no alcanza para cubrir la totalidad del seguro por lo cual el costo es generalmente asumido en parte por el empleador y en parte por el trabajador. 
Cómo afecta a los clientes, proveedores y a OftalmoSalud: Como se ha mencionado, por la parte legal hay dos aristas que pueden ayudar a elevar el número de atenciones. Por el lado de las preventivas, la ley de obligatoriedad del examen médico laboral y por otro lado, se espera un sinceramiento del aporte del empleador hacia las EPS con un porcentaje mayor o total. Este sinceramiento podría elevar el número de atenciones ya sea por el lado preventivo, así como por el no preventivo y afectaría de manera positiva a OftalmosSalud y a los proveedores de esta.

\subsubsection{Análisis de variables sociales, demográficas y culturales.}

\section{a. Análisis social del país}

Situación Actual: El análisis social evalúa el proceso de promoción del bienestar de las personas en conjunción con un proceso de desarrollo económico. En los últimos años este proceso está conduciendo al mejoramiento de las condiciones de vida de toda la población en los diferentes ámbitos como son: salud, educación, nutrición, vivienda, seguridad social, empleo y salarios principalmente. Para ello debe contar con la participación activa del Estado.

En el sector salud, el crecimiento de la formalización del empleo ha repercutido de manera favorable en la economía de las personas, logrando que muchos empleados y sus familiares accedan a atenciones en clínicas privadas mediante el uso del seguro privado de empresas prestadoras de salud (EPS), dejando así de lado la atención en establecimientos públicos; si a esto se le suma la obligatoriedad de los chequeos médicos ocupacionales, estamos delante del desarrollo de una cultura de prevención en salud en la población del país.

Tendencia: Existe un consenso en el cual se indica que el crecimiento económico es un factor primordial para que este desarrollo social se dé. Es por ello que en los últimos diez años, la población de nuestro país sintió este efecto de bienestar y mejoría en este aspecto, sin 
embargo, a pesar del desarrollo experimentado, la situación actual muestra que es bastante probable que esta situación de bienestar se vea frenada por la coyuntura política y económica actual del país, sin embargo, el Director de OftalmoSalud se mostró entusiasta en referencia a que esta cultura de prevención no se verá del todo impactada por la coyuntura económica actual.

Como afecta a los clientes, proveedores y a OftalmoSalud: De mejorar la coyuntura política y económica en el país; el bienestar que generaría el contar con un mayor ingreso per cápita, permite que las personas se preocupen más por su salud en el ámbito principalmente preventivo, lo cual significa mayor mercado para nuestros proveedores y para OftalmoSalud.

\section{b. Análisis Demográfico}

Situación actual Perú: Según el último Censo 2017 elaborado por el Instituto Nacional de Estadística e Informática (INEI), la población del país alcanza los 31’237,385 habitantes, de los cuales $14^{\prime} 450,757$ son hombres y 14'931,127 son mujeres.

Con data tomada en el 2014, se estimó que durante el periodo 2014-2015 nacerían 581,450 personas y fallecerían 172,731 , lo cual equivale a un crecimiento natural o vegetativo de 13 personas por mil habitantes. El saldo neto migratorio internacional (inmigrantes menos emigrantes) arroja una pérdida de 70,046 personas, por lo que finalmente el crecimiento anual al año 2014 ascendió a 338,673 personas, lo cual representa una tasa de crecimiento total de 11 personas por mil habitantes $(1.1 \%)$.

Tendencia: El INEI estima que la tasa de crecimiento demográfico para los siguientes 10 años se mantendrá en rangos entre $1.1 \%$ y $0.9 \%$, tal como se puede apreciar en el siguiente gráfico: 


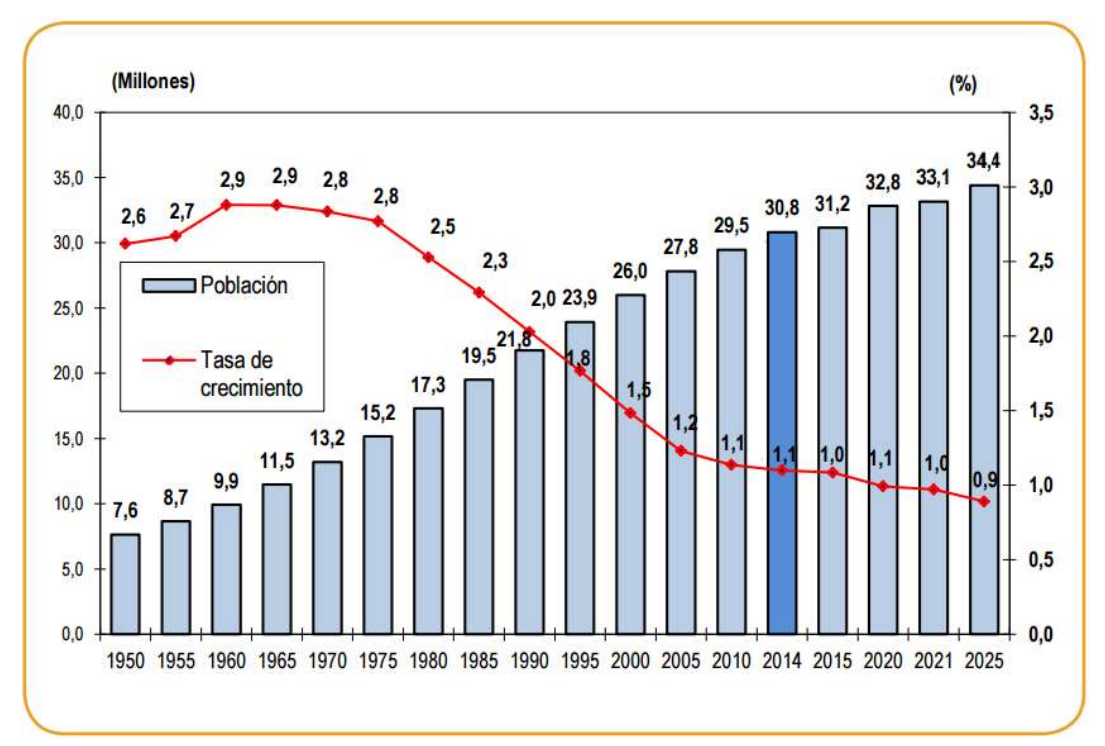

Figura 6. Población y Tasa de Crecimiento 1950 - 2025, INEI

Se han mantenido algunos datos del reporte 2014 ya que el INEI aún no ha generado un reporte con estimaciones sobre la data obtenida en el Censo 2017.

Si sobre la data obtenida de la Organización Panamericana de la Salud donde indican que al 2013 la cifra de ciegos en el Perú era de 160,000, si consideramos que para el 2019 la población de ciegos creció al mismo ritmo de crecimiento demográfico, tendríamos que el número de ciegos aumentó entre 8,600 y 10,500, y si a esto le sumamos aquellos que indicaron tener algún problema visual severo, sumarían otros entre 16,000 a casi 20,000 personas, si tomamos como base los 300 mil del estudio.

Por otro lado, y ya dándole otro enfoque a la parte demográfica, si analizamos la población en los departamentos y distritos: con datos obtenidos en el Censo 2017, la provincia más poblada es Lima con 8’574,974 habitantes, con una tasa de crecimiento anual de 1,2\%; le siguen Arequipa con 1’080,635 habitantes y una tasa de crecimiento de 2,3\%; la Provincia Constitucional del Callao con 994,494 habitantes y una tasa de 1.3\% y Trujillo con 970,000 habitantes, con una tasa de crecimiento anual de 1,8\%.

Por parte de los distritos, San Juan de Lurigancho continúa siendo el distrito más 
poblado, al totalizar 1’038,495 habitantes. Le siguen San Martín de Porres con 654,083

habitantes; Ate con 599,196 habitantes y Comas con 520,450 habitantes.

Estos datos de crecimiento poblacional por provincia o por distrito nos ayudarían si pensamos en expansión o nuevas localizaciones de futuras clínicas.

Como afecta a los clientes, proveedores y a OftalmoSalud: Toda esta información, nos muestra el crecimiento demográfico que se ha experimentado en el país en los últimos años y nos da luces hacia donde apunta tanto el crecimiento del número de posibles pacientes ciegos, así como el número de pacientes con problemas visuales severos.

También nos muestra información importante para que, siguiendo con el programa de expansión planteado como estrategia, determinar la ubicación de futuras sedes para la clínica, y en la medida que se atiendan más localidades, aumenten los clientes, los proveedores también se verán beneficiados de este crecimiento.

\section{c. Análisis Cultural}

En el Perú no existe una cultura de adquisición de seguros, la población vive el día a día y no piensan que podrían enfermarse, es por ello que, en lo regular, adquieren un seguro de salud. A pesar de ello, el incremento en el ingreso per cápita, la reducción notable de los índices de pobreza, así como la formalización del empleo, han llevado a un aumento de la demanda en los servicios de salud. Asimismo, según el INEI, debido a la globalización de la información, cada vez más la población está más y mejor informada por lo que el paciente ya no acepta al unísono lo que el médico le indica, sino que estos también investigan sobre diagnósticos y medicinas y también busca más de una sola opinión.

Según la Encuesta Nacional de Hogares (ENAHO), realizada en el último trimestre del 2017, reveló que el 33.9\% de la población peruana padece de algún problema de salud 
crónica.

Según el INEI en su nota de prensa $N^{\circ} 40$ del 19 de marzo del 2018, del total de personas que padecieron alguna enfermedad crónica y no crónica en el tercer trimestre del año 2017, el 16.2\% se atendió en un establecimiento del Ministerio de Salud, 19.4\% acudió a una farmacia o botica, $6.8 \%$ a un establecimiento del sector privado (i.e., clínicas o consultorios particulares), y 5.7\% a un establecimiento de EsSalud.

Por lo visto en esta encuesta, las farmacias son el principal lugar de atención de algún tipo de enfermedad, principalmente por la existencia de una alta cultura de automedicación en el país o porque la población no logra ser atendida en los establecimientos públicos y no disponen de un seguro que cubra la atención sanitaria privada.

Por otro lado, si bien la medicina tradicional o alternativa solo capta el $0.8 \%$ de las atenciones, existe una tendencia mundial en la búsqueda de productos naturales y orgánicos, y esta tendencia podría presentarse también en el Perú y en Lima.

Sin embargo, las mejoras económicas inciden también en la psicología de la población y en su grado aspiracional, grado que se refleja en el sector salud (pacientes que prefieren atenderse en clínicas privadas versus hospitales públicos). Según E. Rodríguez-Frías, en la Tesis Planeamiento Estratégico del Sector Salud del 2012, los estilos de vida, son factores culturales que van más allá de los niveles económicos de la población; esto quiere decir que indistinto al poder adquisitivo de las personas, cada vez más son los pacientes que suelen buscar a un médico en particular ya sea porque es el "médico de moda" o porque trabaja en la "clínica de moda".

Como afecta a los clientes, proveedores y a OftalmoSalud: Toda esta información nos muestra como los distintos movimientos culturales son factores de decisión en estos 
tiempos que abunda la información sobre todo en redes sociales.

Muchas veces las personas no deciden donde atenderse por un factor netamente económico, sino que siguen tendencias o recurren a información obtenida por recomendación por ello la importancia de mantener el prestigio de la marca. Ahí radica la importancia de destacar en las competencias de la empresa con la finalidad de mantener a los clientes satisfechos y con ello generar valor a la compañía y sus proveedores.

\subsubsection{Análisis Tecnológico.}

El ámbito tecnológico es muy importante para OftalmoSalud ya que es uno de los bastiones en los que apoya su estrategia y es considerada como una de sus principales fortalezas.

Situación actual: Actualmente OftalmoSalud busca contar con la mejor tecnología y tener los mejores equipos destinados al diagnóstico, prevención y tratamiento de las principales enfermedades oftalmológicas. Del mismo modo, sus médicos se encuentran muy bien capacitados en el uso de esta tecnología, así como a la vanguardia en los distintos y más innovadores tratamientos para la salud ocular.

En las entrevistas realizadas a los directivos de OftalmoSalud, nos fue indicado que ellos no escatiman en invertir y mantener la última tecnología que se vaya desarrollando en el mercado, contando con proveedores en distintas partes del mundo, principalmente en Estados Unidos, Japón y Alemania.

Tendencia: A nivel sectorial, en el mundo se han venido presentando avances importantes en el tratamiento de las cataratas, el glaucoma y la degeneración macular causada por la edad, siendo estas tres las enfermedades con mayor presencia en el Perú. Estas últimas innovaciones tecnológicas se han dado principalmente en el campo de la detección y de la 
cirugía y permiten una mayor seguridad y precisión en los procedimientos. Estas mejores parten, para el glaucoma, en los láseres sofisticados de femtosegundo, los que permiten abordar con mayor seguridad y exactitud la cirugía de cristalino o de córnea, e ir hacia dichos procedimientos con un portafolio de pruebas sustentadas en tomografías e inferometrías cada vez más exactas, así como poder comprobar el resultado en el mismo acto quirúrgico a través de aberrómetros intraoperatorios, que permiten detectar las correcciones realizadas. Del mismo modo, en el campo de la retina, se habla de la cirugía 3D como uno de los avances más significativos, puesto que permite una mayor magnificación de la imagen con mejor profundidad de campo lo que permite una gran precisión. Y también se conoce que cada vez los implantes como lentes intraoculares son más pequeños, lo que hará que en el tiempo las cirugías sean mínimamente invasivas y permitirán una recuperación mucho más rápida de los pacientes.

Recientemente se han publicado un par de estudios clínicos en Nature Biotechnology y en Science Translational Medicine que emplean la implantación de parches de células madre embrionarias diferenciadas para el tratamiento de la degeneración macular asociada a la edad. Los principales protagonistas de estos ensayos son Peter Coffey, de la universidad de California en Santa Bárbara, y Amir Kashani, de la Universidad del Sur de California en Los Ángeles. Ambos estudios están en fase I, pero representan una esperanza real en la medicina regenerativa de la retina. Si bien son estudios en fases iniciales, que aún tienen que demostrar su viabilidad, seguridad y resultados a largo plazo (a corto plazo ya lo han demostrado), pero que son muy importantes, pues a pesar de estar enfocados inicialmente a la degeneración macular asociada a la edad, tienen mucho potencial para ser aplicados a otros tipos de patologías degenerativas de la retina.

Todos estos cambios recientes, demuestran lo encaminada que está esta subespecialidad hacia la perfección de los resultados y a generar confianza en los usuarios, pero siempre 
recalcando que la prevención es la mejor arma para evitar estas enfermedades.

Cómo afecta a nuestros proveedores clientes y a OftalmoSalud: De cara al futuro, y en la medida que la tecnología siga avanzando, tal como se mencionó anteriormente, OftalmoSalud buscará siempre mantenerse a la vanguardia en este ámbito, buscando siempre un equilibrio (precio - calidad) adecuado con la finalidad de brindar un servicio accesible para sus clientes.

Los avances mencionado en el análisis de la tendencia, son avances que se viene presentando principalmente en Europa y Estados Unidos, y bajo la estructura que mantiene actualmente OftalmoSalud, la empresa se encuentra siempre muy interesada en ir de la mano con todos cambios, sin embargo la empresa, si bien debe estar a la vanguardia, debe analizar la conveniencia de su implementación local sobre todo por el tema de costos y realizar negociaciones adecuadas con proveedores para poder implementar estas nuevas maquinarias y procedimientos quirúrgicos de la manera más costo efectiva posible.

\subsubsection{Análisis Ecológico.}

Situación actual: En los últimos años se ha generado una corriente dirigida a lograr una mayor cultura ecológica.

En nuestro país, aunque aún falta mucho por trabajar, muchas empresas vienen implementando y desarrollando esquemas y programas dirigidos a lograr una mayor conciencia ecológica.

Cabe mencionar que, en temas de regulación ambiental, no existe un control adecuado para los desechos médicos de clínicas. Sin embargo, existe la normativa Ministerial № 217 2004/MINSA, la cual constituye un instrumento de gestión importante para los administradores de hospitales y responde a un mandato imperativo de la necesidad diaria de 
minimizar y controlar los riesgos que se derivan de los residuos hospitalarios. Según E. Rodríguez-Frías, en la Tesis Planeamiento Estratégico del Sector Salud del 2012, si bien los desechos orgánicos deberían ser destinados a la incineración en ambientes controlados, no existen empresas privadas suficientes que brinden estos servicios, sobre todo en provincias.

Tendencia: Se puede contemplar una tendencia a:

- Reducción de material impreso.

- Creación de productos con tecnología biodegradable.

- Uso de tecnología digital para el desarrollo de procesos electrónicos.

Cómo afecta a nuestros proveedores clientes y a OftalmoSalud: La tendencia señalada hace que los clientes de ahora busquen optar por empresas altamente comprometidas con el cuidado del medio ambiente, ya que son pautas básicas que deben seguir en su mayoría, de manera casi obligatoria, todas las empresas modernas que busquen contribuir con la conciencia ecológica.

Es por ello que, OftalmoSalud ya cuenta con procesos ligados estrechamente al desarrollo de esta conciencia ecológica.

\subsection{Impacto en clientes / proveedores de cada una de las variables del entorno.}

En la siguiente tabla se muestra un resumen de lo mencionado anteriormente en el capítulo, sobre cómo afectan cada una de las variables del entorno a los clientes y proveedores de OftalmoSalud. 
Tabla 8

Impacto en Clientes / Proveedores

\begin{tabular}{|c|c|c|}
\hline $\begin{array}{r}\text { Variables del } \\
\text { Entorno }\end{array}$ & Impacto en clientes & Impacto en proveedores \\
\hline $\begin{array}{c}\text { Político / } \\
\text { Gubernamental } \\
\text { Económico }\end{array}$ & $\begin{array}{l}\text { Inestabilidad por nuevo } \\
\text { gobierno afecta la economía y } \\
\text { por consiguiente el consumo en } \\
\text { salud preventiva }\end{array}$ & Se afectará en la misma medida \\
\hline Legal & $\begin{array}{l}\text { La obligatoriedad de los } \\
\text { chequeos médicos laborales } \\
\text { podría impactar en la cultura de } \\
\text { prevención de los clientes. }\end{array}$ & $\begin{array}{l}\text { La obligatoriedad de los chequeos } \\
\text { médicos laborales se traduce en } \\
\text { mayores atenciones médicas lo } \\
\text { cual favorece a los proveedores de } \\
\text { insumos médicos. }\end{array}$ \\
\hline Social & $\begin{array}{l}\text { El desarrollo de una cultura de } \\
\text { prevención en el sector salud no } \\
\text { se vería frenada por los efectos } \\
\text { sociales. }\end{array}$ & Se impactará en la misma medida \\
\hline Demográfico & No impacta & $\begin{array}{l}\text { El crecimiento demográfico es } \\
\text { directamente proporcional al } \\
\text { crecimiento en atenciones médicas } \\
\text { lo cual favorece a los proveedores } \\
\text { de insumos médicos. }\end{array}$ \\
\hline Cultural & $\begin{array}{l}\text { La cultura de prevención en el } \\
\text { sector salud debe de frenar la } \\
\text { cultura de la automedicación y } \\
\text { el no contar con seguros } \\
\text { médicos. }\end{array}$ & Se impactará en la misma medida \\
\hline Tecnológico & $\begin{array}{l}\text { El avance tecnológico y su } \\
\text { adquisición es un factor } \\
\text { determinante al momento de } \\
\text { elegir la atención médica }\end{array}$ & $\begin{array}{l}\text { Tecnologías emergentes como la } \\
\text { de China e India podrían afectar a } \\
\text { proveedores consolidados }\end{array}$ \\
\hline
\end{tabular}




\begin{tabular}{|l|l|l|}
\hline Ecológico & $\begin{array}{l}\text { El cuidado del medioambiente } \\
\text { es una tendencia que buscan los } \\
\text { clientes }\end{array}$ & \\
\hline
\end{tabular}

Elaboración con información obtenida de OftalmoSalud

\subsection{Efecto en la empresa de cada una de las variables del entorno.}

En la siguiente tabla se muestra un resumen de lo mencionado anteriormente en el capítulo, sobre cómo afectan cada una de las variables del entorno a OftalmoSalud.

Tabla 9

Efecto en OftalmoSalud

\begin{tabular}{|c|l|}
\hline $\begin{array}{c}\text { Variables del } \\
\text { Entorno }\end{array}$ & \multicolumn{1}{|c|}{ Efecto en OftalmoSalud } \\
\hline $\begin{array}{c}\text { Político / } \\
\text { Gubernamental }\end{array}$ & $\begin{array}{l}\text { Una reducción en el consumo en salud preventiva debido al } \\
\text { impacto económico afecta directamente el número de atenciones } \\
\text { primarias y por consiguiente exámenes auxiliares y cirugías en la } \\
\text { empresa. }\end{array}$ \\
\hline Económico & $\begin{array}{l}\text { La obligatoriedad de los chequeos preventivos en salud y dentro } \\
\text { de ellos los despistajes oftalmológicos se transformaría en } \\
\text { mayores atenciones primarias dentro de la empresa. }\end{array}$ \\
\hline Social & $\begin{array}{l}\text { La cultura de prevención en salud por parte de la sociedad se debe } \\
\text { de traducir en mayores atenciones primarias. }\end{array}$ \\
\hline Demográfico & $\begin{array}{l}\text { A medida que crece la población, esto se traduce en más } \\
\text { atenciones médicas dentro de ellas las atenciones primarias de } \\
\text { carácter oftalmológico. }\end{array}$ \\
\hline Ecológico & $\begin{array}{l}\text { La disminución de la automedicación y el contar con seguros } \\
\text { médicos es favorable para OftalmoSalud. }\end{array}$ \\
\hline Cultural & $\begin{array}{l}\text { Contar con tecnología de vanguardia es importante para mantener } \\
\text { un posicionamiento importante en la industria oftalmológica. }\end{array}$ \\
\hline delogico ambiente.
\end{tabular}

Elaboración con información obtenida de OftalmoSalud 


\subsection{Oportunidades y Amenazas.}

A través del análisis macro realizado anteriormente producto de las entrevistas realizadas a los Directivos de OftalmoSalud, se determinarán las siguientes oportunidades y amenazas.

\subsubsection{Oportunidades.}

- Debido al Crecimiento demográfico, se estima que las cifras de pacientes con enfermedades oftalmológicas seguirán creciendo a nivel global (pacientes privados y de seguros EPS).

- Posible recuperación de las economías mundiales y por consiguiente de la economía peruana para los siguientes años; se estima que se crecerá alrededor de $3 \%$ a $5 \%$, lo que se traduce en mayor crecimiento del PBI per cápita para el 2019 en adelante y un mayor poder adquisitivo de la población.

- La ineficiencia y capacidad instalada al límite del sector público hace que la brecha de atenciones deba ser atendida por el sector privado.

- Fortalecimiento de la Cultura de Prevención de los pacientes, principalmente en pacientes con seguros EPS y la obligatoriedad de los Chequeos Médicos Laborales.

- El avance tecnológico, a la larga permitirá mayor número de atenciones.

\subsubsection{Amenazas.}

- Desaceleración moderada del crecimiento peruano por arrastre de las economías mundiales y por el proceso de acople del nuevo gobierno.

- Depreciación de la moneda local (nuevo sol) respecto al dólar estadounidense debido a factores económicos globales como a factores políticos a nivel local disminuye el poder adquisitivo para acceder a tecnología de punta.

- Mayor Inversión en el sector: Inversiones de las EPS en infraestructura llega al campo 
oftalmológico e inversiones extranjeras miran al Perú como plaza atractiva de negocio.

- Fortalecimiento y mayor posicionamiento de la competencia o productos sustitos como se analizará en el Capítulo siguiente de Análisis de la Industria.

En la siguiente tabla se puede apreciar de manera resumida las oportunidades y/o amenazas (OA) asociadas a cada una de las variables externas descritas anteriormente.

Tabla 10

Asociación OA vs. Variables Externas

\begin{tabular}{|c|c|}
\hline Oportunidad / Amenaza & Variable Externa \\
\hline $\begin{array}{l}\text { (O) Crecimiento de pacientes con } \\
\text { enfermedades oftalmológicas. }\end{array}$ & Variable Demográfica: Crecimiento \\
\hline $\begin{array}{l}\text { (O) Mayor poder adquisitivo de la } \\
\text { población }\end{array}$ & Variable Económica: Posible Recuperación \\
\hline $\begin{array}{l}\text { (O) Ineficiencia y pobre capacidad } \\
\text { instalada del sector público. }\end{array}$ & $\begin{array}{l}\text { Variable Política: Deficiente asignación de } \\
\text { recursos }\end{array}$ \\
\hline $\begin{array}{l}\text { (O) Fortalecimiento de la Cultura de } \\
\text { Prevención y Obligatoriedad de Chequeos } \\
\text { Médicos Laborales. }\end{array}$ & $\begin{array}{l}\text { Variable Económica y Cultural: Recursos } \\
\text { enfocados a prevención }\end{array}$ \\
\hline $\begin{array}{l}\text { (O) El avance tecnológico permitirá } \\
\text { mayor número de atenciones }\end{array}$ & Variable Tecnológica \\
\hline $\begin{array}{l}\text { (A) Desaceleración del crecimiento } \\
\text { peruano }\end{array}$ & $\begin{array}{l}\text { Variable Política: Periodo de acople del nuevo } \\
\text { gobierno }\end{array}$ \\
\hline (A) Depreciación de la moneda local & $\begin{array}{l}\text { Variable Económica: Recuperación del dólar a } \\
\text { nivel mundial }\end{array}$ \\
\hline (A) Mayor Inversión en el sector Salud. & Variable Económica \\
\hline
\end{tabular}




\begin{tabular}{|l|l|}
\hline $\begin{array}{l}\text { (A) Fortalecimiento y posicionamiento de } \\
\text { la competencia }\end{array}$ & Variable Económica \\
\hline
\end{tabular}

Elaboración con información obtenida de OftalmoSalud

\subsection{Matriz de Evaluación de los Factores Externos EFE.}

En la siguiente tabla se aprecia la Matriz de Evaluación de los Factores Externos, la cual pondera las oportunidades y amenazas encontradas para OftalmoSalud.

Tabla 11

Matriz EFE

\begin{tabular}{llll}
\hline Factores determinantes de éxito & Peso & Valor & Puntaje \\
\hline Oportunidades & & & \\
1. Crecimiento del mercado oftalmológico (privado y seguros EPS) & 0.10 & 4 & 0.40 \\
2. Mayor poder adquisitivo de la población & 0.10 & 3 & 0.30 \\
3. Ineficiencia en sector público & 0.15 & 4 & 0.60 \\
4. Fortalecimiento de la cultura de prevención & 0.15 & 3 & 0.45 \\
5. Avance Tecnológico & 0.05 & 2 & 0.10 \\
\cline { 2 - 5 } & 0.55 & & 1.85 \\
Amenazas & & & \\
1. Desaceleración del crecimiento & 0.10 & 3 & 0.30 \\
2. Depreciación de la moneda local respecto el dólar estadunidense & 0.10 & 2 & 0.20 \\
3. Mayor inversión en el sector & 0.10 & 3 & 0.30 \\
4. Fortalecimiento y mayor posicionamiento de la competencia o productos sustitos & 0.15 & 2 & 0.30 \\
\cline { 2 - 4 } & 0.45 & & 1.10 \\
\hline Total & $\mathbf{1 . 0 0}$ & $\mathbf{2 . 9 5}$ \\
\hline
\end{tabular}

Elaboración con puntuación de Directivos de OftalmoSalud

De acuerdo a la metodología empleada, el peso indica la importancia relativa que tiene ese factor para alcanzar el éxito en la industria de la empresa y la nomenclatura de los valores es: (1) debilidad mayor, (2) debilidad menor, (3) fortaleza menor, (4) fortaleza mayor y los pesos se asignan en función de la importancia de dicha oportunidad o amenaza sobre el total de factores externos expuestos, debiendo ser la suma de todos los pesos igual a 1 .

Como se puede apreciar el ponderado obtenido en la matriz EFE es de 2.95 lo cual significa que la empresa está capitalizando de manera importante las oportunidades externas 
y evitando las amenazas. 


\section{Capítulo V. Análisis de la Industria}

Este capítulo tiene por objetivo describir el mercado e industria que comprende el sector en estudio, es decir a los clientes, empresas competidoras, sustitutos y proveedores del sector oftalmológico. Desarrollaremos un análisis competitivo aplicando el modelo de las cinco fuerzas de Porter, así como también la matriz de perfil competitivo (MPC).

\subsection{Descripción del Mercado (demanda) e Industria (oferta).}

Hablar de Mercado Oftalmológico Privado, es referirse principalmente a los servicios de Consultas Primarias, Exámenes Auxiliares y Cirugías a pacientes de diferentes edades y nivel socio económico con problemas de visión.

\section{a. Demanda:}

En este mercado existen dos grandes grupos de pacientes, aquellos que se atienden de manera particular y aquellos que, haciendo uso de entidades prestadoras de salud (EPS) utilizan el seguro privado otorgado por sus empleadores. Consultando con el Director de Operaciones de OftalmoSalud, dado el liderazgo en ventas de la empresa en el sector; analizando los ingresos de la misma respecto a estos dos grupos de pacientes y segmentándolo por unidad de negocio podríamos extrapolar este conocimiento y entender esta industria de manera global.

El promedio de los últimos 3 años indica que el 57\% de ingresos proviene de pacientes particulares y un $43 \%$ de ingresos que se da por pacientes que hacen uso del seguro médico (EPS).

Ahora bien, analizando las distintas unidades de negocio, tal como se puede apreciar en el siguiente gráfico, el 73\% de los ingresos provienen de las tres unidades de negocio materia de estudio y tan solo un $18 \%$ proviene de farmacia y $9 \%$ proviene de la óptica. Como parte de la conversación sostenida se nos indicó que el margen principal de la empresa se genera en 
las tres unidades de negocio anteriormente mencionadas.

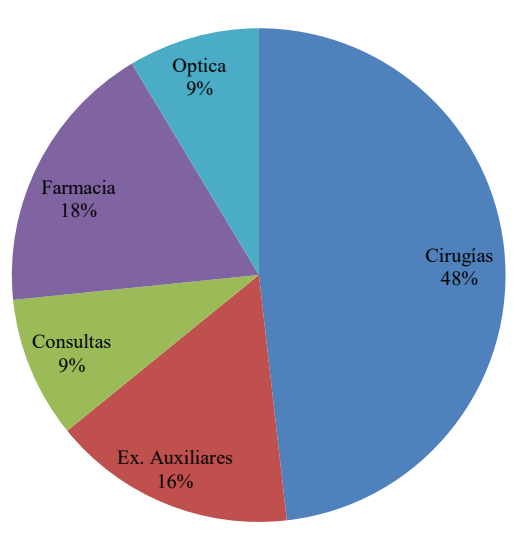

Figura 7. Participación por Unidad de Negocio, elaboración con información obtenida de OftalmoSalud

Con data proporcionada por OftalmoSalud, la participación dentro de los dos tipos de pacientes mencionados (particulares/seguros) de las distintas unidades de negocio de la empresa se puede apreciar en la siguiente tabla:

Tabla 12

Participación Unidades de Negocio por tipo de paciente

\begin{tabular}{|l|r|r|}
\hline Unidad de Negocio & Particulares & Seguros \\
\hline Cirugías & $54.4 \%$ & $39.9 \%$ \\
\hline Ex. Auxiliares & $12.1 \%$ & $21.0 \%$ \\
\hline Consultas & $10.9 \%$ & $7.0 \%$ \\
\hline Farmacia & $7.3 \%$ & $32.1 \%$ \\
\hline Optica & $15.1 \%$ & - \\
\hline Otros & $0.2 \%$ & $0.0 \%$ \\
\hline Total & $\mathbf{1 0 0 . 0} \%$ & $\mathbf{1 0 0 . 0 \%}$ \\
\hline
\end{tabular}

Elaboración con información obtenida de OftalmoSalud

Tal como se puede apreciar el comportamiento de los ingresos de las distintas unidades de negocio por tipo de paciente es distinto en cada caso. Mientras que en el caso de particulares la concentración se da en las atenciones quirúrgicas y exámenes auxiliares ambas 
principalmente derivadas de las consultas primaras, en el caso de seguros, más que existir concentración, la participación es relativamente pareja entre cirugía, farmacia y exámenes auxiliares. Es importante mencionar que la cantidad de atenciones por seguro no es necesariamente menor que las atenciones particulares pero su contribución es menor debido a que las tarifas negociadas por las EPS son bastante menores en comparación a la de los particulares.

\section{b. Oferta:}

En la actualidad las principales empresas que brindan servicios oftalmológicos en Lima Metropolitana (ámbito de acción de la empresa en estudio) son:

Tabla 13

Principales Empresas en el Rubro

\begin{tabular}{|c|c|c|}
\hline Empresa & Dirección & Servicio \\
\hline $\begin{array}{c}\text { INSTITUTO } \\
\text { OFTALMOSALUD SAC }\end{array}$ & $\begin{array}{c}\text { Av. Javier Prado Este 1142, } \\
\text { San Isidro, Lima, Perú }\end{array}$ & $\begin{array}{l}\text { Consulta, Ex. Auxiliares, } \\
\text { Cirugía, Farmacia y Óptica }\end{array}$ \\
\hline OFTÁLMICA SA & $\begin{array}{c}\text { Av. San Borja Norte 783, } \\
\text { San Borja, Lima, Perú. }\end{array}$ & $\begin{array}{l}\text { Consulta, Ex. Auxiliares, } \\
\text { Cirugía, Farmacia y Óptica }\end{array}$ \\
\hline CLÍNICA LA LUZ S.A.C. & $\begin{array}{c}\text { Av. Arequipa } 1148 \text { Urb. } \\
\text { Santa Beatriz, Lince, Lima, } \\
\text { Perú }\end{array}$ & $\begin{array}{l}\text { Consulta, Ex. Auxiliares, } \\
\text { Cirugía, Farmacia y Óptica }\end{array}$ \\
\hline $\begin{array}{c}\text { OFTALMÓLOGOS } \\
\text { CONTRERAS CAMPOS } \\
\text { SOC. CIVIL }\end{array}$ & $\begin{array}{c}\text { Av. Javier Prado Este 1010, } \\
\text { Piso } 10 \text { Torre B, San Isidro, } \\
\text { Lima, Perú }\end{array}$ & $\begin{array}{l}\text { Consulta, Ex. Auxiliares, } \\
\text { Cirugía, Farmacia y Óptica }\end{array}$ \\
\hline $\begin{array}{c}\text { TG LÁSER OFTALMICA } \\
\text { SA. }\end{array}$ & $\begin{array}{l}\text { Av. Dos de Mayo 666, San } \\
\text { Isidro, Lima, Perú }\end{array}$ & $\begin{array}{l}\text { Consulta, Ex. Auxiliares, } \\
\text { Cirugía, Farmacia y Óptica }\end{array}$ \\
\hline $\begin{array}{l}\text { POLICLÍNICO ÑAHUI } \\
\text { EIRL. }\end{array}$ & $\begin{array}{l}\text { Av. Angamos Este 714, } \\
\text { Surquillo, Lima, Perú }\end{array}$ & $\begin{array}{l}\text { Consulta, Ex. Auxiliares, } \\
\text { Cirugía, Farmacia y Óptica }\end{array}$ \\
\hline
\end{tabular}




\begin{tabular}{|c|c|c|}
\hline $\begin{array}{c}\text { CLÍNICA OJOS SELUCE } \\
\text { SRL }\end{array}$ & $\begin{array}{c}\text { Jr. Camaná } 700 \text { 2do Piso, } \\
\text { Lima Cercado, Lima, Perú }\end{array}$ & $\begin{array}{c}\text { Consulta, Ex. Auxiliares, } \\
\text { Cirugía, Farmacia y Óptica }\end{array}$ \\
\hline
\end{tabular}

Elaboración con información obtenida de OftalmoSalud

OftalmoSalud es la empresa que presenta mayor participación, seguido, pero en menor escala de Oftálmica y Clínica La Luz.

En la siguiente tabla se puede apreciar la cuota de mercado (Ingresos) y la evolución de las empresas anteriormente listadas, en el periodo 2010 - 2017:

Tabla 14

Evolución de la Participación de Mercado de las empresas dentro del Mercado Clínico Oftalmológico

\begin{tabular}{|c|c|c|c|c|c|c|c|c|}
\hline RAZON SOCIAL & 2010 & 2011 & 2012 & 2013 & 2014 & 2015 & 2016 & 2017 \\
\hline INSTITUTO OFTALMOSALUD S.A.C. & $26.21 \%$ & $26.95 \%$ & $30.86 \%$ & $34.14 \%$ & $39.57 \%$ & $39.22 \%$ & $42.07 \%$ & $43.36 \%$ \\
\hline OFTALMICA SA & $12.60 \%$ & $11.73 \%$ & $11.49 \%$ & $12.77 \%$ & $12.10 \%$ & $12.54 \%$ & $12.32 \%$ & $12.87 \%$ \\
\hline CLINICA LA LUZ S.A.C. & $1.01 \%$ & $4.52 \%$ & $6.52 \%$ & $7.55 \%$ & $8.63 \%$ & $9.21 \%$ & $8.98 \%$ & $9.21 \%$ \\
\hline OFT CONTRERAS CAMPOS SOC.CIV. & $7.02 \%$ & $7.82 \%$ & $7.73 \%$ & $8.27 \%$ & $8.54 \%$ & $8.60 \%$ & $8.82 \%$ & $8.57 \%$ \\
\hline TGLÁSER OFTALMICA SA. & $6.65 \%$ & $8.55 \%$ & $7.21 \%$ & $6.87 \%$ & $5.92 \%$ & $5.80 \%$ & $6.20 \%$ & $6.40 \%$ \\
\hline POLICLÍNICO ÑAHUI EIRL. & $4.25 \%$ & $4.07 \%$ & $3.90 \%$ & $4.65 \%$ & $5.56 \%$ & $6.20 \%$ & $6.25 \%$ & $6.24 \%$ \\
\hline CLÍNICA OJOS SELUCE SRL & $14.31 \%$ & $11.22 \%$ & $9.64 \%$ & $7.22 \%$ & $5.21 \%$ & $5.18 \%$ & $5.11 \%$ & $5.10 \%$ \\
\hline OTROS & $27.95 \%$ & $25.15 \%$ & $22.64 \%$ & $18.53 \%$ & $14.46 \%$ & $13.25 \%$ & $10.25 \%$ & $8.25 \%$ \\
\hline TOTAL & $100.00 \%$ & $100.00 \%$ & $100.00 \%$ & $100.00 \%$ & $100.00 \%$ & $100.00 \%$ & $100.00 \%$ & $100.00 \%$ \\
\hline
\end{tabular}

Elaboración con información obtenida de OftalmoSalud

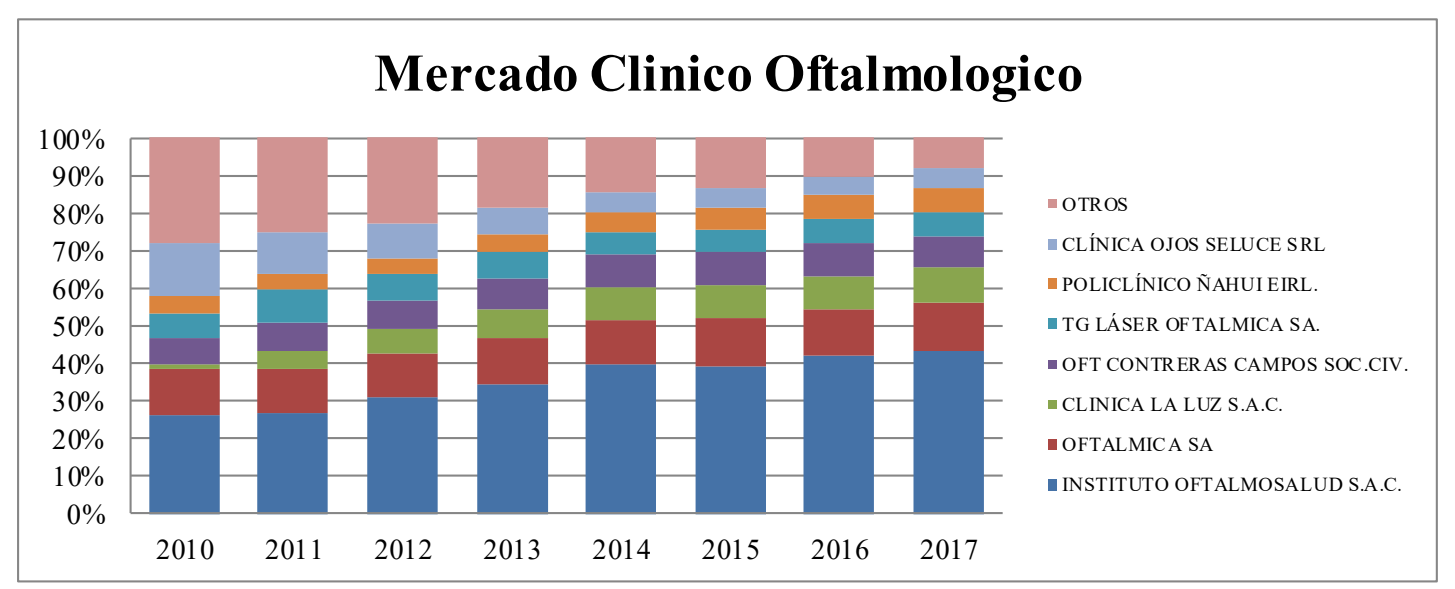

Figura 8. Mercado Clínico Oftalmológico, elaboración con información obtenida de OftalmoSalud

Como se puede apreciar OftalmoSalud año a año gana terreno en el Mercado Clínico

Oftalmológico restándole terreno principalmente a aquellas empresas agrupadas en "Otros" 
(participación de cada una de ellas menor al 5\%). Como se puede apreciar su crecimiento en estos dos últimos años ha sido considerablemente menor a los años anteriores; esto se debe principalmente a la limitante de capacidad instalada que ya se mencionó anteriormente y cuyo análisis profundizaremos más adelante. Respecto de las demás empresas se puede mencionar que mantienen o tienen una oscilación de crecimiento mínimo respecto a su participación del mercado año a año.

Respecto a los proveedores, se puede mencionar que en el mercado Oftalmológico son de importancia los proveedores de insumos quirúrgicos, fármacos y equipos quirúrgicos de última generación con tecnología de punta. En los tres casos los proveedores son empresas extranjeras de reconocido prestigio en el mercado oftalmológico y su número es reducido tal como se muestra en la siguiente tabla:

Tabla 15

Principales Proveedores Industria Oftalmológica

\begin{tabular}{|c|c|c|}
\hline Fármacos & Insumos Quirúrgicos & Equipos Quirúrgicos \\
\hline Alcon & Alcon & Alcon \\
\hline Sophia & Amo & Nidek \\
\hline Merck Sharp \& Dome & Abbott & Zeiss \\
\hline Lancier & & Leica \\
\hline & & Topcom \\
\hline
\end{tabular}

Elaboración con información obtenida de OftalmoSalud

\subsection{Descripción las cinco fuerzas competitivas de la industria.}

Porter establece que las empresas están rodeadas por cinco factores fundamentales dentro de una industria, por lo que hay que considerarlos y aprender a controlarlos para poder competir en el mercado. A continuación, analizaremos cada una de las cinco fuerzas:

\subsubsection{Desarrollo Potencial de Servicios Sustitutos.}

A continuación, analizaremos las presiones competitivas ocasionadas por los productos 
sustitutos:

Tabla 16

Presiones Competitivas de Productos Sustitutos

\begin{tabular}{|c|c|}
\hline Presiones Competitivas & Comentario \\
\hline $\begin{array}{l}\text { Conforme el precio relativo de los } \\
\text { productos sustitutos }\end{array}$ & $\begin{array}{l}\text { En el mercado oftalmológico existen } 2 \text { productos } \\
\text { sustitutos los cuales se pueden encontrar en un } \\
\text { mismo establecimiento; las ópticas. Estos productos } \\
\text { son: la medida de vista que sustituye las atenciones } \\
\text { primarias y los anteojos o lentes de contacto que } \\
\text { sustituyen la cirugía láser. Vale la pena mencionar } \\
\text { que la cirugía láser para corrección de medida es } \\
\text { optativa y se considera mayormente por razones } \\
\text { estéticas. En ambos casos los precios de esos } \\
\text { productos en esos establecimientos son menores } \\
\text { que en las clínicas especializadas. }\end{array}$ \\
\hline $\begin{array}{l}\text { Cuando el costo de cambiar de un } \\
\text { producto a otro también se reduce para } \\
\text { los consumidores }\end{array}$ & $\begin{array}{l}\text { Tal como se mencionó en el comentario anterior el } \\
\text { costo de los servicios sustitutos identificados es } \\
\text { menor en las ópticas, en tal sentido existe una } \\
\text { percepción por parte de los pacientes de encontrar } \\
\text { un ahorro sustancial en atenderse en estos } \\
\text { establecimientos. Para los demás servicios } \\
\text { (exámenes auxiliares y cirugía) no existe producto } \\
\text { sustituto. }\end{array}$ \\
\hline $\begin{array}{l}\text { Cuando la participación del mercado de } \\
\text { los productos sustitutos esta afianzada }\end{array}$ & $\begin{array}{l}\text { Si bien hay un número importante de ópticas } \\
\text { (establecimientos), sólo el } 18 \% \text { de los ingresos que } \\
\text { se genera en el sector privado corresponde a } \\
\text { atenciones primarias y óptica (Figura 7), en tal } \\
\text { sentido no encontramos un afianzamiento } \\
\text { importante de éstos en el mercado. Los servicios de } \\
\text { exámenes auxiliares y cirugía necesariamente } \\
\text { deben de realizarse en clínicas especializadas. }\end{array}$ \\
\hline
\end{tabular}




\begin{tabular}{|l|l|}
\hline & $\begin{array}{l}\text { Pero si es importante mencionar que el crecimiento } \\
\text { del negocio en sus otras áreas; dependen de una } \\
\text { mayor captación de atenciones primarias. }\end{array}$ \\
\hline
\end{tabular}

Elaboración con información obtenida de OftalmoSalud

Por lo expuesto anteriormente no se identifica una amenaza de desarrollo de servicios sustitutos.

\subsubsection{Entrada Potencial de Nuevos Competidores.}

A continuación, analizaremos las barreras para el ingreso de nuevos competidores al mercado, lo cual nos permitirá concluir acerca de la facilidad de nuevos competidores para ingresar al mercado:

Tabla 17

Barreras de Ingreso

\begin{tabular}{|c|c|}
\hline Barreras de Ingreso & Comentario \\
\hline $\begin{array}{l}\text { Los competidores actuales utilizan } \\
\text { herramientas tecnológicas }\end{array}$ & $\begin{array}{l}\text { Todas las empresas mencionadas como } \\
\text { competidoras cuentan con tecnología acorde a los } \\
\text { servicios que brindan; en tal sentido el tema } \\
\text { tecnológico no se considera como una barrera de } \\
\text { ingreso. }\end{array}$ \\
\hline $\begin{array}{l}\text { Los competidores tienen conocimiento } \\
\text { especializado }\end{array}$ & $\begin{array}{l}\text { Igualmente, todas las empresas mencionadas } \\
\text { como competencia cuentan con personal } \\
\text { especializado para las atenciones o servicios que } \\
\text { brindan. }\end{array}$ \\
\hline $\begin{array}{l}\text { El consumidor tiene una fuerte lealtad a las } \\
\text { marcas actuales }\end{array}$ & $\begin{array}{l}\text { En lo regular los pacientes suelen ser leales más } \\
\text { que a la marca a los médicos que conocen y a lo } \\
\text { largo de la historia clínica les han otorgado } \\
\text { diagnósticos adecuados. Pero dependiendo de la } \\
\text { gravedad del diagnóstico suelen buscar segundas } \\
\text { opiniones medicas de preferencia de clínicas o } \\
\text { médicos de la especialidad más renombrados. }\end{array}$ \\
\hline
\end{tabular}




\begin{tabular}{|c|c|}
\hline $\begin{array}{l}\text { Ingresar a competir requiere grandes } \\
\text { necesidades de capital }\end{array}$ & $\begin{array}{l}\text { Si se desea implementar clínicas integrales de } \\
\text { atención oftalmológica se requiere de una fuerte } \\
\text { inversión de capital (más de } \mathrm{S} / .8 \mathrm{MM} \text { sin incluir } \\
\text { terreno). En este punto es importante mencionar } \\
\text { que las EPS están en proceso de implementar } \\
\text { clínicas de atención integral en todas las } \\
\text { especialidades médicas que incluyen atenciones } \\
\text { oftalmológicas las cuales pueden restar } \\
\text { participación de mercado. }\end{array}$ \\
\hline Falta de canales adecuados de distribución & No aplica. \\
\hline Políticas reguladoras gubernamentales & $\begin{array}{l}\text { Tal como se mencionó en el análisis legal, la } \\
\text { regulación de la Dirección de Salud (DISA) del } \\
\text { Ministerio de Salud (MINSA), es estricta en sus } \\
\text { parámetros para otorgar la categorización la cual } \\
\text { aplica desde un puesto de salud hasta un instituto } \\
\text { especializado. }\end{array}$ \\
\hline Elevados costos derivados de los aranceles & No aplica \\
\hline Dificultad para acceder a las materias primas & No aplica \\
\hline Posesión de patentes & No aplica \\
\hline Ubicaciones poco deseables & $\begin{array}{l}\text { Existiendo demanda, cada vez es más difícil } \\
\text { encontrar ubicaciones adecuadas acorde a los } \\
\text { servicios que se prestan; a esto se le suma las } \\
\text { regulaciones de funcionamiento y principalmente } \\
\text { uso otorgadas por las municipalidades. }\end{array}$ \\
\hline $\begin{array}{l}\text { Riesgo de contrataque de empresas bien } \\
\text { afianzadas }\end{array}$ & $\begin{array}{l}\text { Existe un riesgo de que las empresas } \\
\text { competidoras puedan asociarse con un grupo de } \\
\text { salud fuerte a nivel global o regional y que } \\
\text { puedan incursionar en este segmento de salud. }\end{array}$ \\
\hline Posible saturación del mercado & $\begin{array}{l}\text { El mercado no se encuentra saturado, por lo que } \\
\text { siempre existe la posibilidad de ingreso de } \\
\text { nuevos competidores. }\end{array}$ \\
\hline
\end{tabular}

Elaboración con información obtenida de OftalmoSalud 
Según el análisis de cada una de estas barreras de entrada podemos concluir que existe un riesgo bajo de ingreso de nuevos competidores al mercado de servicios oftalmológicos debido principalmente a la alta inversión inicial requerida; pero esta se puede convertir en potencial moderado, si vemos que las EPS están implementando clínicas de atención integral en todas las especialidades médicas que incluyen atenciones oftalmológicas.

\subsubsection{Poder de Negociación de los Clientes.}

A continuación, analizaremos los factores que según Porter son los fundamentos de la capacidad de negociación de los consumidores (clientes particulares y atendidos por seguros EPS):

Tabla 18

Fundamentos capacidad de negociación

\begin{tabular}{|c|c|}
\hline Fundamentos & Comentario \\
\hline $\begin{array}{l}\text { Si los consumidores pueden cambiarse a } \\
\text { marcas competidoras o a sustitutos a un } \\
\text { precio reducido }\end{array}$ & $\begin{array}{l}\text { La competencia ofrece tarifas más } \\
\text { económicas y en lo regular los } \\
\text { pacientes suelen ser leales más que a la } \\
\text { marca a los médicos que conocen y a lo } \\
\text { largo de la historia clínica les han } \\
\text { otorgado diagnósticos adecuados. Pero } \\
\text { dependiendo de la gravedad del } \\
\text { diagnóstico suelen buscar segundas } \\
\text { opiniones medicas de preferencia de } \\
\text { clínicas o médicos de la especialidad } \\
\text { más renombrados. }\end{array}$ \\
\hline $\begin{array}{l}\text { Si son de particular importancia para el } \\
\text { vendedor }\end{array}$ & $\begin{array}{l}\text { Si bien es cierto es importante otorgar } \\
\text { un buen servicio e interesa la opinión } \\
\text { de los pacientes, en este rubro más } \\
\text { importante aún es el renombre que la } \\
\text { empresa llegue a tener por el staff de }\end{array}$ \\
\hline
\end{tabular}




\begin{tabular}{|c|c|}
\hline & $\begin{array}{l}\text { médicos que lo compone y los } \\
\text { resultados obtenidos. }\end{array}$ \\
\hline $\begin{array}{l}\text { Si los vendedores enfrentan una reducción } \\
\text { en la demanda por parte de los } \\
\text { consumidores }\end{array}$ & $\begin{array}{l}\text { Habiendo analizado la coyuntura } \\
\text { económica y demográfica se prevé que } \\
\text { continúe el crecimiento experimentado } \\
\text { desde años atrás. }\end{array}$ \\
\hline $\begin{array}{l}\text { Si los consumidores están informados } \\
\text { acerca de los productos, precios y costos } \\
\text { de los vendedores }\end{array}$ & $\begin{array}{l}\text { Por lo general el paciente conoce los } \\
\text { precios de las consultas primarias, pero } \\
\text { no está informado de los precios de los } \\
\text { servicios que requiere luego de un } \\
\text { diagnóstico inicial. Es por eso que es } \\
\text { usual en este mercado elaborar una } \\
\text { cotización luego del diagnóstico la cual } \\
\text { deberá ser evaluada y aprobada por el } \\
\text { paciente antes de brindar los servicios } \\
\text { requeridos. En el caso de pacientes } \\
\text { atendidos mediante las EPS, se } \\
\text { conocen los copagos y deducibles a los } \\
\text { que están afectos los servicios, pero } \\
\text { para ciertos servicios especiales se } \\
\text { requiere cartas de confirmación o } \\
\text { garantía otorgadas por las compañías } \\
\text { de seguros. }\end{array}$ \\
\hline $\begin{array}{l}\text { Si pueden decidir a su antojo si compran o } \\
\text { no el producto y cuando hacerlo }\end{array}$ & $\begin{array}{l}\text { Para los casos preventivos el cliente } \\
\text { puede elegir cuando hacerlo, pero para } \\
\text { aquellos casos correctivos en donde el } \\
\text { tiempo apremia esa elección queda } \\
\text { limitada a la disponibilidad de atención } \\
\text { del centro médico y su staff. }\end{array}$ \\
\hline
\end{tabular}

Elaboración con información obtenida de OftalmoSalud

Según los fundamentos analizados, podemos concluir que los clientes tienen una capacidad de negociación baja debido principalmente a que si bien es cierto los clientes 
valoran y buscan obtener un excelente diagnóstico y servicio médico en este rubro más importante aún es el renombre que la empresa llegue a tener por el staff de médicos que lo compone y los resultados obtenidos.

\subsubsection{Poder de Negociación de los Proveedores.}

Según Porter, la capacidad de negociación de los proveedores se basa en los tres aspectos que analizaremos a continuación:

Tabla 19

Aspectos Capacidad de Negociación con Proveedores

\begin{tabular}{|c|c|}
\hline Aspecto & Comentario \\
\hline $\begin{array}{l}\text { Cuando existe un reducido número } \\
\text { de proveedores en el mercado }\end{array}$ & $\begin{array}{l}\text { Tal como se mencionó en la descripción del } \\
\text { mercado e industria en lo concerniente a } \\
\text { proveedores, en el mercado Oftalmológico } \\
\text { son de importancia los proveedores de } \\
\text { equipos de cirugía (tratamiento } \\
\text { oftalmológico) de última generación con } \\
\text { tecnología de punta y los farmacéuticos que } \\
\text { brindan tanto medicinas como consumibles } \\
\text { quirúrgicos. En ambos casos los proveedores } \\
\text { son empresas extranjeras de reconocido } \\
\text { prestigio en el mercado oftalmológico y su } \\
\text { número es reducido. Es importante } \\
\text { mencionar que si bien es cierto el número de } \\
\text { proveedores en el mercado oftalmológico es } \\
\text { reducido su participación dentro del costo } \\
\text { del servicio médico es inferior en relación } \\
\text { con el costo del staff médico. }\end{array}$ \\
\hline $\begin{array}{l}\text { Cuando solo existen unas cuantas } \\
\text { materias primas sustitutas }\end{array}$ & No aplica. \\
\hline
\end{tabular}




\begin{tabular}{|lll|l|}
\hline Cuando el costo de cambiar de & \\
materia prima por otra es & No aplica. \\
especialmente alto & & & \\
\hline
\end{tabular}

Elaboración con información obtenida de OftalmoSalud

Según el análisis realizado podemos concluir que hay indicios de una baja capacidad de negociación de los proveedores, ya que, si bien solo se negocia con empresas top del mercado, su participación dentro del costo del servicio médico es inferior en relación con el costo del staff médico. Es importante mencionar en este aspecto que en este negocio el incremento de precio de los proveedores es trasladado siempre al cliente final.

\subsubsection{Rivalidad entre Competidores.}

En el mercado son cuatro las empresas que se reparten el 70\% del mercado clínico oftalmológico las cuales son: OftalmoSalud, Oftálmica, Clínica La Luz y Contreras Campos; en ese sentido se analizará cada uno de los elementos que Porter establece para el factor de rivalidad entre empresas competidoras:

Tabla 20

Elementos para el Factor de Rivalidad entre Empresas Competidoras

\begin{tabular}{|l|l|}
\hline \multicolumn{1}{|c|}{ Elemento } & \multicolumn{1}{|c|}{ Comentario } \\
\hline \multirow{2}{*}{$\begin{array}{l}\text { Se incrementa el número de competidores y y } \\
\text { estos se asemejan en tamaño y capacidad }\end{array}$} & $\begin{array}{l}\text { En la actualidad son 7 empresas las que se reparten } \\
\text { el 92\% del mercado oftalmológico, y ese número se } \\
\text { ha mantenido en los últimos años. } \\
\text { OftalmoSalud es líder en el mercado, concentrando } \\
\text { un poco más del 40\% del mercado, 30\% se lo } \\
\text { reparten Oftálmica, Clínica La Luz y Contreras } \\
\text { Campos, el 30\% restante se lo reparten otras } \\
\text { empresas con representaciones por debajo del 6.5\%. }\end{array}$ \\
\hline
\end{tabular}




\begin{tabular}{|c|c|}
\hline Conforme la demanda disminuye & $\begin{array}{l}\text { La demanda no disminuye y por el contrario se } \\
\text { espera mantenga el crecimiento mostrado en los } \\
\text { últimos años }\end{array}$ \\
\hline Los recortes de precio se vuelven comunes & $\begin{array}{l}\text { No necesariamente, no se cuenta con data } \\
\text { específica, pero por lo general los precios tienden a } \\
\text { incrementarse. }\end{array}$ \\
\hline $\begin{array}{l}\text { Los consumidores tienen la posibilidad de } \\
\text { cambiar fácilmente la marca }\end{array}$ & $\begin{array}{l}\text { En lo regular los pacientes suelen ser leales más que } \\
\text { a la marca a los médicos que conocen y a lo largo de } \\
\text { la historia clínica les han otorgado diagnósticos } \\
\text { adecuados. Pero dependiendo de la gravedad del } \\
\text { diagnóstico suelen buscar segundas opiniones } \\
\text { medicas de preferencia de clínicas o médicos de la } \\
\text { especialidad más renombrados. } \\
\text { Adicionalmente si bien es cierto es importante } \\
\text { otorgar un buen servicio e interesa la opinión de los } \\
\text { pacientes, en este rubro más importante aún es el } \\
\text { renombre que la empresa llegue a tener por el staff } \\
\text { de médicos que lo compone y los resultados } \\
\text { obtenidos. A mayor complejidad del servicio se } \\
\text { reduce la posibilidad de migrar a la competencia. }\end{array}$ \\
\hline $\begin{array}{l}\text { Cuando las barreras para abandonar el } \\
\text { mercado son muchas }\end{array}$ & $\begin{array}{l}\text { Creemos que las barreras para abandonar el mercado } \\
\text { son altas (por el nivel de inversión inicial); } \\
\text { adicionalmente la tendencia es que las clínicas } \\
\text { pequeñas (participación menor al 5\%) desaparezcan } \\
\text { o sean absorbidas por aquella que manejan el } \\
\text { mercado }\end{array}$ \\
\hline Cuando los costos fijos son altos & $\begin{array}{l}\text { Dada la infraestructura necesaria para brindar los } \\
\text { servicios, los costos fijos son un factor } \\
\text { preponderante a tomar en cuenta al momento de } \\
\text { revisar tarifarios. }\end{array}$ \\
\hline Cuando el producto es perecedero & No aplica \\
\hline
\end{tabular}




\begin{tabular}{|l|l|}
\hline $\begin{array}{l}\text { La demanda del consumidor crece lentamente } \\
\text { o declina de tal manera que las empresas } \\
\text { quedan con inventarios excesivos }\end{array}$ & No aplica \\
\hline $\begin{array}{l}\text { Cuando los productos que se venden son } \\
\text { materias primas }\end{array}$ & No aplica \\
\hline $\begin{array}{l}\text { Cuando las estrategias, los orígenes y la } \\
\text { cultura de las empresas rivales son muy } \\
\text { diversos }\end{array}$ & Servicios similares, estrategias y culturas similares \\
\hline $\begin{array}{l}\text { Cuando las fusiones o adquisiciones son } \\
\text { comunes en la industria }\end{array}$ & $\begin{array}{l}\text { No son muy comunes, pero estimamos que dada la } \\
\text { descarta la posibilidad de fusiones o adquisiciones y } \\
\text { porque no alianzas con clínicas de menor tamaño }\end{array}$ \\
\hline
\end{tabular}

Elaboración con información obtenida de OftalmoSalud

Según el análisis realizado, los factores de riesgos que contribuyen a la rivalidad entre competidores son moderados; sin embargo, dada la envergadura y participación en el mercado podemos concluir que la rivalidad entre competidores no es un factor de riesgo en este mercado.

\subsection{Matriz de atractividad de cada una de las cinco fuerzas.}

Resumiendo lo anteriormente descrito tenemos:
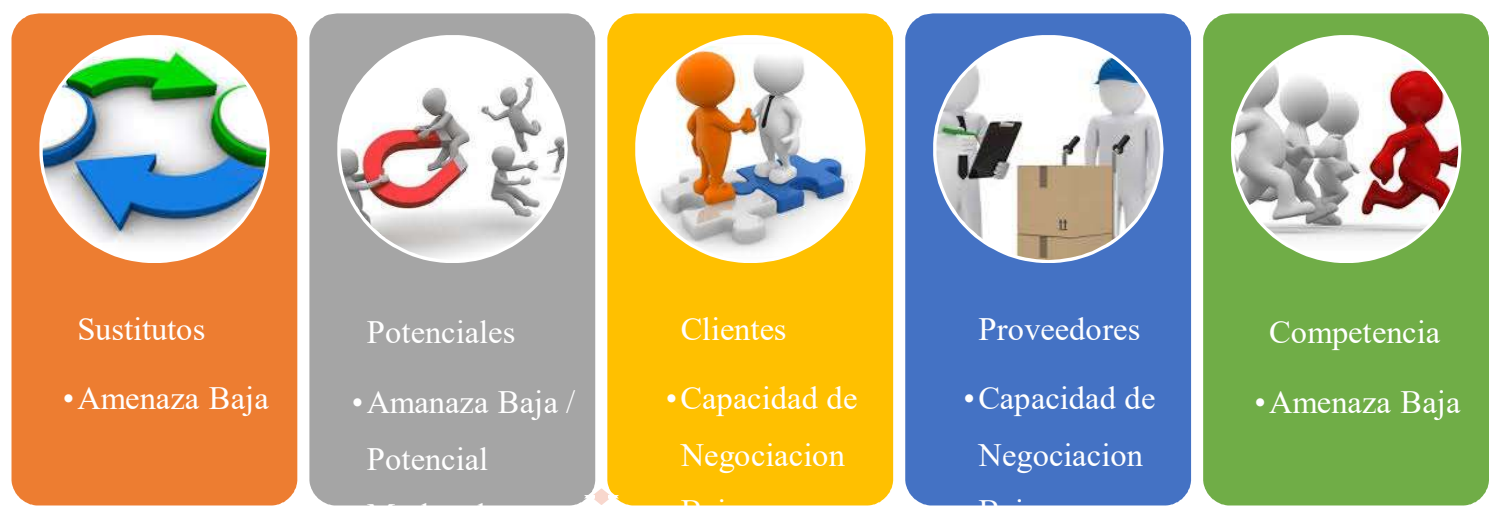

Figura 9. Las 5 Fuerzas de Porter, elaborado sobre el Modelo de Michael Porter 
En función a lo expuesto hasta el momento, se desarrolla la matriz de atractividad de cada una de las fuerzas de Porter a través del cual vamos a identificar si el mercado en el cual se desarrolla OftalmoSalud es favorable y en qué medida. Es importante mencionar que los pesos y valoraciones de estas matrices han sido trabajados en conjunto con el director de operaciones de la empresa.

En las siguientes tablas se desarrollarán el análisis de las Matrices de Atractividad de Amenaza de Productos Sustitutos, Competidores Potenciales, Poder de Negociación de Clientes, Proveedores, Rivalidad entre Competidores. En cada una de ellas se establecerá el factor de relevancia para cada elemento de análisis y en funciona a los criterios que lo hacen poco o muy atractivo se le dará un grado de atractividad a cada elemento para finalmente obtener un ponderado el cual servirá como grado de atractividad de la Organización para cada matriz elaborada. 
Tabla 21

Matriz de Atractividad: Amenaza de Productos Sustitutos

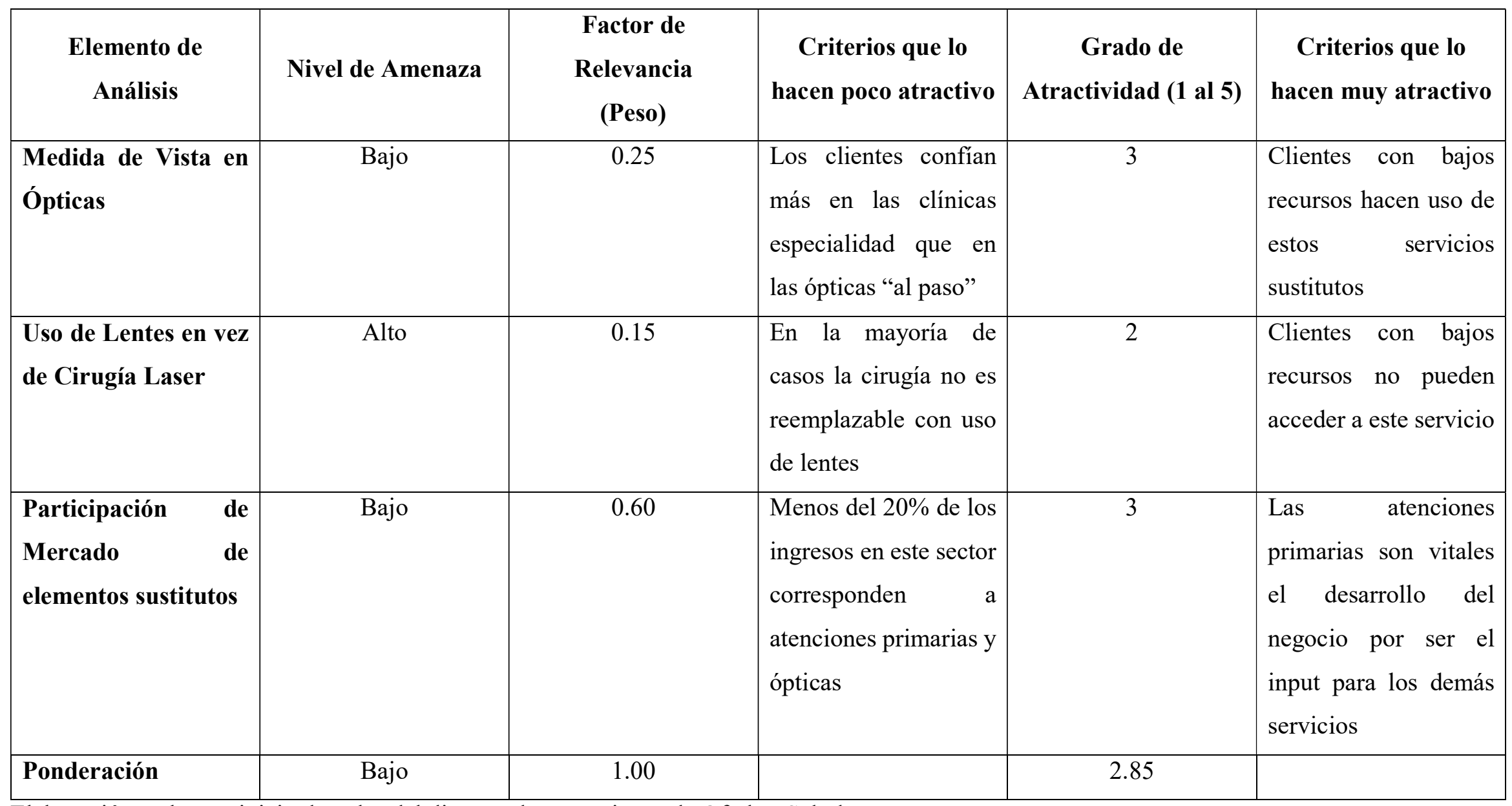

Elaboración en base a juicio de valor del director de operaciones de OftalmoSalud 
De lo expuesto se puede concluir que esta fuerza tiene un grado medio de atractividad en el sector; si bien es cierto los productos sustitutos podrían influir en el crecimiento del mercado, ya sea por confianza o necesidad vital los clientes prefieren asistir a las clínicas especializadas y someterse a la cirugía de ser necesario.

Tabla 22

Matriz de Atractividad: Amenaza de Competidores Potenciales

\begin{tabular}{|c|c|c|c|c|c|}
\hline Elemento de Análisis & Nivel de Amenaza & $\begin{array}{r}\text { Factor de } \\
\text { Relevancia }\end{array}$ & $\begin{array}{c}\text { Criterios que lo hacen } \\
\text { poco atractivo }\end{array}$ & $\begin{array}{c}\text { Grado de } \\
\text { Atractividad (1 al }\end{array}$ & $\begin{array}{c}\text { Criterios que lo hacen } \\
\text { muy atractivo }\end{array}$ \\
\hline Fidelidad & Medio & 0.25 & $\begin{array}{l}\text { Todas las } \\
\text { brindan los línicas } \\
\text { servicios }\end{array}$ & 1 & $\begin{array}{l}\text { Para casos especiales } \\
\text { los clientes buscan una } \\
\text { segunda opinión } \\
\text { medica }\end{array}$ \\
\hline
\end{tabular}




\begin{tabular}{|c|c|c|c|c|c|}
\hline Requisitos de Capital & Medio & 0.25 & $\begin{array}{l}\text { Se requiere fuerte } \\
\text { inversión de capital } \\
\text { para la implementación } \\
\text { de clínicas integrales } \\
\text { oftalmológicas }\end{array}$ & 2 & $\begin{array}{l}\text { Las EPS están en } \\
\text { proceso } \\
\text { implementación de } \\
\text { clínicas de atención } \\
\text { integral lo cual restaría } \\
\text { participación } \\
\text { mercado }\end{array}$ \\
\hline Políticas de Gobierno & Alto & 0.10 & $\begin{array}{l}\text { La regulación } \\
\text { gubernamental es } \\
\text { estricta en sus } \\
\text { parámetros para otorgar } \\
\text { licencias de } \\
\text { funcionamiento }\end{array}$ & 1 & $\begin{array}{l}\text { La falta de fiscalización } \\
\text { adecuada y oportuna es } \\
\text { una invitación a } \\
\text { trabajar en la } \\
\text { informalidad }\end{array}$ \\
\hline Ponderación & Moderado & 1.00 & & 2.05 & \\
\hline
\end{tabular}

Elaboración en base a juicio de valor del director de operaciones de OftalmoSalud 
De lo expuesto se puede concluir que esta fuerza tiene un grado de atractividad bajo en el sector; siempre está latente el ingreso de nuevos competidores principalmente las EPS; ya sea con la implementación de clínicas de atención o integral o comprando alguna empresa ya implementada.

Tabla 23

Matriz de Atractividad: Poder de Negociación de los Clientes

\begin{tabular}{|c|c|c|c|c|c|}
\hline Elemento de Análisis & $\begin{array}{l}\text { Nivel de } \\
\text { Amenaza }\end{array}$ & $\begin{array}{c}\text { Factor de } \\
\text { Relevancia (Peso) }\end{array}$ & $\begin{array}{c}\text { Criterios que lo } \\
\text { hacen poco } \\
\text { atractivo }\end{array}$ & $\begin{array}{c}\text { Grado de } \\
\text { Atractividad (1 al 5) }\end{array}$ & $\begin{array}{c}\text { Criterios que lo hacen } \\
\text { muy atractivo }\end{array}$ \\
\hline $\begin{array}{l}\text { Contracción de la } \\
\text { demanda }\end{array}$ & Bajo & 0.30 & $\begin{array}{l}\text { La carencia de } \\
\text { capacidad económica } \\
\text { puede influir en el } \\
\text { brindar o no el } \\
\text { servicio }\end{array}$ & 5 & $\begin{array}{l}\text { Se prevé que el } \\
\text { crecimiento } \\
\text { experimentado años atrás } \\
\text { de este mercado continúe }\end{array}$ \\
\hline
\end{tabular}




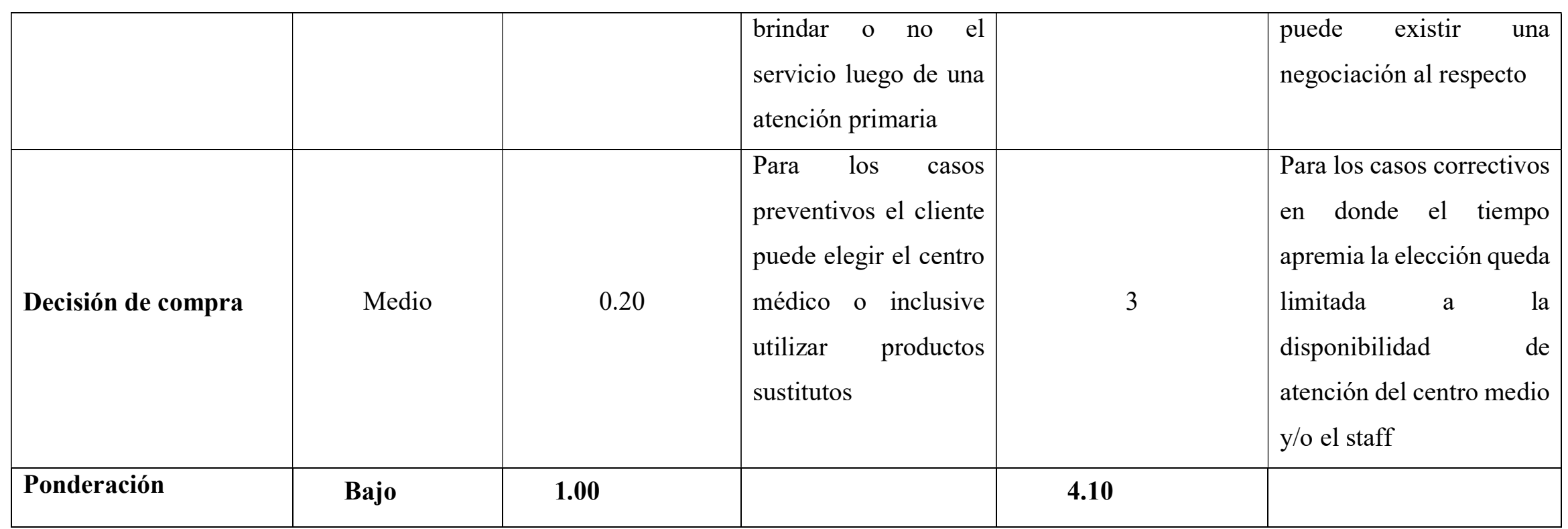

Elaboración emitida en base a juicio de valor del director de operaciones de OftalmoSalud

De lo expuesto se puede concluir que esta fuerza tiene un grado de atractividad alto en el sector; tal como se mencionó anteriormente el poder de negociación de los clientes es bajo dado que valoran la calidad del servicio brindado. 
Tabla 24

Matriz de Atractividad: Poder de Negociación de los Proveedores

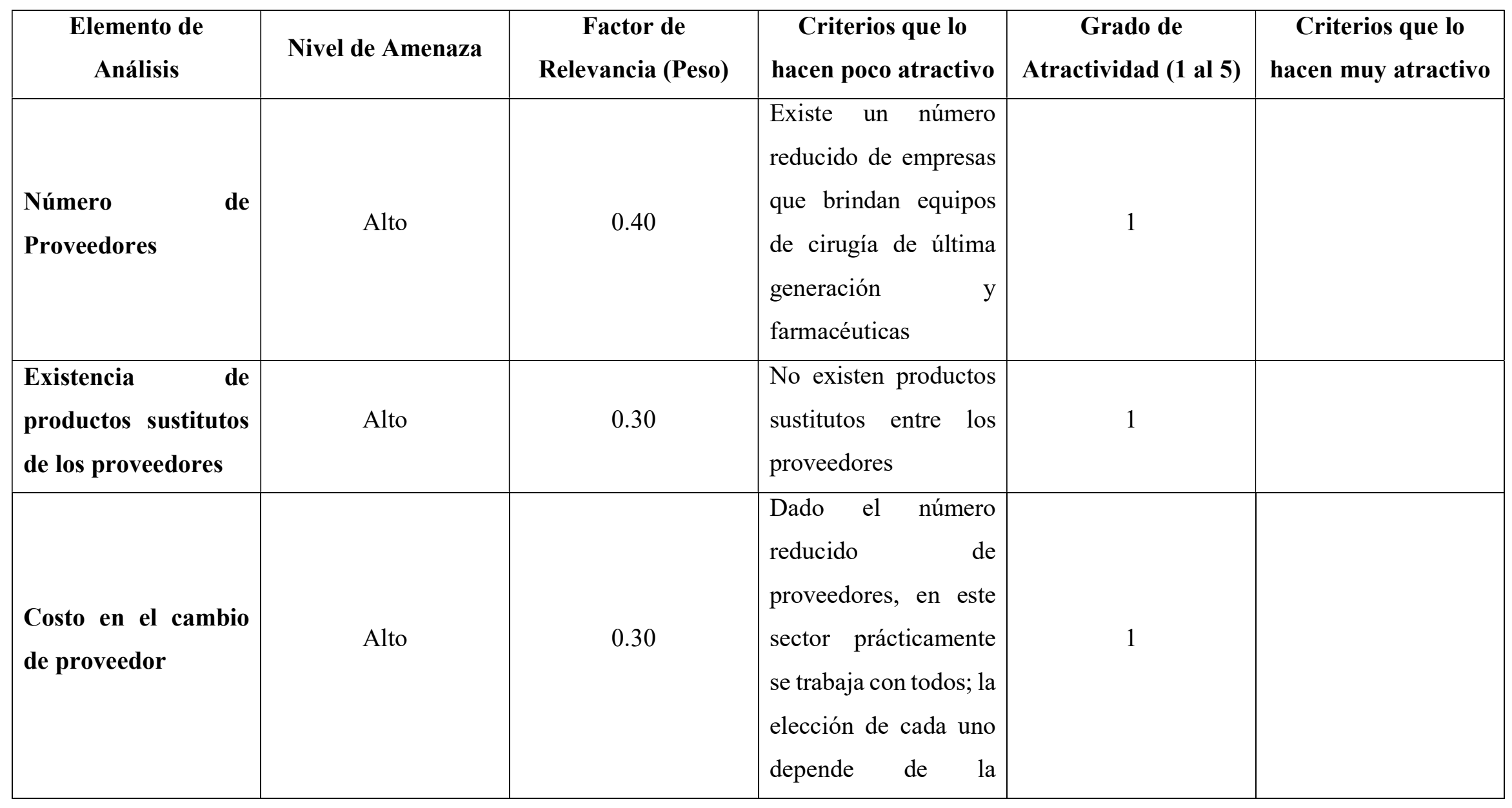




\begin{tabular}{|l|c|c|l|l|l|}
\hline & & & $\begin{array}{l}\text { disponibilidad del } \\
\text { servicio requerido }\end{array}$ & \\
\hline Ponderación & Alto & $\mathbf{1 . 0 0}$ & & $\mathbf{1 . 0 0}$ & \\
\hline
\end{tabular}

Elaboración emitida en base a juicio de valor del director de operaciones de OftalmoSalud

De lo expuesto se puede concluir que esta fuerza tiene un grado de atractividad bajo en el sector; tal como se mencionó anteriormente el poder de negociación de los proveedores es bajo dado que si bien solo se negocia con empresas top del mercado; su participación dentro del costo del servicio médico es inferior en relación con el costo del staff médico. 
Tabla 25

Matriz de Atractividad: Rivalidad entre competidores existentes

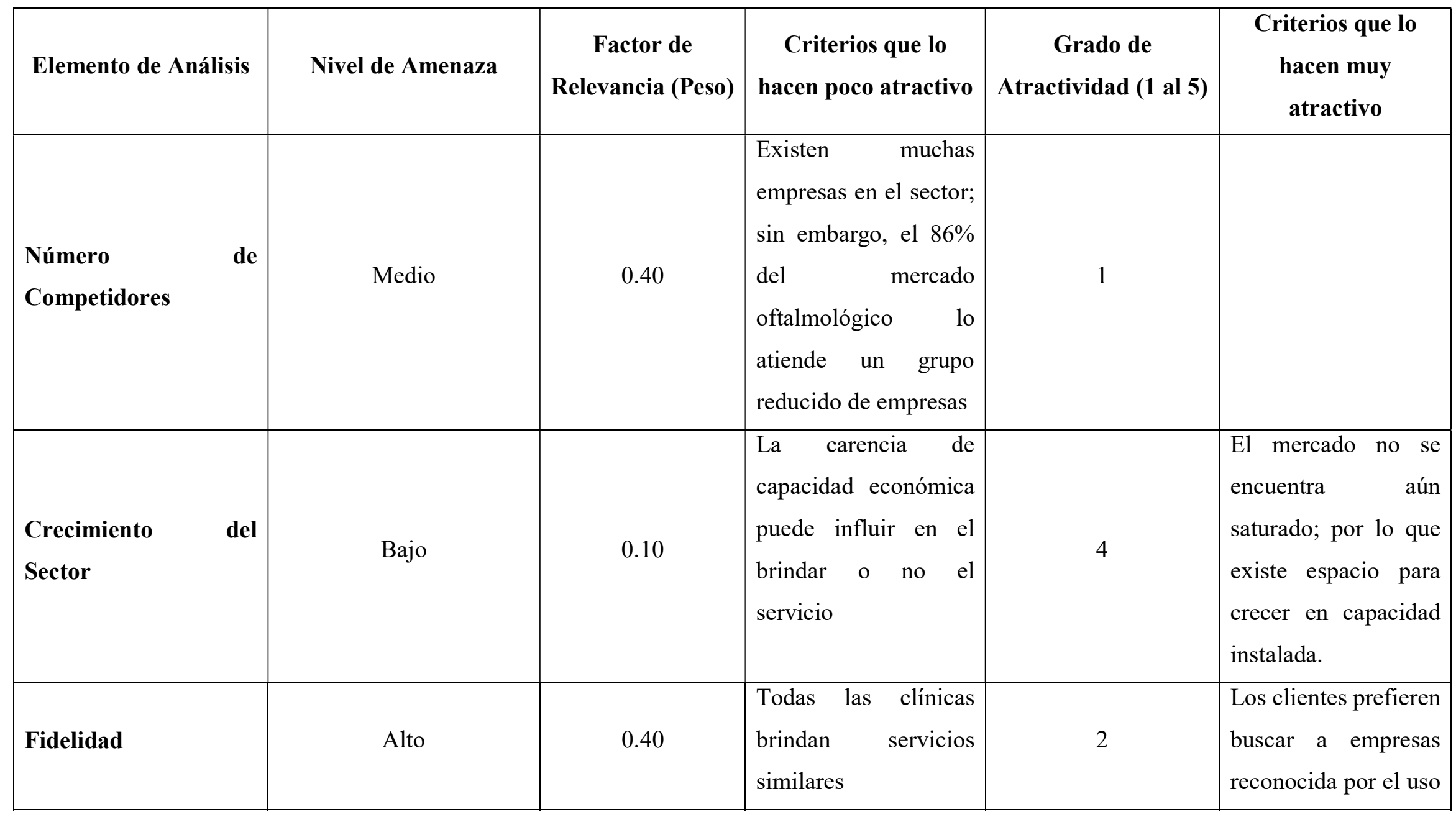




\begin{tabular}{|c|c|c|c|c|c|}
\hline & & & & & $\begin{array}{l}\text { de tecnología de } \\
\text { punta y el staff más } \\
\text { especializado }\end{array}$ \\
\hline Ponderación & Moderado & 1.00 & & 1.90 & \\
\hline
\end{tabular}

Elaboración emitida en base a juicio de valor del director de operaciones de OftalmoSalud

De lo expuesto se puede concluir que esta fuerza tiene un grado de atractividad bajo en el sector; la concentración del mercado en pocos competidores llevará a las empresas pequeñas a la desaparición. 


\subsection{Análisis del Grado de atractividad de la industria.}

Tomando el resultado ponderado de cada matriz anteriormente elaborada se mide el grado de atractividad total del sector:

Tabla 26

Matriz de atractividad de la Industria

\begin{tabular}{|c|c|c|c|c|c|}
\hline Fuerza & Poder & Peso & $\begin{array}{l}\text { Nivel } \\
\text { de } \\
\text { Atract. }\end{array}$ & Observación & $\begin{array}{l}\text { Nivel } \\
\text { Atract. } \\
\text { Pond. }\end{array}$ \\
\hline Sustitutos & Bajo & 0.15 & 2.85 & $\begin{array}{l}\text { No se identifica una amenaza de } \\
\text { desarrollo de servicios sustitutos }\end{array}$ & 0.43 \\
\hline Potenciales & $\begin{array}{l}\text { Modera } \\
\text { do }\end{array}$ & 0.30 & 2.05 & $\begin{array}{l}\text { Las EPS están implementando clínicas de } \\
\text { atención integral en todas las } \\
\text { especialidades médicas que incluyen } \\
\text { atenciones oftalmológicas. }\end{array}$ & 0.62 \\
\hline Clientes & Bajo & 0.15 & 4.10 & $\begin{array}{l}\text { Los clientes valoran de sobremanera la } \\
\text { calidad del servicio y el prestigio ganado. }\end{array}$ & 0.62 \\
\hline Proveedores & Bajo & 0.15 & 1.00 & $\begin{array}{l}\text { Su participación dentro del costo del } \\
\text { servicio médico es inferior en relación con } \\
\text { el costo del staff médico }\end{array}$ & 0.15 \\
\hline Competencia & Bajo & 0.25 & 1.90 & $\begin{array}{l}\text { A excepción del líder, existe rivalidad } \\
\text { entre las demás empresas competidoras; } \\
\text { sin embargo, el } 86 \% \text { del mercado } \\
\text { oftalmológico lo atiende un grupo } \\
\text { reducido de empresas }\end{array}$ & 0.48 \\
\hline Ponderado & Medio & 1.00 & & & 2.28 \\
\hline
\end{tabular}

Elaboración emitida en base a juicio de valor del director de operaciones de OftalmoSalud

De acuerdo al análisis realizado en el punto anterior (tabla 5.15) se concluye que la industria de servicios oftalmológicos en promedio es poco atractiva. 


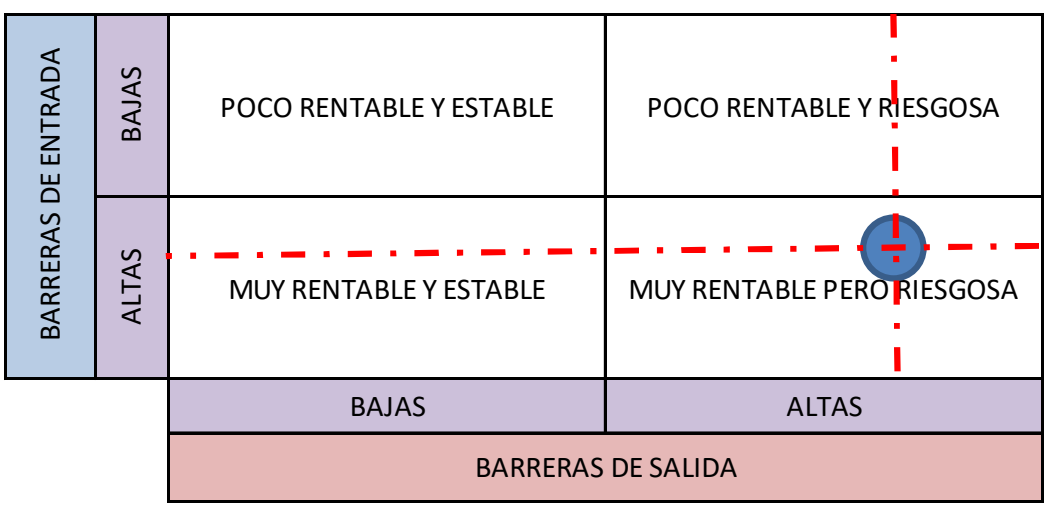

Figura 10. Matriz de Potencial de Utilidad de Porter (atractividad), Elaboración Propia (Fuente Proyecto de Investigación Gerencial Aplicado "Plan Estratégico Cecosami S.A 2015 - 2019”)

Si a esto le sumamos la matriz de potencial de utilidad de Porter, mostrada en el grafico anterior, se concluye que el grado de atractividad del sector es bastante rentable, pero acarrea ciertos riesgos.

\subsection{Matriz de Perfil Competitivo MPC.}

A continuación, en la siguiente tabla se analizan los factores críticos de éxito de la industria (servicios oftalmológicos) tomando en consideración las entrevistas al Director de Operaciones de OftalmoSalud, a uno de los Directores de Oftálmica, el Dr. Carlos Siverio y al Dr. Luis Tobaru, Gerente General de TG Laser, sus opiniones respecto el entorno, la industria y las empresas del sector. Dentro de las entrevistas realizadas a las empresas de la competencia, se pusieron a evaluación los factores críticos de éxito determinados por OftalmoSalud solicitándoles sus observaciones o validaciones sobre los mismos, en ambos casos se ratificaron los factores encontrados, no se invalido ni se agregó ninguno.

Los pesos para cada uno de los factores claves de éxito se determinaron en función a la importancia de los mismos dentro de la industria Oftalmológica y los valores para cada empresa se obtuvieron de las apreciaciones de los entrevistados y visitas a los locales de las diferentes empresas. 
Tabla 27

Matriz de perfil competitivo (MPC)

\begin{tabular}{|c|c|c|c|c|c|c|c|c|c|c|c|c|c|c|c|}
\hline \multirow[b]{2}{*}{ Factores claves de éxito } & \multirow[b]{2}{*}{ Peso } & \multicolumn{2}{|c|}{ OftalmoSahud } & \multicolumn{2}{|r|}{ TG Laser } & \multicolumn{2}{|c|}{ Contreras Campos } & \multicolumn{2}{|r|}{ Oftalmica } & \multicolumn{2}{|r|}{ Seluce } & \multicolumn{2}{|r|}{ LaLuz } & \multicolumn{2}{|r|}{ Ñahui } \\
\hline & & Valor & Ponderación & Valor & Ponderación & Valor & Ponderación & Valor & Ponderación & Valor & Ponderación & Valor & Ponderación & Valor & Ponderación \\
\hline 1. Infraestructura (consultorios, salas de operación, equipamiento en general) & 0.12 & 4 & 0.48 & 3 & 0.36 & 1 & 0.12 & 2 & 0.24 & 2 & 0.24 & 2 & 0.24 & 2 & 0.24 \\
\hline 2. Citas en central telefónica & 0.03 & 4 & 0.12 & 2 & 0.06 & 2 & 0.06 & 2 & 0.06 & 2 & 0.06 & 2 & 0.06 & 2 & 0.06 \\
\hline 3. Atención en counter principal & 0.05 & 2 & 0.10 & 4 & 0.20 & 3 & 0.15 & 3 & 0.15 & 2 & 0.10 & 3 & 0.15 & 3 & 0.15 \\
\hline 4. Tiempo de espera & 0.11 & 1 & 0.11 & 4 & 0.44 & 3 & 0.33 & 3 & 0.33 & 3 & 0.33 & 2 & 0.22 & 2 & 0.22 \\
\hline 5. Atención en consultorio médico & 0.10 & 4 & 0.40 & 3 & 0.30 & 4 & 0.40 & 3 & 0.30 & 3 & 0.30 & 3 & 0.30 & 3 & 0.30 \\
\hline 6. Atención en farmacia & 0.02 & 3 & 0.06 & 3 & 0.06 & 3 & 0.06 & 3 & 0.06 & 3 & 0.06 & 3 & 0.06 & 3 & 0.06 \\
\hline 7. Atención en óptica & 0.02 & 3 & 0.06 & 2 & 0.04 & 3 & 0.06 & 3 & 0.06 & 3 & 0.06 & 3 & 0.06 & 3 & 0.06 \\
\hline 8. Atención en exámenes auxiliares / diagnóstico & 0.05 & 4 & 0.20 & 2 & 0.10 & 2 & 0.10 & 2 & 0.10 & 2 & 0.10 & 2 & 0.10 & 2 & 0.10 \\
\hline 9. Tiempo de entrega de resultados & 0.03 & 3 & 0.09 & 3 & 0.09 & 2 & 0.06 & 2 & 0.06 & 2 & 0.06 & 2 & 0.06 & 2 & 0.06 \\
\hline 10. Atención en cotizaciones & 0.02 & 4 & 0.08 & 3 & 0.06 & 3 & 0.06 & 3 & 0.06 & 2 & 0.04 & 2 & 0.04 & 2 & 0.04 \\
\hline 11. Servicio quirúrgico & 0.12 & 4 & 0.48 & 3 & 0.36 & 3 & 0.36 & 3 & 0.36 & 3 & 0.36 & 3 & 0.36 & 3 & 0.36 \\
\hline 12. Servicio post quirúrgico & 0.05 & 4 & 0.20 & 3 & 0.15 & 3 & 0.15 & 3 & 0.15 & 3 & 0.15 & 3 & 0.15 & 3 & 0.15 \\
\hline 13. Staff médico & 0.12 & 4 & 0.48 & 3 & 0.36 & 3 & 0.36 & 3 & 0.36 & 3 & 0.36 & 3 & 0.36 & 3 & 0.36 \\
\hline 14. Staff técnico / paramédico & 0.05 & 4 & 0.20 & 3 & 0.15 & 3 & 0.15 & 2 & 0.10 & 2 & 0.10 & 2 & 0.10 & 2 & 0.10 \\
\hline 15. Staff administrativo & 0.02 & 4 & 0.08 & 2 & 0.04 & 2 & 0.04 & 2 & 0.04 & 2 & 0.04 & 2 & 0.04 & 2 & 0.04 \\
\hline 16. Salas de espera / distracción ambiental & 0.02 & 4 & 0.08 & 2 & 0.04 & 2 & 0.04 & 2 & 0.04 & 2 & 0.04 & 2 & 0.04 & 2 & 0.04 \\
\hline 17. Cafeteria & 0.02 & 1 & 0.02 & 2 & 0.04 & 2 & 0.04 & 2 & 0.04 & 2 & 0.04 & 2 & 0.04 & 2 & 0.04 \\
\hline 18. Estacionamiento / valet parking & 0.05 & 4 & 0.20 & 4 & 0.20 & 2 & 0.10 & 2 & 0.10 & 2 & 0.10 & 2 & 0.10 & 2 & 0.10 \\
\hline Total & 1.00 & & 3.44 & & 3.05 & & 2.64 & & 2.61 & & 2.54 & & 2.48 & & 2.48 \\
\hline
\end{tabular}

Elaboración emitida en base a juicio de valor de Directivos de la industria Oftalmológica 
Como se puede apreciar OftalmoSalud mantiene el liderazgo en esta evaluación ya que destaca principalmente en infraestructura, staff médico y servicio quirúrgico, factores claves de éxito para la industria. En el caso de Oftálmica el cual es el segundo en ventas podemos apreciar que en esta MPC se encuentra en el puesto 4, debido principalmente a que su capacidad instalada y sus ventas se encuentran estancadas en los últimos 6 años. Muy por el contrario, TG Laser el cual se encuentra quinto en ventas, pero segundo en esta MPC, esta variación se debe a que en los últimos años viene invirtiendo en mejorar los mismos factores de éxito en los cuales OftalmoSalud destaca. 


\section{Capítulo VI. Análisis Interno}

En el presente capítulo tiene por objetivo analizar la empresa, identificar sus fortalezas y debilidades y de esta manera, según los objetivos que desee alcanzar, poder trazar las estrategias adecuadas.

\subsection{Descripción de las actividades de la cadena de valor de la empresa: Logística}

\section{interna, Operaciones, Logística externa, Mercadotecnia, Servicios, Adquisiciones,}

\section{Recursos Humanos, Tecnología, Infraestructura.}

En los siguientes gráficos se pueden apreciar el mapa de proceso macro de

OftalmoSalud, en él se identifican claramente cuáles son los procesos estratégicos,

operacionales y de soporte que requiere la empresa para su correcto funcionamiento, así

como la cadena de valor de la empresa y su interacción con los procesos identificados. Tanto

la Alta Dirección, como la Administración y el resto del equipo de OftalmoSalud se

encuentran en una búsqueda constante de mejora continua de sus procesos, de manera que les permita optimizarlos y seguir creciendo para de esta manera mantener el liderazgo en el mercado. A continuación, explicaremos brevemente dichos procesos:

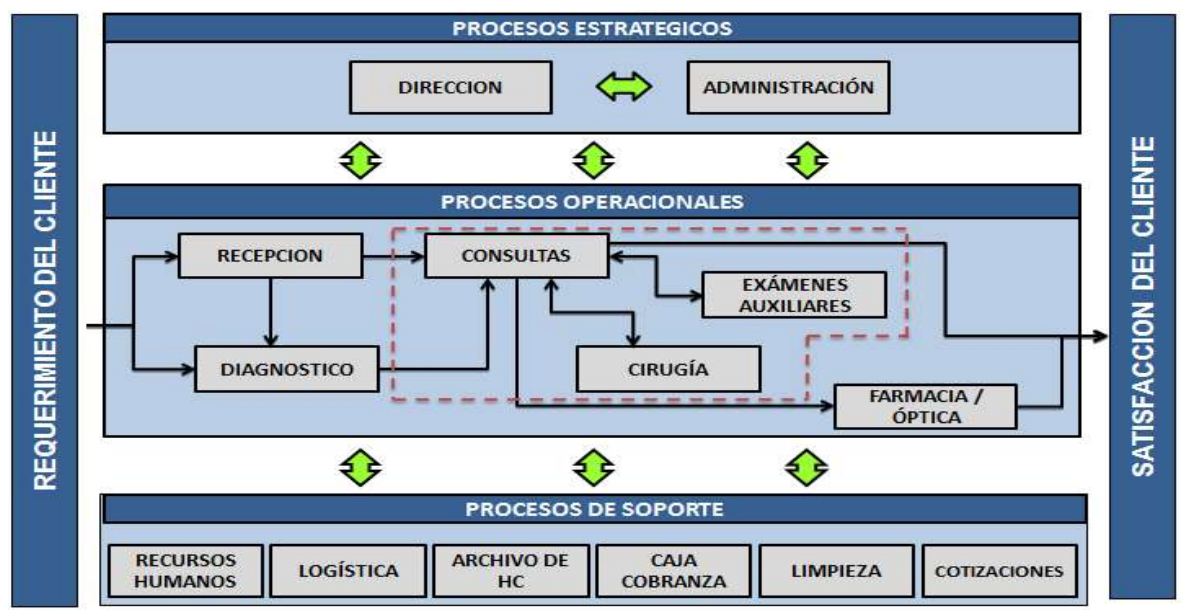

Figura 11. Mapa de Procesos OftalmoSalud, elaborada sobre información otorgada por OftalmoSalud 


\subsubsection{Procesos Operativos Clave.}

Para OftalmoSalud, los procesos operativos clave son cuatro:

Recepción: Proceso en el cual se recibe al paciente, se verifica si tiene una cita agendada o no, si cuenta con seguro médico o el paciente viene por atención particular y si el mismo cuenta o no con una historia clínica existente. Habiendo efectuado la verificación descrita, dependiendo de la atención generada (particular o seguro) se le explica al paciente todos aquellos costos asociados a la consulta. De estar todo conforme se genera el ticket de atención y se deriva al paciente a cancelar su consulta en caja.

Diagnóstico: Es el proceso posterior a la recepción, y antes de la atención por parte del especialista. Por este paso pasan todos los pacientes (salvo excepciones por emergencias). En este proceso el paciente pasa por un primer diagnóstico referencial en donde se le hacen las consultas sobre sus principales molestias y se genera una primera medida de vista. Como se mencionó posteriormente se le deriva al médico especialista para el diagnóstico y tratamiento de su caso en especial

Procesos de atención oftalmológica: En este proceso, el paciente es derivado al médico especialista para tratar la molestia por la cual fue a consulta. El médico hace las revisiones correspondientes y procede a informar al paciente acerca del padecimiento y cuál debe ser el tratamiento a seguir. Posteriormente y de acuerdo al diagnóstico final, el paciente es derivado a farmacia y/u óptica para adquirir los productos necesarios para el tratamiento indicado o en caso de requerirlo el paciente es derivado a exámenes auxiliares, los mismos que, dependiendo de los resultados obtenidos, pueden decantar en que el paciente requiera o no una cirugía. En todos los casos el paciente, luego del tratamiento recetado debe regresar a consulta para los chequeos de rigor con la finalidad de otorgar el alta respectiva o en su defecto proseguir con el tratamiento por un periodo adicional o realizar un cambio de 
tratamiento en caso no exista mejoría alguna.

Farmacia - Óptica: Punto de atención final; en el caso de la farmacia, el paciente puede adquirir las medicinas recetadas para tratar su molestia y en el caso de óptica, el paciente puede adquirir cualquier instrumento óptico que pueda permitirle mejorar su visión. Ambas unidades de negocio también atienden a clientes que no necesariamente han pasado previamente por una consulta en el centro oftalmológico.

\subsubsection{Procesos de Apoyo.}

Recursos Humanos: Son los encargados de la selección y reclutamiento del personal, así como de desarrollar los perfiles de puesto y llevar a cabo la capacitación del personal. Esta área también se encarga de mantener un buen clima laboral en la empresa y del bienestar de la organización en general. Por otro lado, son los encargados de crear, mantener, actualizar y hacer respetar el reglamento interno de trabajo, así como aplicar las sanciones correspondientes en aquellos casos que sea necesario. Otra tarea importante asignada a esta área es la de manejar los procesos de contratación y desvinculación del personal, en este aspecto la empresa ha tenido un alto índice de rotación de personal administrativo y operativo (no staff médico) debido a un mal perfilamiento de puestos de trabajo debido a que se contrató personal joven sin visión de línea de carrera.

Logística: es el departamento encargado de realizar las compras necesarias para el funcionamiento regular de la empresa. Del mismo modo también son los encargados de la evaluación semestral de los proveedores. Adicionalmente son los encargados del almacenamiento de productos farmacéuticos, dispositivos médicos y productos sanitarios en el almacén de la farmacia de acuerdo a las condiciones requeridas para cada uno de ellos. Es importante tener un cuidado especial con aquellos productos que requieran refrigeración o aquellos que requieren algún tipo de atención en especial adicional. 
Su sistema de Inventario es Primero el expirar, primero en salir (FEFO por sus siglas en inglés), por lo cual se debe tener la precaución de colocar estos productos en el orden adecuado por fecha de expiración.

El inventario se realiza dos veces al mes y se lleva a cabo en cada farmacia, laboratorio, óptica y almacén de las distintas sedes y sólo es realizado por personal de la sede principal la cual es Javier Prado (San Isidro).

Archivo de Historia Clínica: es el área encargada de la creación, control y archivo de la historia clínica de cada paciente. Este proceso es llevado a cabo por el encargado de archivo en estrecha relación con el área de recepción. En lo regular el día anterior se generan o recaban todas las historias clínicas de los pacientes que se atenderán al día siguiente con excepción de aquellos que lleguen el mismo día sin cita.

No es muy común, pero existe un procedimiento especial cuándo las historias clínicas deben cambiar de sede. El tiempo promedio de vigencia de una historia clínica es de 5 años. Hay que mencionar que en la actualidad las historias clínicas son físicas y no digitales, consideramos que hay una oportunidad de mejora en ese aspecto.

Caja - Cobranzas: es el área responsable de registrar contablemente las notas de abono y crédito, así como archivar cada una de ellas en su respectivo lugar. También se encarga de coordinar oportunamente con la administración de cada sede para elaborar las notas de pedido de las facturas $\mathrm{y} / \mathrm{o}$ boletas correlativas para la sede.

También debe cautelar la integridad de la información archivada como son las boletas de venta y facturas emitidas por la empresa y enviar a Contabilidad Central toda la documentación pertinente a la Facturación y Cobranzas de cada Sede, teniendo un cargo de lo enviado para conciliación futura. 
Limpieza: es el área encargada de que todas las instalaciones, mobiliario, anuncios y equipos dentro y fuera de las sedes de la Clínica deben estar en perfectas condiciones de mantenimiento y limpieza.

Esta área también se encarga de la fumigación de todas las instalaciones y de llevar los controles necesarios para programar las mismas en los tiempos establecidos y mantener las certificaciones y controles en regla.

Cotizaciones: es el área responsable de cotizar los exámenes auxiliares y cirugías de ser necesarias luego de la consulta médica. Esta área trabaja estrechamente con las compañías de seguro, con los médicos tratantes y el área de logística (tarifario de medicina y consumible quirúrgico) con la finalidad de presentar al paciente cotizaciones integrales para atender la molestia que vino a tratarse. Es el área encargada de verificar el requerimiento de las cartas de garantía por parte de las compañías de seguro de ser requeridas antes de emitir una cotización.

\subsection{Indicadores de cada una de las actividades de la cadena de valor.}

La organización se encuentra bien estructurada y alineada con los procesos requeridos para el normal funcionamiento de las distintas unidades de negocio de las diferentes sedes. Cuentan con certificaciones ISO, por lo cual se encuentran obligados a cumplir con los procesos estipulados según los manuales aprobados bajo esta certificación.

Cada una de las actividades de la cadena de valor tiene un indicador de gestión que le sirve para medir sus niveles de eficiencia y avance a lo largo del año. Estos indicadores son vaciados en un tablero de control por área. A continuación, se muestran aquellos indicadores a los cuales se tuvo acceso en las entrevistas a los Directivos de OftalmoSalud: 
Tabla 28

Indicadores de Gestión

\begin{tabular}{|c|c|}
\hline \multicolumn{2}{|c|}{ OPERATIVOS } \\
\hline $\begin{array}{l}\text { ADMISION } \\
\text { OBJETIVO } \\
\text { ACTUAL }\end{array}$ & $\begin{array}{l}\text { 95\% Eficiencia } \\
\text { 87\% Eficiencia }\end{array}$ \\
\hline \multicolumn{2}{|c|}{} \\
\hline Objetivo & Tiempo de espera \\
\hline Actual & 20 minutos promedio \\
\hline Medición & 25 minutos promedio \\
\hline \multicolumn{2}{|c|}{ Call Center : Llamadas atendidas } \\
\hline Objetivo & 100\% llamadas atendidas \\
\hline Actual & $90 \%$ llamadas atendidas \\
\hline Medición & Medición de llamadas entre atendidas/ no atendidas y perdidas en tiempos de espera \\
\hline
\end{tabular}

\begin{tabular}{|l|l|}
\hline \multicolumn{2}{|l|}{ OPERATIVOS } \\
\hline $\begin{array}{l}\text { SERVICIOS CLINICOS } \\
\text { OBJETIVO } \\
\text { ACTUAL }\end{array}$ & $\begin{array}{l}\text { 95\% Eficiencia } \\
\text { 98\% Eficiencia }\end{array}$ \\
\hline \multicolumn{2}{|c|}{ Exámenes } \\
\hline Medición & 100\% equipos en óptimo estado \\
\hline Medición & Tiempo de demora en emisión de informes (dentro de las primeras 48 horas) \\
\hline \multicolumn{2}{|c|}{ Laboratorio } \\
\hline Medición & 100\% productos reactivos en óptimo estado \\
\hline Medición & Tiempo de demora en emisión de informes (dentro de las primeras 48 horas) \\
\hline \multicolumn{2}{|c|}{ Farmacia } \\
\hline Medición & $100 \%$ de Reposición de surtido en stock según petitorio a tiempo \\
\hline
\end{tabular}

\begin{tabular}{|c|c|}
\hline \multicolumn{2}{|r|}{ OPERATIVOS } \\
\hline \multicolumn{2}{|c|}{ SERVICIOS MÉDICOS Y QUIRÚRGICOS } \\
\hline OBJETIVO & 95\% Satisfacción \\
\hline ACTUAL & 98\% Satisfacción \\
\hline \multicolumn{2}{|r|}{ Encuestas } \\
\hline Medición & Satisfacción en tratamientos de diagnósticos ambulatorios \\
\hline \multicolumn{2}{|r|}{ Satisfacción en resultados quirúrgicos post operatorios } \\
\hline \multirow{2}{*}{\multicolumn{2}{|c|}{$\begin{array}{l}\text { Reclamos en atenciones } \\
\text { AREAS DE SOPORTE }\end{array}$}} \\
\hline & \\
\hline RRHH & ROTACION DE PERSONAL \\
\hline OBJETIVO & menor a $20 \%$ \\
\hline ACTUAL & $31 \%$ \\
\hline Medición & Renuncia de personal / Personal total contratado \\
\hline
\end{tabular}

\begin{tabular}{|lrc|}
\hline FINANZAS & UTILIDAD \\
OBJETIVO & $10 \%$ \\
ACTUAL & $9.50 \%$ & \\
\hline & & \\
\hline Medición & & Utilidad Neta / Ventas \\
\hline
\end{tabular}

Elaboración con información obtenida de OftalmoSalud 
Cabe mencionar que el tablero de control podría ser modificado en el tiempo en la medida que se implementen nuevas estrategias ya que las mismas generarán nuevos indicadores de gestión que deberán ser medidos.

\subsection{Benchmarking y comparación con los líderes de la industria de cada una de las actividades de la cadena de valor.}

La industria no cuenta con un Benchmarking desarrollado por terceros; pero siguiendo la metodología de Benjamín Betancourt Guerrero en su libro Análisis Sectorial y Competitividad, utilizando los datos obtenidos en la matriz MPC se puede desarrollar un Benchmarking Competitivo. A continuación, se muestran gráficamente los resultados de la MPC en donde se analizan los factores competitivos de las empresas:

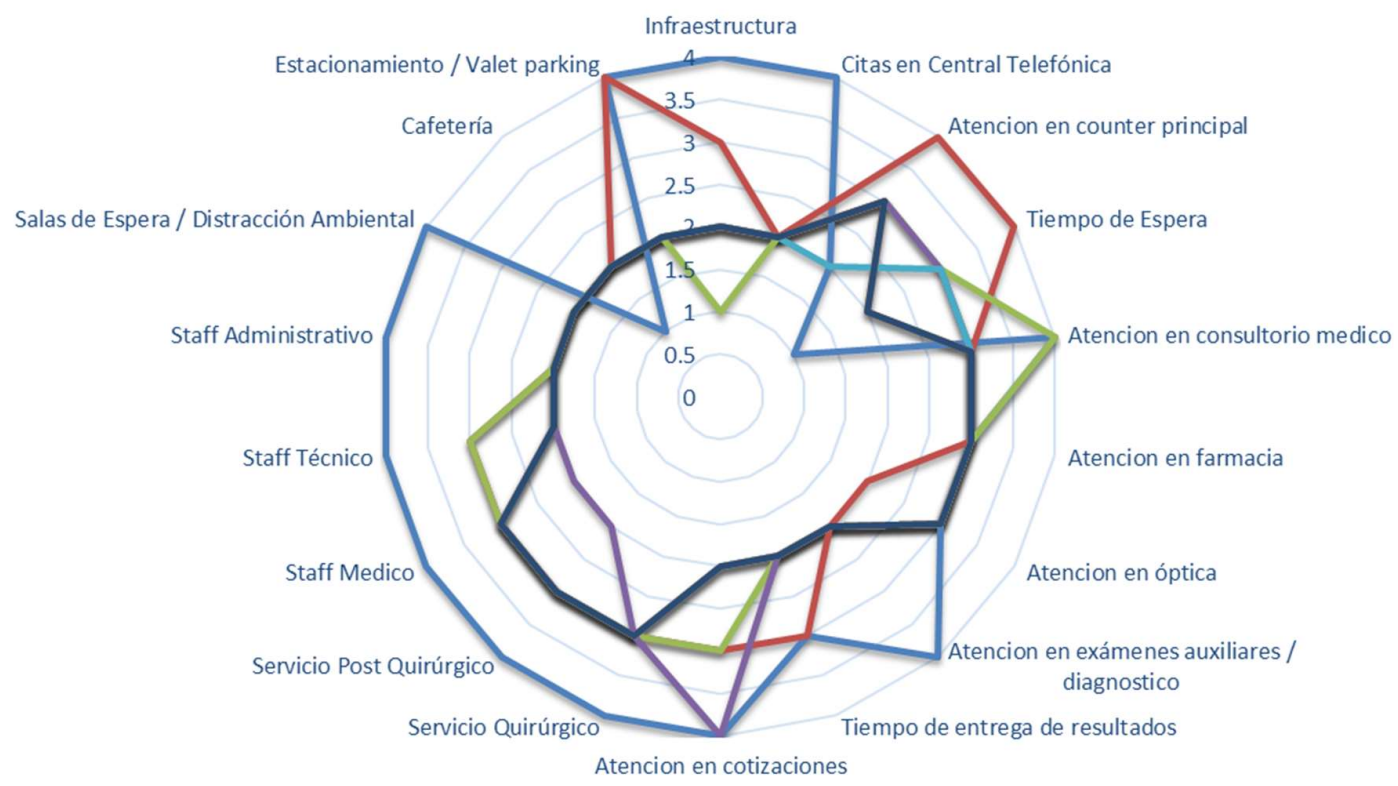

CoftalmoSalud $\quad$ TG Laser Contreras Campos $\quad$ Oftalmica $\quad$ Seluce $\quad$ La Luz $\quad$ Nahui

Figura 13. Radar de Factores Competitivos Sector Oftalmológico, elaborado con información de la MPC 


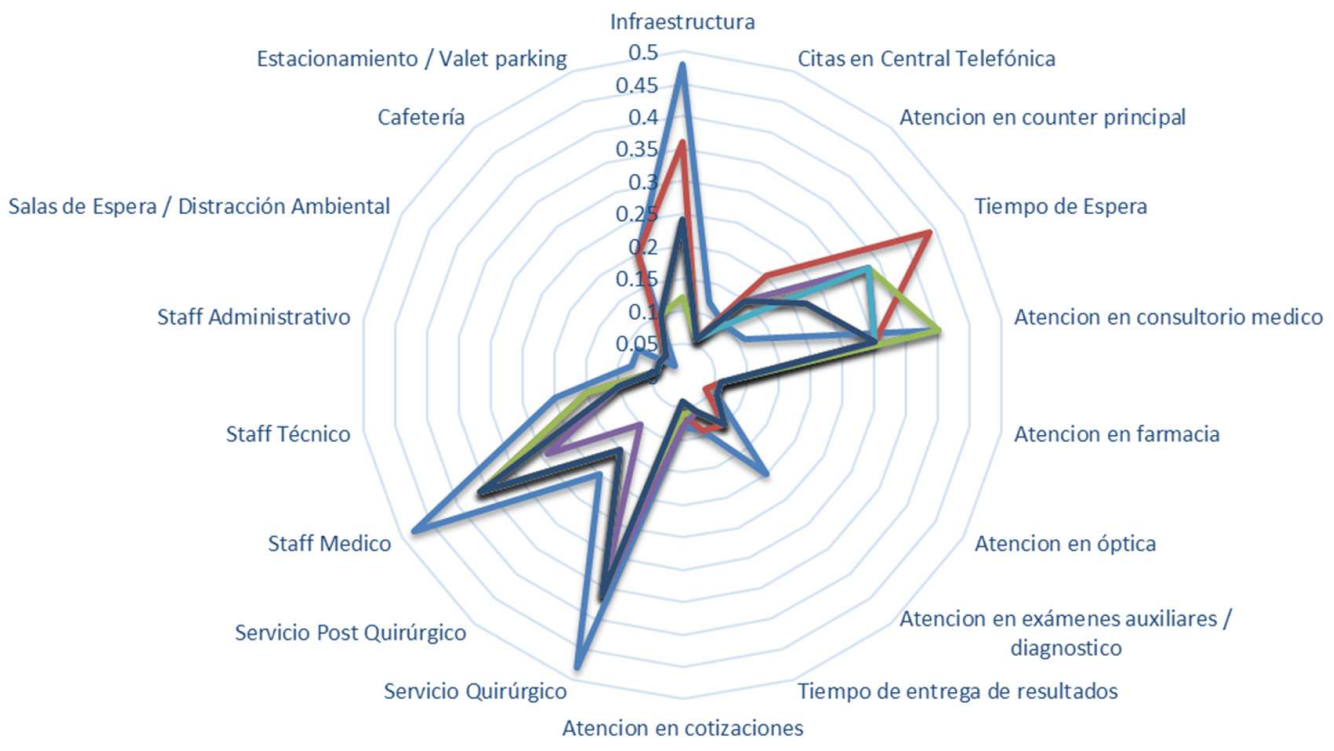

- OftalmoSalud

—TG Laser $\quad$ Contreras Campos

- Oftalmica

—La Luz —Ñahui

Figura 14. Radar de Factores Competitivos Ponderado Sector Oftalmológico, elaborado con información de la MPC

Analizando esta información se observa que los factores competitivos más valorados en el Sector Oftalmológico son 5 los cuales son: la Infraestructura, Tiempo en Espera, Atención en Consultorio Médico, Servicio Quirúrgico y Staff Médico. En tres de ellos OftalmoSalud es el referente del sector y debe de buscar las mejores prácticas ya sea en el Sector o en otro para mejorar el Tiempo de Espera y la Atención en Consultorio Médico

Adicionalmente, de la entrevista con el Director de Operaciones, podríamos situar a OftalmoSalud dentro de un ranking de aquellas empresas de renombre mundial como son: 
Tabla 29

Ranking Servicio Oftalmológico Iberoamericano

\begin{tabular}{|l|c|c|}
\hline \multicolumn{1}{|c|}{ Empresa } & País & Ranking \\
\hline SP Eye Center & Brasil & 1 \\
\hline Visu & España & 2 \\
\hline Clínica Barraquer & Colombia & 3 \\
\hline Bascom Palmer Eye Institute & USA & 4 \\
\hline OFTALMOSALUD & Perú & 5 \\
\hline Hugo Nano & Argentina & 6 \\
\hline Instituto Zaldívar & Chile & 7 \\
\hline Instituto de la Visión & Argentina & 8 \\
\hline
\end{tabular}

Elaboración sobre juicio de valor del director de operaciones de OftalmoSalud

Este ranking toma como punto de referencia los principales factores críticos de éxito de la industria como son infraestructura, staff médico y servicio quirúrgico.

\subsection{Determinar las competencias de la empresa.}

Como ya se ha mencionado en oportunidades anteriores, OftalmoSalud es líder en ventas en el mercado oftalmológico, es referente del cuidado de la visión y por lo tanto cuenta con un buen posicionamiento de marca, es en ese sentido que se puede afirmar que sus principales competencias son las siguientes:

Tabla 30

Competencias de la Empresa

\begin{tabular}{|c|c|}
\hline Competencia & \multicolumn{1}{|c|}{ Comentario } \\
\hline \multirow{3}{*}{ Alta calificación del staff médico } & Los médicos que trabajan en OftalmoSalud son \\
& seleccionados primordialmente por contar con \\
& una alta preparación en su especialidad. \\
\hline
\end{tabular}




\begin{tabular}{|c|c|}
\hline & $\begin{array}{l}\text { Adicionalmente deben ser médicos de reconocido } \\
\text { prestigio y con poder de adecuación a la } \\
\text { metodología de trabajo de la empresa. }\end{array}$ \\
\hline $\begin{array}{l}\text { Administración dinámica que } \\
\text { busca crecimiento constante }\end{array}$ & $\begin{array}{l}\text { Tanto la Alta Dirección, como la Administración } \\
\text { y el resto del equipo de OftalmoSalud se } \\
\text { encuentran en una búsqueda constante de mejora } \\
\text { continua de sus procesos, de manera que les } \\
\text { permita optimizarlos y seguir creciendo para de } \\
\text { esta manera mantener el liderazgo en el mercado. }\end{array}$ \\
\hline $\begin{array}{l}\text { Alineamiento de los procesos con } \\
\text { estructura y cultura del negocio }\end{array}$ & $\begin{array}{l}\text { La organización se encuentra bien estructurada y } \\
\text { alineada con los procesos requeridos para el } \\
\text { normal funcionamiento de las distintas unidades } \\
\text { de negocio de las diferentes sedes. Cuentan con } \\
\text { certificaciones ISO, por lo cual se encuentran } \\
\text { obligados a cumplir con los procesos estipulados } \\
\text { según los manuales aprobados bajo esta } \\
\text { certificación. Existe una cultura de } \\
\text { involucramiento por parte de la organización para } \\
\text { poder mantenerlas. }\end{array}$ \\
\hline $\begin{array}{l}\text { Recurso Humano con vocación de } \\
\text { servicio }\end{array}$ & $\begin{array}{l}\text { Según el indicador de gestión que mide la } \\
\text { satisfacción de los clientes, podemos considerar } \\
\text { que todos los colaboradores de OftalmoSalud se } \\
\text { encuentran plenamente identificados con este } \\
\text { valor, ya que para atender clientes o pacientes se } \\
\text { debe estar enfocado en ellos. Al tratarse de una } \\
\text { cadena de servicio bastante amplia, los clientes } \\
\text { deben sentirse cómodos durante todo el proceso } \\
\text { de su atención, por lo que contar con personal con } \\
\text { una alta vocación de servicio es primordial para } \\
\text { mantener un servicio de alta calidad y que } \\
\text { posteriormente éste sea recomendado. }\end{array}$ \\
\hline $\begin{array}{l}\text { Inversión en Infraestructura y } \\
\text { Tecnología }\end{array}$ & $\begin{array}{l}\text { En sus sedes cuenta con equipos de alta gama y } \\
\text { amplio espectro tecnológico, que le permite }\end{array}$ \\
\hline
\end{tabular}




\begin{tabular}{|l|l|}
\hline & $\begin{array}{l}\text { brindar tratamientos, cirugías oftalmológicas y } \\
\text { atenciones de calidad a sus pacientes en las más } \\
\text { óptimas condiciones. }\end{array}$ \\
\hline
\end{tabular}

Elaboración con información obtenida de OftalmoSalud

\subsection{Identificación y determinación de las ventajas competitivas de la empresa.}

Para poder realizar un análisis interno de la empresa es necesario identificar y determinar sus ventajas competitivas, es decir aquellas que resaltan y la diferencian con respecto a la competencia. De las entrevistas realizadas los Directivos de OftalmoSalud afirman que sus ventajas competitivas se centran en:

\section{Tabla 31}

Ventajas Competitivas OftalmoSalud

\begin{tabular}{|l|l|}
\hline \multicolumn{1}{|c|}{ Ventaja Competitiva } & \multicolumn{1}{|c|}{ Comentario } \\
\hline \multirow{5}{*}{ Localización Estratégica } & \begin{tabular}{l} 
OftalmoSalud cuenta con 4 sedes ubicadas \\
estratégicamente en las principales zonas de Lima \\
Metropolitana como son: Lima Norte (Los \\
Olivos), Lima Sur (San Juan de Lurigancho), el \\
Polo y San Isidro (Sede Javier Prado). \\
Tal como se mencionó anteriormente el pleno \\
empleo de la capacidad instalada actual de la \\
empresa viene afectando la percepción de calidad \\
en el servicio y en el corto plazo afectará el \\
crecimiento de la empresa. \\
\hline Staff Médico de renombre
\end{tabular} \\
$\begin{array}{l}\text { El fundador de la empresa, el Dr. Izquierdo ha } \\
\text { sido presidente de la sociedad peruana de } \\
\text { Oftalmología y junto con sus hijos son } \\
\text { considerados dentro de los mejores en esta } \\
\text { especialidad. }\end{array}$ \\
\hline
\end{tabular}




\begin{tabular}{|l|l|}
\hline Semillero de Staff Médico y & $\begin{array}{l}\text { OftalmoSalud tiene un área Docente - } \\
\text { Académica, la cual recibe a oftalmólogos y } \\
\text { residentes de la especialidad, que completan su } \\
\text { formación }\end{array}$ \\
\hline
\end{tabular}

Elaboración con información obtenida de OftalmoSalud

Para determinar si estas ventajas expuestas por los directores son realmente las ventajas competitivas de OftalmoSalud emplearemos la metodología del Análisis, análisis mediante el cual la empresa es capaz de detectar cuáles son los recursos y capacidades que pueden proporcionarle una determinada ventaja competitiva sostenible, es decir, una posición de superioridad en el mercado frente a sus competidores a lo largo del tiempo.

El Análisis VRIO se basa en el enfoque de recursos y capacidades y surge del análisis interno de la empresa; los términos y definiciones que componen el Análisis VRIO (Valioso, Raro, Inimitable y Organizado) aparecen recogidos en la siguiente tabla:

Tabla 32

Análisis VRIO

\begin{tabular}{|c|c|}
\hline \multicolumn{1}{|c|}{ VALIOSOS } & \multicolumn{1}{c|}{ RAROS, ÚNICOS O ESCASOS } \\
\hline $\begin{array}{l}\text { Permiten nuevas oportunidades } \\
\text { en el mercado. }\end{array}$ & $\begin{array}{l}\text { Específicos de la empresa y difíciles } \\
\text { de obtene.r en el mercado }\end{array}$ \\
\hline \multicolumn{1}{|c|}{ INIMITABLES } & \multicolumn{1}{c|}{ ORGANIZADOS } \\
\hline $\begin{array}{l}\text { Difíciles de copiar o imitar por la } \\
\text { competencia. }\end{array}$ & $\begin{array}{l}\text { Explotados eficientemente por la } \\
\text { empresa y complementarios. }\end{array}$ \\
\hline
\end{tabular}

Elaboración sobre modelo Análisis VRIO

De lo mencionado anteriormente se ha obtenido los siguientes resultados: 
Tabla 33

Análisis VRIO OftalmoSalud

\begin{tabular}{|c|c|c|c|c|c|}
\hline Ventaja Competitiva & v & $\mathbf{R}$ & I & 0 & Comentario \\
\hline Liderazgo en el Mercado & & & & & Ventaja Competitiva Temporal \\
\hline Calidad del Producto & & & & & Ventaja Competitiva Temporal \\
\hline Localización Estratégica & & & & & Igualdad competitiva \\
\hline Conocimiento del Mercado & & & & & Igualdad competitiva \\
\hline Staff Médico de renombre & & & & & Ventaja Competitiva Sostenible \\
\hline Semillero de Staff Médico y Sucesiones & & & & & Ventaja Competitiva Temporal \\
\hline
\end{tabular}

Elaboración con información obtenida de OftalmoSalud

Sobre el resultado de la Tabla 33 podemos mencionar que, de las seis ventajas identificadas, OftalmoSalud cuenta con una ventaja competitiva sostenible la cual es su Staff Médico de renombre y tres temporales que son el Liderazgo en el Mercado, la Calidad del Producto y el Semillero de Staff Médico y Sucesiones, y con respecto a la Localización Estratégica y el Conocimiento del Mercado vemos que únicamente son una igualdad competitiva dado que cualquier empresa de la competencia pueden acceder a ellas.

\subsection{Matriz de Evaluación de los Factores Internos EFI.}

En entrevista con el Director de Operaciones, el presidente del Directorio y el Director de Finanzas de OftalmoSalud se obtuvieron las fortalezas y debilidades de la Organización, las cuales se muestran a continuación: 
Tabla 34

Matriz EFI

\begin{tabular}{lccr}
\hline Factores determinantes de éxito & Peso & Valor & Puntaje \\
\hline Fortalezas & & & 0.15 \\
1. Posicionamiento de Marca & 0.05 & 3 & 0.15 \\
2. Localización estratégica & 0.05 & 3 & 0.60 \\
3. Staff Médico & 0.15 & 4 & 0.60 \\
4. Infraestructura y Tecnologia & 0.15 & 4 & 0.15 \\
5. Visión de crecimiento & 0.05 & 3 & 1.65 \\
& 0.45 & & 0.15 \\
Debilidades & & & 0.30 \\
1. Gobierno Corporativo familiar & 0.15 & 1 & 0.20 \\
2. Staff Médico familiar & 0.15 & 2 & 0.05 \\
3. Capacidad Instalada & 0.20 & 1 & 0.70 \\
4. Tecnologia de la Información & 0.05 & 1 & $\mathbf{2 . 3 5}$ \\
\hline Total & 0.55 & 1.00 & \\
\hline
\end{tabular}

Elaboración sobre juicio de valor del director de operaciones de OftalmoSalud

De acuerdo a la metodología empleada, la nomenclatura de los valores es: (1) rpta. pobre, (2) rpta. promedio, (3) sobre promedio, (4) rpta. superior y los pesos se asignan en función de la importancia de dicha fortaleza o debilidad sobre el total de factores internos expuestos, debiendo ser la suma de todos los pesos igual a 1.

Como se puede apreciar el ponderado obtenido en la matriz EFI es de 2.35 lo cual significa que la empresa está capitalizando de manera importante las fortalezas internas y manejando de manera apropiada las debilidades. 


\section{Capítulo VII. Formulación de los Objetivos y Diseño de las Estrategias}

En el presente capitulo se identificarán y analizarán los diferentes objetivos estratégicos a ser empleados en el planeamiento evaluado.

\subsection{Alcance y planteamiento de los objetivos estratégicos.}

\subsubsection{Objetivos Estratégicos.}

Producto de las entrevistas a profundidad con el Director de Operaciones, el presidente del Directorio y el Director de Finanzas, los objetivos estratégicos, todos ellos alineados a la visión y misión planteados, que OftalmoSalud debe de cumplir para los próximos 3 años deben ser:

Tabla 35

Objetivos Estratégicos

\begin{tabular}{|c|c|}
\hline \\
\hline \multicolumn{2}{|c|}{$\begin{array}{l}\text { Mantener el liderazgo en el mercado peruano en servicios oftalmológicos, siendo } \\
\text { reconocidos por la calidad de nuestro servicio, teniendo como pilares del servicio la } \\
\text { atención al cliente y la utilización de la tecnología más avanzada del momento a } \\
\text { nivel mundial. }\end{array}$} \\
\hline \multicolumn{2}{|r|}{ MISIÓN } \\
\hline \multicolumn{2}{|c|}{$\begin{array}{l}\text { Brindar servicios oftalmológicos respaldados en el expertise de nuestro staff } \\
\text { médico y el empleo de la tecnología más avanzada del momento, con el firme } \\
\text { propósito de generar valor y mejorar la calidad de vida de nuestros clientes, } \\
\text { colaboradores, accionistas y la sociedad. }\end{array}$} \\
\hline \multicolumn{2}{|c|}{ FORMULACIÓN DE OBJETIVOS ESTRATÉGICOS } \\
\hline Ámbito & Objetivo \\
\hline \multirow{2}{*}{ Estratégicos } & $\begin{array}{l}\text { - Sostener un crecimiento del nivel de ventas del } \\
10 \% \text { anualmente. }\end{array}$ \\
\hline & $\begin{array}{l}\text { - Crecer un } 2 \% \text { en participación del mercado } \\
\text { oftalmológico anualmente }\end{array}$ \\
\hline \multirow[b]{2}{*}{ Financiero } & $\begin{array}{l}\text { - Aumentar la utilidad neta promedio de } 9 \% \text { a } \\
12 \% \text { en los próximos } 3 \text { años } \\
\end{array}$ \\
\hline & $\begin{array}{l}\text { - Mejorar el EBITDA(Earnings before interest } \\
\text { and taxes, depreciation and amortization, por sus } \\
\text { siglas en inglés) anualmente hasta lograr un } 20 \%\end{array}$ \\
\hline \multirow[t]{2}{*}{ Organizacional } & $\begin{array}{l}\text { - Lograr un } 95 \% \text { de satisfacción del cliente para } \\
\text { los próximos } 3 \text { años }\end{array}$ \\
\hline & - Lograr un $90 \%$ satisfacción en clima laboral \\
\hline
\end{tabular}

Elaboración con información obtenida de OftalmoSalud 


\subsubsection{Análisis de los objetivos estratégicos.}

Sostener un crecimiento del nivel de ventas del $10 \%$ anualmente: En la siguiente tabla se aprecia el crecimiento en ventas de los 5 años anteriores:

Tabla 36

Cuadro de Ventas (S/.)

\begin{tabular}{|c|c|c|c|c|c|c|c|c|}
\hline & dic-10 & dic-11 & dic-12 & dic-13 & dic-14 & dic-15 & dic-16 & dic-17 \\
\hline Ventas netas & $13,211,401$ & $16,908,598$ & $22,072,609$ & $27,763,734$ & $34,090,774$ & $41,761,818$ & $46,282,198$ & $52,761,706$ \\
\hline
\end{tabular}

Elaboración sobre información brindada por OftalmoSalud en sus estados financieros.

Si bien es cierto, el crecimiento que ha presentado la empresa durante los últimos 5 años ha sido en promedio $19 \%$, el mantener estos niveles no es sostenible debido principalmente a que la capacidad instalada a la fecha ha llegado a su límite superior. La proyección para el año 2018 es de llegar a ventas netas de S/. 56.6 MM; lo que representa únicamente un crecimiento apenas del 6\% respecto el año 2017. El reto de poder sostener crecimientos del 10\% durante los próximos años, valor obtenido de las entrevistas a los directivos de la empresa, radica en analizar estrategias que nos permitan aumentar la capacidad instalada actual como son ampliaciones de las sedes existentes.

Sostener un crecimiento en el mercado oftalmológico del $2 \%$ anualmente: En la tabla 5.2 referido a la evolución del mercado clínico oftalmológico se aprecia que en los últimos años OftalmoSalud ha ganado terreno en este mercado a razón del 5\% anualmente. Dada la limitación del crecimiento en ventas debido a su actual capacidad instalada comparado con el crecimiento del mercado clínico oftalmológico, vemos que por el momento es irreal exigir el sostener dicho crecimiento en participación de mercado, es por ello que, los directivos mencionaron que solo se les debiera exigir crecer a razón de 2\% anualmente en dicha medición. Dado que la variable de crecimiento del mercado oftalmológico es una 
variable exógena a la empresa, esto conlleva a exigir al máximo el crecimiento en ventas aunado a la capacidad instalada.

Aumentar la utilidad neta promedio de $9 \%$ a $12 \%$ en los próximos 3 años: Este objetivo va de la mano con la optimización y gasto racional de los recursos tanto en el costo de ventas operacionales, así como de los gastos operativos.

Mejorar el EBITDA anualmente, hasta lograr un 20\%: Este objetivo guarda relación con el objetivo anterior ya que se refiere directamente a la reducción del costo de ventas.

Lograr un 95\% de satisfacción del cliente para los próximos 3 años: El ratio actual es de $98 \%$ de satisfacción con riesgo a disminuir debido a la falta de capacidad instalada; este objetivo busca lograr mantener los estándares de atención actuales de la empresa y cumplir con las certificaciones que mantiene. Dado el riesgo identificado es importante crecer a una capacidad instalada óptima para lograr dicho objetivo.

Lograr un 90\% de clima laboral: Si bien es cierto, en la actualidad cuentan con pequeñas encuestas de clima laboral, con resultados superiores al 90\%, el ratio que genera preocupación es el de rotación de personal administrativo, que está por encima del 30\%. Es por ello que se ha propuesto conseguir el objetivo reducir este número encontrando un perfil adecuado del colaborador administrativo de la empresa: es decir colaboradores que busquen un crecimiento personal a través de estudios superiores y que para lograrlo requieran de la remuneración y los horarios ofrecidos por OftalmoSalud, los mismos que deberán estar de acuerdo al mercado.

Tanto los resultados de las encuestas de Satisfacción al cliente como las de clima laboral, fueron obtenidos en conversaciones con los directivos de OftalmoSalud. Ellos nos 
indicaron que se trabajaron encuestas con la empresa Global Research Marketing (GRM) pero el informe de la empresa no nos fue proporcionado físicamente.

\subsection{Diseño y formulación de estrategias.}

\subsubsection{Modelo Océano Azul.}

La estrategia del Océano Azul fue formulada por W. Chan Kim y Renée Mauborgne en un libro del mismo nombre ("Blue Ocean Strategy"), en el que defiende la importancia de la innovación a la hora de abrir nuevos mercados, alejándonos de la competencia destructiva que existe en los terrenos empresariales más explotados, en otras palabras, plantean la posibilidad de crear una estrategia ganadora basándose en la "no competencia", algo que solo es posible explorando nuevos territorios, que simbolizan con un océano azul, contrario al rojo que representa la lucha encarnizada entre las empresas.

Para realizar este análisis hay que, primeramente, elaborar un cuadro estratégico donde se compilan los factores de éxito de la empresa y/o aquellos aspectos que valoran los clientes y se confrontan con los de la industria y los de la competencia (océanos rojos). Asimismo, se analiza la creación de nuevos factores de éxito que pueden generar mejores resultados en el futuro (océanos azules).

En conversaciones con los directivos de OftalmoSalud, al momento, los aspectos más valorados por los clientes y que deseamos conocer tanto en OftalmoSalud como en la competencia son:

Tiempos de espera: En la actualidad OftalmoSalud viene manejando altos tiempos de espera en la atención de sus clientes tanto a nivel de Counter como en espera de consulta, esto principalmente debido a que la capacidad instalada se encuentra en su límite superior. Si bien es cierto, la empresa cuenta con estándares establecidos para los tiempos de atención, los 
mismos no vienen cumpliéndose. Esta situación viene generando a la fecha, incomodidad o pérdida de clientes que prefieren atenderse en otro lugar con tal de evitar largos tiempos de espera en la atención. Es por ello que el tiempo de espera es una debilidad para la empresa.

Calidad en Infraestructura: La infraestructura con la que cuenta, en contraste con la competencia, es bastante más grande (única con varias sedes); dotada, principalmente en sus centros operatorios con tecnología de vanguardia a nivel nacional e internacional.

Hay que remarcar que, en la actualidad, no es un proceso sencillo el abrir una clínica y certificarla para que se puedan brindar atenciones médicas. Hay que cumplir con estándares y certificaciones nacionales e internacionales que permitan atender consultas primarias, pero principalmente el realizar operaciones de gran complejidad brindando la mayor de las garantías para con los pacientes. En el caso de OftalmoSalud, ya cuenta con mucha experiencia en la implementación de las mismas por lo que este factor es considerado como un factor diferenciador y de éxito.

Capacidad instalada: Este aspecto perteneciente también a la calidad en Infraestructura se prefirió analizar por separado dado que el mismo viene atravesando en la actualidad por un momento realmente crítico y afecta a toda la empresa; principalmente en su proyección de crecimiento tanto en para el nivel de ventas como para el posicionamiento en el mercado. La capacidad instalada ha llegado a su límite debido a que no cuenta con más espacio para incrementar consultorios y atender, principalmente, un mayor número de atenciones primarias. Si bien es cierto, OftalmoSalud, a diferencia de la competencia cuenta con diferentes sedes, el espacio requerido para atender la demanda actual a nivel Lima Metropolitana es insuficiente, por lo tanto, es una debilidad.

Calidad de atención: Es un factor que, peligrosamente, se encuentra directamente relacionado a los anteriores. Si bien, la atención en OftalmoSalud es de primera calidad y 
tiene estándares muy altos que cumplir y este factor de éxito, podría verse afectado por la percepción de los tiempos de espera y la capacidad instalada. No es una debilidad per sé, pero al momento se busca mantener los estándares de atención de acuerdo a los protocolos establecidos.

Calidad Staff Médico y Técnico: El mismo que viene a ser el factor de éxito para OftalmoSalud. La empresa se ha preocupado por reclutar en su staff a los mejores oftalmólogos del país e incluso uno de ellos ha sido reconocido como el mejor a nivel mundial: el Dr. Luis Izquierdo Villavicencio, quien luego de obtener el galardón mencionado ha sido nombrado embajador de la Marca Perú.

La empresa cuenta con un proceso de selección bastante exhaustivo con la finalidad de seleccionar a los mejores profesionales en esta rama; en la actualidad OftalmoSalud ofrece diversas capacitaciones especializadas, dictadas por reconocidos profesionales del medio y es en ese sentido que sus profesionales cuentan con una preparación de calidad otorgada y certificada por ellos mismos.

\subsubsection{Lienzo de la estrategia actual de la empresa.}

Para lograr el lienzo de la estrategia actual de la empresa, según la estrategia del Océano Azul, es necesario ordenar y ponderar los factores claves de éxito previamente mencionados.

Para ello se coloca en el eje X los aspectos valorados por los clientes y entendidos del medio y en el eje Y la calificación obtenida en cada uno de estos factores; con ello se tiene: 


\section{Lienzo Estrategia Actual de OfalmoSalud}

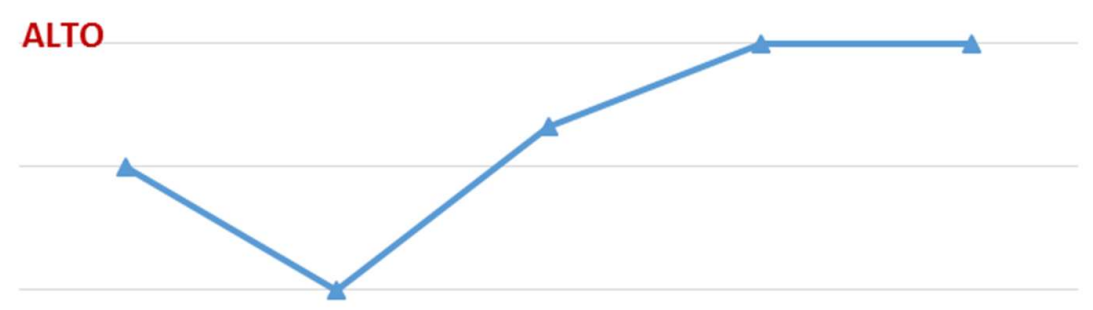

- Oftalmo Actual

BAJO

\begin{tabular}{|c|c|c|c|c|}
\hline $\begin{array}{l}\text { Tiempo de } \\
\text { Espera }\end{array}$ & $\begin{array}{l}\text { Capacidad } \\
\text { Instalada }\end{array}$ & $\begin{array}{l}\text { Calidad de } \\
\text { Atencion }\end{array}$ & $\begin{array}{c}\text { Calidad Staff } \\
\text { Medico y } \\
\text { Técnico }\end{array}$ & $\begin{array}{c}\text { Calidad } \\
\text { Infraestructura }\end{array}$ \\
\hline
\end{tabular}

Figura 15. Lienzo Estrategia Actual OftalmoSalud, basado en modelo Estrategia Océano Azul

La forma como se presenta la curva gráfica de esta valoración es cómo está posicionada OftalmoSalud en la actualidad con respecto a la valoración de sus factores claves de éxito o los aspectos que valoran los clientes y como se puede observar, la puntuación que obtiene OftalmoSalud a excepción del tiempo de espera y capacidad instalada es alta, sin embargo, siempre se puede mejorar.

\subsubsection{Lienzo de la estrategia de la industria.}

Para lograr el lienzo de la estrategia de la industria se sigue el mismo procedimiento anteriormente mencionado, pero en este caso se evalúa a la industria en general; para este caso se tomaron en cuenta las 7 empresas con mayores ventas en la industria y que representan el $85 \%$ del mercado oftalmológico privado; con ello se tiene: 


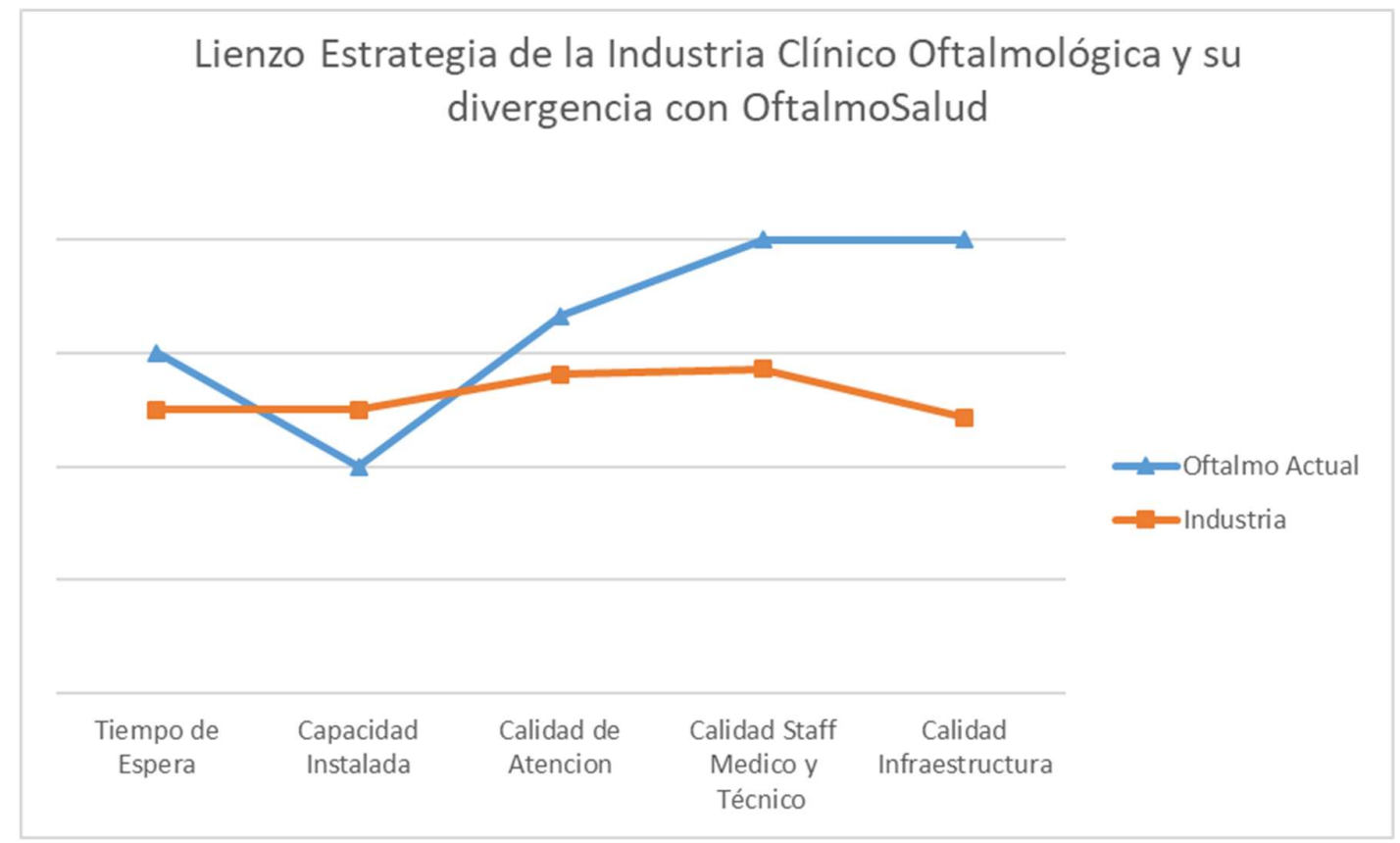

Figura 16 Lienzo Estrategia de la Industria, basado en modelo Estrategia Océano Azul

Con respecto a la industria, vemos que en general la mayoría de las empresas presenta aspectos o características similares, pero también se puede observar que en la valoración, ratificando lo mencionado en la Matriz del Perfil Competitivo (MPC), OftalmoSalud es líder de la industria.

Es por ello que se hace necesario, plantear a través del siguiente punto de la matriz, todo aquello que es necesario eliminar, reducir, incrementar y crear para formar las nuevas estrategias.

\subsubsection{Matriz (eliminar, reducir, incrementar, crear).}

A través de esta herramienta es posible determinar qué hay que hacer en cada factor analizado y que factores y/o estrategias aun la industria no ha implementado con la finalidad de obtener la vanguardia en las mismas. Luego del análisis se tiene: 


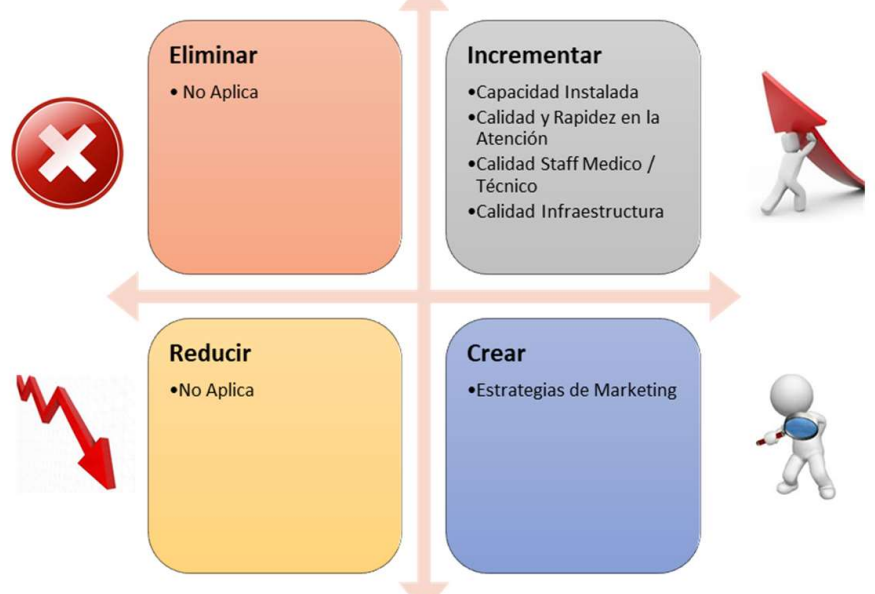

Figura 17 Matriz (eliminar, reducir, incrementar, crear), basado en modelo de la Estrategia Océano Azul

Incrementar: Por lo anteriormente expuesto, principalmente la capacidad instalada, luego y con la finalidad de no descuidar el liderazgo de la industria, se debe seguir trabajando en incrementar la calidad y rapidez de la atención, del personal médico, técnico, y la infraestructura.

Crear: Analizando el mercado oftalmológico, vemos que este adolece de campañas preventivas, tours de salud y promociones a través de redes sociales y páginas especializadas. Creemos que su implementación revolucionará el marketing del mercado ampliando las fronteras del mismo.

\subsubsection{Lienzo de la nueva estrategia considerada.}

En este nuevo lienzo se muestra cómo quedaría la nueva OftalmoSalud con respecto a la que estamos analizando actualmente y a la industria. Se puede ver que en el nuevo lienzo se busca mejorar los factores claves de éxito actuales y crear nuevas estrategias para poder captar nuevos clientes. 


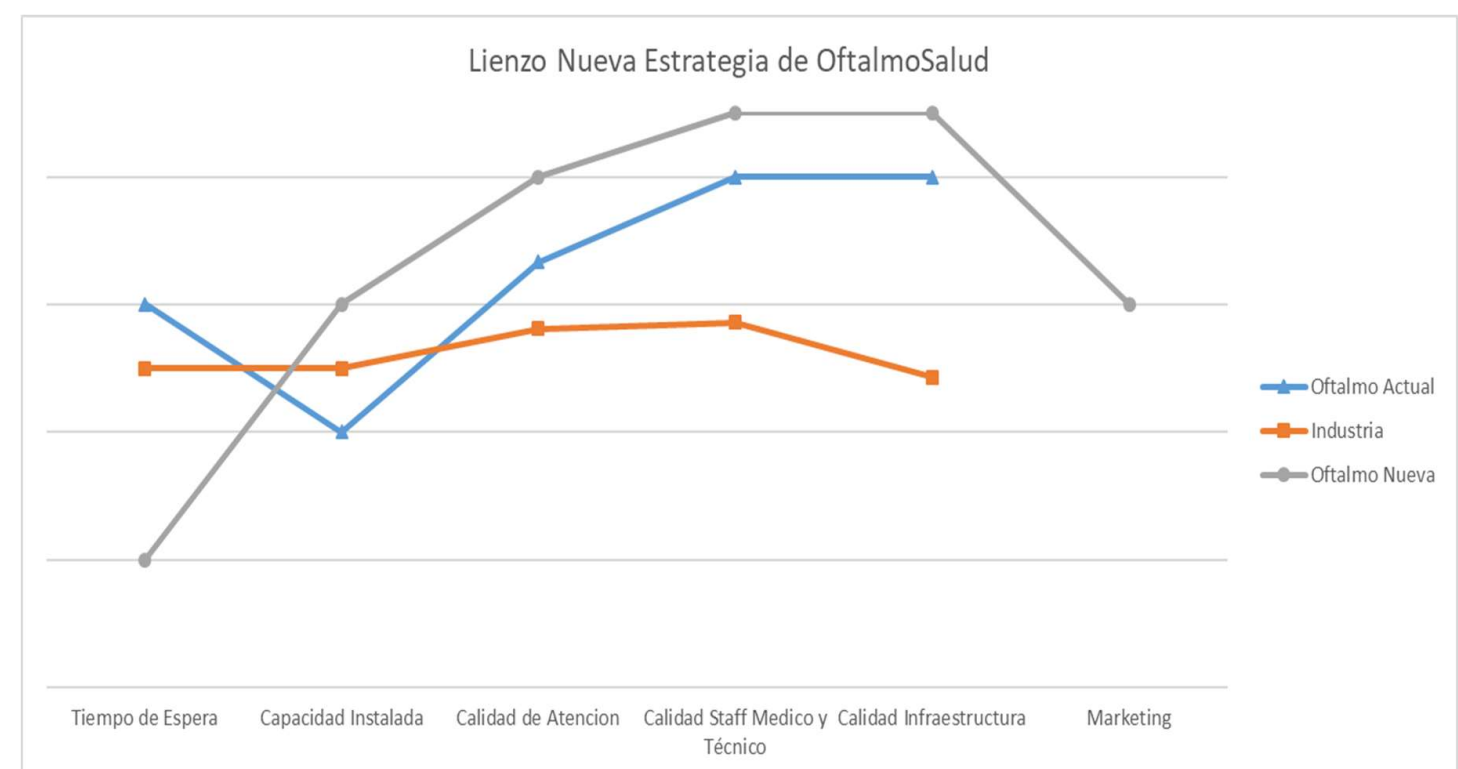

Figura 18 Lienzo de la nueva estrategia considerada, elaborada sobre juicio de valor del director de operaciones

Con respecto a mejorar los factores de éxito actuales, en su gran mayoría, estos se lograrán si se incrementa, principalmente, la capacidad instalada y a su vez la infraestructura que va de la mano con este incremento. La ampliación (en la medida de lo posible) de los locales actuales y/o la creación de nuevas sedes, incrementaría el desarrollo de nuevo consultorios para atenciones primarias, lo que mejoraría los tiempos de atención y por consiguiente la percepción de servicio por parte de los clientes. En cuanto al staff médico y técnico, OftalmoSalud en la actualidad cuenta con personal de muy alto nivel, pero, bajo la premisa de que todo es mejorable; sería importante enfocarse en las especializaciones de su personal, y también es importante mejorar el reclutamiento del personal técnico para que no presente alta rotación, motivándolos a través de horarios flexibles que se acomoden a sus necesidades familiares o de estudios.

Por el lado de las estrategias a crear, vale la pena mencionar que OftalmoSalud está buscando captar un mayor número de clientes a través de las siguientes estrategias de Marketing: 
Campañas preventivas: Las mismas que se desarrollarán en colegios, universidades, institutos, asociaciones y clubes, buscando despertar una conciencia de prevención con respecto a las enfermedades oftalmológicas. En la actualidad la gente no previene sino reacciona cuando ya la enfermedad está presente, por lo que se hace muy necesario desarrollar una cultura preventiva para evitar en un futuro que el número de enfermos y/o gente incapacitada aumente.

Tours de Salud: En la actualidad el Mincetur ya tiene desarrollado programas de salud para que peruanos que viven en el extranjero vengan a realizar sus tratamientos médicos en el país, sin embargo, no se le ha dado mucha fuerza a estas campañas y mucho menos en el sector oftalmológico, por lo que se buscaría reforzarla ofreciendo paquetes para personas interesadas en tomar estos servicios aquí, aprovechando que vienen también a disfrutar un tiempo de su familia y sus cuidados.

Promociones en Redes Sociales y Páginas Web especializadas: A lo que se refiere esta estrategia es a promocionar la empresa a través de redes sociales priorizando la prevención y adicionalmente realizar promociones de tratamientos como operaciones para corregir la medida de la vista a precios especiales. Con el avance de la tecnología y las plataformas que brindan las redes sociales es sencillo capacitar a la gente respecto al cuidado de la vista, las enfermedades más comunes y las posibles soluciones a cada problema.

En la actualidad mucha gente tiene la intención de operarse para corregir su medida de vista, pero los precios son algo caros debido a que esta operación es considerada como cosmética y no es cubierta por los seguros. Es por ello que, con promociones especiales, se podría conseguir un mayor número de clientes.

\subsubsection{Matrices de formulación de estrategias.}

En capítulos anteriores se han desarrollado las matrices de información como son la 
EFE y la EFI, donde se mencionan los factores internos y externos de la compañía, colocando puntuaciones y ponderando de acuerdo a la relevancia de los factores con respecto a la empresa. También se ha desarrollado la Matriz de Perfil Competitivo (MPC), donde se muestra un comparativo contra las otras empresas de la industria y también se coloca una puntuación con respecto a los factores claves de éxito de cada una.

Una vez recogida esta información, este capítulo pretende desarrollar el análisis necesario para generar estrategias factibles para la empresa a través de 5 matrices como son:

- FODA (Fortalezas, Oportunidades, Debilidades y Amenazas)

- PEYEA (Matriz de evaluación de la posición estratégica)

- BCG (Boston Consulting Group)

- IE (Matriz Interna externa)

- Matriz de la Estrategia Principal.

Estas matrices mencionadas, encuentran sustento en la información vertida en los capítulos anteriores.

\subsubsection{Matriz FODA.}

Esta matriz, a través del análisis de las fortalezas y debilidades de la empresa, así como de las oportunidades y amenazas de la industria, ayuda a la toma decisiones con respecto a la elección entre diferentes alternativas a efectos de resolver las más variadas situaciones.

Para realizar una acertada toma de decisiones respecto a un tema específico, es necesario conocerlo, comprenderlo y analizarlo, para así poder darle solución, y que mejor si esto se realiza de una manera estructurada. Aquí es donde radica la importancia de la Matriz FODA como elemento necesario para conocer la situación real de la empresa. Su confección permitirá buscar y analizar, de forma proactiva y sistemática, todas las variables que 
intervienen en el negocio, con el fin de tener más y mejor información al momento de tomar decisiones, es decir que, realizando correctamente el análisis FODA, se pueden establecer las acciones ofensivas, defensivas, de supervivencia y de reordenamiento necesarias para cumplir con los objetivos empresariales planteados.

En la siguiente figura podemos observar cómo se elabora una Matriz FODA:

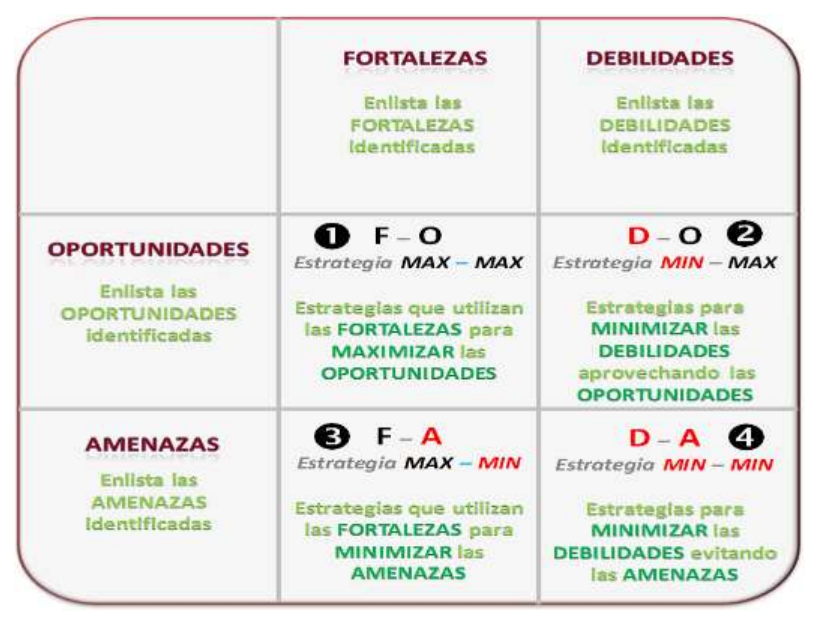

Figura 19 Matriz FODA

Confrontando las fortalezas, oportunidades, debilidades y amenazas, formularemos acciones que nos permitirán usar las fortalezas, aprovechar las oportunidades (FO) y enfrentar las amenazas (FA), así como también mejorar las debilidades que permitirán aprovechar las oportunidades (DO) y que expondrán a las empresas ante amenazas (DA). 
Tabla 37

Análisis FODA OftalmoSalud

\begin{tabular}{|c|c|c|}
\hline & Fortalezas & Deblidades \\
\hline & $\begin{array}{l}\text { 1. Posicionamiento de Marca } \\
\text { 2. Localización estratégica } \\
\text { 3. Staff Médico } \\
\text { 4. Iffraestructura y Tecnologia } \\
\text { 5. Visión de crecimiento }\end{array}$ & $\begin{array}{l}\text { 1. Gobierno Corporatro familiar } \\
\text { 2. Staff Médico familar } \\
\text { 3. Capacidad Instalada } \\
\text { 4. Tecnologia de la Información }\end{array}$ \\
\hline Oportunidades & F0. Explote & D0. Busque \\
\hline $\begin{array}{l}\text { 1. Crecimiento del mercado oftalmológico } \\
\text { (prirado y seguros EPS) } \\
\text { 2. Mavor poder adquisitio de la población } \\
\text { 3. Ineficiencia en sector público } \\
\text { 4. Fortalecimiento de la cultura de prevención } \\
\text { 5. Avance Tecnológico }\end{array}$ & $\begin{array}{l}\text { Desarrollo de Mercado - Alianza con Essalud para atender crnugias complejas (F1-4- } \\
5,03-4) \\
\text { Pentetración y Desarrollo de Mercado - Promoción en redes sociales y páaginas web } \\
\text { especializadas (F1-4-5, 01-2-4-5) } \\
\text { Desarrollo de Mercado - Implementación de campañas preventivas y tours de saud } \\
\text { (F1-4-5,01-2-4) }\end{array}$ & $\begin{array}{l}\text { Penetración de Mercado - Implementación de mayor numero de } \\
\text { consultorios primarios (D3, 01-2-4) } \\
\text { Implementación de Teconologia - Automatizacíón de sistemas manuales } \\
\text { de historias cilinicas (D4, 05) }\end{array}$ \\
\hline Amenazas & FA Confronte & DA. Evite \\
\hline $\begin{array}{l}\text { 1. Desaceleración del crecimiento } \\
\text { 2. Depreciación de la moneda local respecto el } \\
\text { dólar estadounidense } \\
\text { 3. Mayor inversión en el sector } \\
\text { 4. Fortalecimiento y mayor posicionamiento de } \\
\text { la competencia o productos sustitos }\end{array}$ & 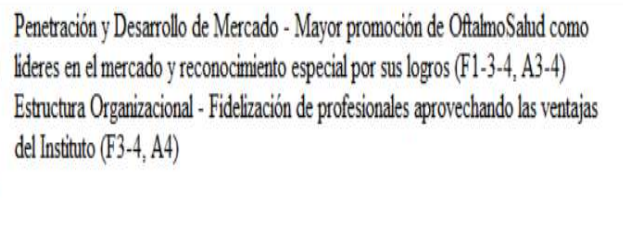 & $\begin{array}{l}\text { Estructura Organizacional - Implementación de gobierno corporativo } \\
\text { institucional dejando de lado el modelo familiar (D1-2, A3-4) }\end{array}$ \\
\hline
\end{tabular}

Elaboración con información obtenida de OftalmoSalud

De acuerdo al análisis FODA realizado, pasamos a proponer las siguientes acciones para cada cuadrante:

Cuadrante FO: Para este cuadrante se proponen tres acciones que nos permitirán explotar las fortalezas de la empresa aprovechando las oportunidades del entorno. Estas son:

Alianzas con ESSALUD para atender cirugías complejas, debido a que las atenciones en el sector público están sujetas a programaciones con tiempos de espera bastante amplios y para casos de emergencia o de mucha gravedad, OftalmoSalud podría generar alianzas para atender y operar pacientes de este sector. Esta acción va asociada con la estrategia de Desarrollo de Mercado.

Otra acción sería la promoción en redes sociales y páginas web especializadas, 
buscando generar un nuevo mercado de clientes que busquen atenciones preventivas o cosméticas a mejores precios. Esta acción va asociada también con la estrategia de Desarrollo de Mercado.

Por último, para este cuadrante también se propone la implementación de campañas preventivas y tours de salud. Por el lado de las campañas preventivas, estas se desarrollarían en colegios, institutos, universidades y clubs, buscando generar una conciencia de atención para prevenir las enfermedades oftalmológicas y por el lado de los Tours de Salud, estos se puede trabajar de la mano con el Mincetur, ya que como es bien conocido, muchos tratamientos médicos son más económicos en el Perú, por lo que peruanos residentes en el extranjero, sus familiares y extranjeros podrían venir a operarse y pasar un tiempo con sus familiares o conocer nuestro país. Esta acción va asociada con la estrategia de Desarrollo de Producto.

Cuadrante DO: En este cuadrante se plantean dos acciones que nos permitirán atender un mayor número de pacientes, a través de un aumento de la capacidad instalada, principalmente a nivel de consultorios primarios que, como sabemos, son el driver del negocio - se deberá evaluar la ampliación de los locales existentes, esta acción va asociada con la estrategia de Penetración de Mercado - y la automatización del sistema de historias clínicas el cual reducirá el tiempo de atención al facilitar en menor tiempo la información de la historia clínica de los pacientes antes de su atención, esta acción va asociada con la estrategia de Implementación de Tecnología.

Cuadrante FA: En este cuadrante se proponen dos acciones que se considera, ayudarán a enfrentar las amenazas del entorno utilizando las fortalezas de la empresa

Primeramente, se debe de reforzar la promoción y/o publicidad de la empresa, haciendo énfasis sobre todo en los logros de la empresa y de su staff médico, en este caso en exclusiva, 
aprovechando que el Dr. Luis Izquierdo ha logrado recientemente el reconocimiento como el mejor oftalmólogo del mundo y actualmente ha sido nombrado como embajador de la marca Perú. Esta acción va asociada con la estrategia de Penetración y Desarrollo de Mercado.

También se ha determinado que es posible reforzar la formación de los colaboradores y fidelizarlos a través de especializaciones o programas especiales en el Instituto o Escuela de OftalmoSalud. Esta acción va asociada con la estrategia de Estructura Organizacional.

Cuadrante DA: En este cuadrante encontramos una acción que respalda la idea de implementar un gobierno corporativo institucional frente a uno familiar. Actualmente la empresa se encuentra en un nivel de crecimiento y madurez que lo demanda y ha dejado de ser una empresa pequeña para ser la líder en el mercado; en este sentido y dada la mayor inversión en el sector y fortalecimiento de la competencia se requiere toma de decisiones dejando de lado el manejo familiar que se le dio hasta la fecha. Esta acción va asociada con la estrategia de Estructura Organizacional.

\subsubsection{Matriz PEYEA.}

Esta matriz es una herramienta para conocer la tendencia que deben llevar las estrategias planteadas, las mismas que podrán ser agresivas, conservadoras, defensivas o comparativas.

Los ejes verticales de la matriz son Fortaleza Financiera (FF) y Estabilidad Ambiental (EA), mientras que los ejes horizontales son Ventaja Competitiva (VC), y Fortaleza Industrial (FI), dos de estos cuadrantes pertenecen a la situación interna por lo que la valoración se obtiene del análisis de la Matriz EFI y los otros dos son de la situación externa y su valoración se obtiene del análisis de la Matriz EFE. A continuación, desarrollaremos la matriz PEYEA, para lo cual proponemos los factores determinantes para cada posición: 
Tabla 38

Matriz PEYEA OftalmoSalud

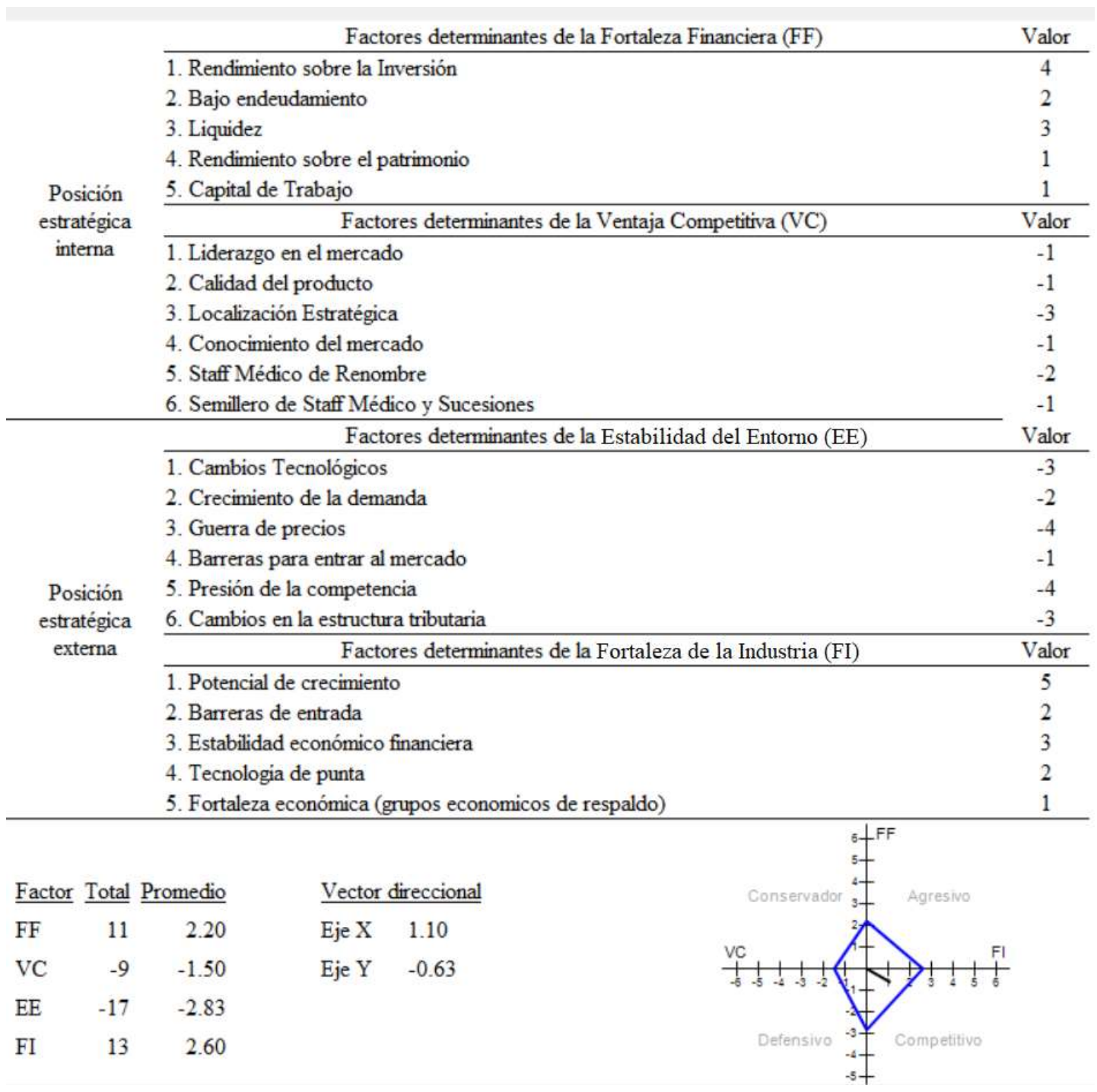

Elaboración sobre información obtenida de OftalmoSalud

Para el caso de OftalmoSalud, analizando los resultados de la matriz PEYEA podemos afirmar que la empresa demuestra ser financieramente fuerte y haber obtenido ventajas competitivas en una industria estable y creciente. Es por ello que la empresa debe seguir una estrategia que le permita utilizar sus ventajas competitivas con el propósito de aprovechar las oportunidades externas, superar sus debilidades internas y evitar amenazas externas, por lo tanto, de acuerdo a la metodología planteadas por Fred David, es posible utilizar las 
siguientes estrategias:

- Penetración de mercado

- Desarrollo de mercado y producto

- Integración vertical y horizontal

- Diversificación en conglomerados

\subsubsection{Matriz Interna Externa.}

La matriz Interna Externa representa una herramienta para evaluar a una organización, tomando en cuenta sus Factores Internos (Fortalezas y Debilidades) y sus Factores Externos (Oportunidades y Amenazas), cuantificando un índice que se puede graficar y ubicar en uno de los 9 cuadrantes de dicha matriz.

Para ello es necesario identificar y recabar los Factores claves del éxito, internos y externos a través de las matrices EFE y EFI desarrolladas en capítulos anteriores.

Los índices obtenidos en las matrices anteriores, se grafican en la Matriz Interna Externa. El resultado del cruce de ambas matrices recaerá en uno de los 9 cuadrantes mencionados y de acuerdo a ello se elige el tipo de estrategias que debe seguirse.

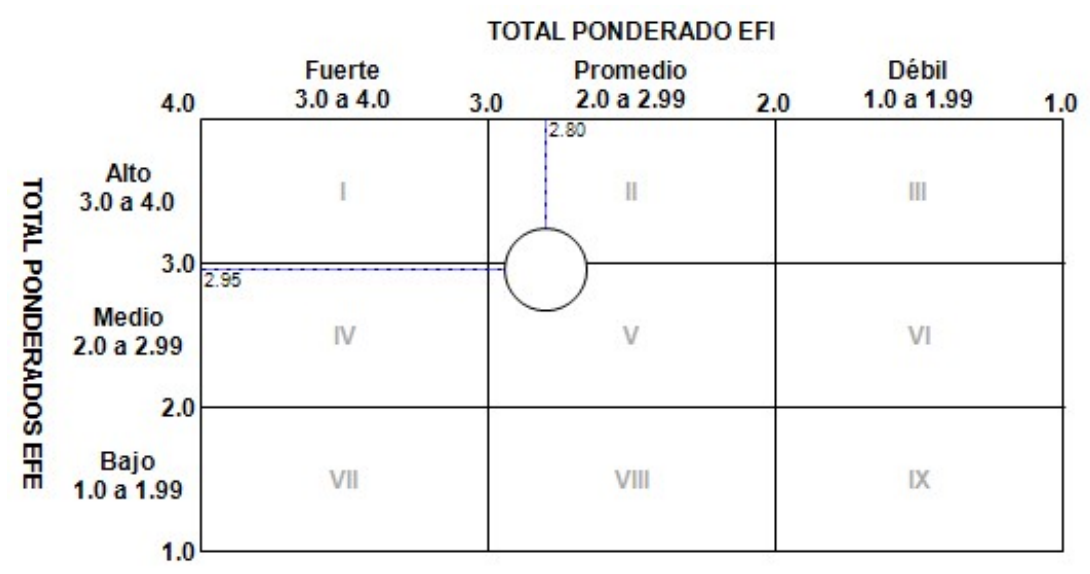

Figura 20 Matriz Interna Externa OftalmoSalud, elaborada sobre información obtenida de OftalmoSalud 


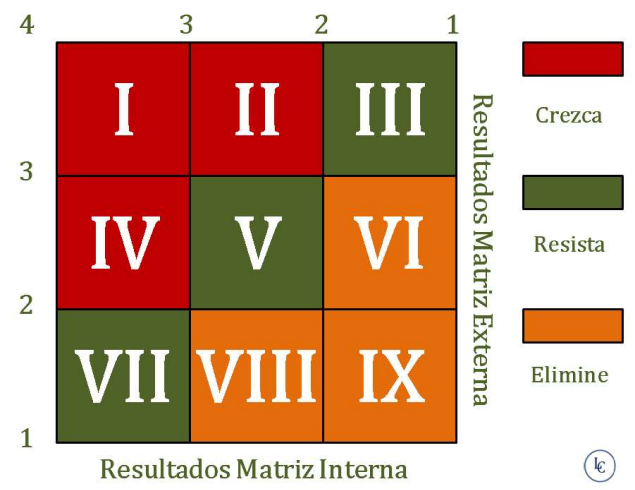

Figura 21 Tipos de Estrategia según el cuadrante, elaborada sobre modelo Matriz IE

En la figura anterior se puede observar que OftalmoSalud se ubica en el cuadrante V, la cual indica RESISTIR, por lo tanto, debe de enfocarse en Conservar y Mantener, promoviendo estrategias intensivas que protejan la posición de la empresa como penetración en el mercado, desarrollo del mercado o desarrollo del producto o integrativas (integración hacia atrás, hacia adelante u horizontal) lo cual es lo más conveniente para este servicio.

En este caso se van a utilizar estrategias de penetración de mercado y desarrollo de productos a través de crecimiento por medio de capacidad instalada y promoción a través de páginas web y especializadas, así como la implementación de campañas preventivas y tours de salud.

\subsubsection{Matriz Boston Consulting Group.}

Se trata de una sencilla matriz de participación de mercado vs. crecimiento, la cual consta de cuatro cuadrantes, cada uno de los cuales propone una estrategia diferente para una unidad de negocio. Cada cuadrante viene representado por una figura y/o icono.

El método utiliza una matriz de 2 × 2 para agrupar distintos tipos de negocios que una empresa en particular posee. El eje vertical de la matriz define el crecimiento en el mercado, y el horizontal la cuota de mercado. Así las unidades de negocio se situarán en uno de los 
cuatro cuadrantes en función de su valor estratégico. Los cuadrantes son:

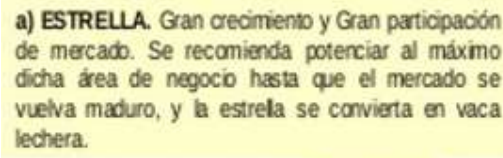

b) INCOGNITA. Gran crecimiento y Poca participaoín de mercado. Hay que reevaluar la estrategia en dicha área, que eventualmente se puede converti en una estrella o en un perro.

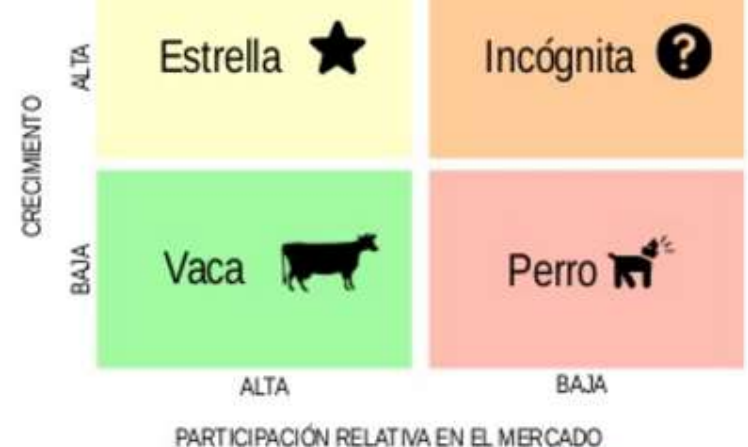

VACA LECHERA. POCo cecimierto y alta paricipación de cadb. Se trata de un área de negocio que servirá para generar d) PERRO. Poco crecimiento y poca partioipacón de mercado. Areas de negocio con baja rertabildad 0 incluso negativa. Se recomienda deshacerse de ella cuandb sea posible. Generalmente son negocios / productos en su úlima etapa de vica. Raras veces conviene mantenerlos ctivo necesario para crear nuevas estrelas.

en el portafoio de la empresa.

Figura 22 Cuadrantes Matriz BCG, elaborada sobre modelo de Matriz Boston Consulting Group

Bajo esta premisa, a continuación, utilizaremos la matriz de BCG para identificar la posición del Servicio Oftalmológico con respecto al mercado. 


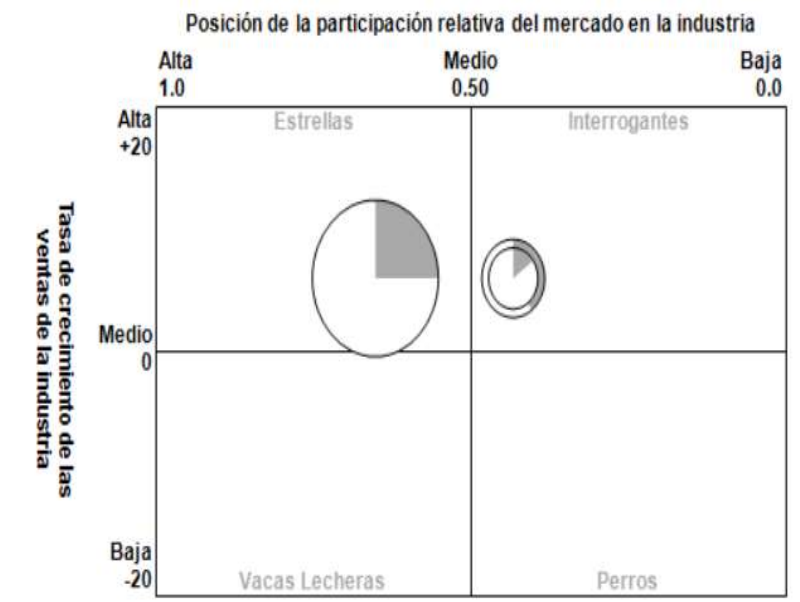

\begin{tabular}{|l|r|r|r|r|r|}
\hline \multicolumn{1}{|c|}{ División } & \multicolumn{1}{|c|}{ Ingresos } & \multicolumn{1}{c|}{$\begin{array}{c}\text { \% de } \\
\text { Ingresos }\end{array}$} & \multicolumn{1}{c|}{$\begin{array}{c}\text { Utilidades } \\
\text { Brutas }\end{array}$} & \multicolumn{1}{c|}{$\begin{array}{c}\text { Participación } \\
\text { de Mercado }\end{array}$} & \multicolumn{1}{c|}{$\begin{array}{c}\text { Crecimiento } \\
\text { de la Industria }\end{array}$} \\
\hline 1. Cirugia & $25,300,000.00$ & $65.73 \%$ & $25.00 \%$ & $65.24 \%$ & $6.00 \%$ \\
\hline 2. Exámenes Auxiliares & $8,440,000.00$ & $21.93 \%$ & $40.00 \%$ & $43.36 \%$ & $6.00 \%$ \\
\hline 3. Consultas & $4,750,000.00$ & $12.34 \%$ & $15.00 \%$ & $43.36 \%$ & $6.00 \%$ \\
\hline Total & $38,490,000.00$ & $100.00 \%$ & & & \\
\hline
\end{tabular}

Figura 23 Matriz BCG, Elaborada sobre información otorgada por OftalmoSalud

La unidad de Cirugía se encuentra en el cuadrante estrella y las unidades de Exámenes Auxiliares y Consultas se encuentran ubicadas en el cuadrante interrogante, esto se explica principalmente por el liderazgo en el área de cirugía (con participación de mercado superior al 50\%) y si bien es cierto OftalmoSalud es líder en el mercado por los ingresos que genera, la participación de mercado de las unidades Exámenes Auxiliares y Consultas está en un 43\% y su crecimiento se encuentra en riesgo debido a la capacidad instalada actual .

En tal sentido las estrategias que se deben utilizar deben estar enfocadas a intentar consolidar los servicios lo máximo que se pueda con el fin de colocar barreras que la competencia no pueda pasar. En este tipo de cuadrante interrogante, las estrategias que mejor funcionan son la de los precios, por lo que consideramos que una buena estrategia es incrementar el número de consultorios para atenciones primarias en localidades en donde el m2 de terreno, construcción y/o arriendo es menor. La empresa podría emplear esta estrategia 
y paralelamente resuelve el problema latente de la capacidad instalada.

Otras estrategias alineadas a los resultados obtenidos de esta matriz son las mencionadas anteriormente referidas a la penetración de mercado y desarrollo de productos a través de promoción en páginas web y especializadas, así como la implementación de campañas preventivas y tours de salud.

\subsubsection{Matriz de la Gran Estrategia.}

La Matriz de la Gran Estrategia es muy utilizada para formular estrategias alternativas. Utiliza dos dimensiones para la evaluación: la posición competitiva y el crecimiento de mercado.

En la siguiente figura podemos apreciar el posicionamiento de OftalmoSalud en función a los puntajes obtenidos tanto en la matriz BCG como en la EFI.

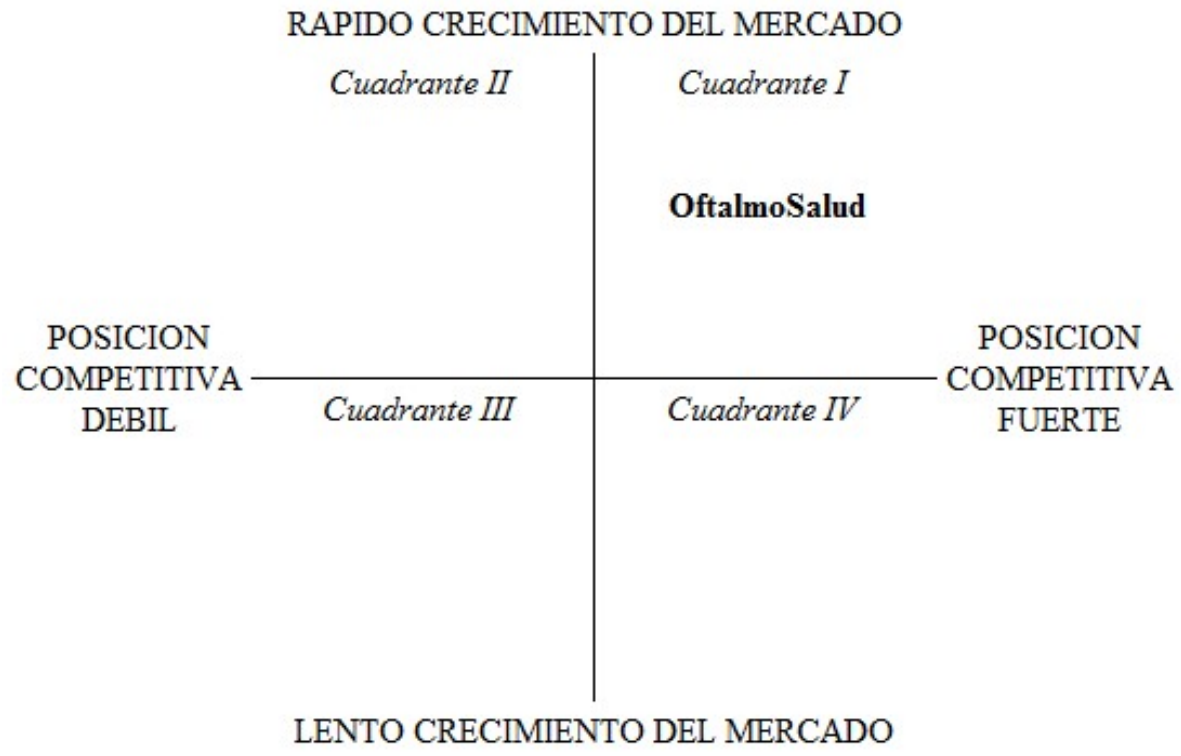

Figura 24 Matriz de la Gran Estrategia, elaborado con información brindada por OftalmoSalud

Al ubicarse en el cuadrante I, las estrategias convenientes que se deberían de emplear son aquellas referidas a seguir concentrándose en los mercados y/o los productos presentes 
sin descuidar sus ventajas competitivas establecidas. Se puede aprovechar las oportunidades externas en muchas áreas; inclusive correr riesgos agresivamente cuando esto resulte necesario.

\subsection{Resumen de las Estrategias Formuladas.}

En la siguiente tabla se puede apreciar el resumen de las estrategias alternativas resultantes del análisis efectuado anteriormente:

Tabla 39

Resumen de Estrategias

\begin{tabular}{|c|c|}
\hline $\begin{array}{c}\text { Formulación de } \\
\text { Estrategias }\end{array}$ & Estrategia \\
\hline $\begin{array}{l}\text { Modelo Océano } \\
\text { Azul }\end{array}$ & $\begin{array}{l}\text { Penetración de Mercado - Incrementar capacidad instalada } \\
\text { Servicio al Cliente - Incrementar la calidad de atención, del } \\
\text { personal médico, técnico y la infraestructura. } \\
\text { Establecimiento de Procesos Efectivos- Reducir los tiempos de } \\
\text { espera. } \\
\text { Penetración y Desarrollo de Mercado - Crear estrategias de } \\
\text { Marketing (campañas preventivas, tours de salud, promociones a } \\
\text { través de redes sociales y páginas especializadas) }\end{array}$ \\
\hline Matriz FODA & $\begin{array}{l}\text { Penetración de Mercado - Alianzas con ESSALUD para atender } \\
\text { cirugías complejas, } \\
\text { Penetración y Desarrollo de Mercado - Promoción en redes } \\
\text { sociales y páginas web especializadas, } \\
\text { Desarrollo de Mercado - Implementación de campañas } \\
\text { preventivas y tours de salud. } \\
\text { Penetración de Mercado - Aumento de la capacidad instalada } \\
\text { Implementación de Tecnología - Automatización del sistema de } \\
\text { historias clínicas. } \\
\text { Penetración y Desarrollo de Mercado - Reforzar la promoción y/o } \\
\text { publicidad de la empresa }\end{array}$ \\
\hline
\end{tabular}




\begin{tabular}{|c|c|}
\hline & $\begin{array}{l}\text { Estructura Organizacional - Reforzar la formación de los } \\
\text { colaboradores } \\
\text { Estructura Organizacional - Reforzar la fidelizarlos de los } \\
\text { colaboradores } \\
\text { Estructura Organizacional - Implementar un gobierno corporativo } \\
\text { institucional frente a uno familiar. }\end{array}$ \\
\hline Matriz Peyea & $\begin{array}{l}\text { Penetración de mercado } \\
\text { Desarrollo de mercado y producto } \\
\text { Integración vertical y horizontal } \\
\text { Diversificación en conglomerados }\end{array}$ \\
\hline $\begin{array}{l}\text { Matriz Interna } \\
\text { Externa }\end{array}$ & $\begin{array}{l}\text { Penetración de mercado } \\
\text { Desarrollo de productos }\end{array}$ \\
\hline Matriz BCG & $\begin{array}{l}\text { Precios } \\
\text { Incremento de Capacidad Instalada } \\
\text { Penetración de Mercado } \\
\text { Desarrollo de Productos }\end{array}$ \\
\hline $\begin{array}{l}\text { Matriz de la } \\
\text { Gran Estrategia }\end{array}$ & $\begin{array}{l}\text { Concentración de Mercados } \\
\text { Concentración de Productos }\end{array}$ \\
\hline
\end{tabular}

Elaborada sobre los resultados de las matrices analizadas

En el siguiente capítulo se trabajará la selección de la estrategia o estrategias que guiaran la planificación estrategia para los próximos 3 años con la finalidad de lograr los objetivos y metas trazadas. Dichas estrategias serán escogidas no sólo por su preponderancia o repetición en los diferentes análisis efectuados sino principalmente por el juicio intuitivo de los estrategas en coordinación con los expertos consultados, que son los que conocen la realidad de la empresa y la industria, tal como lo indica Fred David. 


\section{Capítulo VIII. Selección de la Estrategia}

En el presente capitulo se va a llevar a cabo la evaluación y selección de las estrategias adecuadas que conlleven a las acciones necesarias para que OftalmoSalud de aquí al 2021, se enfoque en su misión y visión. Para la elección de las mejores estrategias nos apoyaremos en dos métodos comúnmente utilizados: (i) El Método de Factores Estratégicos Claves y (ii) La Matriz de Planeación Estratégica Cuantitativa (MPEC); asimismo usaremos como insumo el análisis llevado a cabo hasta el capítulo anterior.

\subsection{Método Factores Estratégicos Claves.}

Analizando la preponderancia o repetición de las estrategias en cada uno de los diferentes análisis efectuados se tendría:

Tabla 40

Repetición de las estrategias en los diferentes análisis

\begin{tabular}{|c|c|c|c|c|c|c|}
\hline 1. Desarrollo de Mercado - Alianza con Essahud para atender cinugias complejas (F1-4-5, 03-4) & $x$ & $x$ & & & & 2 \\
\hline $\begin{array}{l}\text { 2. Penetración y Desarrollo de Mercado - Promoción en redes sociales y páginas web especializadas } \\
\text { (F1-4-5,01-2-4-5) }\end{array}$ & $\mathrm{x}$ & $\mathrm{x}$ & $\mathrm{x}$ & $\mathrm{x}$ & & 4 \\
\hline $\begin{array}{l}\text { 3. Desarrollo de Mercado - Implementación de campañas preventivas y tours de salud (F1-4-5, 01-2- } \\
\text { 4) }\end{array}$ & $\mathrm{x}$ & $\mathrm{x}$ & $\mathrm{x}$ & $\mathrm{x}$ & & 4 \\
\hline $\begin{array}{l}\text { 4. Penetración de Mercado - Implementación de mayor número de consultorios primarios (D3, 01-2- } \\
\text { 4) }\end{array}$ & $\mathrm{x}$ & $\mathrm{x}$ & $\mathrm{x}$ & $\mathrm{x}$ & $\mathrm{x}$ & 5 \\
\hline 5. Implementación de Tecnologial - Automatización de sistemas manuales de historias clinicas $(\mathrm{D4}, 05)$ & $\mathrm{x}$ & & & & & 1 \\
\hline $\begin{array}{l}\text { 6. Penetración y Desarrollo de Mercado - Mayor promoción de OftalmoSalud como lideres en el } \\
\text { mercado y reconocimiento especial por sus logros (F1-3-4, A3-4) }\end{array}$ & $\mathrm{x}$ & $\mathrm{x}$ & & & $\mathrm{x}$ & 3 \\
\hline $\begin{array}{l}\text { 7. Estructura Organizacional - Fidelización de profesionales aprovechando las ventajas del Instituto ( } F 3 \text { - } \\
4, \mathrm{A4})\end{array}$ & $\mathrm{x}$ & & & & $\mathrm{x}$ & 2 \\
\hline $\begin{array}{l}\text { 8. Estructura Organizacional - Implementación de gobierno corporativo institucional dejando de lado el } \\
\text { modelo familiar (D1-2, A3-4) }\end{array}$ & $\mathrm{x}$ & & & & $\mathrm{x}$ & 2 \\
\hline
\end{tabular}

Elaborada sobre los resultados de las matrices anteriores 


\subsubsection{Criterios de selección.}

De la tabla anterior hemos pre- seleccionado las tres estrategias que presentan una mayor repetición en los diferentes análisis; estas son:

E1: Implementación de mayor número de consultorios primarios, la misma que se refiere a Penetración de Mercado

E2: Promoción en redes sociales y páginas web especializadas, la misma que se refiere a Penetración y Desarrollo de Mercado.

E3: Implementación de campañas preventivas y tours de salud, la misma que se refiere a Desarrollo de Mercado.

Adicionalmente creemos importante seleccionar también dos estrategias importantes que deberán trabajarse sin excluir a las principales obtenidas del ejercicio de la Tabla 40 las cuales son:

E4: Automatización de Sistemas Manuales de Historias Clínicas, la misma que se refiere a una estrategia de Implementación de Tecnología (mejora en los Procesos Operativos).

E5: Implementación de Gobierno Corporativo Institucional dejando de lado el modelo familiar, la misma que se refiere a una Estrategia de Estructura Organizacional.

\subsubsection{Matriz de evaluación de estrategias.}

Con el fin de determinar cuáles son las estrategias que se implementarán en este plan, utilizaremos la matriz de Rumelt como matriz de evaluación, la misma que al ser cualitativa, nos llevará a un análisis a través de los 4 criterios:

- Consistencia: las estrategias deben estar alineadas a los objetivos y políticas de la empresa

- Consonancia: las estrategias deberán tener la capacidad de adaptarse a los cambios en el entorno. 
- Ventaja: las estrategias deben fortalecer las ventajas competitivas actuales y por desarrollar.

- Factibilidad: éstas deben poder ser implementadas teniendo un presupuesto aprobado y que su incorporación en los estados financieros genere mejores rendimientos futuros. 
Tabla 41

\section{Matriz de Rumelt}

\begin{tabular}{|c|c|c|c|c|c|}
\hline Evaluación de Estrategias: & 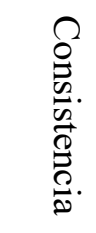 & $\begin{array}{l}\Omega \\
0 \\
0 \\
0 \\
0 \\
0 \\
0 \\
0\end{array}$ & 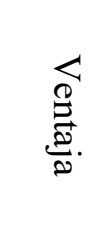 & 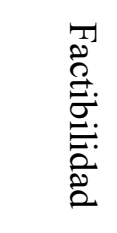 & 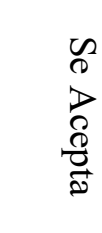 \\
\hline $\begin{array}{l}\text { Penetración de Mercado: A través de la implementación de } \\
\text { mayor número de consultorios primarios. }\end{array}$ & SI & SI & SI & SI & SI \\
\hline $\begin{array}{l}\text { Penetración y Desarrollo de Mercado: A través de la } \\
\text { promoción en redes sociales y páginas web especializadas }\end{array}$ & SI & SI & SI & SI & SI \\
\hline $\begin{array}{l}\text { Desarrollo de Mercado: A través de la implementación de } \\
\text { campañas preventivas y tours de salud }\end{array}$ & SI & SI & SI & SI & SI \\
\hline $\begin{array}{l}\text { Implementación de Tecnología: Automatización de } \\
\text { Sistemas Manuales de Historias Clínicas }\end{array}$ & SI & SI & SI & SI & SI \\
\hline $\begin{array}{l}\text { Estructura Organizacional: Implementación de Gobierno } \\
\text { Corporativo Institucional dejando de lado el modelo } \\
\text { familiar }\end{array}$ & SI & SI & SI & SI & SI \\
\hline
\end{tabular}

Elaborada con información obtenida de OftalmoSalud 
Al evaluar las estrategias pre seleccionadas podemos ver que todas y cada una de ellas calzan perfectamente con los criterios de evaluación aplicados, por lo que podemos mencionar que estas son las que se tomaran en cuenta para la evaluación y selección de la estrategia principal.

Antes de pasar a la siguiente etapa de evaluación y selección por el método de escenarios, es necesario explicar el tipo de estrategia de mercado a la que pertenece cada una de ellas:

a) Penetración de mercado: Son estrategias que buscan aumentar las ventas de productos actuales en los mercados actuales.

Existen 6 mecanismos para conseguir la penetración de mercados:

- Desarrollo de la demanda primaria, que se puede dar por el aumento de la tasa de penetración (lograr un mayor volumen de consumo por ocasión y/o una mayor frecuencia de consumo en los clientes actuales por medio de nuevos usos del producto); o un aumento de la tasa de ocupación (lograr atraer a nuevos clientes no consumidores del producto, por medio del incremento de la publicidad, promoción de ventas y/o la disminución de precios).

- Aumento de la participación de mercado, atrayendo clientes de la competencia, esto se consigue cuando no existe lealtad de marca en la competencia por lo que se puede mejorar el producto o servicio ofertado, reposicionando la marca, reduciendo el precio, reforzando la red de distribución y utilizando promociones de ventas

- Adquisición de mercados a través de convenios, compras de otras empresas o joint ventures.

- Defensa de la posición en el mercado, a través del mejoramiento del producto 
y reposicionarlo o una estrategia defensiva de precio (precio bajo)

- Reforzando la red de distribución, a través de recurrir a distribuidores más eficaces o fijando cantidades mínimas por pedido a los intermediarios, también reforzando o reorientando las promociones de ventas o reorganizando el canal de distribución, para atender mercados desabastecidos.

- Reorganización del mercado, para mejorar la rentabilidad, es decir concentrarse en los segmentos más rentables, reduciendo el número de clientes, eliminando a los no rentables y abandonando selectivamente segmentos no rentables.

b) Desarrollo de Mercado: Son estrategias de crecimiento empresarial que consisten en identificar y desarrollar nuevos segmentos de mercado para productos existentes. Para lograr esto se pueden generar nuevos mercados geográficos, nuevas dimensiones del producto, nuevos empaques del producto, nuevos canales de distribución o a través de diferentes políticas de precios para atraer nuevos clientes o crear nuevos segmentos.

c) Establecimiento de Procesos Efectivos: esta estrategia hace referencia a el posicionamiento y la diferenciación como piezas fundamentales para el éxito de una organización, sin embargo, a veces, resultan insuficientes para mantenerlo. Sin embargo, esto no quita que, una vez conseguida una posición de privilegio en el mercado, la organización esté en la necesidad de alcanzar la excelencia en la realización de sus actividades, lo que se conoce como excelencia operacional. La excelencia no es diferenciación, sino que consiste en hacer las cosas de la mejor forma posible, empleando de manera eficiente los recursos con los que se cuenta. La excelencia es independiente de la estrategia que se siga y sólo debe ser tomada en cuenta una vez que se haya conseguido el posicionamiento. Cuando una organización se encuentra en pleno desarrollo de su estrategia y posicionamiento es difícil que pueda ser 
excelente; ya que los constantes cambios, ingreso a mercados o establecimiento de un espacio en la industria originan que esta deba redefinir constantemente cuáles serán las actividades que realizará, no pudiendo estandarizarlas, un requisito necesario para alcanzar la excelencia en la ejecución de las actividades.

d) Estructura Organizacional: es el tipo de estrategia que se refiere a la creación, implementación y evaluación de las decisiones dentro de una organización, en base a la cual se alcanzarán los objetivos a largo plazo, es decir, con enfoque en un plano estratégico.

\subsection{Método de Escenarios.}

Todas las organizaciones, independientemente de su tamaño e importancia en el mercado deben adaptarse a su entorno, y esto lo harán de la mejor manera si se han propuesto objetivos organizacionales que involucren tanto a la empresa como al entorno, ello quiere decir que la organización como un todo se moldeará de acuerdo al escenario. Para lograr que una estrategia sea aplicada a una organización es necesario crear puentes o políticas, las cuáles guiarán la conducta del personal para alcanzar dicho objetivo.

En el plan estratégico, la planeación de escenarios se distingue por su enfoque explícito sobre la ambigüedad y la incertidumbre. La importancia de introducir la incertidumbre en el factor estratégico es que la planeación para el futuro pasa de ser de una planeación episódica, que ocurre una sola vez, a ser una propuesta de aprendizaje que nunca se detiene.

La estrategia habla del futuro y, por ende, implica incertidumbre. La planeación de escenarios supone la existencia de ambigüedad en cualquier situación que enfrente el administrador estratega, ya que solo es posible desarrollar una estrategia exitosa si se tiene en cuenta dicha ambigüedad.

Las etapas que deben seguirse para construir un escenario son: (i) identificación de las 
variables clave a las que se enfrentará la empresa, (ii) asignación de valores y probabilidades a cada una de las variables relevantes, y (iii) construcción de los futuros más y menos probables.

Para llevar a cabo las dos primeras etapas se entrevistó al Director de Operaciones y el Director de Finanzas para luego analizar la información obtenida con la finalidad de utilizarla para proyectar sucesos futuros, así como para precisar el periodo en que van a ocurrir y su importancia.

Posteriormente hay que elaborar los futuros más y menos probables, donde es preciso identificar cuáles serán los futuros más y menos probables para la empresa teniendo diferentes variables, sus valores, probabilidad e interdependencia y sobre todo el impacto que esta tendrá sobre la empresa en ese escenario.

Una manera sencilla de construir escenarios consiste en:

- Elegir un valor por cada variante relevante.

- Estudiar cuales son las interacciones entre ellas. Las posibles inconsistencias entre variables que deben eliminarse.

Como el número de variables, y sus posibles valores, es grande, mediante el análisis de impactos cruzados se pueden generar múltiples escenarios. Para que estos sean una estructura operativa útil a la dirección, los expertos sugieren que tres escenarios significativamente diferentes es el número adecuado.

\subsubsection{Descripción de escenarios considerados.}

Para la elaboración de los escenarios es necesario tener un marco de referencia que nos permita establecer las variables del entorno a los que la empresa deberá acomodarse o no en el futuro. 
En tal sentido hemos tomado como marco de referencia el Plan Estratégico de Desarrollo Nacional al 2021 emitido por CEPLAN, el cual plantea que el logro de los objetivos estratégicos del mismo deberá traducirse el 2021 en los siguientes índices:

- Una población de 33 millones de peruanos sin pobreza extrema, desempleo, desnutrición, analfabetismo, ni mortalidad infantil.

- Un ingreso per cápita entre US\$ 8000 y US\$ 10000.

- Un producto bruto interno duplicado entre 2010 y 2021.

- Un volumen de exportaciones cuadruplicado entre 2010 y 2021.

- Una tasa de crecimiento anual promedio cercana al 6\% anual.

- Una tasa de inversión anual promedio cercana al 25\%.

- Una mejora de la tributación promedio anual en 5 puntos respecto del PBI.

- Una reducción de la pobreza a menos del 10\% de la población total.

En función de estos objetivos y tomando en consideración las últimas tendencias, se plantean tres situaciones / escenarios para los años 2019-2021 para cada variable por analizar, las mismas que podemos agrupar en: demográficos, económicos, tecnológicos y político- sociales. 
Tabla 42

Situaciones / Escenarios 2019-2021

\begin{tabular}{|c|c|c|c|}
\hline $2019-2021$ & 1 & 2 & 3 \\
\hline \multicolumn{4}{|l|}{ Demografía } \\
\hline $\begin{array}{l}\text { Tasa de crecimiento } \\
\text { demográfico }\end{array}$ & A la baja $<1 \%$ & Estable $1.1 \%$ & $\mathrm{Al}$ alza $>1.1 \%$ \\
\hline $\begin{array}{l}\text { Distribución } \\
\text { pirámide poblacional }\end{array}$ & Mas Adultos & Más Jóvenes & Estancado \\
\hline Distribución por NSE & Mayoría A-B & Mayoría C & Mayoría D-E \\
\hline \multicolumn{4}{|l|}{ Economía } \\
\hline Crecimiento PBI & Por debajo 3\% & Entre 3 y $5 \%$ & Por encima 5\% \\
\hline $\begin{array}{l}\text { Tendencia del tipo de } \\
\text { cambio }\end{array}$ & A la baja & Estable & Al alza \\
\hline Balanza comercial & A la baja & Estable & Al alza \\
\hline Ingreso per cápita & Disminuye & Estable & Crece \\
\hline \multicolumn{4}{|l|}{ Tecnología } \\
\hline $\begin{array}{l}\text { Mayor promoción por } \\
\text { redes sociales }\end{array}$ & Estable & $\begin{array}{l}\text { Aumenta entre } \\
10 \% \text { y } 20 \%\end{array}$ & $\begin{array}{l}\text { Aumenta por } \\
\text { encima del } 20 \%\end{array}$ \\
\hline $\begin{array}{l}\text { Mejora en sistemas } \\
\text { de bases de datos }\end{array}$ & Sin mejora & Mej. menores & Mej. drásticas \\
\hline \multicolumn{4}{|l|}{ Social / Político } \\
\hline $\begin{array}{l}\text { Nuevo gobierno - } \\
\text { Estabilidad Política }\end{array}$ & Sin mejora & Mej. menores & Mej. drásticas \\
\hline $\begin{array}{l}\text { Estabilidad jurídica e } \\
\text { institucional }\end{array}$ & A la baja & Estable & Al alza \\
\hline Conflictos sociales & A la baja & Estable & Al alza \\
\hline Mercado laboral & A la baja & Estable & Al alza \\
\hline
\end{tabular}

Elaborado con información obtenida del análisis externo e interno de la empresa. 
Una vez preparados los escenarios, debemos escoger dos escenarios posibles los cuáles serían a nuestro entender los más probables y menos probables, estos se detallan en la siguiente tabla:

Tabla 43

Escenarios Más y Menos Probables 2019 - 2021

\begin{tabular}{|c|c|c|}
\hline $2019-2021$ & Más Probable & Menos Probable \\
\hline \multicolumn{3}{|l|}{ Demografía } \\
\hline $\begin{array}{l}\text { Tasa de crecimiento } \\
\text { demográfico }\end{array}$ & Estable $1.1 \%$ & A la baja $<1 \%$ \\
\hline $\begin{array}{l}\text { Distribución } \quad \text { pirámide } \\
\text { poblacional }\end{array}$ & Mas Adultos & Más Jóvenes \\
\hline Distribución por NSE & Mayoría C & Mayoría D-E \\
\hline \multicolumn{3}{|l|}{ Economía } \\
\hline Crecimiento PBI & Entre 3 y $5 \%$ & Por encima 5\% \\
\hline Tendencia del tipo de cambio & A la baja & $\mathrm{Al}$ alza \\
\hline Balanza comercial & Estable & Al alza \\
\hline Ingreso per cápita & Crece & Disminuye \\
\hline \multicolumn{3}{|l|}{ Tecnología } \\
\hline $\begin{array}{l}\text { Mayor promoción por redes } \\
\text { sociales }\end{array}$ & $\begin{array}{l}\text { Aumenta entre } 10 \% \mathrm{y} \\
20 \%\end{array}$ & $\begin{array}{l}\text { Aumenta por encima del } \\
20 \%\end{array}$ \\
\hline $\begin{array}{l}\text { Mejora en sistemas de bases de } \\
\text { datos }\end{array}$ & Mej. menores & Mej. drásticas \\
\hline \multicolumn{3}{|l|}{ Social / Político } \\
\hline $\begin{array}{l}\text { Nuevo gobierno - Estabilidad } \\
\text { Política }\end{array}$ & Mej. menores & Mej. drásticas \\
\hline $\begin{array}{lll}\text { Estabilidad } & \text { jurídica } & \text { e } \\
\text { institucional } & & \end{array}$ & Al alza & A la baja \\
\hline
\end{tabular}




\begin{tabular}{|l|l|l|}
\hline Conflictos sociales & A la baja & Al alza \\
\hline Mercado laboral & Al alza & A la baja \\
\hline
\end{tabular}

Elaborado con información obtenida del análisis externo e interno de la empresa

Haciendo un resumen de ambos escenarios, se tiene:

a) Escenario 1: El escenario con más probabilidades y basados en la confianza que genera el nuevo gobierno, se espera presente una tasa demográfica en crecimiento según los análisis del INEI, donde el segmento $\mathrm{C}$ tendrá un aumento de acuerdo con las mejoras económicas moderadas que se estiman vendrán en los siguientes años y que se verá reflejado a través del aumento del PBI a tasas por encima del 3\% actual. Adicionalmente se estima que todos los indicadores económicos como son balanza comercial y tipo de cambio tendrán mayor estabilidad o mejorarán en el tiempo, apoyado principalmente en un régimen político con mayor aceptación y con mejoras sustanciales a nivel institucional, que brindará mayor estabilidad y mejoras a nivel institucional, laboral, esperando también que se reduzca el número de conflictos sociales a nivel de todo el país.

b) Escenario 2: El cual consideramos menos probable, ya que presenta un panorama demográfico con crecimiento negativo, un crecimiento del PBI por encima del 5\% lo cual es superior a lo estimado para los siguientes dos o tres años, acompañado de una situación política muy desequilibrada y con efectos directos sobre la economía, polarizando los crecimientos de los sectores A y D-E.

\subsubsection{Comparación de estrategias con escenarios.}

Tomando en consideración los impactos que podrían tener ambos escenarios en el mercado oftalmológico, estos se han analizado principalmente en función al mercado y la competencia; los resultados se pueden ver en la siguiente tabla: 
Tabla 44

Escenarios Probables 2019 - 2021

\begin{tabular}{|c|c|c|}
\hline \multicolumn{1}{|c|}{ Impacto en el mercado } & $\begin{array}{c}\text { Más } \\
\text { Probable }\end{array}$ & $\begin{array}{c}\text { Menos } \\
\text { Probable }\end{array}$ \\
\hline Crecimiento & Moderado & Alto \\
\hline $\begin{array}{l}\text { Necesidad de nuevos canales de } \\
\text { promoción }\end{array}$ & Alto & Alto \\
\hline Impacto en la competencia & Poco & Probable \\
\hline Ingreso de nuevos actores & probable & \\
\hline Crecimiento productos sustitutos & $\begin{array}{c}\text { Poco } \\
\text { probable }\end{array}$ & Poco probable \\
\hline
\end{tabular}

Elaborado con información obtenida del análisis externo e interno de la empresa

En función de estos impactos, determinaremos en qué grado afectan a cada una de las estrategias planteadas.

Tabla 45

Impactos de los Escenarios en las Estrategias

\begin{tabular}{|l|c|c|}
\hline \multicolumn{1}{|c|}{ Estrategia / Escenarios } & Más Probable & Menos Probable \\
\hline $\begin{array}{l}\text { Penetración de Mercado: A través de la } \\
\text { implementación de mayor numero de } \\
\text { consultorios primarios }\end{array}$ & Favorable & Altamente Favorable \\
\hline $\begin{array}{l}\text { Penetración y Desarrollo de Mercado: A } \\
\text { través de la promoción en redes sociales y } \\
\text { páginas web especializadas }\end{array}$ & Altamente Favorable & Altamente Favorable \\
\hline $\begin{array}{l}\text { Desarrollo de Mercado: A través de la } \\
\text { implementación de campañas preventivas y } \\
\text { tours de salud }\end{array}$ & Altamente Favorable & Altamente Favorable \\
\hline
\end{tabular}




\begin{tabular}{|l|l|l|}
\hline $\begin{array}{l}\text { Implementación de Tecnología: } \\
\text { Automatización de Sistemas Manuales de } \\
\text { Historias Clínicas }\end{array}$ & Favorable & Favorable \\
\hline $\begin{array}{l}\text { Estructura Organizacional: Implementación } \\
\text { de Gobierno Corporativo Institucional } \\
\text { dejando de lado el modelo familiar }\end{array}$ & Altamente Favorable & Altamente Favorable \\
\hline
\end{tabular}

Elaborado con información obtenida de OftalmoSalud

Es entonces que vemos que en el primer escenario que es ciertamente el más probable debido a las circunstancias actuales del país y del entorno en general, en donde consideramos que la recuperación del país se dará de manera gradual, es bastante positivo y favorable para las estrategias planteadas.

\subsection{Matriz de Planeación Estratégica Cuantitativa (MCPE).}

La MCPE es un instrumento que permite a los estrategas evaluar las estrategias alternativas planteadas en forma objetiva, con base en los factores críticos para el éxito, internos y externos, identificados en capítulos anteriores. Esta matriz, tanto como los otros instrumentos analíticos que se han venido preparando para formular estrategias, requiere que se hagan buenos juicios intuitivos. 
Tabla 46

Matriz MPEC OftalmoSalud

\begin{tabular}{|c|c|c|c|c|c|c|c|c|c|c|c|c|c|c|c|c|c|}
\hline \multirow[b]{2}{*}{$\begin{array}{l}\text { Factores criticos } \\
\text { para el éxito }\end{array}$} & \multirow[b]{2}{*}{ Peso } & \multicolumn{2}{|c|}{$\begin{array}{c}\text { Desarrollo de } \\
\text { Mercado - Alianza } \\
\text { con Essalud para } \\
\text { atender cirugias } \\
\text { complejas (F1-4- } \\
5, \mathrm{O}-4) \\
\end{array}$} & \multicolumn{2}{|c|}{$\begin{array}{c}\text { Penetración y Desarrollo } \\
\text { de Mercado - } \\
\text { Promoción en redes } \\
\text { sociales y páginas web } \\
\text { especializadas (F1-4-5, } \\
\text { O1-2-4-5) }\end{array}$} & \multicolumn{2}{|c|}{$\begin{array}{l}\text { Desarrollo de Mercado } \\
\text { - Implementación de } \\
\text { campañas preventivas y } \\
\text { tours de salud (F1-4-5, } \\
\text { O1-2-4) }\end{array}$} & \multicolumn{2}{|c|}{$\begin{array}{l}\text { Penetración de Mercado } \\
\text { - Implementación de } \\
\text { mayor número de } \\
\text { consultorios primarios } \\
\text { (D3, O1-2-4) }\end{array}$} & \multicolumn{2}{|c|}{$\begin{array}{l}\text { Implementación de } \\
\text { Tecnologial - } \\
\text { Automatización de } \\
\text { sistemas manuales de } \\
\text { historias clinicas (D4, } \\
\text { O5) } \\
\end{array}$} & \multicolumn{2}{|c|}{$\begin{array}{l}\text { Penetración y Desarrollo de } \\
\text { Mercado - Mayor promoción } \\
\text { de OftalmoSalud como lideres } \\
\text { en el mercado y } \\
\text { reconocimiento especial por } \\
\text { sus logros }(\mathrm{F} 1-3-4, \mathrm{~A} 3-4)\end{array}$} & \multicolumn{2}{|c|}{$\begin{array}{c}\text { Organizacional - } \\
\text { Fidelización de } \\
\text { profesionales } \\
\text { aprovechando las } \\
\text { ventajas del Instituto } \\
\text { (F3-4, A4) } \\
\end{array}$} & \multicolumn{2}{|c|}{$\begin{array}{l}\text { Estructura Organizacional - } \\
\text { Implementación de } \\
\text { gobierno corporativo } \\
\text { institucional dejando de } \\
\text { lado el modelo familiar } \\
\text { (D1-2, A3-4) }\end{array}$} \\
\hline & & $\mathrm{PA}$ & TPA & PA & TPA & PA & TPA & PA & TPA & PA & TPA & PA & TPA & PA & TPA & $\mathrm{PA}$ & TPA \\
\hline \multicolumn{18}{|l|}{ Oportunidades } \\
\hline $\begin{array}{l}\text { 1. Crecimiento del } \\
\text { mercado offalmológico } \\
\text { (privado y seguros } \\
\text { EPS) }\end{array}$ & 0.10 & & & 4 & 0.40 & 4 & 0.40 & 4 & 0.40 & 3 & 0.30 & & & & & 2 & 0.20 \\
\hline $\begin{array}{l}\text { 2. Mayor poder } \\
\text { adquisitivo de la } \\
\text { población }\end{array}$ & 0.10 & & & 4 & 0.40 & 3 & 0.30 & 4 & 0.40 & 1 & 0.10 & & & & & 1 & 0.10 \\
\hline $\begin{array}{l}\text { 3. Ineficiencia en } \\
\text { sector público }\end{array}$ & 0.15 & & & 1 & 0.15 & 1 & 0.15 & 1 & 0.15 & 1 & 0.15 & & & & & 1 & 0.15 \\
\hline $\begin{array}{l}\text { 4. Fortalecimiento de } \\
\text { 1a cultura de } \\
\text { prevención }\end{array}$ & 0.15 & & & 3 & 0.45 & 4 & 0.60 & 2 & 0.30 & 2 & 0.30 & & & & & 2 & 0.30 \\
\hline $\begin{array}{l}\text { 5. Avance Tecnológico } \\
\text { Amenazas }\end{array}$ & 0.05 & & & 3 & 0.15 & 3 & 0.15 & 2 & 0.10 & 4 & 0.20 & & & & & 3 & 0.15 \\
\hline $\begin{array}{l}\text { 1. Desaceleración del } \\
\text { crecimiento }\end{array}$ & 0.10 & & & 1 & 0.10 & 1 & 0.10 & 2 & 0.20 & 1 & 0.10 & & & & & 1 & 0.10 \\
\hline $\begin{array}{l}\text { 2. Depreciación de la } \\
\text { moneda local respecto } \\
\text { el dólar estadounidense }\end{array}$ & 0.10 & & & 1 & 0.10 & 1 & 0.10 & 2 & 0.20 & 1 & 0.10 & & & & & 1 & 0.10 \\
\hline $\begin{array}{l}\text { 3. Mayor inversión en } \\
\text { el sector }\end{array}$ & 0.10 & & & 3 & 0.30 & 3 & 0.30 & 4 & 0.40 & 1 & 0.10 & & & & & 2 & 0.20 \\
\hline $\begin{array}{l}\text { 4. Fortalecimiento y } \\
\text { mayor posicionamiento } \\
\text { de la competencia o } \\
\text { productos sustitos } \\
\text { Fortalezas }\end{array}$ & 0.15 & & & 4 & 0.60 & 4 & 0.60 & 4 & 0.60 & 1 & 0.15 & & & & & 2 & 0.30 \\
\hline $\begin{array}{l}\text { 1. Posicionamiento de } \\
\text { Marca }\end{array}$ & 0.05 & & & 4 & 0.20 & 4 & 0.20 & 4 & 0.20 & 3 & 0.15 & & & & & 2 & 0.10 \\
\hline $\begin{array}{l}\text { 2. Localización } \\
\text { estratégica }\end{array}$ & 0.05 & & & 2 & 0.10 & 2 & 0.10 & 3 & 0.15 & 1 & 0.05 & & & & & 1 & 0.05 \\
\hline 3. Staff Médico & 0.15 & & & 4 & 0.60 & 3 & 0.45 & 2 & 0.30 & 2 & 0.30 & & & & & 3 & 0.45 \\
\hline $\begin{array}{l}\text { 4. Infraestructura y } \\
\text { Tecnologia }\end{array}$ & 0.15 & & & 4 & 0.60 & 3 & 0.45 & 4 & 0.60 & 4 & 0.60 & & & & & 3 & 0.45 \\
\hline $\begin{array}{l}\text { 5. Visión de } \\
\text { crecimiento }\end{array}$ & 0.05 & & & 3 & 0.15 & 3 & 0.15 & 4 & 0.20 & 3 & 0.15 & & & & & 4 & 0.20 \\
\hline Debilidades & & & & & & & & & & & & & & & & & \\
\hline $\begin{array}{l}\text { 1. Gobierno } \\
\text { Corporativo familiar }\end{array}$ & 0.15 & & & 2 & 0.30 & 2 & 0.30 & 3 & 0.45 & 2 & 0.30 & & & & & 4 & 0.60 \\
\hline $\begin{array}{l}\text { 2. Staff Médico } \\
\text { familiar }\end{array}$ & 0.15 & & & 2 & 0.30 & 2 & 0.30 & 2 & 0.30 & 1 & 0.15 & & & & & 4 & 0.60 \\
\hline 3. Capacidad Instalada & 0.20 & & & 2 & 0.40 & 2 & 0.40 & 4 & 0.80 & 2 & 0.40 & & & & & 4 & 0.80 \\
\hline $\begin{array}{l}\text { 4. Tecnologia de la } \\
\text { Información }\end{array}$ & 0.05 & & & 3 & 0.15 & 2 & 0.10 & 2 & 0.10 & 4 & 0.20 & & & & & 3 & 0.15 \\
\hline Total & 2.00 & & 0.00 & & 5.45 & & 5.15 & & 5.85 & & 3.80 & & 0.00 & & 0.00 & & 5.00 \\
\hline
\end{tabular}

Elaborado con información obtenida bajo juicio del Director OftalmoSalud 


\subsection{Elaboración Propia Descripción de estrategia seleccionada.}

Como se puede observar, la estrategia más preponderante y que en definitiva debe ser la estrategia principal seleccionada es la de Implementación de un mayor número de consultorios para atenciones primarias. Este se refiere al aumento de capacidad instalada, el mismo que se dará a través de la revisión del uso de la actual capacidad instalada (procesos y reingeniería) y la ampliación de la sede de Javier Prado (empleo de actual espacio administrativo como consultorios primarios). La empresa tiene considerado para el 2022, la construcción e implementación de una nueva torre en la Sede de Javier Prado y dos clínicas en San Juan de Lurigancho (terreno ya adquirido) y San Miguel por lo que la implementación de un mayor número de consultorios va de la mano con esta inversión a largo plazo.

Se espera que de la revisión del uso actual de la capacidad instalada, se pueda incrementar el número de atenciones en un $5 \%$ en cada sede, lo cual dará un respiro mientras se inicia y desarrolla la ampliación de la sede de Javier Prado, con lo cual se espera incrementar el número de atenciones en un 30\% en dicha sede; es importante mencionar que la empresa a la fecha ya cuenta con el terreno necesario para levantar la nueva edificación, la cual alojara los nuevos consultorios y las oficinas administrativas.

\subsection{Descripción de estrategia contingente.}

Las estrategias consideradas como contingentes, pero necesarias ya que van de la mano con la estrategia principal, serán las relacionadas a desarrollo y penetración de mercado como son: (i) creación de campañas especiales y tours de salud, así como (ii) la promoción a través de páginas especializadas y redes sociales generando, en ambos casos, un nuevo mercado, el mismo que deberá ser atendido en los nuevos consultorios de atenciones primarias.

Se estima que ambas estrategias logren cubrir la capacidad instalada que se irá 
generando en la medida que se implementen los nuevos consultorios en las distintas sedes.

Tal como se mencionó anteriormente también se deberán tomar en consideración las estrategias relacionadas a (i) la Implementación de Tecnología a través de la Automatización de Sistemas Manuales de Historias Clínicas y (ii) la de Estructura Organizacional a través de la Implementación de Gobierno Corporativo Institucional dejando de lado el modelo familiar. 


\section{Capítulo IX. Implantación de la Estrategia}

En este capítulo se analizará de manera detallada la implementación de cada una de las estrategias seleccionadas para OftalmoSalud; para ello se deberá tomar en cuenta los recursos y cultura organizacional actual de la empresa; analizando de qué manera cada uno de los involucrados aportará con su participación para el desarrollo de las mismas y en qué medida será necesario una adecuación de la situación actual para lograr los objetivos trazados. Es importante mencionar que toda la empresa deberá estar involucrada en la implantación de las estrategias para que el resultado sea acorde con lo que la empresa está buscando. Para ello es necesario trabajar en la organización y sus colaboradores preparándolos y comprometiéndolos para los cambios futuros, alineándolos y motivándolos para que apoyen y participen en cada uno de los movimientos estratégicos. De esta manera se hará más fácil el proceso de cambio y se lograrán mejores resultados.

Para realizar un correcto monitoreo de la implementación de las estrategias se utilizará el Balance Scorecard (BSC) como la principal herramienta.

El BSC es una herramienta que permite sintetizar e implementar la estrategia de cara al cumplimiento de los objetivos de una empresa a partir de un conjunto de medidas de actuación. Ha sido utilizada por reconocidas corporaciones internacionales las cuales han obtenido excelentes resultados, y desde su divulgación en 1992 por sus dos autores: Robert Kaplan y David Norton, ha sido incorporada a los procesos de gerencia estratégica de grandes corporaciones a nivel mundial.

El BSC proporciona una estructura para transformar la estrategia en acción. Posibilita a través del diagrama causa efecto establecer las hipótesis estratégicas, permitiendo anticipar a futuro, cómo el negocio creará valor para los clientes. 
Lo que uno mide, es lo que logrará. Así que, si se mide únicamente el desempeño financiero, solo obtendrá un buen desempeño financiero. Si por el contrario se amplía la visión, y se incluyen medidas desde otras perspectivas, entonces se tendrá la posibilidad de alcanzar objetivos que van más allá de lo financiero, para ello es necesario tener presente las perspectivas que se deben analizar para el BSC:

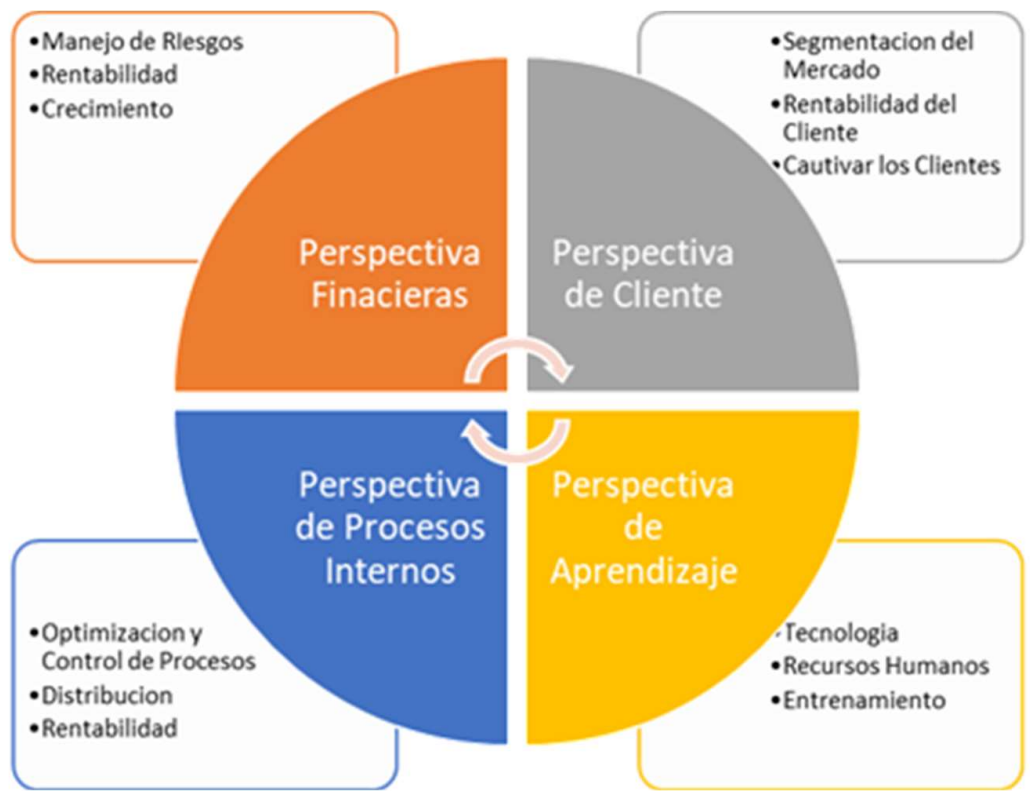

Figura 25 Perspectivas del BSC, elaborado en base al modelo de análisis del BSC

Definidos el modelo de negocio y los indicadores de acción y resultados, es posible implementar el BSC de dos formas:

a) Modelo de control y seguimiento: En caso de que la visión, estrategias e indicadores estén perfectamente definidos y acordados, el BSC puede implementarse como un tradicional modelo de análisis por excepción. Se da un seguimiento puntual sobre los avances en el logro de las estrategias con respecto a lo planteado y el BSC libera una cantidad de trabajo importante al directivo, al realizar análisis por excepción de aquellos procesos conocidos que, eventualmente, requieren de más tiempo para su análisis; un análisis que solo se da cuando no corresponden los datos con el objetivo. 
b) Modelo de aprendizaje organizativo y comunicación: En empresas donde no existe un acuerdo unánime, que están en crecimiento o se quiere aprovechar el potencial de los empleados sin perder el control de la empresa, el BSC no debe utilizarse como un modelo de control, sino como un modelo de aprendizaje, un modelo proactivo que enriquezca las definiciones originales. En este caso, los valores de los indicadores pueden aprovecharse para adecuar la estrategia planteada originalmente y, por extensión, los rumbos de la empresa. A diferencia del modelo de control, el estratega necesita constantemente analizar los indicadores y tomar decisiones que reorienten los esfuerzos para obtener máximos beneficios.

Los beneficios que se obtienen luego de aplicar el BSC se pueden resumir en los siguientes puntos:

- Contribuye a maximizar la rentabilidad y a la creación de valor en el tiempo.

- Ayuda a alinear los indicadores estratégicos a todos los niveles de la organización.

- Ofrece a la gestión una imagen gráfica y clara de las operaciones del negocio.

- Su metodología facilita la comunicación y entendimiento de los objetivos de la compañía en todos los niveles de la organización

- El mismo concepto del BSC permite ir aprendiendo de la estrategia.

- Ayuda a reducir la cantidad de información que puede obtener de los sistemas de información, ya que, de ellos, el BSC extrae lo esencial.

- Mide el grado de contribución personal con los resultados de la empresa.

- Convierte la estrategia en acción.

- Logra que la estrategia sea el objetivo de todos y de todos los días.

- Genera indicadores de control efectivo.

- Permite tomar decisiones oportunas. 
- Aumenta la satisfacción de sus clientes.

- Instaura un proceso continuo de generación y modificación de estrategias

\subsection{Mapa de la Estrategia.}

Cuando una organización ha desarrollado un Plan Estratégico y quiere implantarlo de forma eficiente, fácil de comunicar y ágil de medir; con el fin de alcanzar los objetivos planificados de una manera efectiva y rentable, debe definir su Mapa Estratégico.

Un Mapa Estratégico es una poderosa herramienta que permite alinear a todos los miembros de la organización hacia la consecución de los objetivos descritos en su Plan Estratégico, a comunicarlos y a definir qué es lo que tiene que hacer para alcanzarlos.

Si una organización cuenta con un Mapa Estratégico, éste le va a permitir concentrar en un solo documento, a modo de hoja de ruta, lo que se debe hacer para alcanzar los objetivos planteados en el Plan Estratégico, con el fin de facilitar el entendimiento y compromiso de sus miembros y por ende, el desarrollo de las estrategias de una forma precisa, clara y medible hacia el logro de dichos objetivos.

El Mapa Estratégico se construye en 4 niveles los mismos que coinciden con las perspectivas anteriormente descritas.

a) El primer nivel es la "Perspectiva Financiera": cuyo fin es identificar los objetivos financieros de la empresa para un período determinado, deben ser objetivos cuantificables y por tanto medibles.

b) El segundo nivel es la "Perspectiva del Cliente": cuyo fin es identificar qué tenemos que hacer para conseguir los objetivos financieros teniendo en cuenta la satisfacción de nuestros clientes; es decir, lograr satisfacer los clientes con la venta de productos y/o prestación de servicios para facilitar alcanzar las metas planteadas en la perspectiva 
financiera (objetivos financieros).

c) El tercer nivel es la "Perspectiva Interna": cuyo objetivo es definir qué tenemos que hacer de manera interna para satisfacer la perspectiva de nuestros clientes y alcanzar nuestra perspectiva financiera.

d) El cuarto nivel es la "Perspectiva de Aprendizaje": con el fin de definir cuál es el conocimiento y/o capacidades a desarrollar para cumplir la "Perspectiva Interna".

La definición del Mapa Estratégico puede ser relativamente fácil, dependiendo del tamaño de la organización y del número de participantes en el equipo de trabajo. En este sentido, el equipo de trabajo debe tener siempre presente durante el proceso de definición del Mapa Estratégico la perspectiva de los clientes, es decir, lo que realmente el cliente desea obtener de la organización; la perspectiva interna que ayude a la organización a definir cuáles son las actuaciones que realizar para cumplir el compromiso hacia el cliente y la perspectiva de aprendizaje, para identificar las carencias internas en materia de recursos humanos y de infraestructura.

En la siguiente tabla y valiéndose de responder a las preguntas claves para el alineamiento con la visión y misión de la organización, se procede a identificar los objetivos que acompañan el mapa estratégico de OftalmoSalud: 
Tabla 47

Objetivos del Mapa Estratégico de OftalmoSalud

\begin{tabular}{|c|c|}
\hline \multicolumn{2}{|r|}{ MAPA ESTRATEGICO } \\
\hline Pregunta Clave & Objetivo \\
\hline $\begin{array}{l}\text { En qué debemos centrarnos para } \\
\text { sostener financieramente nuestra } \\
\text { misión? }\end{array}$ & $\begin{array}{l}\text { - Incrementar rentabilidad obteniendo utilidad neta } \\
\text { de } 12 \% \\
\text { - Obtener EBITDA de } 20 \% \\
\text { - Crecer en ventas a razón del } 10 \%\end{array}$ \\
\hline $\begin{array}{l}\text { Cómo deben vernos nuestros } \\
\text { clientes para satisfacer nuestra } \\
\text { visión? }\end{array}$ & $\begin{array}{l}\text { - Mantener el liderazgo del mercado creciendo a } \\
\text { razón de } 2 \% \text { por año en participación de mercado. } \\
\text { - Obtener } 95 \% \text { de satisfacción al cliente. }\end{array}$ \\
\hline $\begin{array}{l}\text { En qué procesos operacionales } \\
\text { debemos destacarnos para } \\
\text { satisfacer a nuestros clientes? }\end{array}$ & $\begin{array}{l}\text { - Incrementar la capacidad instalada actual en } 20 \% \\
\text { - Optimizar los tiempos de atención para reducir el } \\
\text { tiempo de espera en } 5 \% \\
\text { - Mejorar el indicador de eficiencia operativa en } 1 \%\end{array}$ \\
\hline $\begin{array}{l}\text { Cómo mantendremos nuestra } \\
\text { capacidad de cambiar y mejorar? }\end{array}$ & $\begin{array}{l}\text { - Reducir anualmente en 5\% el ratio de rotación de } \\
\text { personal } \\
\text { - Capacitar } 30 \text { horas a todo el personal año a año } \\
\text { - Lograr la digitalización del } 100 \% \text { de las historias } \\
\text { clínicas en } 3 \text { años. } \\
\text { - Cumplir el plan estratégico al } 95 \% \text { como nota } \\
\text { mínima. }\end{array}$ \\
\hline
\end{tabular}

Elaborado con información obtenida de OftalmoSalud

Dicho esto, se procede a elaborar el Mapa Estratégico propuesto para OftalmoSalud, en él se ilustra de manera ordenada y concisa la estrategia de la empresa y de una manera gráfica se puede ver la relación causa-efecto que existe entre los distintos objetivos, siendo el objetivo centralizador y o principal el de Incrementar Rentabilidad para los accionistas. 


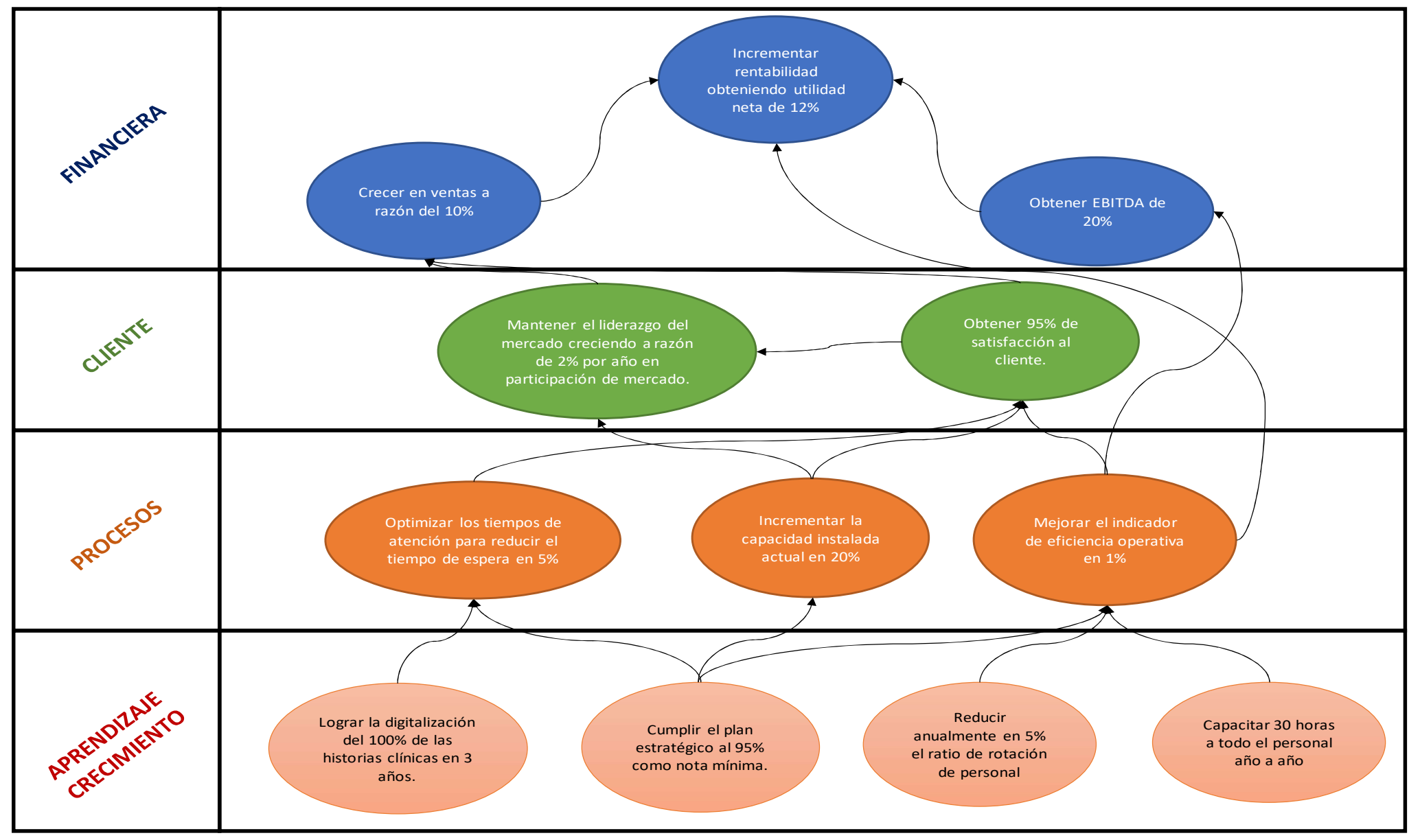

Figura 26. Mapa Estratégico OftalmoSalud. Elaborado en base a la información recabada en capítulos anteriores sobre la empresa OftalmoSalud 


\subsection{Objetivos específicos según el mapa de la estrategia.}

Alineados con la misión y visión de OftalmoSalud y en la búsqueda del cumplimiento de los objetivos estratégicos de la empresa, es de suma importancia plantear los objetivos específicos enmarcados en cada una de las perspectivas del BSC.

Para ello es importante recordar la formulación de los objetivos estratégicos planteados en el capítulo VII:

Tabla 48

Formulación de Objetivos Estratégicos

\begin{tabular}{|c|c|}
\hline Ámbito & Objetivo \\
\hline Estratégicos & $\begin{array}{l}\text { - Sostener un crecimiento del nivel de ventas del } 10 \% \text { anualmente. } \\
\text { - Crecer un } 2 \% \text { en participación del mercado oftalmológico anualmente }\end{array}$ \\
\hline Financiero & $\begin{array}{l}\text { - Aumentar la utilidad neta promedio de } 9 \% \text { a } 12 \% \text { en los próximos } 3 \text { años } \\
\text { - Mejorar el EBITDA anualmente hasta lograr un } 20 \%\end{array}$ \\
\hline Organizacional & $\begin{array}{l}\text { - Lograr un 95\% de satisfacción del cliente para los próximos } 3 \text { años } \\
\text { - Lograr un 90\% satisfacción en clima laboral }\end{array}$ \\
\hline
\end{tabular}

Elaborada en base a información obtenida de OftalmoSalud

La declaración de los objetivos específicos en cada perspectiva del BSC brindará el soporte necesario para la implementación de la estrategia seleccionada.

Vale la pena mencionar que para la creación de estos objetivos específicos sobre los estratégicos hemos utilizado la metodología SMART (por sus siglas en inglés), las mismas que deben de cumplir con las siguientes características: 


\section{ESPECIFICO:}

Tus objetivos deben ser lo más específicos y detallados que puedas. Debe quedar, al sólo repasarlo, qué es lo que

quieres conseguir.

\section{MEDIBLE:}

Todo objetivo debe ser perfectamente medible. Se deberán marcar los parámetros necesarios para saber que se está

yendo por el buen camino y que definitivamente, cuando asi sea, los objetivos se podrán cumplir.

yendo por el buen camino y que definitivamente, cuando asi sea, los objetivos se podrán cumplir.

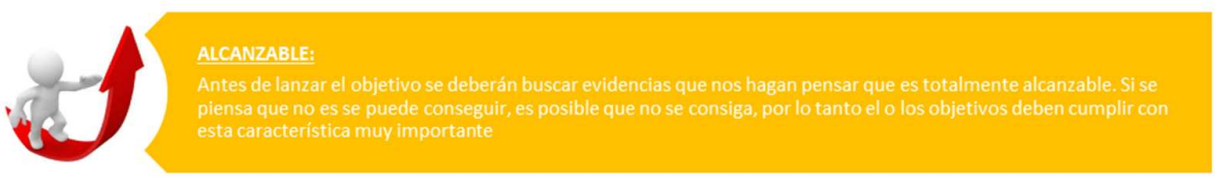

REALISTA:

Que sea alcanzable es una cosa y otra cosa bien distinta es que sea realista. Es importante que se tenga pleno

conocimiento de los recursos de los que se dispone y los recursos que se necesitarán para la consecución del objetivo.

Es importante que se tome consciencia real sobre si esos recursos que se necesitan están a la mano o si serán muy
dificiles de conseguir para entonces mejor no centrar las esperanzas en algo que no podrá hacerse realidad en el

tiempo

\section{TEMPORIZADO:}

El objetivo debe de estar puesto en el tiempo, todo aquello que no se agende jamás se hará. Además es bueno que se marquen hitos temporales a lo largo del objetivo. Es decir, si el objetivo es a un año, no estaría demás que cada mes se

fuera viendo la progresión del mismo y marcar acciones correctoras si los resultados en estos hitos no son los deseado.

Figura 27 Metodología SMART, elaborado en base a las especificaciones de la metodología SMART

En tal sentido, los objetivos específicos para OftalmoSalud desde las distintas perspectivas son:

Tabla 49

\section{Objetivos Especificos OftalmoSalud}

\begin{tabular}{|c|c|}
\hline Perspectiva & Objetivo Especifico \\
\hline Financiera & $\begin{array}{l}\text { - F1 Incrementar rentabilidad obteniendo utilidad neta de 12\% } \\
\text { - F2 Obtener EBITDA de } 20 \% \\
\text { - F3 Crecer en ventas a razón del 10\% }\end{array}$ \\
\hline Cliente & $\begin{array}{l}\text { - C1 Mantener el liderazgo del mercado creciendo a razón de } \\
2 \% \text { por año en participación de mercado. } \\
\text { - C2 Obtener } 95 \% \text { de satisfacción al cliente. }\end{array}$ \\
\hline Procesos & $\begin{array}{l}\text { - P1 Incrementar la capacidad instalada actual en } 20 \% \\
\text { - P2 Optimizar los tiempos de atención para reducir el tiempo } \\
\text { de espera en } 5 \%\end{array}$ \\
\hline
\end{tabular}




\begin{tabular}{|c|c|}
\hline & - $\quad$ P3 Mejorar el indicador de eficiencia operativa en $1 \%$ \\
\hline Aprendizaje & $\begin{array}{l}\text { - A1 Reducir anualmente en 5\% el ratio de rotación de personal } \\
\text { - A2 Capacitar } 30 \text { horas a todo el personal año a año } \\
\text { - A3 Lograr la digitalización del } 100 \% \text { de las historias clínicas } \\
\text { en } 3 \text { años. } \\
\text { - A4 Cumplir el plan estratégico al } 95 \% \text { como nota mínima. }\end{array}$ \\
\hline
\end{tabular}

Elaborada en base a información propuesta para OftalmoSalud

\subsection{Indicadores para cada uno de los objetivos específicos}

Dicho indicador, debe ser la expresión cuantitativa del comportamiento y desempeño de los objetivos específicos trazados; esta herramienta se establece para que al ser comparada con algún nivel de referencia (meta), puede evidenciar una desviación sobre la cual, luego de un análisis se puedan tomar acciones correctivas o preventivas según el caso.

Tabla 50

Indicadores Objetivos Especificos OftalmoSalud

\begin{tabular}{|c|c|c|}
\hline Persp. & Objetivo Especifico & Indicador \\
\hline \multirow{3}{*}{ 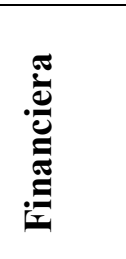 } & $\begin{array}{l}\text { F1 Incrementar rentabilidad obteniendo } \\
\text { utilidad neta de } 12 \%\end{array}$ & Utilidad \\
\hline & F2 Obtener EBITDA de $20 \%$ & EBITDA \\
\hline & F3 Crecer en ventas a razón del 10\% & Ventas \\
\hline \multirow[t]{2}{*}{ 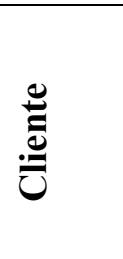 } & $\begin{array}{l}\text { C1 Mantener el liderazgo del mercado } \\
\text { creciendo a razón de } 2 \% \text { por año en } \\
\text { participación de mercado. }\end{array}$ & Participación de Mercado \\
\hline & C2 Obtener 95\% de satisfacción al cliente. & Satisfacción de Cliente \\
\hline \multirow{3}{*}{ 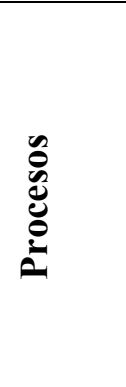 } & $\begin{array}{l}\text { P1 Incrementar la capacidad instalada } \\
\text { actual en } 20 \%\end{array}$ & Capacidad Instalada \\
\hline & $\begin{array}{l}\text { P2 Optimizar los tiempos de atención para } \\
\text { reducir el tiempo de espera en } 5 \%\end{array}$ & Tiempo Atención Promedio \\
\hline & $\begin{array}{l}\text { P3 Mejorar el indicador de eficiencia } \\
\text { operativa en } 1 \%\end{array}$ & Eficiencia Operativa \\
\hline
\end{tabular}




\begin{tabular}{|l|l|c|}
\hline \multirow{2}{*}{} & $\begin{array}{l}\text { A1 Reducir anualmente en 5\% el ratio de } \\
\text { rotación de personal }\end{array}$ & Rotación de Colaboradores \\
\cline { 2 - 3 } & $\begin{array}{l}\text { A2 Capacitar 30 horas a todo el personal } \\
\text { año a año }\end{array}$ & Horas Capacitadas \\
\cline { 2 - 3 } & $\begin{array}{l}\text { A3 Lograr la digitalización del 100\% de las } \\
\text { historias clínicas en 3 años. }\end{array}$ & Historias Clínicas Digitales \\
\cline { 2 - 3 } & $\begin{array}{l}\text { A4 Cumplir el plan estratégico al 95\% } \\
\text { como nota mínima. }\end{array}$ & Cumplimiento Plan Estratégico \\
\hline
\end{tabular}

Elaborada en base a información propuesta para OftalmoSalud

\subsection{Metas para cada uno de los objetivos específicos.}

Seguidamente a la identificación de los indicadores de cada uno de los objetivos específicos es importante establecer las metas a alcanzar en cada uno de los objetivos planteados y sus responsables. Su fijación y principalmente su cumplimiento requiere el compromiso individual y/o colectivo de las distintas áreas de la organización, por lo que la elección de cada meta debe de cumplir los siguientes requisitos:
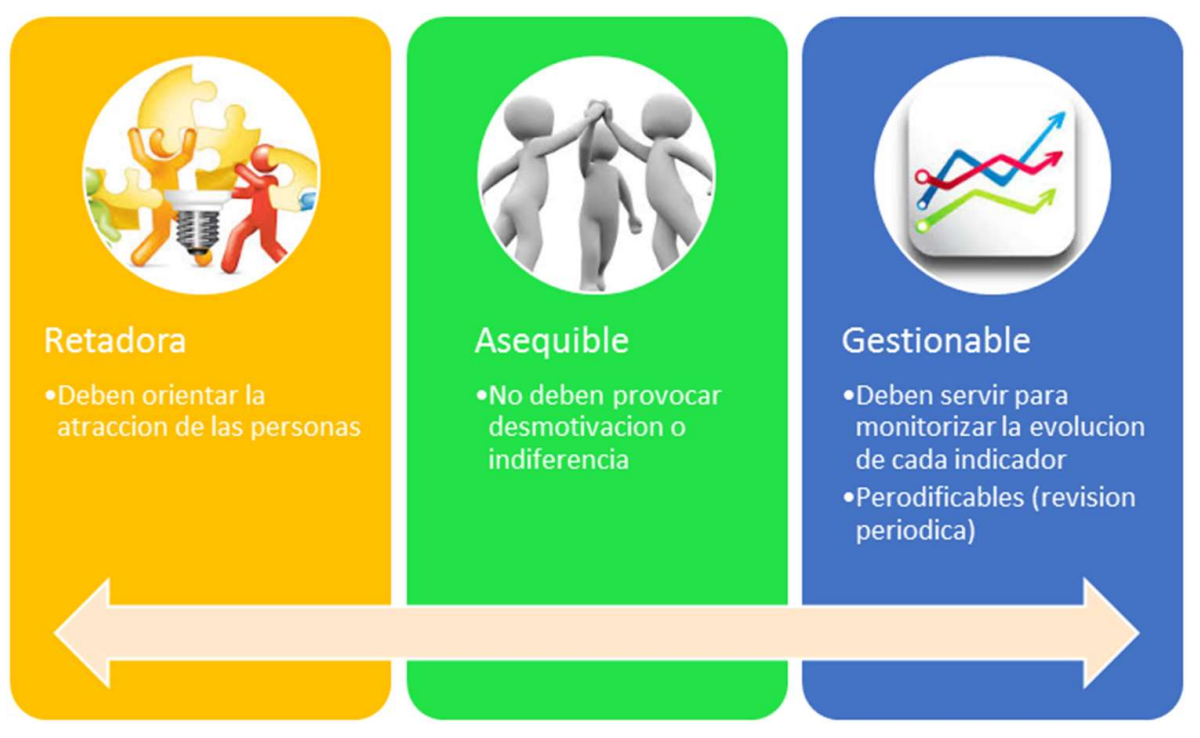

Figura 28 Requisitos para la elaboración de metas, elaboración en base a apreciación personal

Las métricas de cada indicador deben estar asociadas a cada objetivo específico y estos a su vez a cada objetivo estratégico; en ese sentido en la siguiente tabla se muestra la relación 
existente entre los objetivos estratégicos, los específicos y su métrica (indicador):

Tabla 51

Métrica para cada Objetivo Especifico asociado al Objetivo Estratégico

\begin{tabular}{|c|c|c|}
\hline Objetivo Estratégico & Objetivo Especifico & Métrica \\
\hline \multirow{2}{*}{$\begin{array}{l}\text { Sostener un crecimiento del } \\
\text { nivel de ventas del } 10 \% \\
\text { anualmente. }\end{array}$} & $\begin{array}{l}\text { F3 Crecer en ventas a razón } \\
\text { del } 10 \%\end{array}$ & $\begin{array}{l}\text { Ventas Periodo Actual vs. } \\
\text { Periodo Anterior }\end{array}$ \\
\hline & $\begin{array}{l}\text { P1 Incrementar la capacidad } \\
\text { instalada actual en } 20 \%\end{array}$ & $\begin{array}{l}\text { Capacidad Instalada Periodo } \\
\text { Actual vs. Periodo Anterior }\end{array}$ \\
\hline $\begin{array}{l}\text { Crecer un } 2 \% \text { en } \\
\text { participación del mercado } \\
\text { oftalmológico anualmente }\end{array}$ & $\begin{array}{l}\text { C1 Mantener el liderazgo del } \\
\text { mercado creciendo a razón de } \\
2 \% \text { por año en participación } \\
\text { de mercado. }\end{array}$ & $\begin{array}{l}\text { Participación Mercado } \\
\text { Periodo Actual vs. Periodo } \\
\text { Anterior }\end{array}$ \\
\hline \multirow{2}{*}{$\begin{array}{l}\text { Aumentar la utilidad neta } \\
\text { promedio de } 9 \% \text { a } 12 \% \text { en los } \\
\text { próximos } 3 \text { años }\end{array}$} & $\begin{array}{l}\text { F1 Incrementar rentabilidad } \\
\text { obteniendo utilidad neta de } \\
12 \%\end{array}$ & $\begin{array}{l}\text { Utilidad Neta Periodo Actual } \\
\text { vs. Periodo Anterior }\end{array}$ \\
\hline & $\begin{array}{l}\text { P3 Mejorar el indicador de } \\
\text { eficiencia operativa en } 1 \%\end{array}$ & $\begin{array}{l}\text { Ingreso vs. Costos de Ventas } \\
\text { y Gastos de Salud Periodo } \\
\text { Actual vs. Periodo Anterior }\end{array}$ \\
\hline $\begin{array}{l}\text { Mejorar el EBITDA } \\
\text { anualmente hasta lograr un } \\
20 \%\end{array}$ & F2 Obtener EBITDA de $20 \%$ & EBITDA en $\%$ \\
\hline \multirow{3}{*}{$\begin{array}{l}\text { Lograr un } 95 \% \text { de } \\
\text { satisfacción del cliente para } \\
\text { los próximos } 3 \text { años }\end{array}$} & $\begin{array}{lll}\text { C2 } 2 \text { Obtener } 95 \% & \text { de } \\
\text { satisfacción al cliente. } & \end{array}$ & $\begin{array}{l}\text { Medición } \\
\text { Periodo Actual vs. Periodo } \\
\text { Anterior }\end{array}$ \\
\hline & $\begin{array}{l}\text { P2 Optimizar los tiempos de } \\
\text { atención para reducir el } \\
\text { tiempo de espera en } 5 \%\end{array}$ & $\begin{array}{l}\text { Tiempo Atención Promedio } \\
\text { Periodo Actual vs. Periodo } \\
\text { Anterior }\end{array}$ \\
\hline & $\begin{array}{l}\text { A3 Lograr la digitalización } \\
\text { del } 100 \% \text { de las historias } \\
\text { clínicas en } 3 \text { años. }\end{array}$ & $\begin{array}{l}\% \text { de Historias Clínicas } \\
\text { Digitales vs. Manuales }\end{array}$ \\
\hline
\end{tabular}




\begin{tabular}{|c|c|c|}
\hline \multirow{3}{*}{$\begin{array}{l}\text { Lograr un } 90 \% \text { satisfacción } \\
\text { en clima laboral }\end{array}$} & $\begin{array}{l}\text { A1 Reducir anualmente en } \\
5 \% \text { el ratio de rotación de } \\
\text { personal }\end{array}$ & $\begin{array}{l}\text { Rotación Periodo Actual vs. } \\
\text { Periodo Anterior }\end{array}$ \\
\hline & $\begin{array}{l}\text { A2 Capacitar } 30 \text { horas a todo } \\
\text { el personal año a año }\end{array}$ & $\begin{array}{l}\text { Horas de Capacitación por } \\
\text { Colaborador }\end{array}$ \\
\hline & $\begin{array}{l}\text { A4 Cumplir el plan } \\
\text { estratégico al 95\% como nota } \\
\text { mínima. }\end{array}$ & $\begin{array}{l}\% \quad \text { Cumplimiento } \\
\text { Estratégico }\end{array}$ \\
\hline
\end{tabular}

Elaborada en base a información propuesta para OftalmoSalud

Para cada uno de los objetivos específicos se han fijado las siguientes metas para los próximos años: 
Tabla 52

Metas para cada Objetivo Especifico

\begin{tabular}{|c|c|c|c|c|c|c|}
\hline Objetivo Especifico & Indicador & Meta & Base & Año 1 & Año 2 & $\begin{array}{c}\text { Año } \\
3\end{array}$ \\
\hline $\begin{array}{l}\text { F1 Incrementar rentabilidad } \\
\text { obteniendo utilidad neta de } 12 \%\end{array}$ & Utilidad & $\begin{array}{l}12 \% \text { constante al } \\
3 \text { er año }\end{array}$ & $9 \%$ & $10 \%$ & $11 \%$ & $12 \%$ \\
\hline F3 Crecer en ventas a razón del $10 \%$ & Incremento de Venta & $10 \%$ anual & $\begin{array}{c}\text { S/. } 56.0 \\
\text { MM }\end{array}$ & $\begin{array}{c}\text { S/. } 61.5 \\
\text { MM }\end{array}$ & $\begin{array}{c}\text { S/. } 67.7 \\
\text { MM }\end{array}$ & $\begin{array}{c}\text { S/. } 74.4 \\
\text { MM }\end{array}$ \\
\hline F2 Obtener EBITDA de 20\% & EBITDA en $\%$ & $20 \%$ al 3er año & $17 \%$ & $18 \%$ & $19 \%$ & $20 \%$ \\
\hline $\begin{array}{l}\text { C1 Mantener el liderazgo del mercado } \\
\text { creciendo a razón de } 2 \% \text { por año en } \\
\text { participación de mercado. }\end{array}$ & Participación Mercado & $2 \%$ anual & $40 \%$ & $42 \%$ & $44 \%$ & $46 \%$ \\
\hline $\begin{array}{l}\text { C2 Obtener } 95 \% \text { de satisfacción al } \\
\text { cliente. }\end{array}$ & Satisfacción & Constante al $95 \%$ & $95 \%$ & $95 \%$ & $95 \%$ & $95 \%$ \\
\hline $\begin{array}{l}\text { P1 Incrementar la capacidad instalada } \\
\text { actual en } 20 \%\end{array}$ & Capacidad Instalada & $20 \%$ & $\begin{array}{l}\text { Capacida } \\
\text { d Actual }\end{array}$ & $10 \%$ & $15 \%$ & $20 \%$ \\
\hline $\begin{array}{l}\text { P2 Optimizar los tiempos de atención } \\
\text { para reducir el tiempo de espera en } \\
5 \%\end{array}$ & $\begin{array}{l}\text { Tiempo Atención } \\
\text { Promedio }\end{array}$ & $\begin{array}{l}\text { Max. } 20 \text { minutos } \\
\text { espera }\end{array}$ & $35 \mathrm{~min}$ & $33 \mathrm{~min}$ & $30 \mathrm{~min}$ & $28 \mathrm{~min}$ \\
\hline
\end{tabular}




\begin{tabular}{|c|c|c|c|c|c|c|}
\hline $\begin{array}{l}\text { P3 Mejorar el indicador de eficiencia } \\
\text { operativa en } 1 \%\end{array}$ & Eficiencia Operativa & $\begin{array}{l}\text { Reducción de 1\% } \\
\text { año a año }\end{array}$ & $\begin{array}{l}46.0 \% \\
21.5 \%\end{array}$ & $\begin{array}{c}45 \% \\
20.5 \%\end{array}$ & $\begin{array}{c}44 \% \\
19.5 \%\end{array}$ & $\begin{array}{c}43 \% \\
18.5 \%\end{array}$ \\
\hline $\begin{array}{l}\text { A1 Reducir anualmente en } 5 \% \text { el ratio } \\
\text { de rotación de personal }\end{array}$ & $\begin{array}{c}\text { Rotación de } \\
\text { Colaboradores }\end{array}$ & $\begin{array}{l}\text { Llegar al } 15 \% \text { al } \\
\text { tercer año }\end{array}$ & $30 \%$ & $25 \%$ & $20 \%$ & $15 \%$ \\
\hline $\begin{array}{l}\text { A2 Capacitar } 30 \text { horas a todo el } \\
\text { personal año a año }\end{array}$ & Capacitación & $\begin{array}{l}\text { Implementar } 30 \\
\text { horas de } \\
\text { capacitación }(\mathrm{HC}) \\
\text { anual }\end{array}$ & $0 \mathrm{HC}$ & $30 \mathrm{HC}$ & $30 \mathrm{HC}$ & $30 \mathrm{HC}$ \\
\hline $\begin{array}{l}\text { A3 Lograr la digitalización del 100\% } \\
\text { de las historias clínicas en } 3 \text { años. }\end{array}$ & $\begin{array}{l}\text { Historias Clínicas } \\
\text { Digitales }\end{array}$ & $\begin{array}{c}100 \% \text { al tercer año } \\
\text { a razón de } 1 / 3 \text { por } \\
\text { año }\end{array}$ & $0 \%$ & $33 \%$ & $66 \%$ & $100 \%$ \\
\hline $\begin{array}{l}\text { A4 Cumplir el plan estratégico al 95\% } \\
\text { como nota mínima. }\end{array}$ & $\begin{array}{l}\text { Cumplimiento Plan } \\
\text { Estratégico }\end{array}$ & $\begin{array}{l}\text { Cumplimiento al } \\
95 \%\end{array}$ & $0 \%$ & $95 \%$ & $95 \%$ & $95 \%$ \\
\hline
\end{tabular}

Elaborada en base a información propuesta para OftalmoSalud 


\subsection{Iniciativas (acciones a llevar a cabo para cada uno de los objetivos específicos) Estrategias, programas, políticas, reglas, procedimiento.}

Es importante aterrizar los Objetivos Específicos (los cuales como vimos están alineados con los Objetivos Estratégicos y con las Perspectivas del BSC) con iniciativas que logren conseguir las metas trazadas.

Las iniciativas serán definidas siguiendo el proceso de planificación que los autores Kaplan y Norton proponen para el alineamiento de la organización y la estrategia; la cual podemos esquematizar en el siguiente gráfico:

Traducir la estrategia en terminos operacionales

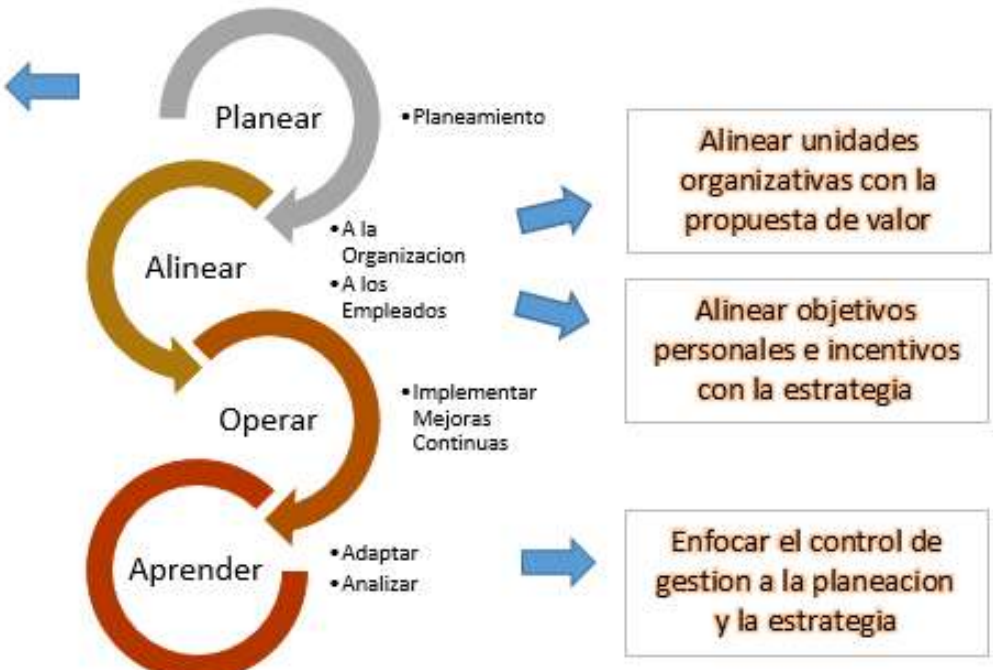

Figura 29 Alineación de las Organización con la Estrategia, en base a bibliografía de Kaplan y Norton

A continuación, se presentan las iniciativas estratégicas que OftalmoSalud debería implementar con la finalidad de cumplir con las expectativas estratégicas identificadas: 
Tabla 53

Iniciativas Estratégicas asociadas a los Objetivos Específicos

\begin{tabular}{|c|c|}
\hline OBJETIVO ESPECIFICO (12) & INICIATIVA ESTRATEGICA (13) \\
\hline \multirow{3}{*}{$\begin{array}{l}\text { OE - F1 Incrementar rentabilidad obteniendo } \\
\text { utilidad neta de } 12 \% \\
\text { OE - F2 Obtener EBITDA de } 20 \%\end{array}$} & $\begin{array}{l}\text { IE } 1 \text { Implementar un sistema de control presupuestal para el control del } \\
\text { gasto administrativo. }\end{array}$ \\
\hline & IE 2 Reducir costo promedio de la deuda \\
\hline & IE 3 Reducir tasa efectiva anual para el pago de impuestos \\
\hline \multirow{4}{*}{$\begin{array}{l}\text { OE - F3 Crecer en ventas a razón del } 10 \% \\
\text { OE - C1 Mantener el liderazgo del mercado } \\
\text { creciendo a razón de } 2 \% \text { por año en participación } \\
\text { de mercado. } \\
\text { OE - P1 Incrementar la capacidad instalada actual } \\
\text { en } 20 \%\end{array}$} & $\begin{array}{l}\text { IE } 4 \text { Reforzar relaciones con las áreas de bienestar social de grandes } \\
\text { empresas o corporaciones }\end{array}$ \\
\hline & IE 5 Desarrollo de Nuevos Productos \\
\hline & IE6 Desarrollo de Nuevos Canales de Captación de Clientes \\
\hline & IE 7 Remodelación y ampliación de la sede de Javier Prado \\
\hline \multirow{3}{*}{$\begin{array}{l}\text { OE - C2 Obtener } 95 \% \text { de satisfacción al cliente. } \\
\text { OE - P2 Optimizar los tiempos de atención para } \\
\text { reducir el tiempo de espera en } 5 \% \\
\text { OE - P3 Mejorar el indicador de eficiencia } \\
\text { operativa en } 1 \%\end{array}$} & IE 8 Fortalecer cultura de atención al cliente \\
\hline & IE 9 Revisión de Procesos Críticos de Atención \\
\hline & $\begin{array}{l}\text { IE } 10 \text { Desarrollar un programa de optimización e innovación de } \\
\text { procesos. }\end{array}$ \\
\hline \multirow{2}{*}{$\begin{array}{l}\text { OE - A1 Reducir anualmente en } 5 \% \text { el ratio de } \\
\text { rotación de personal } \\
\text { OE - A2 Capacitar } 30 \text { horas a todo el personal año } \\
\text { a año } \\
\text { OE- A4 Cumplir el plan estratégico al } 95 \% \text { como } \\
\text { nota mínima. }\end{array}$} & IE 11 Definir e implementar plan de capacitación y retención \\
\hline & IE 12 Definir e implementar plan de change management \\
\hline $\begin{array}{l}\text { OE - A3 Lograr la digitalización del } 100 \% \text { de las } \\
\text { historias clínicas en } 3 \text { años. }\end{array}$ & IE 13 Implementación de Historias Clínicas Digitales \\
\hline
\end{tabular}

Elaborada en base a información propuesta para OftalmoSalud

Para cada una de estas iniciativas, se deben identificar planes de acción; que no son otra cosa que las actividades que debe de desarrollar la organización para el cumplimiento de cada iniciativa.

A estos planes de acción son a los que finalmente se les deben de asignar responsables, presupuestar, planificar y controlar durante la ejecución del planeamiento estratégico: 
Tabla 54

Planes de Acción de cada Iniciativas Estratégicas

\begin{tabular}{|c|c|c|}
\hline OBJETIVO ESPECIFICO (12) & INICIATIVA ESTRATEGICA (13) & PLANES DE ACCION (50) \\
\hline \multirow{11}{*}{$\begin{array}{l}\text { OE - F1 Incrementar rentabilidad obteniendo } \\
\text { utilidad neta de } 12 \% \\
\text { OE - F2 Obtener EBITDA de } 20 \%\end{array}$} & \multirow{3}{*}{$\begin{array}{l}\text { IE } 1 \text { Implementar un sistema de control presupuestal } \\
\text { para el control del gasto administrativo. }\end{array}$} & PA 1 - IE 1 Identificar posibles fuentes de ahorros administrativos y desarrollar propuestas de ahorro. \\
\hline & & PA 2 - IE 1 Realizar seguimiento a la implementación de las propuestas de ahorros en todos los niveles de la organización. \\
\hline & & $\begin{array}{l}\text { PA 3- - I I Presentarl los presupuestos de cada area para autorizacion por parte de directorio } \\
\text { PA 4 - IE } 1 \text { Seguimiento y Control a los presupuestos aprobados } \\
\end{array}$ \\
\hline & \multirow{4}{*}{ IE 2 Reducir costo promedio de la deuda } & PA 5 - IE 2 Calificar nuevas líneas de crédito con tasas de interés más bajas. \\
\hline & & PA 6 - IE 2 Renegociar las actuales líneas de crédito para disminuir las tasas de interés. \\
\hline & & PA 7 - IE 2 Presentar nuevos esquemas de financiamiento para la organización \\
\hline & & PA 8 - IE 2 Mejorar la administración de trabajo para evitar tomar créditos de capital de trabajo a corto plazo. \\
\hline & \multirow{4}{*}{$\begin{array}{l}\text { IE } 3 \text { Reducir tasa efectiva anual para el pago de } \\
\text { impuestos }\end{array}$} & PA 9 - IE 3 Establecer políticas de gastos para evitar gastos no deducibles. \\
\hline & & PA 10 - IE 3 Establecer políticas de pago a proveedores para evitar gastos no deducibles. \\
\hline & & PA 11 - IE 3 Revisar los gastos no deducibles y buscar la forma de hacerlos deducibles. \\
\hline & & PA 12 - IE 3 Capacitar a las distintas sedes de la Organización sobre planes de control de gastos \\
\hline \multirow{14}{*}{$\begin{array}{l}\text { OE - F3 Crecer en ventas a razón del } 10 \% \\
\text { OE - C1 Mantener el liderazgo del mercado } \\
\text { creciendo a razón de 2\% por año en participación } \\
\text { de mercado. } \\
\text { OE - P1 Incrementar la capacidad instalada actual } \\
\text { en } 20 \%\end{array}$} & \multirow{3}{*}{$\begin{array}{l}\text { IE } 4 \text { Reforzar relaciones con las áreas de bienestar } \\
\text { social de grandes empresas o corporaciones }\end{array}$} & PA 13 - IE 4 Análisis situación de atención por empresa \\
\hline & & PA 14 - IE 4 Elaboración de plan de incentivos enfocado a empresas \\
\hline & & PA 15 - IE 4 Visita y reforzamiento de relación con cada empresa \\
\hline & \multirow{4}{*}{ IE 5 Desarrollo de Nuevos Productos } & PA 16 - IE 5 Desarrollo del Producto de Campañas Preventivas y Tour de Salud \\
\hline & & PA 17 - IE 5 Alianzas estratégicas con Organizaciones como Colegios, Universidades, Clubes, Institutos, Asociaciones, Mincetur, otros con apertura mercado internacional \\
\hline & & PA 18 - IE 5 Implementación Campañas Preventivas y Tour de Salud en dichas Organizaciones \\
\hline & & PA 19 - IE 5 Monitoreo de Ingresos por intermedio de estos productos \\
\hline & \multirow{3}{*}{$\begin{array}{l}\text { IE6 Desarrollo de Nuevos Canales de Captación de } \\
\text { Clientes }\end{array}$} & PA 20- IE 6 Desarrollo de Promociones en Redes Sociales y Pág. Web Especializadas \\
\hline & & PA 21 - IE 6 Puesta en Marcha Promociones \\
\hline & & PA 22 - IE 6 Monitoreo de Ingresos por cada plan. \\
\hline & \multirow{4}{*}{$\begin{array}{l}\text { IE } 7 \text { Remodelación y ampliación de la sede de Javier } \\
\text { Prado }\end{array}$} & PA 23 - IE 7 Análisis de Evaluación de Impactos y Planes de Mitigación en Atenciones Actuales producto de la remodelación y ampliación. \\
\hline & & PA 24 - IE 7 Contratar empresa a cargo de diseño y remodelación (anexo sede actual) \\
\hline & & PA 25 - IE 7 Iniciar Remodelación y Ampliación \\
\hline & & PA 26 - IE 7 Puesta en Marcha operación de la remodelación \\
\hline \multirow{8}{*}{$\begin{array}{l}\text { OE - C2 Obtener } 95 \% \text { de satisfacción al cliente. } \\
\text { OE - P2 Optimizar los tiempos de atención para } \\
\text { reducir el tiempo de espera en } 5 \% \\
\text { OE - P3 Mejorar el indicador de eficiencia } \\
\text { operativa en } 1 \%\end{array}$} & \multirow[b]{2}{*}{ IE 8 Fortalecer cultura de atención al cliente } & PA 27 - IE 8 Desarrollar plan de fidelización al cliente. \\
\hline & & PA 28 - IE 8 Identificar actores dentro de la organización con influencia en la satisfacción del cliente. \\
\hline & \multirow{3}{*}{ IE 9 Revisión de Procesos Críticos de Atención } & $\begin{array}{l}\text { PA } 29 \text { - IE } 8 \text { Capacitar a actores claves sobre su rol en la satisfacción del cliente } \\
\text { PA } 30 \text { - IE } 9 \text { Análisis situacional de Procesos de Atención }\end{array}$ \\
\hline & & PA 31 - IE 9 Identificación de oportunidades de mejora \\
\hline & & \\
\hline & \multirow{3}{*}{$\begin{array}{l}\text { IE } 10 \text { Desarrollar un programa de optimización e } \\
\text { innovación de procesos. }\end{array}$} & $\begin{array}{l}\text { PA 33 - IE } 9 \text { Implementación de Procesos Críticos de Atención aprobados } \\
\text { PA } 34 \text { - IE } 10 \text { Definir programa de incentivos para optimización e innovación de procesos }\end{array}$ \\
\hline & & PA 35 - IE 10 Lanzar y comunicar programa \\
\hline & & PA 36 - IE 10 Seleccionar y consolidar iniciativas de innovación para su implementación \\
\hline \multirow{10}{*}{$\begin{array}{l}\text { OE - A1 Reducir anualmente en } 5 \% \text { el ratio de } \\
\text { rotación de personal } \\
\text { OE - A2 Capacitar } 30 \text { horas a todo el personal año } \\
\text { a año } \\
\text { OE- A4 Cumplir el plan estratégico al } 95 \% \text { como } \\
\text { nota mínima. }\end{array}$} & \multirow{6}{*}{$\begin{array}{l}\text { IE } 11 \text { Definir e implementar plan de capacitación y } \\
\text { retención }\end{array}$} & PA 37 - IE 11 Identificar fuentes de reclutamiento \\
\hline & & PA 38 - IE 11 Ordenar proceso de reclutamiento y selección \\
\hline & & PA 39- IE 11 Implementar proceso de evaluación y desempeño \\
\hline & & PA 40 - IE 11 Actualizar manuales de función y desempeño \\
\hline & & $\begin{array}{l}\text { PA } 41 \text { - IE } 11 \text { Desarrollar mapa de talentos identificando posiciones y personal clave } \\
\text { PA 42 -JF11 Definir nolítica vestrategia de administración salarial }\end{array}$ \\
\hline & & \begin{tabular}{|l} 
PA 42-IE 11 Definir politica y estrategia de administración salarial \\
PA 43 -IE 11 Diseñar v arobar planes de línea de carrera
\end{tabular} \\
\hline & \multirow{4}{*}{$\begin{array}{l}\text { IE } 12 \text { Definir e implementar plan de change } \\
\text { management }\end{array}$} & PA 44 - IE 12 Gestionar el diagnóstico de Clima Organizacional \\
\hline & & PA 45 - IE 12 Diseñar el plan de change management \\
\hline & & PA 46 - IE 12 Desarrollar los planes de acción por área para su implementación \\
\hline & & PA 47 - IE 12 Identificar los factores que influyen en el clima organizacional y realizar los planes de comunicación dirigidos a cada uno de los factores. \\
\hline \multirow{2}{*}{$\begin{array}{l}\text { OE - A3 Lograr la digitalización del } 100 \% \text { de las } \\
\text { historias clínicas en } 3 \text { años. }\end{array}$} & \multirow[b]{2}{*}{ IE 13 Implementación de Historias Clínicas Digitales } & PA 48 - IE 13 Análisis situacional de Historias Clínicas \\
\hline & & PA 49 - IE 13 Contratación de Software y Hardware idóneo para implementación de Historias Clínicas Digitales \\
\hline
\end{tabular}

Elaborada en base a información propuesta para OftalmoSalud 
Estas Iniciativas Estratégicas identificadas deben se ser clasificadas en categorías que permitan priorizar apropiadamente la implementación de cada una de ellas.

La metodología usada para dicha clasificación es la utilizada para la clasificación de proyectos de inversión dentro de un enfoque de negocio: Cranfield Grid el cual las clasifica en: (i) ideas estratégicas, (ii) ventajas estratégicas, (iii) rutinas de apoyo y (iv) competencia esencial, tal como se puede apreciar en el siguiente grafico; esta clasificación dependerá de la ubicación de cada iniciativa en un cuadro el cual tiene dos ejes: uno que contempla el riesgo de hacer o no hacer y el otro con el impacto en el resultado (factor monetario)

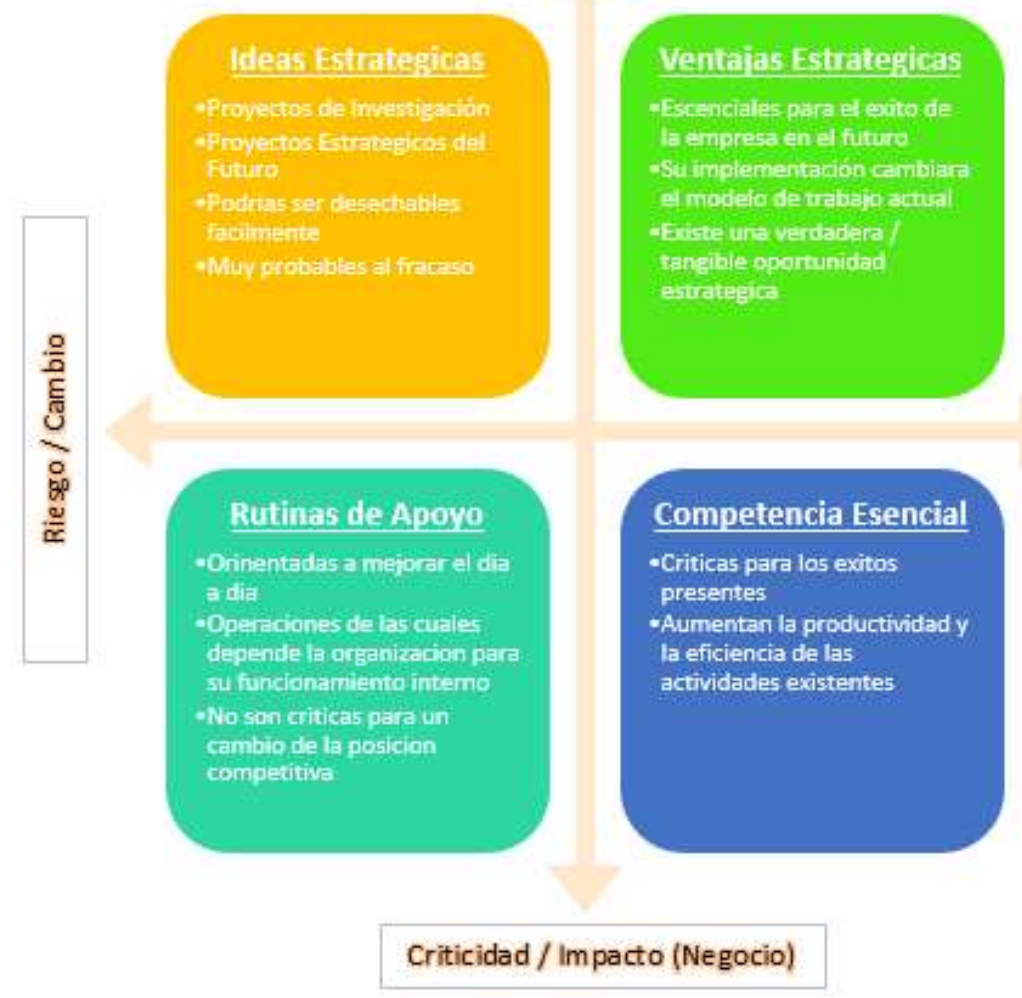

Figura 30 Cranfield Grid

En función a este criterio se clasifica las iniciativas, las mismas que servirán de base para priorizar su implementación y por ende su programación: 
Tabla 55

\section{Clasificación Cranfield Iniciativas Estratégicas}

\begin{tabular}{|c|c|c|c|c|}
\hline OBJETIVO ESPECIFICO (12) & INICIATIVA ESTRATEGICA (13) & Riesgo & Impacto & Clasificación \\
\hline \multirow{3}{*}{$\begin{array}{l}\text { OE - F1 Incrementar rentabilidad obteniendo } \\
\text { utilidad neta de } 12 \% \\
\text { OE - F2 Obtener EBITDA de } 20 \%\end{array}$} & $\begin{array}{l}\text { IE } 1 \text { Implementar un sistema de control presupuestal para el control del } \\
\text { gasto administrativo. }\end{array}$ & Bajo & Alto & Competencia Esencial \\
\hline & IE 2 Reducir costo promedio de la deuda & Bajo & Alto & Competencia Esencial \\
\hline & IE 3 Reducir tasa efectiva anual para el pago de impuestos & Bajo & Alto & Competencia Esencial \\
\hline \multirow{4}{*}{$\begin{array}{l}\text { OE - F3 Crecer en ventas a razón del 10\% } \\
\text { OE - C1 Mantener el liderazgo del mercado } \\
\text { creciendo a razón de } 2 \% \text { por año en participación } \\
\text { de mercado. } \\
\text { OE - P1 Incrementar la capacidad instalada actual } \\
\text { en } 20 \%\end{array}$} & $\begin{array}{l}\text { IE } 4 \text { Reforzar relaciones con las áreas de bienestar social de grandes } \\
\text { empresas o corporaciones }\end{array}$ & Alto & Alto & Ventaja Estratégica \\
\hline & IE 5 Desarrollo de Nuevos Productos & Alto & Alto & Ventaja Estratégica \\
\hline & IE6 Desarrollo de Nuevos Canales de Captación de Clientes & Alto & Alto & Ventaja Estratégica \\
\hline & IE 7 Remodelación y ampliación de la sede de Javier Prado & Alto & Alto & Ventaja Estratégica \\
\hline \multirow{3}{*}{$\begin{array}{l}\text { OE - C2 Obtener } 95 \% \text { de satisfacción al cliente. } \\
\text { OE - P2 Optimizar los tiempos de atención para } \\
\text { reducir el tiempo de espera en } 5 \% \\
\text { OE - P3 Mejorar el indicador de eficiencia } \\
\text { operativa en } 1 \%\end{array}$} & IE 8 Fortalecer cultura de atención al cliente & Bajo & Alto & Competencia Esencial \\
\hline & IE 9 Revisión de Procesos Críticos de Atención & Bajo & Bajo & Rutinas de Apoyo \\
\hline & $\begin{array}{l}\text { IE } 10 \text { Desarrollar un programa de optimización e innovación de } \\
\text { procesos. }\end{array}$ & Bajo & Bajo & Rutinas de Apoyo \\
\hline \multirow{2}{*}{$\begin{array}{l}\text { OE - A1 Reducir anualmente en 5\% el ratio de } \\
\text { rotación de personal } \\
\text { OE - A2 Capacitar } 30 \text { horas a todo el personal año } \\
\text { a año } \\
\text { OE- A4 Cumplir el plan estratégico al } 95 \% \text { como } \\
\text { nota mínima. }\end{array}$} & IE 11 Definir e implementar plan de capacitación y retención & Bajo & Bajo & Rutinas de Apoyo \\
\hline & IE 12 Definir e implementar plan de change management & Alto & Alto & Ventaja Estratégica \\
\hline $\begin{array}{l}\text { OE - A3 Lograr la digitalización del } 100 \% \text { de las } \\
\text { historias clínicas en } 3 \text { años. }\end{array}$ & IE 13 Implementación de Historias Clínicas Digitales & Bajo & Bajo & Rutinas de Apoyo \\
\hline
\end{tabular}

Elaborada en base a información propuesta para OftalmoSalud 


\subsection{Responsable de cada una de las iniciativas.}

Para que cada iniciativa se cumpla; el sponsor o responsable de cada una de ellas debe ser una gerencia o jefatura que tenga cierto poder de decisión dentro de la organización, muy por el contrario, los responsables de cada plan de acción son los ejecutores directos de dicha actividad; en ese sentido los responsables de cada iniciativa y planes de acción se aprecian en la siguiente tabla: 


\section{Tabla 56}

Responsables de las Iniciativas Estratégicas y sus respectivos Planes de Acción

\begin{tabular}{|c|c|c|}
\hline OBJETIVO ESPECIFICO (12) & INICIATIVA ESTRATEGICA (13) & RESPONSABLE \\
\hline \multirow{3}{*}{$\begin{array}{l}\text { OE - F1 Incrementar rentabilidad obteniendo } \\
\text { utilidad neta de } 12 \% \\
\text { OE - F2 Obtener EBITDA de } 20 \%\end{array}$} & $\begin{array}{l}\text { IE } 1 \text { Implementar un sistema de control presupuestal para el control del } \\
\text { gasto administrativo. }\end{array}$ & Director General \\
\hline & IE 2 Reducir costo promedio de la deuda & Director General \\
\hline & IE 3 Reducir tasa efectiva anual para el pago de impuestos & Director General \\
\hline \multirow{4}{*}{$\begin{array}{l}\text { OE - F3 Crecer en ventas a razón del } 10 \% \\
\text { OE - C1 Mantener el liderazoo del mercado } \\
\text { creciendo a razón de } 2 \% \text { por año en participación } \\
\text { de mercado. } \\
\text { OE - P1 Incrementar la capacidad instalada actual } \\
\text { en } 20 \%\end{array}$} & $\begin{array}{l}\text { IE } 4 \text { Reforzar relaciones con las áreas de bienestar social de grandes } \\
\text { empresas o corporaciones }\end{array}$ & Director Corporativo de Operaciones \\
\hline & IE 5 Desarrollo de Nuevos Productos & Director Corporativo de Operaciones \\
\hline & IE6 Desarrollo de Nuevos Canales de Captación de Clientes & Director Corporativo de Operaciones \\
\hline & IE 7 Remodelación y ampliación de la sede de Javier Prado & Director Corporativo de Operaciones \\
\hline \multirow{3}{*}{$\begin{array}{l}\text { OE - C2 Obtener } 95 \% \text { de satisfacción al cliente. } \\
\text { OE - P2 Optimizar los tiempos de atención para } \\
\text { reducir el tiempo de espera en } 5 \% \\
\text { OE - P3 Mejorar el indicador de eficiencia } \\
\text { operativa en } 1 \%\end{array}$} & IE 8 Fortalecer cultura de atención al cliente & Director General \\
\hline & IE 9 Revisión de Procesos Críticos de Atención & Director Corporativo de Operaciones \\
\hline & $\begin{array}{l}\text { IE } 10 \text { Desarrollar un programa de optimización e innovación de } \\
\text { procesos. }\end{array}$ & Director Corporativo de Operaciones \\
\hline \multirow{2}{*}{$\begin{array}{l}\text { OE - A1 Reducir anualmente en } 5 \% \text { el ratio de } \\
\text { rotación de personal } \\
\text { OE - A2 Capacitar } 30 \text { horas a todo el personal año } \\
\text { a año } \\
\text { OE- A4 Cumplir el plan estratégico al } 95 \% \text { como } \\
\text { nota mínima. }\end{array}$} & IE 11 Definir e implementar plan de capacitación y retención & Analista de Gestión de Talento Humano \\
\hline & IE 12 Definir e implementar plan de change management & Analista de Gestión de Talento Humano \\
\hline $\begin{array}{l}\text { OE - A3 Lograr la digitalización del } 100 \% \text { de las } \\
\text { historias clínicas en } 3 \text { años. }\end{array}$ & IE 13 Implementación de Historias Clínicas Digitales & Director Corporativo de Operaciones \\
\hline
\end{tabular}

Elaborada en base a información propuesta para OftalmoSalud 


\subsection{Presupuesto de cada una de las iniciativas}

El presupuesto de cada una de las iniciativas será la sumatoria de los presupuestos de los Planes de Acción.

El presupuesto asignado estará en función de los resultados a corto y mediano plazo y tendrán relación directa con el volumen de ventas planeado; dicho esto los presupuestos para cada iniciativa en el tiempo se muestran en la siguiente tabla: 
Tabla 57

Presupuestos de las Iniciativas Estratégicas

\begin{tabular}{|c|c|c|}
\hline \multirow{4}{*}{$\begin{array}{l}\text { IE } 1 \text { Implementar un sistema de control presupuestal } \\
\text { para el control del gasto administrativo. }\end{array}$} & PLANES DE ACCION (50) & PRESUPUESTO \\
\hline & PA 1 - IE 1 Identificar posibles fuentes de ahorros administrativos y desarrollar propuestas de ahorro. & \multirow{10}{*}{ Se realiza con recursos ya existentes en la organización } \\
\hline & $\begin{array}{l}\text { PA - IE T } \\
\text { PA } 3 \text { - IE } 1 \text { Presentar los presupuestos de cada área para autorización por parte de directorio }\end{array}$ & \\
\hline & PA 4 - IE 1 Seguimiento y Control a los presupuestos aprobados & \\
\hline \multirow{3}{*}{ IE 2 Reducir costo promedio de la deuda } & PA 5 - IE 2 Calificar nuevas líneas de crédito con tasas de interés más bajas. & \\
\hline & 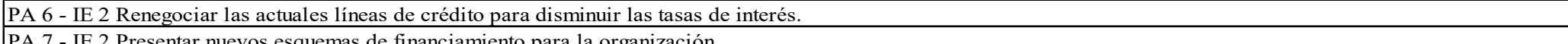 & \\
\hline & 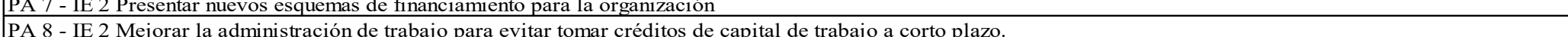 & \\
\hline \multirow{3}{*}{$\begin{array}{l}\text { IE } 3 \text { Reducir tasa efectiva anual para el pago de } \\
\text { impuestos }\end{array}$} & $\begin{array}{l}\text { PA 9 - IE } 3 \text { Establecer politicas de gastos para evitar gastos no deducibles. } \\
\text { Pon }\end{array}$ & \\
\hline & PA 10 - IE 3 Establecer politicas de pago a proveedores para evitar gastos no deducibles. & \\
\hline & PA 11 - IE 3 Revisar los gastos no deducibles y buscar la forma de hacerlos deducibles. & \\
\hline \multirow{3}{*}{$\begin{array}{l}\text { IE } 4 \text { Reforzar relaciones con las áreas de bienestar } \\
\text { social de grandes empresas o corporaciones }\end{array}$} & $\begin{array}{l}\text { PA 12 - IE } 3 \text { Capacitar a las distintas sedes de la Organización sobre planes de control de gastos } \\
\text { PA } 13 \text { - IE } 4 \text { Análisis situación de atención por empresa }\end{array}$ & \\
\hline & PA 14 - IE 4 Elaboración de plan de incentivos enfocado a empresas & S/. 95,000 por año (merchandising, atenciones varias) \\
\hline & PA 15 - IE 4 Visita y reforzamiento de relación con cada empresa & S/. 2,500 adicionales al mes (almuerzos con empresas) \\
\hline \multirow{3}{*}{ IE 5 Desarrollo de Nuevos Productos } & \begin{tabular}{|l} 
PA 16 - IE 5 Desarrollo del Producto de Campañas Preventivas y Tour de Salud \\
PA 17 - IE 5 Alianzas estratégicas con Organizaciones como Colegios, Universidades, Clubes, Institutos, Asociaciones, Mincetur, otros con apertura mercado internacional
\end{tabular} & $\begin{array}{l}\text { Se realiza con recursos ya existentes en la organización } \\
\text { S/. 2,000 por año (gastos de representación) }\end{array}$ \\
\hline & PA 18 - IE 5 Implementación Campañas Preventivas y Tour de Salud en dichas Organizaciones & S/. 10,000 por año (campañas) \\
\hline & PA 19 - IE 5 Monitoreo de Ingresos por intermedio de estos productos & \multirow{2}{*}{ Se realiza con recursos ya existentes en la organización } \\
\hline \multirow{3}{*}{$\begin{array}{l}\text { IE6 Desarrollo de Nuevos Canales de Captación de } \\
\text { Clientes }\end{array}$} & PA 20-IE 6 Desarrollo de Promociones en Redes Sociales y Pág. Web Especializadas & \\
\hline & PA 21 - IE 6 Puesta en Marcha Promociones & $\begin{array}{l}\text { Costo igual a y con reduccion de } 2 \% \text { anual: } \\
-45 \% \text { de las ventas netas } \\
-20 \% \text { de los gastos de servicio de salud } \\
\end{array}$ \\
\hline & PA 22 - IE 6 Monitoreo de Ingresos por cada plan. & \multirow{2}{*}{ Se realiza con recursos ya existentes en la organización } \\
\hline \multirow[b]{3}{*}{$\begin{array}{l}\text { IE } 7 \text { Remodelación y ampliación de la sede de Javier } \\
\text { Prado }\end{array}$} & PA 23 - IE 7 Análisis de Evaluación de Impactos y Planes de Mitigac & \\
\hline & PA 24 - IE 7 Contratar empresa a cargo de diseño y remodelación (anexo sede actual) & US\$ $\$ .5 \mathrm{~K}$ por diseño \\
\hline & 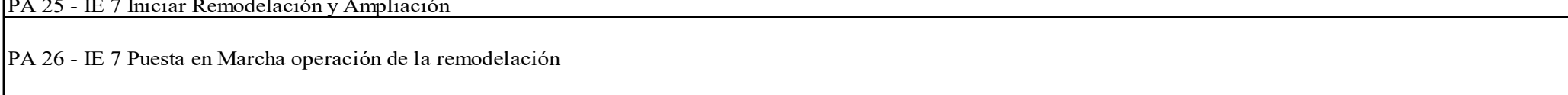 & $\begin{array}{l}\text { US } 1.2 \text { MM remodelacion y ampliacionde } 1,000 \mathrm{~m} 2 \\
\text { Costo igual a y con reduccion de } 2 \% \text { anual: } \\
-45 \% \text { de las ventas netas } \\
-20 \% \text { de los gastos de servicio de salud }\end{array}$ \\
\hline \multirow{2}{*}{ IE 8 Fortalecer cultura de atención al cliente } & PA 27 - IE 8 Desarrollar plan de fidelización al cliente. & \multirow{2}{*}{ S/. 5,000 mensuales (contratación de especialista en procesos) } \\
\hline & $\begin{array}{l}\text { PA 28-1E } 8 \text { Identificara actores dentro de la organizizción non influencia en la satisfacción del cliente. } \\
\text { PA } 29 \text { - IE } 8 \text { Capacitar a actores claves sobre su rol en la satisfacción del cliente }\end{array}$ & \\
\hline \multirow{3}{*}{ IE 9 Revisión de Procesos Críticos de Atención } & PA 30 - IE 9 Análisis situacional de Procesos de Atención & \multirow[b]{2}{*}{ Se realiza con recursos de cultura de atención al cliente } \\
\hline & PA 31 - IE 9 Identificación de oportunidades de mejora & \\
\hline & $\begin{array}{l}\text { PA } 32 \text { - IE } 9 \text { Reingeniería (revisión y mejora) de los Procesos Críticos de Atención } \\
\text { PA } 33 \text { - IE } 9 \text { Implementación de Procesos Críticos de Atención aprobados }\end{array}$ & \multirow[b]{2}{*}{ Se realiza con recursos ya existentes en la organización } \\
\hline \multirow{2}{*}{$\begin{array}{l}\text { IE } 10 \text { Desarrollar un programa de optimización e } \\
\text { innovación de procesos. }\end{array}$} & $\begin{array}{l}\text { PA 34 - IE } 10 \text { Definir programa de incentivos para optimización e innovación de procesos } \\
\text { PA 35-IF } 10 \text { marar vomunicar noromama }\end{array}$ & \\
\hline & $\begin{array}{l}\text { PA 35-IE } 10 \text { Lanzar y comunicar proggama } \\
\text { PA } 36-\text { Ee } 10 \text { Seleccionar y consolidar iniciativas de innovación para su implementación } \\
\end{array}$ & \multirow{10}{*}{ Se realiza con recursos ya existentes en la organización } \\
\hline \multirow{6}{*}{$\begin{array}{l}\text { IE } 11 \text { Definir e implementar plan de capacitación y } \\
\text { retención }\end{array}$} & PA 37 - IE 11 Identificar fuentes de reclutamiento & \\
\hline & PA 38 - IE 11 Ordenar proceso de reclutamiento y selección & \\
\hline & 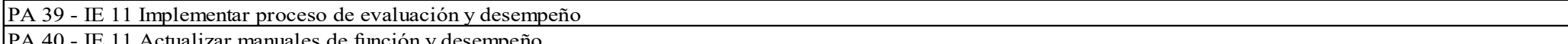 & \\
\hline & $\begin{array}{l}\text { PA 40-II } 11 \text { Actualizar mannales de función y desempenio } \\
\text { PA } 41 \text { - IE } 11 \text { Desarrollar mapa de talentos identificando posiciones y personal clave }\end{array}$ & \\
\hline & PA 42 - IE 11 Definir política y estrategia de administración salarial & \\
\hline & PA 43 - IE 11 Diseñar y aprobar planes de línea de carrera & \\
\hline \multirow{3}{*}{$\begin{array}{l}\text { IE } 12 \text { Definir e implementar plan de change } \\
\text { management }\end{array}$} & PA 44 - IE 12 Gestionar el diagnóstico de Clima Organizacional & \\
\hline & PA 45 - IE 12 Diseñar el plan de change management & \\
\hline & 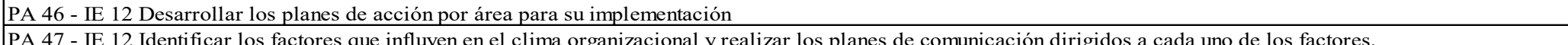 & \\
\hline \multirow[b]{2}{*}{ IE 13 Implementación de Historias Clínicas Digitales } & & \multirow{2}{*}{$\begin{array}{l}\text { US\$ } 480,000 \text { compra de licencias y migración } \\
\text { US\$ } 66,000 \text { anuales mantenimiento }\end{array}$} \\
\hline & $\begin{array}{l}\text { PA 49 - IE } 13 \text { Contratación de Software y Hardware idóneo para implementación de Historias Clínicas Digitales } \\
\text { PA } 50 \text { - IF }\end{array}$ & \\
\hline
\end{tabular}

Elaborada en base a información propuesta para OftalmoSalud 


\subsection{Cronograma de cada una de las iniciativas.}

Los cronogramas de cada una de las iniciativas serán la integración de los cronogramas de los planes de acción de cada una de ellas; en ese sentido se tiene:

Tabla 58

Cronograma de actividades por iniciativa

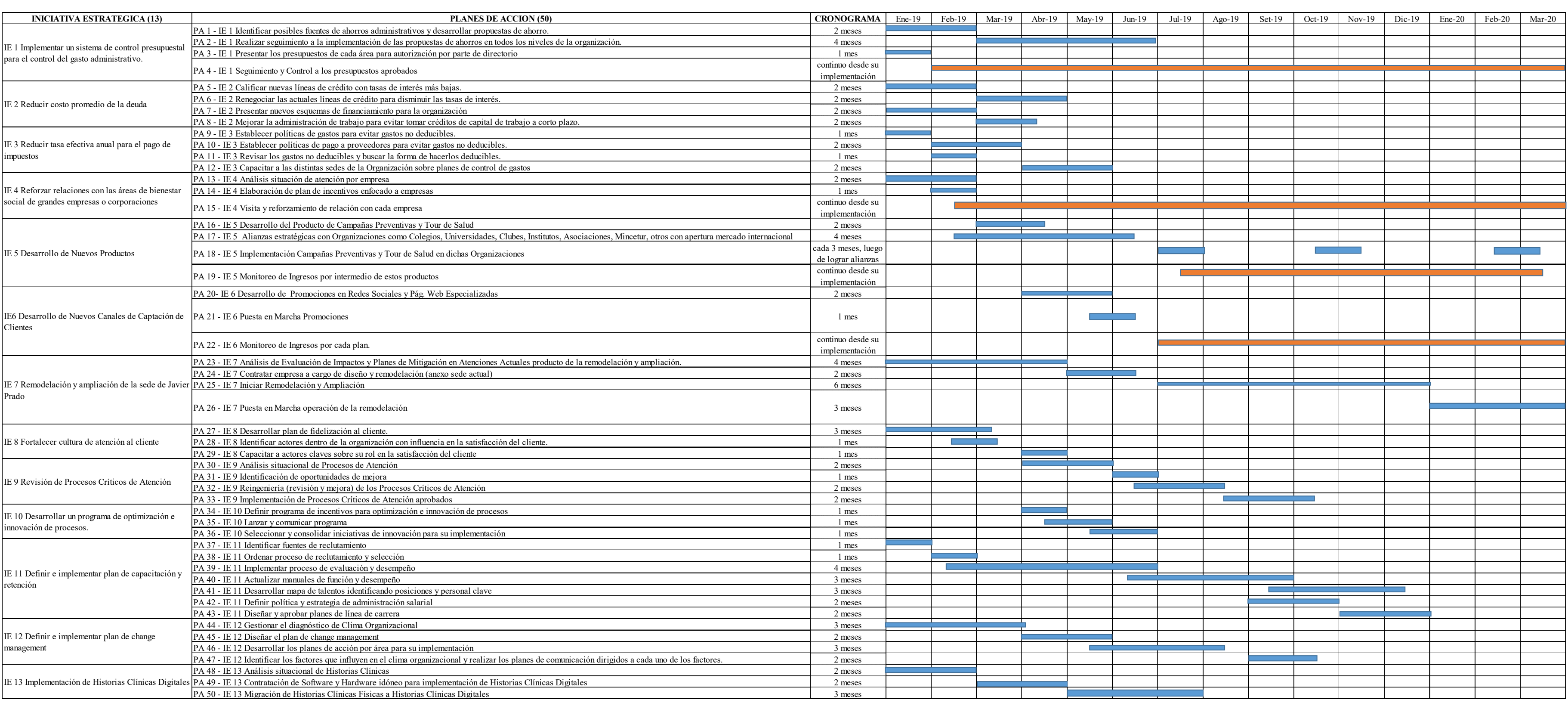

Elaborada en base a información propuesta para OftalmoSalud 


\section{Capítulo X. Evaluación}

En este capítulo se revisará la conveniencia de implementar la estrategia recomendada bajo el análisis financiero de la proyección de la empresa (comparación de estados financieros) así como los ratios resultantes de esta proyección en el horizonte de tiempo estudiado.

\subsection{Evaluación Cualitativa.}

Una evaluación cualitativa es de vital importancia más aun cuando las matrices trabajadas tienen un gran componente subjetivo el cual se complementa con planteamientos que de alguna manera intentan dar objetividad a lo expuesto en capítulos anteriores.

Por otro lado, consideramos que esta evaluación se vuelve relevante dado el liderazgo de la empresa y considerando que la misma viene enfrentando a la fecha factores que limitan su crecimiento como lo es la capacidad instalada y ponen en riesgo no sólo el liderazgo sino también el crecimiento futuro y los márgenes esperados.

\subsubsection{Criterios de Evaluación.}

Tal como lo mencionáramos y utilizáramos en capítulos anteriores, los criterios de evaluación son los descritos en la matriz de Rumelt los cuales son Consistencia, Consonancia, Ventaja y Factibilidad, los mismos que profundizaremos en los siguientes párrafos.

\subsubsection{Comparación de la estrategia con los criterios.}

A continuación, compararemos las estrategias escogidas (principal y contingente) para OftalmoSalud con respecto a los criterios anteriormente mencionados:

Consistencia: Tanto las estrategias de implementación de un mayor número de consultorios primarios (penetración de mercado) como las de marketing como las de 
penetración y desarrollo de mercado (promoción en redes sociales, páginas web especializadas y la implementación de campañas preventivas y tours de salud), están totalmente alineadas con la misión y visión de la empresa dado que todas ellas conllevan a mantener el liderazgo en la industria oftalmológica.

Consonancia: Las estrategias planteadas responden de manera asertiva a las tendencias del entorno actual de la industria oftalmológica vista en el capítulo V y posibles cambios según la matriz de situaciones y escenarios planteada en el capítulo VIII.

Ventaja: Las estrategias planteadas fortalecen las ventajas competitivas dado que consolidan la Inversión en Infraestructura y Tecnología, así como también permitirán apuntalar el prestigio del Staff Medico lo que a futuro se reflejará en el desarrollo de un semillero de nuevos médicos.

Factibilidad: Tal como lo veremos a detalle en la evaluación financiera de las estrategias planteadas, las mismas cuentan con un presupuesto asignado y su incorporación en los estados financieros deberán generar mejores rendimientos futuros.

\subsection{Evaluación Financiera de la Estrategia.}

\subsubsection{Proyección de estados financieros (sin estrategia y con estrategia).}

Debido a que la capacidad instalada es el principal factor que viene desacelerando el crecimiento de la empresa, el criterio utilizado para la proyección de los estados financieros en la situación actual es un crecimiento en ventas mínimas sustentado en la tasa de inflación y las demás condiciones referidas al gasto se mantienen igual. En cambio, para la proyección de los estados financieros de la nueva estrategia se ha considerado ventas acordes a la nueva capacidad instalada y ahorros importantes en los gastos debido a la optimización de procesos. 


\subsubsection{Estado de resultados (sin estrategia y con estrategia).}

Situación actual: Hemos proyectado los estados de resultados de OftalmoSalud teniendo en consideración un crecimiento de 3\% producto únicamente de la inflación dado que como hemos explicado anteriormente la capacidad instalada actual de la empresa se encuentra totalmente utilizada. Para los costos de ventas, gastos de servicios de salud, así como los gastos de ventas y administrativos se mantienen los ratios actuales. 
Tabla 59

Estado de Resultados Situación Actual

\begin{tabular}{|c|c|c|c|}
\hline \multirow[t]{2}{*}{ Modelo } & 2019 & 2020 & 2021 \\
\hline & Dic-19 & Dic-20 & Dic-21 \\
\hline \multicolumn{4}{|l|}{ Macro } \\
\hline Credimiento Ventas & $3.00 \%$ & $3.00 \%$ & $3.00 \%$ \\
\hline \multicolumn{4}{|l|}{ Estado de Resultados } \\
\hline \multicolumn{4}{|l|}{ (Expres ado en $5 /)$} \\
\hline Ventas netas & $57,605,230$ & $59,333,387$ & $61,113,389$ \\
\hline Costo de nentas & $-26,366,920$ & $-27,157,927$ & $-27,972,665$ \\
\hline Utilidad bruta & $31,238,311$ & $32,175,460$ & $33,140,724$ \\
\hline $\operatorname{cogs}(\%$ ventas) & $-45.8 \%$ & $-45.8 \%$ & $-45.8 \%$ \\
\hline Gastos de servicios de salud & $-12,413,718$ & $-12,786,130$ & $-13,169,714$ \\
\hline Gastos de servicios de salud ( $\%$ ventas) & $-21.5 \%$ & $-21.5 \%$ & $-21.5 \%$ \\
\hline Gastos de ventas & $-2,558,845$ & $-2,635,610$ & $-2,714,678$ \\
\hline Gastos de ventas ( $\%$ ventas) & $-4.4 \%$ & $-4.4 \%$ & $-4.4 \%$ \\
\hline Incremental Nueva Estrategia & 0 & 0 & 0 \\
\hline Gastos de administración & $-7,473,493$ & $-7,697,697$ & $-7,928,628$ \\
\hline Gastos de administración ( $\%$ ventas) & $-13.0 \%$ & $-13.0 \%$ & $-13.0 \%$ \\
\hline Incremental Nueva Estrategia & 0 & 0 & 0 \\
\hline \multicolumn{4}{|l|}{ Otros gastos } \\
\hline Total Gastos operativos exDeprediación & $-22,446,056$ & $-23,119,437$ & $-23,813,020$ \\
\hline \multicolumn{4}{|l|}{ Total $G$ astos operativos exDepredación (Nuev a Estrategia) } \\
\hline Depreciación y Am ortización & $-2,041,738$ & $-2,145,864$ & $-2,255,365$ \\
\hline Utilidad Oper ativa & $6,750,517$ & $6,910,159$ & $7,072,339$ \\
\hline Gastos de ventas/Gastos Opera tivos exServicios Salud & $25.4 \%$ & $25.4 \%$ & $25.4 \%$ \\
\hline Gastos de administración/ Gastos Operativos ex Servicios Salud & $74.6 \%$ & $74.6 \%$ & $74.6 \%$ \\
\hline BITDA & $8,792,255$ & $9,056,023$ & $9,327,703$ \\
\hline Ingresos Finandieros & 0 & 0 & 0 \\
\hline Ingresos Ex cepcionales & 0 & 0 & 0 \\
\hline Ingresos Diversos & 52,170 & 52,170 & 52,170 \\
\hline Cargas Excepcionales & $-30,087$ & $-30,087$ & $-30,087$ \\
\hline Gastos Financieros & $-464,955$ & $-429,680$ & $-392,288$ \\
\hline Costo financiero promedio & $-4.2 \%$ & $-4.2 \%$ & $-4.2 \%$ \\
\hline Gastos Financieros (Nueva Estrategia) & 0 & 0 & 0 \\
\hline Diferenda Cambio (Neto) & $-1,466$ & $-1,466$ & $-1,466$ \\
\hline Utilidad an tes de impues tos & $6,306,179$ & $6,501,096$ & $6,700,668$ \\
\hline Partidpaciones & $-258,349$ & $-266,334$ & $-274,510$ \\
\hline Participaciones (\% UAI) & $-4.10 \%$ & $-4.10 \%$ & $-4.10 \%$ \\
\hline Im pto a la renta & $-1,891,854$ & $-1,950,329$ & $-2,010,200$ \\
\hline Toso impositivo efectiva & $-30.0 \%$ & $-30.0 \%$ & $-30.0 \%$ \\
\hline Utilidad neta & $4,155,976$ & $4,284,433$ & $4,415,957$ \\
\hline
\end{tabular}

Elaborada en base a información propuesta para OftalmoSalud 
Situación Nueva Estrategia: Para este escenario se ha considerado que con el incremento del número de atenciones producto del aumento de la capacidad instalada y las nuevas estrategias de marketing planteadas las ventas deberían crecer a razón del 10\% anualmente. Para los costos de ventas, gastos de servicios de salud, así como los gastos de ventas y administrativos se ha considerado una reducción del $1.2 \%$ anual debido a las estrategias referidas a la eficiencia y mejora continua de los procesos operativos, así como la utilización de la capacidad administrativa actual para atender la nueva capacidad instalada. Es importante mencionar que en estos estados de resultados se han incorporado los presupuestos de los planes de acción de cada una de las iniciativas estratégicas propuestas y se debe prestar especial atención a la inversión en los nuevos consultorios los cuales están siendo financiados a través de arrendamiento financieros lo que origina un mayor gasto financiero. 
Tabla 60

Estado de Resultados Nueva Estrategia

\begin{tabular}{|c|c|c|c|}
\hline \multirow[t]{2}{*}{ Modelo } & 2019 & 2020 & 2021 \\
\hline & Dic-19 & Dic-20 & Dic-21 \\
\hline \multicolumn{4}{|l|}{ Macro } \\
\hline Crecimiento Ventas & $10.00 \%$ & $10.00 \%$ & $10.00 \%$ \\
\hline \multicolumn{4}{|l|}{ Estado de Resultados } \\
\hline \multicolumn{4}{|l|}{ (Expres ado en $5 /)$} \\
\hline Ventas netas & $61,520,149$ & $67,672,164$ & $74,439,380$ \\
\hline Cos to de nentas & $-27,420,604$ & $-29,350,599$ & $-31,392,386$ \\
\hline Utilidad bruta & $34,099,545$ & $38,321,565$ & $43,046,994$ \\
\hline $\operatorname{cogs}(\%$ ventas) & $-44.6 \%$ & $-43.4 \%$ & $-42.2 \%$ \\
\hline Gastos de servidios de salud & $-12,519,127$ & $-12,958,974$ & $-13,361,599$ \\
\hline Gastos de servicios de salud ( $\%$ ventas) & $-20.3 \%$ & $-19.1 \%$ & $-17.9 \%$ \\
\hline Gastos de ventas & $-2,732,747$ & $-3,006,021$ & $-3,306,624$ \\
\hline Gastos de ventas ( $\%$ ventas) & $-4.4 \%$ & $-4.4 \%$ & $-4.4 \%$ \\
\hline Incremental Nueva Estra tegia & $-440,905$ & $-90,724$ & $-90,724$ \\
\hline Gastos de administradión & $-7,981,400$ & $-8,779,540$ & $-9,657,494$ \\
\hline Gastos de admimistración (\% ventas) & $-13.0 \%$ & $-13.0 \%$ & $-13.0 \%$ \\
\hline Incremental Nueva Estra tegia & $-1,297,945$ & $-267,076$ & $-267,076$ \\
\hline \multicolumn{4}{|l|}{ Otros gastos } \\
\hline Total Gastos operativos ex Depredación & $-23,233,274$ & $-24,744,535$ & $-26,325,716$ \\
\hline \multicolumn{4}{|l|}{ Total Gastos operativos exDepredación (Nueva Estrategia) } \\
\hline Depredación y Am ortización & $-2,041,738$ & $-2,341,888$ & $-2,461,092$ \\
\hline Utilidad Operativa & $8,824,533$ & $11,235,142$ & $14,260,186$ \\
\hline Gastos de ventas/Gastos Operativos exSer vicios Salud & $25.4 \%$ & $25.4 \%$ & $25.4 \%$ \\
\hline Gastos de administración/Gastos 0per ativos ex Servicios Salud & $74.6 \%$ & $74.6 \%$ & $74.6 \%$ \\
\hline EBITDA & $10,866,271$ & $13,577,029$ & $16,721,278$ \\
\hline Ingres os Financieros & 0 & 0 & 0 \\
\hline Ingres $\alpha$ Excepcionales & 0 & 0 & 0 \\
\hline Ingres as Divers as & 52,170 & 52,170 & 52,170 \\
\hline Cargas Ex cepdionales & $-30,087$ & $-30,087$ & $-30,087$ \\
\hline Gastos Financieros & $-464,955$ & $-429,680$ & $-392,288$ \\
\hline Costo financiero promedio & $-4.2 \%$ & $-4.2 \%$ & $-4.2 \%$ \\
\hline Gastos Financieros (Nueva Estrategia) & $-296,206$ & $-274,338$ & $-250,720$ \\
\hline Diferenda Cambio (Neto) & $-1,466$ & $-1,466$ & $-1,466$ \\
\hline Utilidad an tes de impuestos & $8,083,989$ & $10,551,742$ & $13,637,795$ \\
\hline Participaciones & $-331,182$ & $-432,280$ & $-558,708$ \\
\hline Participaciones (\% UAI) & $-4.10 \%$ & $-4.10 \%$ & $-4.10 \%$ \\
\hline Impto a la renta & $-2,425,197$ & $-3,165,522$ & $-4,091,339$ \\
\hline Taso impositiva efectiva & $-30.0 \%$ & $-30.0 \%$ & $-30.0 \%$ \\
\hline Utilidad neta & $5,327,610$ & $6,953,939$ & $8,987,749$ \\
\hline
\end{tabular}

Elaborada en base a información propuesta para OftalmoSalud 
Como se puede apreciar en el siguiente grafico la utilidad neta en la situación actual crece a razón de $3.0 \%$ promedio y con el empleo de la nueva estrategia la utilidad crece a razón de \% promedio.

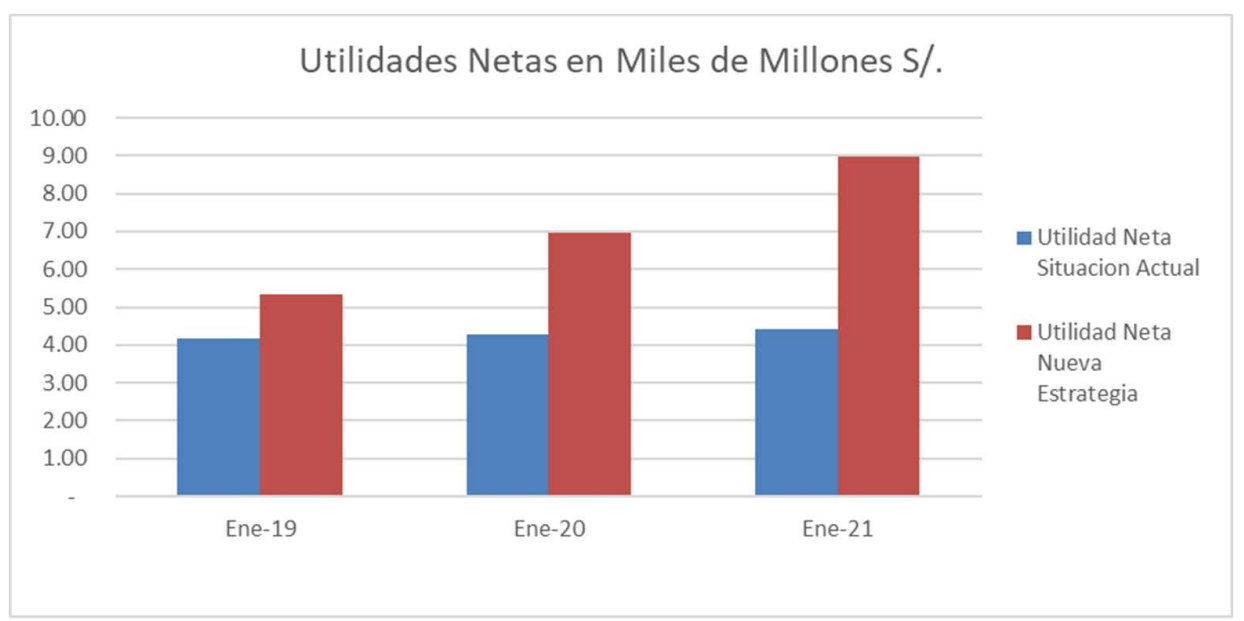

Figura 31 Comparativo Utilidad Neta Situación Actual vs Nueva Estrategia, elaborada en función a los EEFF proyectados

\subsubsection{Estado de Situación Financiera (sin estrategia y con estrategia).}

El Balance General de ambas situaciones se puede apreciar en las siguientes tablas: 
Tabla 61

Balance General Situación Actual

Modelo

2019

2020

2021

Dic-19

Dic 20

Dic-21

\section{Balance Generad}

(Expresado en Soles)

\section{Activo}

\section{Activos Corrientes}

Caja y Banoos

Ouentas por Cobrar Comerciales

Ouentas por Cobrar ACs. y Personal

Ouentas por Cobrar diversas

Mercaderias

Cargas Diferidas

Total activos corrientes

\begin{tabular}{|ccc}
$2,615,659$ & $3,024,048$ & $3,426,741$ \\
$5,523,789$ & $5,689,503$ & $5,860,188$ \\
$2,160,810$ & $2,160,810$ & $2,160,810$ \\
$2,367,338$ & $2,438,358$ & $2,511,509$ \\
$1,444,763$ & $1,488,106$ & $1,532,749$ \\
865,838 & 865,838 & 865,838 \\
$\mathbf{1 4 , 9 7 8 , 1 9 7}$ & $\mathbf{1 5 , 6 6 6 , 6 6 3}$ & $\mathbf{1 6 , 3 5 7 , 8 3 4}$ \\
& & \\
& & \\
$1,203,791$ & $1,203,791$ & $1,200,791$ \\
$\mathbf{4 0 , 4 1 3 , 7 9 2}$ & $42,414,313$ & $44,513,862$ \\
$\mathbf{- 1 7 , 6 5 2 , 0 0 1}$ & $-19,652,522$ & $-21,752,070$ \\
$2,017,036$ & $2,162,379$ & $2,318,195$ \\
$\mathbf{- 3 8 5 , 6 9 9}$ & $-531,042$ & $-686,858$ \\
$\mathbf{2 5 , 5 9 6 , 9 1 9}$ & $\mathbf{2 5 , 5 9 6 , 9 1 9}$ & $\mathbf{2 5 , 5 9 6 , 9 1 9}$ \\
& & \\
\hline $\mathbf{4 0 , 5 7 5 , 1 1 6}$ & $\mathbf{4 1 , 2 6 3 , 5 8 2}$ & $\mathbf{4 1 , 9 5 4 , 7 5 4}$ \\
\hline
\end{tabular}

\section{Activos no corrientes}

Cargas Diferidas

Inmuebles, haquinaria y Equipo

Depreciacion Acumulada

Intangibles

Amortización Acumuada

Total activos no corrientes

\begin{tabular}{|c|c|c|c|}
\hline Total activos & $40,575,116$ & $41,263,582$ & $41,954,754$ \\
\hline \multicolumn{4}{|l|}{ Pasivo y Patrimonio Neto } \\
\hline \multicolumn{4}{|l|}{ Pasivos corrientes } \\
\hline Sobregiro Bancario & 8,980 & 8,980 & 8,980 \\
\hline Tributos por pagar & 106,592 & 106,592 & 106,592 \\
\hline Remuneraciones por pagar & 960,280 & 960,280 & 960,280 \\
\hline Proveedores & $2,889,525$ & $2,976,211$ & $3,065,498$ \\
\hline Proveedores Relacionados & 231,688 & 231,688 & 231,688 \\
\hline Ouentas por pagar Diversas & $3,611,907$ & $3,720,264$ & $3,831,872$ \\
\hline Obligaciones Financieras & $1,462,170$ & $1,334,929$ & $1,200,053$ \\
\hline Total Pasivos corrientes & $9,271,143$ & $9,338,944$ & $9,404,963$ \\
\hline \multicolumn{4}{|l|}{ Pasivos no corrientes } \\
\hline Tributos por pagar & 0 & 0 & 0 \\
\hline Proveedores & 0 & 0 & 0 \\
\hline Quentas por pagar Diversas & $1,517,001$ & $1,562,511$ & $1,609,386$ \\
\hline Beneficios Sociales del Trabajador & 0 & 0 & 0 \\
\hline Obligaciones Financieras & $5,699,165$ & $5,203,211$ & $4,677,499$ \\
\hline Obligaciones Financieras (Nueva Estrategia) & 0 & 0 & 0 \\
\hline Total pasivos no corrientes & $7,216,165$ & $6,765,721$ & $6,286,885$ \\
\hline Total pasiyos & $16,487,308$ & $16,104,666$ & $15,691,848$ \\
\hline \multicolumn{4}{|l|}{ Patrimonio neto } \\
\hline Capital Socia & $13,126,511$ & $13,126,511$ & $13,126,511$ \\
\hline Reserva Legal & 574,039 & 574,009 & 574,039 \\
\hline Resultados Acumulados & $6,231,282$ & $7,173,934$ & $8,146,399$ \\
\hline Resultado del Ejercicio & $4,155,976$ & $4,284,433$ & $4,415,957$ \\
\hline Total $P$ atrimorio neto & $24,087,808$ & $25,158,917$ & $26,262,906$ \\
\hline Total P asi vo y Patrimonio neto & $40,575,116$ & $41,263,582$ & $41,954,754$ \\
\hline
\end{tabular}

Elaborada en base a información propuesta para OftalmoSalud 
Tabla 62

Balance General Nueva Estrategia

Modelo

2019

2020

2021

Balance Generad

(Expresado en Soles)

\section{Activo}

\section{Activos Carrientes}

Caja y Bancos

Quentas por Cobrar Comerciales

Ouentas por Cobrar A $\propto$, y Personal

Ouentas por Cobrar diversas

Mercaderias

Cargas Diferidas

Total activos corrientes

$\begin{array}{ccc}2,361,620 & 2,820,119 & 3,669,658 \\ 5,899,192 & 6,489,112 & 7,138,023 \\ 2,160,810 & 2,160,810 & 2,160,810 \\ 2,528,225 & 2,781,048 & 3,059,153 \\ 1,502,499 & 1,608,252 & 1,720,131 \\ 865,808 & 865,838 & 865,838 \\ \mathbf{1 5 , 3 1 8 , 1 8 4} & \mathbf{1 6 , 7 2 5 , 1 7 8} & \mathbf{1 8 , 6 1 3 , 6 1 2}\end{array}$

Activos no corrientes

\begin{tabular}{lccc} 
Cargas Diferidas & $1,203,791$ & $1,203,791$ & $1,200,791$ \\
Inmuebles, haquinaria y Equipo & $44,373,792$ & $46,570,337$ & $48,875,612$ \\
Depreciacion Acumulada & $-17,652,001$ & $-19,848,546$ & $-22,153,821$ \\
Intangibles & $2,017,006$ & $2,162,379$ & $2,318,195$ \\
Am ortización Acumulada & $-385,699$ & $-531,042$ & $-686,858$ \\
Total acti wos no corrientes & $\mathbf{2 9 , 5 5 6 , 9 1 9}$ & $\mathbf{2 9 , 5 5 6 , 9 1 9}$ & $\mathbf{2 9 , 5 5 6 , 9 1 9}$ \\
\hline
\end{tabular}

Total activos

$44,875,104$

$46,282,098$

$48,170,531$

\section{Pasivo y Patrimanio Neto}

P asivos carrientes

Sobregiro Bancario

Tributos por pagar

Remuneraciones por pagar

Proveedores

Proveedores Relacionados

Ouentas por pagar Diversas

Obligaciones Financieras

Total Pasivos corrientes

$\begin{array}{ccc}8,980 & 8,980 & 8,980 \\ 106,592 & 106,592 & 106,592 \\ 960,280 & 960,280 & 960,280 \\ 3,004,998 & 3,216,504 & 3,440,261 \\ 231,688 & 231,688 & 231,688 \\ 3,756,247 & 4,020,630 & 4,300,327 \\ 1,462,170 & 1,334,929 & 1,200,053 \\ \mathbf{9 , 5 3 0 , 9 5 5} & \mathbf{9 , 8 7 9 , 6 0 3} & \mathbf{1 0 , 2 4 8 , 1 8 2}\end{array}$

\section{Pasivos no corrientes}

Tributos por pagar

Proveedores

Ouentas por pagar Diversas

Beneficios Sociales del Trabajador

Obligaciones Financieras

Obligaciones Financieras (Nueva Estrategia)

Total pasivos no corrientes

\begin{tabular}{ccc}
0 & 0 & 0 \\
0 & 0 & 0 \\
$1,577,624$ & $1,688,665$ & $1,806,137$ \\
0 & 0 & 0 \\
$5,699,165$ & $5,203,211$ & $4,677,499$ \\
$3,686,643$ & $3,391,418$ & $3,072,575$ \\
$\mathbf{1 0 , 9 6 3 , 4 3 2}$ & $\mathbf{1 0 , 2 8 3 , 2 9 3}$ & $\mathbf{9 , 5 5 6 , 2 1 1}$ \\
& & \\
\hline $\mathbf{2 0 , 4 9 4 , 3 8 7}$ & $\mathbf{2 0 , 1 6 2 , 8 9 6}$ & $\mathbf{1 9 , 8 0 4 , 3 9 3}$ \\
\hline
\end{tabular}

\begin{tabular}{|c|c|c|c|}
\hline Total pasivos & $20,494,387$ & $20,162,896$ & $19,804,393$ \\
\hline \multicolumn{4}{|l|}{ Patrimonio neto } \\
\hline Capital Socia & $13,126,511$ & $13,126,511$ & $13,126,511$ \\
\hline Reserva Legal & 574,039 & 574,039 & 574,039 \\
\hline Resultados Aaumulados & $5,352,557$ & $5,464,712$ & $5,677,840$ \\
\hline Resultado del Ejercicio & $5,327,610$ & $6,953,939$ & $8,987,749$ \\
\hline Total P atrimonio neto & $24,380,717$ & $26,119,202$ & $28,366,139$ \\
\hline Total P asivo y Patrimonio neto & $44,875,104$ & $46,282,098$ & $48,170,531$ \\
\hline
\end{tabular}

Elaborada en base a información propuesta para OftalmoSalud 


\subsubsection{Flujo de efectivo (sin estrategia y con estrategia).}

Tabla 63

Flujo de Efectivo Situación Actual

Modelo

Dik-19 Dic-20 Dic-21

Flujo de efectivo

\begin{tabular}{|c|c|c|c|}
\hline Utididad neta & $4,155,976$ & $4,284,433$ & $4,415,957$ \\
\hline Depreciación & $1,906,164$ & $\mathrm{z}, 000,5 \mathrm{Z1}$ & $2,099,549$ \\
\hline amortizxión & 135,574 & 145,345 & 155,816 \\
\hline var capital trabajo & $-38,373$ & $-39,524$ & $-40, \pi 09$ \\
\hline \multicolumn{4}{|l|}{ otros } \\
\hline Fluja netos de adividades de operación & $6,159,342$ & $6,390,773$ & $6,630,612$ \\
\hline Capex(Activo fijo) & $-1,906,164$ & $-2,000,521$ & $-2,099,549$ \\
\hline CapE (Wueve Estrategia) & 0 & 0 & \\
\hline CapEx (Intangbles) & $-135,574$ & $-145,343$ & $-155,816$ \\
\hline Fluje netos de actividades de inversián & $-2,041,738$ & $-2,145,864$ & $-2,255,365$ \\
\hline \multicolumn{4}{|l|}{ Emisiones } \\
\hline Amortizaciones & $-587,920$ & $-6 Z, 195$ & $-660,587$ \\
\hline Lessirg (Nueve Estrategia) & 0 & 0 & \\
\hline Dividendos & $-3,116,982$ & $-3,213,325$ & $-3,311, * 8$ \\
\hline So utilidad del periodo. & 75.08 & $75.0 \mathrm{~s}$ & 75.08 \\
\hline Fluja netos de actividades de financiamiento & $-3,704,902$ & $-3,836,520$ & $-3,972,555$ \\
\hline Cambios en efectivo & 412,701 & 408,389 & 402,693 \\
\hline Caja nical & $2,202,957$ & $2,615,659$ & $3,024,048$ \\
\hline Caja final & $2,615,659$ & $3,024,048$ & $3,426,741$ \\
\hline
\end{tabular}

Elaborada en base a información propuesta para OftalmoSalud 
Tabla 64

Flujo de Efectivo Nueva Estrategia

\begin{tabular}{|c|c|c|c|}
\hline Modelo & 2019 & 2020 & 2021 \\
\hline & Dic-19 & Dic-20 & Dic-21 \\
\hline Flüjo de efectivo & & & \\
\hline utilidad neta & $5,327,610$ & $6,953,939$ & $8,987,749$ \\
\hline Depreciación & $1,906,164$ & $2,196,545$ & $2,305,276$ \\
\hline Amortizaxión & 135,574 & 145,343 & 155,816 \\
\hline varcapital trabajo & $-311, \approx 3$ & $-361,565$ & $-417,968$ \\
\hline 0 tros & & & \\
\hline Flujos net os de actividades de operación & $3,053,385$ & $8,934,262$ & $11,030,873$ \\
\hline CapEX(Ác tivo fijo) & $-1,906,164$ & $-2,196,545$ & $-2,305,276$ \\
\hline CapEx(Nueva Estrategia) & $-3,960,000$ & 0 & \\
\hline CapE $\times($ Intangibles) & $-135,574$ & $-145,343$ & $-155,816$ \\
\hline Flujos netos de actividades de inversión & $-6,001,738$ & $-2,341,888$ & $-2,461,092$ \\
\hline Emisiones & & & \\
\hline Amortizaciones & $-861,207$ & $-918,421$ & $-979,430$ \\
\hline Leasing (Nueva Estrategia) & $3,960,000$ & 0 & \\
\hline Dividendos & $-3,995,708$ & $-5,215,454$ & $-6,740,811$ \\
\hline sc utilidad del periodo & 75.086 & 75.08 & 75.098 \\
\hline Flujos netos de actividades de fínanciamiento & $-896,985$ & $-6,133,875$ & $-7,720,242$ \\
\hline Cambios en efectivo & 158,662 & 458,499 & 849,539 \\
\hline Caja inicial & $2,202,957$ & $2,361,620$ & $2,820,119$ \\
\hline Caja final & $2,361,620$ & $2,820,119$ & $3,669,658$ \\
\hline
\end{tabular}

Elaborada en base a información propuesta para OftalmoSalud

\subsubsection{Proyección de flujos (sin estrategia y con estrategia).}

Tabla 65

Flujos Netos de Actividades de Operación Situación Actual

Modelo

$\begin{array}{ccc}\text { 2019 } & \text { zozo } & \text { z0Z1 } \\ \text { DiK-19 } & \text { Dic-20 } & \text { Dic-21 }\end{array}$

F tyjo de efectivo

\begin{tabular}{|c|c|c|c|}
\hline Utilidad neta & $4,155,976$ & $4,284,433$ & $4,415,957$ \\
\hline Depreciación & $1,906,164$ & $2,000,521$ & $2,099,547$ \\
\hline Amortización & 135,574 & 145,348 & 155,816 \\
\hline varcapital trabajo & $-38,373$ & $-39,524$ & $-40,709$ \\
\hline \multicolumn{4}{|l|}{ otros } \\
\hline I lujos netos de axtividades de operación & $6,159,342$ & $6,390, \pi 33$ & $6,630,612$ \\
\hline
\end{tabular}


Tabla 66

Flujos Netos de Actividades de Operación Nueva Estrategia

Modelo

2019

2020

2021

Fluiode efectivo

Dic-19 Dik-20 Dic-21

Utididad neta
Depreciación
amortización
var capital trabajo
otros

Flujos neta de actividades de operación

Elaborada en base a información propuesta para OftalmoSalud

$\begin{array}{ccc}5,327,610 & 6,953,939 & 8,987,749 \\ 1,906,164 & 2,196,545 & 2,305,276 \\ 135,574 & 145,345 & 155,816 \\ -311,963 & -361,565 & -417,968\end{array}$

$7,057,385 \quad 8,934,262 \quad 11,030,873$

\subsubsection{Evaluación Financiera (VAN, TIR y ratios financieros)}

La evaluación financiera se refiere al impacto global de la implementación de las estrategias y el crecimiento natural del negocio:

Tabla 67

Cálculo del Costo del Patrimonio (Ke)

\begin{tabular}{|c|c|c|c|}
\hline $\begin{array}{r}\text { Indicadores } \\
\text { i) Costo del patrimonio (Ke) }\end{array}$ & Descripción & Valor & Fuente \\
\hline Rf & Tasa de Interes del Bono del Tesoro Americano (promedio ul & $2.42 \%$ & Bloomberg \\
\hline ERP & Tasa de rendimiento del portafolio & $4.77 \%$ & \\
\hline Riesgo Perú & Multiplicacion EMBI por Volatilidad & $2.24 \%$ & \\
\hline EMBI Spread & Diferencial de bonos emergentes emitidos en US\$ contra la $t$ & $1.49 \%$ & Bloomberg \\
\hline Relative Equity Volatility & Volatilidad Relativa del Mercado de Acciones & 1.50 & Bloomberg \\
\hline Beta desapalancada sector & Beta desapalancada sector & 0.76 & Damodaran \\
\hline$D / E$ & Deuda / Patrimonio & $33.62 \%$ & EEFF \\
\hline Caja/Valor Firma & Caja/Valor Firma & $7.15 \%$ & EEFF \\
\hline Tasa de impuestos & Tasa de impuestos & $30.00 \%$ & \\
\hline Beta apalancada & Beta de una empresa que no cotiza en bolsa & 0.94 & \\
\hline Beta apalancada (corregida por caja) & Beta apalancada x (1-Caja/Valor Firma) & $0.9 x$ & \\
\hline Ke USD & Costo del Capital US\$ & $8.81 \%$ & \\
\hline Inflación LP país & Inflación Largo Plazo Peru & $2.50 \%$ & $B C R$ \\
\hline Inflación USA & Inflación USA (promedio de proyección 2019 - 2021) & $2.30 \%$ & Bloomberg \\
\hline Ke PEN & Costo del Capital S/. & $9.03 \%$ & \\
\hline Patrimonio Neto & Patrimonio Neto & $23,048,814$ & EEFF \\
\hline Deuda Financiera & Deuda Financiera & $7,749,255$ & EEFF \\
\hline$E /(D+E)$ & Patrimonio / (Deuda + Patrimonio) & $74.84 \%$ & \\
\hline$D /(D+E)$ & Deuda / (Deuda + Patrimonio) & $25.16 \%$ & \\
\hline \multicolumn{4}{|l|}{ ii) Costo de deuda } \\
\hline Ke PEN & Costo de la Deuda (leasing) & $8.00 \%$ & Promedio BBVA, Interbank, BCP \\
\hline WACC & Costo Promedio Ponderado de Capital & $8.16 \%$ & \\
\hline Tasa de Crecimiento de Largo Plazo & & $2.00 \%$ & \\
\hline
\end{tabular}

Elaborada en base a información propuesta para OftalmoSalud 
Tabla 68

Valoración Situación Actual

\begin{tabular}{lccc} 
& 1 & 2 & 3 \\
DCF & 2019 & 2020 & 2021 \\
\hline & & & \\
EBIT & & & \\
Tasa efectiva de impuestos & $6,750,517$ & $6,910,159$ & $7,072,339$ \\
\hline NOPLAT & $30 \%$ & $30 \%$ & $30 \%$ \\
\hline+ ) DaA & $4,725,362$ & $4,837,111$ & $4,950,637$ \\
(-) Capex & $2,041,738$ & $2,145,864$ & $2,255,365$ \\
A Capital de trabajo & - & - & - \\
\hline FCFF & $-38,373$ & $-39,524$ & $-40,709$ \\
\hline
\end{tabular}

\begin{tabular}{|lr} 
Valor Presente F lujos Explícitos & $17,817,979$ \\
Valor Presente F lujos Perpetuos & $93,699,986$ \\
\hline Valor Empresa - OftalmoSalud & $111,517,965$
\end{tabular}

Elaborada en base a información propuesta para OftalmoSalud

Tabla 69

Valoración Nueva Estrategia

\begin{tabular}{lccc} 
& 1 & 2 & 3 \\
DCF & 2019 & 2020 & 2021 \\
\hline & & & \\
EBIT & $8,824,533$ & $11,235,142$ & $14,260,186$ \\
Tasa efectiva de impuestos & $30 \%$ & $30 \%$ & $30 \%$ \\
\hline NOPLAT & $6,177,173$ & $7,864,599$ & $9,982,130$ \\
(+) DaA & $2,041,738$ & $2,341,888$ & $2,461,092$ \\
(-) Capex & $-3,960,000$ & - & - \\
A Capital de trabajo & $\mathbf{- 3 1 1 , 9 6 3}$ & $\mathbf{- 3 6 1 , 5 6 5}$ & $\mathbf{- 4 1 7 , 9 6 8}$ \\
\hline FCFF & $\mathbf{3 , 9 4 6 , 9 4 7}$ & $\mathbf{9 , 8 4 4 , 9 2 2}$ & $\mathbf{1 2 , 0 2 5 , 2 5 4}$
\end{tabular}

Valor Presente F lujos Explícitos Valor Presente F lujos Perpetuos Valor Empresa - OftalmoSalud
$21,566,666$

$157,253,339$

$178,820,006$

Elaborada en base a información propuesta para OftalmoSalud

En la siguiente tabla se puede apreciar los indicadores producto de la aplicación de la nueva estrategia en donde se muestra una mejora en ROE y en el EBITDA. Ambas mejoras 
fueron sugeridas en las iniciativas estratégicas; las mismas que cubren las expectativas de los accionistas.

Tabla 70

Indicadores Nueva Estrategia

Dic-19 Dic-20 Dic-21

Crecimierto

\begin{tabular}{|c|c|c|c|}
\hline ventas & 10.096 & 10.086 & 10.098 \\
\hline $\operatorname{cogs}$ & 7.196 & $7.0 \%$ & 7.096 \\
\hline Utilidad operativa & $33.8 \%$ & $27.3 \%$ & 26.996 \\
\hline EBITLM & 27.896 & 24.996 & 23.286 \\
\hline utilidad Neta & 29.596 & 30.596 & 29.286 \\
\hline Patrimonio Neto & 5.886 & 7.196 & 8.696 \\
\hline \multicolumn{4}{|c|}{ Rentabilidad y márgenes } \\
\hline Wagen operativo & $14.3 \%$ & 16.696 & 19.280 \\
\hline Magen EBITLM & 17.786 & 20.186 & 27.59 \\
\hline wargen neto & 8. 786 & 10.396 & 12.196 \\
\hline ROA & 11.986 & 15.096 & 18.786 \\
\hline ROE & 21.996 & $26.6 \%$ & 31.76 \\
\hline
\end{tabular}

Elaborada en base a información propuesta para OftalmoSalud 


\section{Conclusiones y Recomendaciones}

\section{Conclusiones.}

En términos financieros, la implementación de las estrategias de aumento de la capacidad instalada a través de la remodelación de la sede de Javier Prado y las nuevas estrategias de marketing planteadas, sí generarían valor para la empresa. En tal sentido, se anticipa que la combinación de las estrategias antes señaladas permitirá que los ingresos de OftalmoSalud incrementen su ritmo de crecimiento, pasando de un crecimiento estancado en $3 \%$ (lo cual implicaría un crecimiento real prácticamente de $0 \%$ ) a un crecimiento de $10 \%$, explicado básicamente por un mayor número de atenciones, pero que también repercutiría en mayores ingresos de las unidades complementarias.

Al mismo tiempo, la estrategia de Establecimiento de Procesos Efectivos (revisión de procesos operativos) y la mayor escala obtenida con la ampliación de la operación (utilización de la capacidad administrativa actual para atender los nuevos consultorios) permitirían una mejora en los márgenes de la empresa ya que su implementación reduciría en $1.2 \%$ los costos de ventas, gastos de servicios de salud, así como los gastos de ventas y administrativos.

Mediante estas implementaciones, el margen EBITDA pasaría de un 15.3\% bajo una situación actual y lograría dar un salto que va desde el 17.5\% el año 2019 hasta un $22.5 \%$ el año 2021.

En cuanto a la deuda, es claro que el apalancamiento de la empresa sube de forma drástica como consecuencia de la implementación de las estrategias propuestas. Al respecto, es importante resaltar que la deuda incremental como consecuencia de la optimización no afecta al apalancamiento de la empresa, puesto que la mayor deuda es compensada con el 
mayor ingreso y los ahorros obtenidos. De otro lado, la deuda relacionada con la ampliación de la operación debido a la remodelación no incrementa de manera importante el indicador de apalancamiento (medido como Deuda Financiera Neta/ EBITDA), el cual alcanza su valor máximo en el año 2019 para luego bajar de forma gradual en la medida que el mayor número de atenciones genere mayores ingresos de la operación. Asimismo, es importante mencionar que, de acuerdo a nuestros estimados y proyecciones, la empresa es capaz de hacer frente al pago de sus obligaciones, sin necesidad de recurrir a refinanciamientos o tomar nueva deuda. En este punto, queremos resaltar la importancia de conseguir condiciones de financiamiento favorables para la empresa (creemos que es crítico). En el caso de OftalmoSalud se estima que podría captar recursos de la banca tradicional, haciendo uso de arrendamientos financieros con tasas relativamente bajas y competitivas, así como plazos lo suficientemente amplios como para permitir que la estrategia madure y pueda hacer frente a sus obligaciones sin problemas.

Es justamente el apalancamiento, y por ende el mayor gasto financiero, lo que hace que el incremento de venta no refleje en un incremento importante del margen neto y el ROE y por el contrario su crecimiento mantenga su tendencia histórica. En la medida que la operación y las estrategias se van consolidando, los indicadores de margen neto y ROE convergerán en $12 \%$ y $31 \%$ respectivamente.

Respecto a la creación de valor como resultado de la implementación de las estrategias propuestas, se estima que el valor de la empresa tendría un potencial de apreciación de $60 \%$, es decir, el valor de OftalmoSalud sería de más del 150\%. Para alcanzar este valor se procedió a valorizar el patrimonio (bajo la metodología de descuentos del flujo de caja libre) de OftalmoSalud en su estado actual (Valor: S/ 111.5 millones) y en el nuevo escenario (Valor: S/ 178.8 millones). En conclusión, se recomienda implementar las estrategias de crecimiento propuestas, toda vez que agregarán valor al accionista. 


\section{Recomendaciones.}

OftalmoSalud es la empresa líder en el mercado de servicios oftalmológicos en el país y como se ha podido ver a lo largo del presente trabajo, a la fecha mantiene esta posición con una amplia ventaja por encima de sus principales competidores. Sin embargo, si desea mantenerse en esa posición y tener continuidad en el tiempo, es necesario gestionar determinadas estrategias que acompañen su futuro crecimiento para los próximos años. Es bajo este precepto que se ha desarrollado este plan que debería apoyar el crecimiento mencionado para los siguientes 3 años.

A lo largo de nuestra interacción con los accionistas y la plana gerencial de la empresa, pudimos determinar a pesar de la envergadura de esta institución, consideramos que aún es una empresa familiar y las decisiones se toman con el consentimiento de todos los involucrados, sin embargo, se recomendaría que, si desean continuar con el crecimiento, la toma de decisiones sea más estratégica y las mismas vengan siempre acompañadas de un planeamiento de este tipo y el apoyo gerencial.

Durante el desarrollo de este trabajo, hemos podido detectar que su principal debilidad a la fecha es su capacidad instalada, la cual, al estar casi en su nivel máximo de utilización, no les permite seguir creciendo e incluso pueden llegar hasta perder calidad en el servicio y por consiguiente clientes, debido a que los tiempos de atención o para la generación de citas cada vez se hacen más largos.

Por otro lado, se ha podido ver que hay procesos que se pueden revisar en la búsqueda de mejorar la productividad y reducir costos.

Por el lado de los esfuerzos comerciales, se espera poder incrementar el número de atenciones clínicas una vez aumentada la capacidad instalada a través de la remodelación de 
la Sede Javier Prado. Estos esfuerzos irán desde el mejor manejo de proveedores hasta el desarrollo de campañas especializadas, así como explotando el marketing por redes sociales se debe llegar a un nicho de clientes que no tenemos captados buscando fortalecer el concepto de prevención.

Consideramos que la implementación de las estrategias previamente mencionadas requiere un compromiso importante de la organización, ya que los cambios que se presentarán a futuro incidirán de manera positiva en toda la organización. Para ello se hace necesario establecer controles periódicos mediante los indicadores de gestión propuestos de forma tal que se puedan tomar las medidas correctivas necesarias y de esta manera cumplir con los objetivos propuestos para el periodo en estudio. 


\section{ANEXO 1.}

\section{Resumen Entrevista a Profundidad a Directivos de OftalmoSalud (Jose Ramos Izaguirre, Fernando Izquierdo Villavicencio)}

¿Cómo se decide formar OftalmoSalud?:

OftalmoSalud aparece como la iniciativa del Dr. Luis Izquierdo Vásquez, el cual detecta en el mercado la necesidad de brindar una atención especializada e integral para personas con problemas oftalmológicos, desde enfermedades severas o críticas hasta atenciones de menor complejidad. En ese momento, los rubros de Oftalmología y Odontología eran especialidades que las Clínicas no manejaban y estaban desatendidas. De esa necesidad empezaron a surgir algunas clínicas con estas especialidades, entre ella OftalmoSalud, que inició sus actividades comerciales en 1el año de 1993.

¿Cuáles cree que han sido los pilares de crecimiento?:

Para OftalmoSalud consideramos que hay dos pilares que han sido y serán aquellos que nos han permitido crecer y ser líderes en el mercado. Estos son:

Soporte tecnológico de última generación

Actualización constante del Staff Médico, el mismo que ya cuenta con un renombre ganado, incluso a nivel mundial.

¿Qué servicios brinda actualmente OftalmoSalud?

OftalmoSalud es un Instituto dedicado a la prevención y atención de enfermedades oftalmológicas (salud oftalmológica) con cinco unidades de negocio: atención clínica, también conocida como atenciones primarias, exámenes auxiliares, cirugías, farmacia y óptica. 
¿Cuenta actualmente OftalmoSalud con un plan estratégico?

No, al momento no cuenta con un plan estratégico per sé, pero sí cuentan con lineamientos establecidos por parte del directorio que guían el rumbo de la empresa en cuanto a crecimiento (infraestructura) y tecnología (equipamiento).

¿Cuál considera que es el principal problema o limitante de OftalmoSalud en la actualidad?

Al momento, consideramos que el principal problema que venimos enfrentando es que el espacio de operación nos ha quedado ya corto, es decir que estamos operando casi a la máxima capacidad instalada de la empresa y este problema, limitará en el futuro inmediato (este año) el crecimiento de la empresa. Esto ya empieza a notarse en la saturación de las operaciones de atención clínica, lo que incluso ha llegado a generar incomodidad en algunos clientes por las constantes demoras en la atención (percepción de calidad en el servicio)

¿Qué crecimiento esperan mantener, tanto para el sector Oftalmológico como para OftalmoSalud?

Como es bien sabido, las cifras de pacientes con enfermedades oftalmológicas seguirán creciendo (pacientes privados y de seguros EPS) en ese sentido debemos de crecer para atender esa demanda.

En los últimos años el mercado de salud privada ha presentado crecimientos del 6\%; y se espera que el mercado oftalmológico crezca en un rango del 10\% (principalmente en atenciones o consultas primarias), e incluso podría llegar a crecer en rangos de $15 \%$ a $20 \%$ si se logra buenas negociaciones a través de los tarifarios de las EPS.

En el caso directo de OftalmoSalud, la misma viene experimentando crecimientos superiores a los números mencionados anteriormente, pero debido a lo comentado sobre la 
capacidad instalada este año vamos a experimentar una frenada y tal vez crecer a un ritmo bastante menor que podría estar en rangos de entre de 3 a $6 \%$

¿Qué factores externos contribuirán al crecimiento del sector en el ámbito privado?

En definitiva, existen factores externos que ayudarán a incrementar el número de atenciones privadas, Si mencionamos algunos, estos serían.

La ineficiencia y poca capacidad instalada del sector público para hacer frente a todas las atenciones oftalmológicas y que genera una brecha que debe ser atendida por el sector privado.

Generación de una cultura de Prevención para los pacientes

Obligatoriedad de los Chequeos Médicos Laborales.

El avance tecnológico, a la larga permitirá mayor número de atenciones

¿En qué debería centrar sus esfuerzos inmediatos OftalmoSalud para lograr crecimientos como años anteriores?

Consideramos que, en la actualidad, nuestro talón de Aquiles se encuentra en la capacidad instalada, estamos a full, sobre todo en nuestra sede principal que es Javier Prado. De crecer esta sede en espacios para consultorios, generará un crecimiento en exámenes auxiliares y también en la unidad de cirugía.

¿Cuántas Sedes tiene la empresa?

OftalmoSalud cuenta con 4 sedes ubicadas en las principales zonas de Lima Metropolitana, como son: Los Olivos, San Juan de Lurigancho, el Polo y San Isidro.

¿Cuál es el núcleo del negocio? ¿Por qué? 
El core business son las consultas primarias, ya sean de atención correctiva o aquellas previsionales ya que de ellas parte la utilización de las otras unidades de negocio como son: exámenes auxiliares, cirugía, farmacia y óptica.

¿Se consideran empresa líder en el sector?

No es que lo creamos, en realidad los números así lo demuestran; somos la empresa líder con casi un 45\% de participación en el mercado en Lima Metropolitana y la actual capacidad instalada pone en riesgo todo lo logrado a la fecha.

¿Qué factores externos cree ponen en riesgo el liderazgo de OftalmoSalud en el Sector?

Hay varios riesgos externos, entre ellos y uno de los más importantes es la mayor inversión en el sector, inversiones de las EPS en infraestructura, las mismas que incluso están llegando al campo oftalmológico y también las inversiones extranjeras que miran al Perú como una plaza atractiva de negocio.

También existe la posibilidad de que algunas empresas de la competencia puedan asociarse con un grupo de salud fuerte a nivel global o regional y que puedan incursionar en este segmento de salud.

¿Cuáles considera son sus principales competidores?

De un estudio realizado al interior de empresa, OftalmoSalud es la empresa que presenta mayor participación, seguido, pero en menor escala de Oftálmica y Clínica La Luz., siendo, las tres en conjunto, las que ocupamos el mayor \% del mercado.

A la fecha, el sector no se encuentra saturado, por lo que siempre existe la posibilidad de ingreso de nuevos competidores

¿Considera que en este sector existen productos sustitutos? 
Sí claro que los hay. Existen principalmente dos productos sustitutos: los primeros son la medida simple de vista, que se obtiene en cualquier óptica y que sustituye las atenciones primarias y los anteojos o lentes de contacto que sustituyen la cirugía láser.

¿Por qué cree usted que los pacientes prefieren OftalmoSalud?

En general, una característica importante del sector salud, es que los pacientes son leales, más que a la marca, a los médicos que conocen y a lo largo de la historia a la clínica les han otorgado diagnósticos adecuados. También, y dependiendo de la gravedad del diagnóstico suelen buscar segundas opiniones medicas de preferencia de clínicas o médicos de la especialidad más renombrados.

¿Se requiere de mucha inversión el implementar una clínica oftalmológica?

Sí, para empezar una clínica oftalmológica se requiere contar con una capital inicial de aproximadamente $\mathrm{S} / .8 \mathrm{MM}$, sin incluir el terreno

¿Qué proveedores considera importante OftalmoSalud en este sector?

Los proveedores que consideramos importantes son:

Los proveedores de equipos de cirugía (tratamiento oftalmológico)

Los farmacéuticos (medicinas y consumibles quirúrgicos).

En ambos casos, son empresas extranjeras de reconocido prestigio y de número reducido.

Si existiese un ranking internacional, ¿cómo cree que estaría posicionado OftalmoSalud?

Efectivamente no existe un ranking internacional pero internamente hemos realizado 
investigaciones y llegamos al siguiente ranking.

\begin{tabular}{|l|c|c|}
\hline \multicolumn{1}{|c|}{ Empresa } & País & Ranking \\
\hline SP Eye Center & Brasil & 2 \\
\hline Visu & España & 3 \\
\hline Clínica Barraquer & Colombia & 4 \\
\hline Bascom Palmer Eye Institute & USA & $\mathbf{5}$ \\
\hline OFTALMOSALUD & Perú & 6 \\
\hline Hugo Nano & Argentina & 7 \\
\hline Instituto Zaldívar & Chile & 8 \\
\hline Instituto de la Visión & Argentina & \\
\hline
\end{tabular}

\section{¿Cuáles cree que son las principales competencias de OftalmoSalud?}

\begin{tabular}{|c|c|}
\hline Competencia & Comentario \\
\hline Alta calificación del staff médico & $\begin{array}{l}\text { Los médicos que trabajan en OftalmoSalud son seleccionados } \\
\text { primordialmente por contar con una alta preparación en su } \\
\text { especialidad. Adicionalmente deben ser médicos de reconocido } \\
\text { prestigio y con poder de adecuación a la metodología de trabajo } \\
\text { de la empresa. }\end{array}$ \\
\hline $\begin{array}{l}\text { Administración dinámica que busca } \\
\text { crecimiento constante }\end{array}$ & $\begin{array}{l}\text { Tanto la Alta Dirección, como la Administración y el resto del } \\
\text { equipo de OftalmoSalud se encuentran en una búsqueda } \\
\text { constante de mejora continua de sus procesos, de manera que } \\
\text { les permita optimizarlos y seguir creciendo para de esta manera } \\
\text { mantener el liderazgo en el mercado. }\end{array}$ \\
\hline $\begin{array}{l}\text { Alineamiento de los procesos con } \\
\text { estructura y cultura del negocio }\end{array}$ & $\begin{array}{l}\text { La organización se encuentra bien estructurada y alineada con } \\
\text { los procesos requeridos para el normal funcionamiento de las } \\
\text { distintas unidades de negocio de las diferentes sedes. Cuentan } \\
\text { con certificaciones ISO, por lo cual se encuentran obligados a } \\
\text { cumplir con los procesos estipulados según los manuales } \\
\text { aprobados bajo esta certificación. Existe una cultura de } \\
\text { involucramiento por parte de la organización para poder } \\
\text { mantenerlas. }\end{array}$ \\
\hline $\begin{array}{l}\text { Recurso Humano con vocación de } \\
\text { servicio }\end{array}$ & $\begin{array}{l}\text { Según el indicador de gestión que mide la satisfacción de los } \\
\text { clientes, podemos considerar que todos los colaboradores de } \\
\text { OftalmoSalud se encuentran plenamente identificados con este } \\
\text { valor, ya que para atender clientes o pacientes se debe estar }\end{array}$ \\
\hline
\end{tabular}




\begin{tabular}{|l|l|l|}
\hline & $\begin{array}{l}\text { enfocado en ellos. Al tratarse de una cadena de servicio bastante } \\
\text { amplia, los clientes deben sentirse cómodos durante todo el } \\
\text { proceso de su atención, por lo que contar con personal con una } \\
\text { alta vocación de servicio es primordial para mantener un } \\
\text { servicio de alta calidad y que posteriormente éste sea } \\
\text { recomendado. }\end{array}$ \\
\hline $\begin{array}{l}\text { Inversión en Infraestructura y y y } \\
\text { Tecnología }\end{array}$ & $\begin{array}{l}\text { En sus sedes cuenta con equipos de alta gama yamplio espectro } \\
\text { tecnológico, que le permite brindar tratamientos, cirugías } \\
\text { oftalmológicas y atenciones de calidad a sus pacientes en las } \\
\text { más óptimas condiciones. }\end{array}$ \\
\hline
\end{tabular}

¿Cuáles cree que son las principales ventajas competitivas de OftalmoSalud?

$$
\begin{gathered}
\text { Ventaja } \\
\text { Competitiva }
\end{gathered}
$$

Localización

Estratégica

¿Cuáles considera usted son las fortalezas de OftalmoSalud? servicio y en el corto plazo afectará el crecimiento de la empresa.

Staff Médico de renombre mejores en esta especialidad. Médico y Sucesiones

OftalmoSalud cuenta con 4 sedes ubicadas estratégicamente en las principales zonas de Lima Metropolitana como son: Lima Norte (Los Olivos), Lima Sur (San Juan de Lurigancho), el Polo y San Isidro (Sede Javier Prado). Tal como se mencionó anteriormente el pleno empleo de la capacidad instalada actual de la empresa viene afectando la percepción de calidad en el El fundador de la empresa, el Dr. Izquierdo ha sido presidente de la sociedad peruana de Oftalmología y junto con sus hijos son considerados dentro de los

Semillero de Staff OftalmoSalud tiene un área Docente - Académica, la cual recibe a oftalmólogos y residentes de la especialidad, que completan su formación

Las fortalezas de OftalmoSalud son principalmente:

Su marca, que es bastante reconocida.

Su infraestructura, la tecnología y su localización (sedes)

El Staff Medico, que es de primera.

¿Sobre las debilidades de OftalmoSalud, cuales podría mencionar? 
A la fecha, principalmente su capacidad Instalada al límite superior. También que es una empresa familiar y muchas decisiones se toman de esa manera, "familiarmente", y otra carencia importante y que es un descuido, son las historias clínicas manuales, lo cual representa un alto riesgo para la organización.

¿Cuáles considera deben ser los objetivos estratégicos para OftalmoSalud para los próximos 3 años?

Como te comenté, no tenemos un plan estratégico cerrado, ni estructurado, pero si tenemos algunos lineamientos que te puedo comentar, como son:

Sostener un crecimiento del nivel de ventas del $10 \%$ anualmente.

Crecer un $2 \%$ en participación del mercado oftalmológico anualmente

Aumentar la utilidad neta promedio de $9 \%$ a $12 \%$ en los próximos 3 años

Mejorar el EBITDA anualmente hasta lograr un 20\%

Lograr un 95\% de satisfacción del cliente para los próximos 3 años

Lograr un 90\% satisfacción en clima laboral 


\section{Resumen Segunda entrevista a Jose Ramos Izaguirre}

¿Sobre las siguientes oportunidades y amenazas trabajadas para OftalmoSalud indique el peso (importancia relativa que tiene ese factor para alcanzar el éxito) y valor (oportunidad o amenaza mayor o menor) y justifique:

\begin{tabular}{llll}
\hline Factores determinantes de éxito & Peso & Valor \\
\hline Oportunidades & & \\
1. Crecimiento del mercado oftalmológico (privado y seguros EPS) & 0.10 & 4 \\
2. Mayor poder adquisitivo de la población & 0.10 & 3 \\
3. Ineficiencia en sector público & 0.15 & 4 \\
4. Fortalecimiento de la cultura de prevención & 0.15 & 3 \\
5. Avance Tecnológico & 0.05 & 2 \\
& 0.55 & \\
Amenazas & & & \\
1. Desaceleración del crecimiento & 0.10 & 3 \\
2. Depreciación de la moneda local respecto el dólar estadunidense & 0.10 & 2 \\
3. Mayor inversión en el sector & 0.10 & 3 \\
4. Fortalecimiento y mayor posicionamiento de la competencia o productos sustitos & 0.15 & 2 \\
\cline { 2 - 4 } & 0.45 & \\
\hline Total & 1.00 & \\
\hline
\end{tabular}

¿De las siguientes matrices indique el nivel de amenaza de los siguientes elementos de análisis, su factor de relevancia y el posible grado de atractividad (entre 1 y 5 -justificar) 
Amenaza de Productos Sustitutos

\begin{tabular}{|l|c|c|l|c|c|}
\hline \multicolumn{1}{|c|}{ Elemento de Análisis } & $\begin{array}{l}\text { Nivel de } \\
\text { Amenaza }\end{array}$ & $\begin{array}{c}\text { Factor de } \\
\text { Relevancia } \\
\text { (Peso) }\end{array}$ & Criterios que lo hacen poco atractivo & $\begin{array}{l}\text { Grado de } \\
\text { Atractivid } \\
\text { ad (1 al 5) }\end{array}$ & Criterios que lo hacen muy atractivo \\
\hline $\begin{array}{l}\text { Medida de Vista en } \\
\text { Ópticas }\end{array}$ & Bajo & 0.25 & $\begin{array}{l}\text { Los clientes confían más en las clínicas } \\
\text { especialidad que en las ópticas "al } \\
\text { paso" }\end{array}$ & $\begin{array}{l}\text { Clientes con bajos recursos hacen uso de estos } \\
\text { servicios sustitutos }\end{array}$ \\
\hline $\begin{array}{l}\text { Uso de Lentes en vez de } \\
\text { Cirugía Laser }\end{array}$ & Alto & 0.15 & $\begin{array}{l}\text { En la mayoría de casos la cirugía no es } \\
\text { reemplazable con uso de lentes }\end{array}$ & 2 & $\begin{array}{l}\text { Clientes con bajos recursos no pueden acceder a } \\
\text { este servicio }\end{array}$ \\
\hline $\begin{array}{l}\text { Participación de } \\
\text { Mercado de elementos } \\
\text { sustitutos }\end{array}$ & Bajo & 0.60 & $\begin{array}{l}\text { Menos del 20\% de los ingresos en este } \\
\text { sector corresponden a atenciones } \\
\text { primarias y ópticas }\end{array}$ & 3 & $\begin{array}{l}\text { Las atenciones primarias son vitales el desarrollo } \\
\text { del negocio por ser el input para los demás } \\
\text { servicios }\end{array}$ \\
\hline
\end{tabular}

Amenaza de Competidores Potenciales

\begin{tabular}{|c|c|c|c|c|c|}
\hline Elemento de Análisis & $\begin{array}{l}\text { Nivel de } \\
\text { Amenaza }\end{array}$ & $\begin{array}{l}\text { Factor de } \\
\text { Relevancia } \\
\text { (Peso) }\end{array}$ & Criterios que lo hacen poco atractivo & $\begin{array}{c}\text { Grado de } \\
\text { Atractividad } \\
\text { (1 al 5) }\end{array}$ & Criterios que lo hacen muy atractivo \\
\hline $\begin{array}{l}\text { Tecnología } \quad \text { y } \\
\text { Especialización }\end{array}$ & Bajo & 0.30 & $\begin{array}{l}\text { Todas las empresas cuentan con } \\
\text { tecnología y especialización acorde al } \\
\text { servicio que brindan }\end{array}$ & 3 & $\begin{array}{l}\text { Los clientes prefieren buscar a empresas } \\
\text { reconocida por el uso de tecnología de punta y el } \\
\text { staff más especializado }\end{array}$ \\
\hline Fidelidad & Medio & 0.25 & $\begin{array}{l}\text { Todas las clínicas brindan los mismos } \\
\text { servicios }\end{array}$ & 1 & $\begin{array}{l}\text { Para casos especiales los clientes buscan una } \\
\text { segunda opinión medica }\end{array}$ \\
\hline Requisitos de Capital & Medio & 0.25 & $\begin{array}{l}\text { Se requiere fuerte inversión de capital } \\
\text { para la implementación de clínicas } \\
\text { integrales oftalmológicas }\end{array}$ & 2 & $\begin{array}{l}\text { Las EPS están en proceso de implementación de } \\
\text { clínicas de atención integral lo cual restaría } \\
\text { participación de mercado }\end{array}$ \\
\hline
\end{tabular}




\begin{tabular}{|l|c|c|l|c|c|}
\hline Políticas de Gobierno & Alto & 0.10 & $\begin{array}{l}\text { La regulación gubernamental es estricta } \\
\text { en sus parámetros para otorgar licencias } \\
\text { de funcionamiento }\end{array}$ & 1 & $\begin{array}{l}\text { La falta de fiscalización adecuada y oportuna es } \\
\text { una invitación a trabajar en la informalidad }\end{array}$ \\
\hline Ubicación & Medio & 0.10 & $\begin{array}{l}\text { Cada vez es más difícil encontrar } \\
\text { ubicaciones adecuadas acorde a los } \\
\text { servicios que se presta (costo m2, } \\
\text { regulaciones, otros) }\end{array}$ & $\begin{array}{l}\text { El mercado no se encuentra aún saturado; por lo } \\
\text { que existe espacio para crecer en otros puntos de } \\
\text { atención. }\end{array}$ \\
\hline
\end{tabular}

\section{Poder de Negociación de los Clientes}

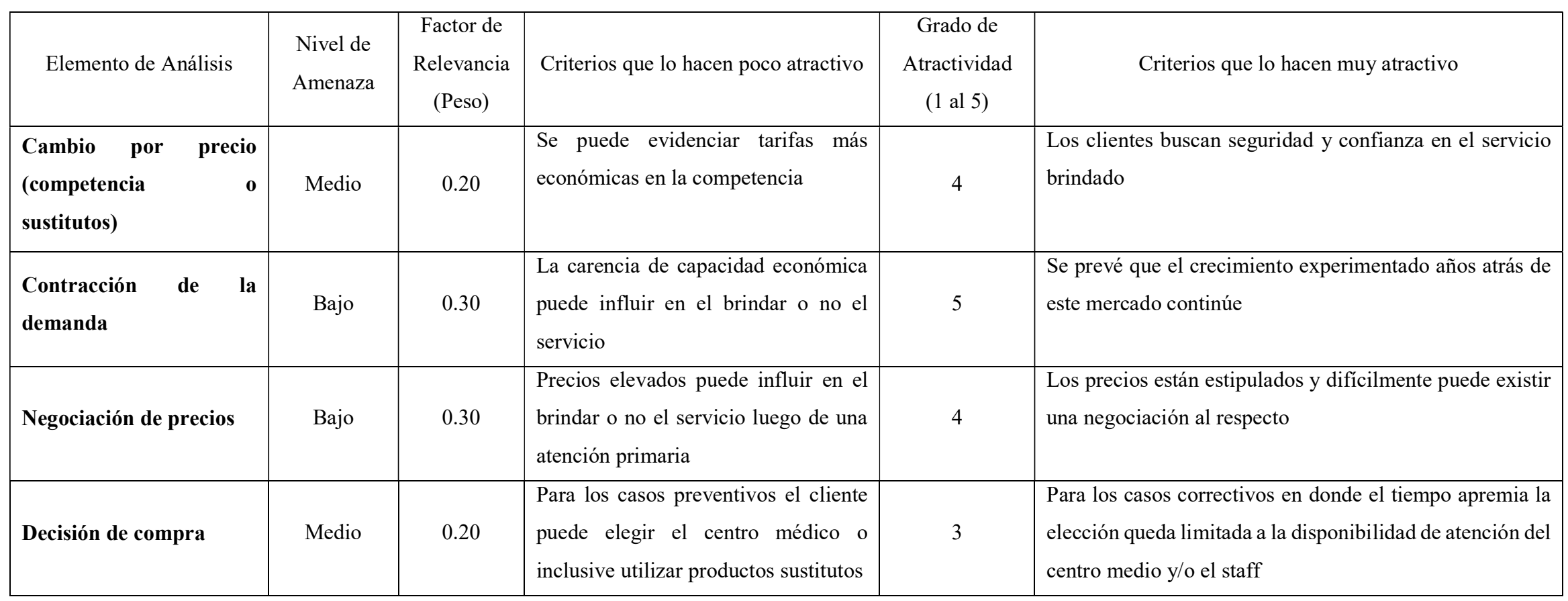

Poder de Negociación de los Proveedores 


\begin{tabular}{|c|c|c|c|c|c|}
\hline Elemento de Análisis & $\begin{array}{l}\text { Nivel de } \\
\text { Amenaza }\end{array}$ & $\begin{array}{l}\text { Factor de } \\
\text { Relevancia } \\
\text { (Peso) }\end{array}$ & Criterios que lo hacen poco atractivo & $\begin{array}{c}\text { Grado de } \\
\text { Atractividad } \\
\quad(1 \text { al } 5)\end{array}$ & Criterios que lo hacen muy atractivo \\
\hline Número de Proveedores & Alto & 0.40 & $\begin{array}{l}\text { Existe un número reducido de empresas que } \\
\text { brindan equipos de cirugía de última } \\
\text { generación y farmacéuticas }\end{array}$ & 1 & \\
\hline $\begin{array}{lrr}\text { Existencia } & \text { de } & \text { productos } \\
\text { sustitutos } & \text { de } \quad \text { los } \\
\text { proveedores } & & \\
\end{array}$ & Alto & 0.30 & $\begin{array}{l}\text { No existen productos sustitutos entre los } \\
\text { proveedores }\end{array}$ & 1 & \\
\hline $\begin{array}{l}\text { Costo en el cambio de } \\
\text { proveedor }\end{array}$ & Alto & 0.30 & $\begin{array}{l}\text { Dado el número reducido de proveedores, } \\
\text { en este sector prácticamente se trabaja con } \\
\text { todos; la elección de cada uno depende de } \\
\text { la disponibilidad del servicio requerido }\end{array}$ & 1 & \\
\hline
\end{tabular}

Rivalidad entre competidores existentes

\begin{tabular}{|l|l|l|l|l|l|}
\hline \multicolumn{1}{|c|}{ Elemento de Análisis } & $\begin{array}{l}\text { Nivel de } \\
\text { Amenaza }\end{array}$ & $\begin{array}{c}\text { Factor de } \\
\text { Relevancia } \\
\text { (Peso) }\end{array}$ & $\begin{array}{c}\text { Criterios que lo hacen poco } \\
\text { atractivo }\end{array}$ & $\begin{array}{c}\text { Atractividad (1 al } \\
5)\end{array}$ & Criterios que lo hacen muy atractivo \\
\hline $\begin{array}{l}\text { Número } \\
\text { Competidores }\end{array}$ & Medio & 0.40 & $\begin{array}{l}\text { Existen muchas empresas en el } \\
\text { sector; sin embargo el } 86 \% \text { del } \\
\text { mercado oftalmológico lo } \\
\text { atiende un grupo reducido de } \\
\text { empresas }\end{array}$ & 1 \\
\hline
\end{tabular}




\begin{tabular}{|l|l|l|l|c|l|}
\hline Crecimiento del Sector & Bajo & 0.10 & $\begin{array}{l}\text { La carencia de capacidad } \\
\text { económica puede influir en el } \\
\text { brindar o no el servicio }\end{array}$ & 4 & $\begin{array}{l}\text { El mercado no se encuentra aún saturado; por lo que } \\
\text { existe espacio para crecer en capacidad instalada. }\end{array}$ \\
\hline Fidelidad & Alto & 0.40 & $\begin{array}{l}\text { Todas las clínicas brindan } \\
\text { servicios similares }\end{array}$ & 2 & $\begin{array}{l}\text { Los clientes prefieren buscar a empresas reconocida } \\
\text { por el uso de tecnología de punta y el staff más } \\
\text { especializado }\end{array}$ \\
\hline Barreras de Salida & Alta & 0.10 & $\begin{array}{l}\text { Los costos para abandonar el } \\
\text { mercado son escasos }\end{array}$ & $\begin{array}{l}\text { La tendencia es que las empresas pequeñas } \\
\text { desaparezcan o sean absorbidas por aquellas que } \\
\text { manejan el mercado }\end{array}$ \\
\hline
\end{tabular}


¿De los siguientes factores de éxito en el sector oftalmológico indíquenos el peso que le asignaría en función a su importancia y el valor de las mismas dentro de las distintas empresas del sector

\begin{tabular}{|c|c|c|c|c|c|c|c|c|}
\hline Factores claves de éxito & Peso & OftalmoSalud & TG Laser & Contreras Campos & Oftalmica & Seluce & LaLuz & Ñahui \\
\hline $\begin{array}{l}\text { 1. Infraestructura (consultorios, salas de operación, } \\
\text { equipamiento en general) }\end{array}$ & 0.12 & 4 & 3 & 1 & 2 & 2 & 2 & 2 \\
\hline 2. Citas en central teleforica & 0.03 & 4 & 2 & 2 & 2 & 2 & 2 & 2 \\
\hline 3. Atencion en counter principal & 0.05 & 2 & 4 & 3 & 3 & 2 & 3 & 3 \\
\hline 4. Tiempo de espera & 0.11 & 1 & 4 & 3 & 3 & 3 & 2 & 2 \\
\hline 5. Atencion en consultorio medico & 0.10 & 4 & 3 & 4 & 3 & 3 & 3 & 3 \\
\hline 6. Atencion en farmacia & 0.02 & 3 & 3 & 3 & 3 & 3 & 3 & 3 \\
\hline 7. Atencion en optica & 0.02 & 3 & 2 & 3 & 3 & 3 & 3 & 3 \\
\hline 8. Atencion en examenes auxiliares / diagnostico & 0.05 & 4 & 2 & 2 & 2 & 2 & 2 & 2 \\
\hline 9. Tiempo de entrega de resultados & 0.03 & 3 & 3 & 2 & 2 & 2 & 2 & 2 \\
\hline 10. Atencion en cotizaciones & 0.02 & 4 & 3 & 3 & 3 & 2 & 2 & 2 \\
\hline 11. Servicio quirurgico & 0.12 & 4 & 3 & 3 & 3 & 3 & 3 & 3 \\
\hline 12. Servicio post quirurgico & 0.05 & 4 & 3 & 3 & 3 & 3 & 3 & 3 \\
\hline 13. Staff medico & 0.12 & 4 & 3 & 3 & 3 & 3 & 3 & 3 \\
\hline 14. Staff tecnico / paramedico & 0.05 & 4 & 3 & 3 & 2 & 2 & 2 & 2 \\
\hline 15. Staff administrativo & 0.02 & 4 & 2 & 2 & 2 & 2 & 2 & 2 \\
\hline 16. Salas de espera / distraccion ambiental & 0.02 & 4 & 2 & 2 & 2 & 2 & 2 & 2 \\
\hline 17. Cafeteria & 0.02 & 1 & 2 & 2 & 2 & 2 & 2 & 2 \\
\hline 18. Estacionamiento / valet parking & 0.05 & 4 & 4 & 2 & 2 & 2 & 2 & 2 \\
\hline Total & 1.00 & & & & & & & \\
\hline
\end{tabular}

¿Sobre las siguientes fortalezas y debilidades trabajadas para OftalmoSalud indique el peso (importancia relativa que tiene ese factor para alcanzar el éxito) y valor (fortaleza o debilidad mayor o menor)

\begin{tabular}{lcc}
\hline Factores determinantes de éxito & Peso & Valor \\
\hline Fortalezas & & \\
1. Posicionamiento de Marca & 0.10 & 4 \\
2. Localización estrategica & 0.10 & 3 \\
3. Staff Medico & 0.15 & 4 \\
4. Infraestructura y Tecnologia & 0.15 & 4 \\
5. Vision de crecimiento & 0.10 & 3 \\
& 0.60 & \\
Debilidades & & \\
1. Gobierno Corporativo familiar & 0.10 & 1 \\
2. Staff Medico familiar & 0.10 & 1 \\
3. Capacidad Instalada & 0.15 & 2 \\
4. Tecnologia de la Información & 0.05 & 2 \\
\cline { 2 - 3 } & 0.40 & \\
\hline Total & $\mathbf{1 . 0 0}$ & \\
\hline
\end{tabular}




\section{ANEXO 2.}

\section{Resumen Entrevista a Profundidad a Directivo de Oftálmica (Carlos Siverio)}

¿Cómo se decide formar Oftálmica?:

Oftálmica parte de la iniciativa de tres amigos: Gerardo Arana, Carlos Siverio y Juan Carlos Corbera, cada uno con distintas especialidades y cuya intención fue formar una nueva clínica de Salud para problemas oftalmológicos, principalmente de alta complicación.

Comenzamos en el año 1994 y desde esa fecha hemos venido creciendo de manera importante posicionándonos como la segunda clínica más importante en tratamientos de salud oftalmológica.

¿Cuáles cree que han sido los pilares de crecimiento?:

Considero que el pilar de nuestro crecimiento ha sido el tener un staff médico de todas las especialidades, lo que nos ha permitido poder atender, de la mejor manera y con excelentes resultados todos los casos que se nos han presentado.

Además, somos como una pequeña familia, por lo que los clientes también se sienten en casa y sienten que la atención es muy personalizada, lo cual en comparación con otras empresas hace que tengamos mucha recomendación por parte de nuestros clientes

¿Qué servicios brinda actualmente Oftálmica?

En Oftálmica atendemos todo tipo de patologías relacionadas con la salud oftalmológica. Particularmente hemos segmentado el universo de nuestros posibles pacientes de acuerdo a la posible incidencia y con distintas patologías. Esta segmentación es:

Adulto Mayor: Catarata, Degeneración macular seca y húmeda y Glaucoma. 
Altos Miopes: Desgarro y desprendimiento de retina, así como Glaucoma

Deportistas de riesgo o alto impacto: Catarata y Desprendimiento o desgarro de retina.

Diabéticos: Catarata, Glaucoma y Retinopatía diabética.

Trabajadores de alto riesgo: Catarata., desgarro o desprendimiento de retina, Abrasión, leucoma y úlcera corneal.

Y también atendemos pacientes con patologías más comunes como son miopía, astigmatismo, presbicia y edema macular.

¿Cuenta actualmente Oftálmica con un plan estratégico?

Sí, nuestra gerencia, cada año, junto con el directorio, generamos un plan estratégico que nos servirá de guía para el siguiente año. No significa que no tomemos o cambiemos decisiones en la medida que vayamos avanzando, pero preferimos trabajar de manera organizada para llevar un control sobre nuestro crecimiento.

¿Cuál considera que es el principal problema o limitante de Oftálmica en la actualidad?

Considero que, al momento, nuestro principal problema es la infraestructura para atención de pacientes. Hace unos 7 años decidimos crecer en una sede más y compramos una casa al frente de nuestra sede actual, pero al momento, el crecimiento que hemos experimentado nos ha sobrepasado y ya esa "nueva" sede ya nos está quedando chica y está dentro del plan seguir expandiéndonos.

¿Qué crecimiento esperan mantener, tanto para el sector Oftalmológico como para OftalmoSalud?

El sector viene creciendo en promedio entre 9-10\% por año y nos gustaría poder tomar algo de ese crecimiento. Sabemos que debemos tomar decisiones y hacer inversiones grandes 
pronto, pero estamos evaluando cómo vamos a generar nuestro crecimiento.

¿Qué factores externos contribuirán al crecimiento del sector en el ámbito privado?

Dentro de los factores externos que debemos considerar y que impulsarán el crecimiento del sector creo que hay que resaltar principalmente dos, que son:

Mayores atenciones preventivas generadas principalmente por la obligatoriedad de exámenes médicos en las empresas,

La poca capacidad de atención de los institutos de salud del sector público.

¿En qué debería centrar sus esfuerzos inmediatos Oftálmica para lograr crecimientos como años anteriores?

Como les mencioné anteriormente, nuestro principal problema en el largo plazo es la infraestructura para poder atender a más pacientes. Si bien al momento aún tenemos espacio para seguir creciendo, dentro de poco nuestra capacidad se verá totalmente tomada y previamente tenemos que tomar decisiones frente a nuestro futuro crecimiento.

¿Cuántas Sedes tiene la empresa?

Oftálmica tiene dos sedes, ambas ubicadas la Avenida San Borja Norte.

¿Cuál es el núcleo del negocio? ¿Por qué?

El principal generador de ingresos en las clínicas son las atenciones correctivas, que pueden generar una o dos consultas adicionales y el uso de exámenes adicionales, pero que son que son de rápida corrección.

¿Se consideran empresa líder en el sector?

Sí lo somos, tal vez no somos la más grande, pero consideramos que ,dentro de nuestro 
tamaño, que es el tamaño de la mayoría de empresas, después de OftalmoSalud, somos en definitiva los más importantes y los que generamos mejores números en general..

¿Qué factores externos cree ponen en riesgo el liderazgo de OftalmoSalud en el Sector?

Consideramos que a nivel externo, nuestro principal riesgo es el riesgo político y que puede llevar a nuestro país a sumirse en un escenario económico no tan optimista. El tema de salud ocular, salvo casos críticos, es ciertamente infravalorado. LA gente prefiere satisfacer otras necesidades antes que prevenir enfermedades en el largo plazo.

¿Cuáles considera son sus principales competidores?

Nuestro principal competidor es sin duda OftalmoSalud, seguido por Clínica La Luz, que, a pesar de ser más chica, viene creciendo de forma importante en el mercado local, aunque ofrece también otras especialidades no relacionadas al sector oftalmológico.

¿Considera que en este sector existen productos sustitutos?

Sí claro que sí los hay, aunque no sé si llamarlos productos sustitos o diversas alternativas para tratar una misma afección. Por ejemplo, los lentes de contacto, en lugar de los lentes de medida clásicos, o la cirugía en lugar de los lentes de medida o de contacto. Creo que son opciones distintas para distintos poderes adquisitivos.

¿Por qué cree usted que los pacientes prefieren Oftálmica?

Considero que nos hemos ganado un nombre en el mercado hace varios años. Los pacientes confían en nosotros por nuestro excelente staff médico y la calidad de atención que brindamos. Hemos generado una excelente boca a boca, lo que nos ha llevado a lo que somos ahora. Si bien aún somos una empresa no tan grande, ese factor nos ha llevado a preocuparnos por los detalles mínimos y hacer que nuestros clientes/pacientes se sientan 
como en casa,

¿Se requiere de mucha inversión el implementar una clínica oftalmológica?

Sí, al momento no tengo mapeado cuánto se requiere pero es un tema que próximamente lo estaremos evaluando dentro del plan de crecimiento.

¿Qué proveedores considera importante OftalmoSalud en este sector?

Los proveedores que consideramos importantes son:

Los proveedores de equipos de cirugía

Los de óptica

Los farmacéuticos

Los de servicio de limpieza y suplementos

Si existiese un ranking internacional, ¿cómo cree que estaría posicionado Oftálmica?

No tengo ese dato a la mano, y no sabría decirte si existe un ranking de las mejores empresas de tratamientos oftalmológicos. Si bien manejamos un benchmark, no sabía indicarte posiciones en un ranking.

¿Cuáles cree que son las principales competencias de Oftálmica?

En definitiva, nuestro excelente staff médico, que es seleccionado dentro de los mejores del país, eso como primera competencia.

Por otro lado, también creería que nuestro crecimiento ha sido bastante ordenado y que manejamos muy bien todo el proceso de atención al cliente, manejando tiempos adecuados de atención y reserva de citas, lo cual nos hace confiables. También creería que todo nuestro personal está perfectamente alineado con el propósito de la compañía por lo que estamos 
generando un excelente trabajo que repercute directamente en la satisfacción del cliente final.

¿Cuáles cree que son las principales ventajas competitivas de Oftálmica?

Nuestra principal ventaja es nuestro servicio a los pacientes y es principalmente por nuestro tiempo de espera reducido tanto en las citas como en la atención. Creería que un factor que los pacientes valoran mucho.

Otra ventaja es nuestro staff médico, como ya lo he mencionado antes, nuestro proceso de selección es muy especial y busca vincular a los mejores médicos de todas las especialidades.

¿Cuáles considera usted son las fortalezas de Oftálmica?

Las fortalezas de Oftálmica son principalmente:

Nuestro Servicio

Nuestro Staff Médico

Nuestros procesos y certificaciones

¿Sobre las debilidades de Oftálmica, cuales podría mencionar?

Teniendo en consideración lo que hemos mencionado anteriormente, creería que nuestra debilidad se basa principalmente en nuestra capacidad actual de crecimiento, que si bien, aún tiene espacio, dentro de poco podría jugarnos en contra.

¿Cuáles considera deben ser los objetivos estratégicos para OftalmoSalud para los próximos 3 años?

No tengo los datos exactos a la mano, pero queremos:

Seguir creciendo a un ritmo sostenido de entre 6 y $9 \%$ a nivel de ventas por año para 
los siguientes 5 años. Obviamente este crecimiento debe ir acompañado de un crecimiento a nivel de infraestructura.

Aumentar la utilidad neta promedio en un 5\% cada año.

Lograr no menos del 95\% en nuestras encuestas de satisfacción del cliente para los próximos 5 años

¿Dentro de nuestro análisis junto con la empresa OftalmoSalud se determinaron los siguientes factores críticos de éxito para la industria (se muestra listado de 18 factores elaborados con OftalmoSalud). ¿Considera usted que estos factores son los adecuados? ¿Agregaría o eliminaría alguno?

Considero que han abarcado un buen número de factores claves de éxito, por mi parte no agregaría ni quitaría ninguno 


\section{ANEXO 3.}

\section{Resumen Entrevista a Profundidad a Directivos de TG Laser (Luis Tobaru)}

¿Cómo se decide formar TG Laser?:

TG Laser nació en el año 1991con la idea y le reto de cuidar la salud visual de nuestros pacientes, por lo tanto, es una clínica dedicada a brindar atención médica especializada en oftalmología, sustentada en la actualización científica permanente.

¿Cuáles cree que han sido los pilares de crecimiento?:

El pilar de crecimiento de TG Láser ha sido nuestro staff médico tremendamente especializado y la tecnología con la que acompañamos nuestros tratamientos. En los últimos años nos hemos enfocado en adquirir la última tecnología para los tratamientos de las enfermedades más recurrentes.

¿Qué servicios brinda actualmente en TG Láser?

En TG Láser atendemos todas las posibles enfermedades oftalmológicas en los distintos grados que se puedan presentar

Tratamos Catata, Presbicia, Glaucoma, Miopía, Astigmatismo y problemas de córnea y retina.

También hacemos cirugías refractivas y trabajamos con distintos tipos de lentes intraoculares.

¿Cuenta actualmente TG Láser con un plan estratégico?

Sí, hemos elaborado un plan estratégico para los siguientes 5 años y cada año vamos adecuándolo a las distintas coyunturas que se van presentando. 
¿Cuántas Sedes tiene la empresa?

A la fecha tiene sólo una sede ubicada en el distrito de San Isidro

¿Cuál es el núcleo del negocio? ¿Por qué?

El núcleo del negocio son las atenciones en consulta y las cirugías.

¿Se consideran empresa líder en el sector?

Sí, en definitiva, somos de los primeros. El líder es OftalmoSalud y nuestra intención es seguir creciendo en el tiempo, con nuestro expertise y buenas prácticas, para llegar a ser los primeros en el sector, en el mediano plazo.

¿Qué factores externos cree ponen en riesgo el liderazgo de TG Láser en el Sector?

En los últimos años hemos venido experimentando un crecimiento importante en el sector Salud originado principalmente por grupos extranjeros, y que están generando una competencia importante en el sector porque vienen con nuevas formas de administración. Creería que ese podría ser un riesgo importante para este segmento si deciden inclinarse por clínicas especializadas.

¿Cuáles considera son sus principales competidores?

Nuestros principales competidores son OftalmoSalud, Oftálmica, y Clínica La Luz, el resto son más pequeños, pero igual no hay que subestimarlos. (ríe)

¿Considera que en este sector existen productos sustitutos?

Sí, sí los hay, de hecho, las ópticas son un producto sustituto importante en nuestro 
mercado donde la gente opta más por atenderse en una óptica pequeña con un bajo costo frente a una clínica de renombre que probablemente sea un poco más cara pero asegura un mejor diagnóstico.

¿Por qué cree usted que los pacientes prefieren TG Láser?

Hemos explotado mucho el concepto de trabajar con la última tecnología del mercado, por lo que nuestros clientes muestran mucha inclinación a ser atendidos con esta tecnología. Por otro lado, nuestro staff médico es excelente y están muy bien capacitados en el uso de la tecnología y nuestros procesos también se han adecuado al uso de esta tecnología.

¿Se requiere de mucha inversión el implementar una clínica oftalmológica?

Sí es una inversión fuerte, en infraestructura si no es propia, o en alquileres, máquinas, personal, etc, etc.

¿Qué proveedores considera importante TG Láser en este sector?

Los proveedores que consideramos más importantes son:

De equipos de tratamiento como: LASER de Femtosegundo LEN-SX, para la cirugía exacta de la catarata y de la miopía con rayos laser sin cuchillas; EXCIMER Laser Allegretto Wave Eye Q y la plataforma Centurión Vision System, que alcanzan resultados superiores tanto en la cirugía de la miopía como en la cirugía de catarata.

Los de lentes intraoculares de nueva generación.

Los de Equipos de exámenes de última generación como el Spectralis de Heidelberg para el análisis de la retina y LENSTAR LS 900, para el cálculo exacto de lente intraocular previo a la cirugía de la catarata

Proveedores de productos farmacéuticos y de laboratorio. 
Si existiese un ranking internacional, ¿cómo cree que estaría posicionado TG Láser?

No he escuchado de un ranking internacional previamente y no hemos realizado ese análisis. Sólo sabemos el dato de Perú, donde estamos ubicados entre los 5 primeros del sector.

¿Cuáles cree que son las principales competencias de TG Laser?

Dentro de nuestras principales competencias, como lo hemos mencionado anteriormente, es contar con la mejor tecnología del momento para la atención de enfermedades oftalmológicas y claro está, nuestro excelente personal médico, quienes cuenta con las preparación necesaria y adecuada para atender las distintas patologías que puedan presentar nuestros pacientes.

¿Cuáles cree que son las principales ventajas competitivas de TG Láser?

Nuestra principal ventaja es la constante actualización científica a nivel de conocimientos, y procedimientos de nuestro staff médico y también a nivel de tecnología para poder hacer uso adecuado de la maquinaria de avanzada que manejamos en la clínica.

¿Cuáles considera usted son las fortalezas de TG Láser?

Las fortalezas de TG Láser son principalmente:

Nuestro Staff Médico

Nuestra tecnología de avanzada

Nuestro plan de desarrollo en investigación científica

Nuestro servicio personalizado 
¿Sobre las debilidades de TG Láser, cuales podría mencionar?

Toda empresa tiene debilidades, pero en nuestro caso lo vemos más como oportunidades de mejora. Por el momento no quisiera hablar de ellas, y prefiero enfocarme en las fortalezas.

¿Cuáles considera deben ser los objetivos estratégicos para OftalmoSalud para los próximos 3 años?

Nuestros objetivos estratégicos se basan principalmente en:

Mantener un sólido crecimiento no menor a 5\% anual.

Seguir implementando mayor tecnología y avanzar en la investigación científica.

Seguir a la vanguardia en implementación tecnológica para brindar la mejor atención a nuestros clientes.

¿Dentro de nuestro análisis junto con la empresa OftalmoSalud se determinaron los siguientes factores críticos de éxito para la industria (se muestra listado de 18 factores elaborados con OftalmoSalud). ¿Considera usted que estos factores son los adecuados? ¿Agregaría o eliminaría alguno?

Los factores mostrados son los adecuados, no considero necesario agregar ninguno más. 


\section{BIBLIOGRAFÍA.}

FLEITMAN, Jack. Negocios Exitosos. McGraw Hill, 2000

DAVID, Fred R. Conceptos de Administración Estratégica. 14 a edición México D.F.: Pearson Educación, 2014

JOHNSON, Gerry; SCHOLES, Kevan. Dirección Estratégica. 5a edición Madrid: Pearson Educación, 2001

KAPLAN, Robert S; NORTON, David P. Mapas Estratégicos. Madrid: Gestión 2000, 2004.

KIM, W. Chan; MAUBORGNE, R. La estrategia del Océano Azul. Bogotá: Norma, 2005

PORTER, Michael E. Estrategia Competitiva. 2a edición reformada México D.F.: Editorial Patria, 2015

BETANCOURT, Benjamín; Análisis Sectorial y Competitividad. ECOE Ediciones 


\section{REFERENCIAS ELECTRÓNICAS}

ORGANIZACIÓN PANAMERICANA DE LA SALUD: Informe Año 2013

http://www.paho.org/per/images/stories/FtPage/2013/PlanENSOPC-RD-

julio2013_1v.pdf?ua=1

ORGANIZACIÓN PANAMERICANA DE LA SALUD: Plan Estratégico Nacional de Salud Ocular y Prevención de la Ceguera Evitable (2014-2021)

https:/www.paho.org/per/images/stories/FtPage/2013/PlanENSOPC-RD6julio2013 1v.pdf?ua $=1$

MAPA DE RIESGO POLÍTICO 2019.

https://www.marsh.com/uy/es/campaigns/political-risk-map-2019.html

INFORME ESTRATEGIA GLOBAL INTELIGO BANK IQ 2019

https://www.inteligobank.com/es/productos/informeestrategia-2019.html

EL COMERCIO: Cuanto destina el Estado al Sector Salud

https://elcomercio.pe/economia/dia-1/dinero-destina-sector-salud-noticia-500315

ATLAS MUNDIAL DE DATOS: Perú / Economía

https://knoema.es/atlas/Per\%C3\%BA/PIB-per-c\%C3\%A1pita

GESTION.PE: Perú gasta en salud por debajo del promedio en América Latina https://gestion.pe/economia/comex-peru-gasta-salud-debajo-promedio-america-latina268172-noticial 
INEI: Población del Perú / Nota de Prensa: Censo 2017

https://www.inei.gob.pe/prensa/noticias/poblacion-del-peru-totalizo-31-millones-237-mil385-personas-al-2017-10817/

INEI: Nota de Prensa: Estatus Seguro de Salud http://m.inei.gob.pe/media/MenuRecursivo/noticias/nota-de-prensa-n-040-2018-inei.pdf FODA: Matriz o Análisis FODA - Una herramienta esencial para el estudio de la empresa. https://www.analisisfoda.com/

MANUEL LEON: Conceptos de administración estratégica https://www.academia.edu/18952450/Conceptos_de_administraci $\% \mathrm{C} 3 \% \mathrm{~B} 3 \mathrm{n}$ estrat $\% \mathrm{C} 3$ \%A9gica

WOLTER KLUER: Metodología Análisis VRIO http://diccionarioempresarial.wolterskluwer.es/Content/Documento.aspx?params

UNMSN: Modelos de las Estrategias de Marketing http://sisbib.unmsm.edu.pe/bibvirtual/publicaciones/administracion/v05_n9/modelo_estra tegias marketing1.htm

CRECIMIENTO EMPRESARIAL ESTRATEGICO: Estrategias de Desarrollo de Mercado https://sites.google.com/site/competenciaestrategia/estrategias-de-crecimiento--$\underline{\text { ansoff/estrategias-de-desarrollo-de-mercados }}$

CENTRUM THINK: Excelencia Operacional https://centrumthink.com/excelencia-operacional 
CUIDA TU DINERO: Definición de Estrategia Organizacional

https://www.cuidatudinero.com/13098701/definicion-de-estrategia-organizacional

ADMINISTRACION MODERNA: Técnica de Escenarios

http://www.administracionmoderna.com/2012/08/tecnica-de-escenarios.html

COACHING PROJECT: Buena formulación de Objetivos, Método SMART

http://coaching-para-emprendedores.es/emprendimiento-estrategico/buena-formulacionde-objetivos-metodo-smart/

BLOOMBERG: tasa de referencia Reserva Federal

https://www.bloomberg.com/markets/rates-bonds

DAMODARAN: Betas by Sector (US)

http://www.stern.nyu.edu/ adamodar/pc/datasets/betas.xls

BCR: Tasa de referencia de la política monetaria

https://estadisticas.bcrp.gob.pe/estadisticas/series/mensuales/resultados/PD04722MM/ht $\underline{\mathrm{ml}}$

BCR: Reporte de inflación 2019

https://www.bcrp.gob.pe/index.php 